Final Report

FHWA/IN/JTRP-2005/10

\title{
DEVELOPMENT OF CRITERIA FOR THE UTILIZATION OF CEMENT KILN DUST (CKD) IN HIGHWAY INFRASTRUCTURES
}

\author{
by \\ Asha Sreekrishnavilasam \\ Graduate Research Assistant \\ and \\ Maria Caterina Santagata \\ Assistant Professor \\ School of Civil Engineering \\ Purdue University \\ Joint Transportation Research Program \\ Project No. C-36-50Y \\ File No. 6-19-24 \\ SPR-2784 \\ Conducted in Cooperation with the \\ Indiana Department of Transportation \\ and the U.S. Department of Transportation \\ Federal Highway Administration
}

The contents of this report reflect the views of the authors who are responsible for the facts and the accuracy of the data presented herein. The contents do not necessarily reflect the official views or policies of the Indiana Department of Transportation or the Federal Highway Administration at the time of publication. This report does not constitute a standard, specification, or regulation.

\author{
School of Civil Engineering \\ Purdue University \\ December 2006
}




\section{TABLE OF CONTENTS}

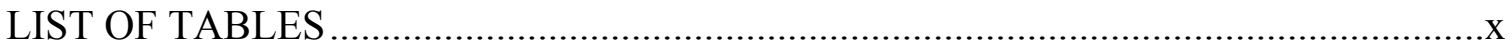

LIST OF FIGURES ..................................................................................... xiii

LIST OF ABBREVATIONS AND NOTATIONS............................................... xviii

CHAPTER 1 -- INTRODUCTION ………………………..................................

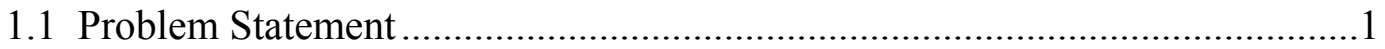

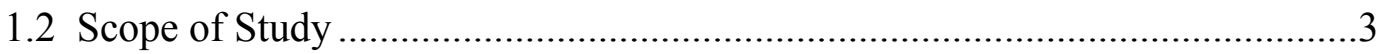

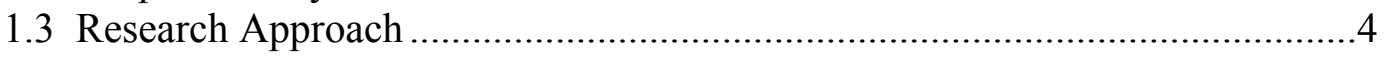

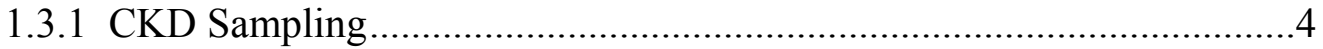

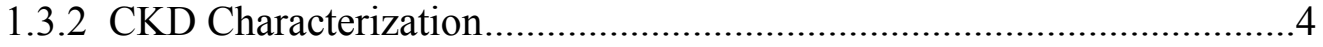

1.3.3 CKD Applications...........................................................................5

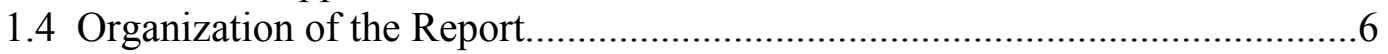

CHAPTER 2 -- CEMENT KILN DUST- GENERATION, DISPOSAL PRACTICE AND ENVIRONMENTAL REGULATIONS ..............................................8

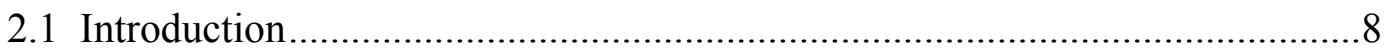

2.2 Overview of Cement Manufacturing and CKD Production ..............................10

2.2.1 Portland Cement and its Manufacturing Processes...........................10

2.2.2 Formation of Cement Kiln Dust .....................................................13

2.2.3 Cement Kiln Dust (CKD) - General ................................................15

2.2.4 CKD Collection System.................................................................16

2.2.5 Cost Associated with Generation of CKD .....................................17

2.2.6 CKD Generation Rates and Disposal Practice in United States ......18

2.2.7 Cement and CKD Generation in Indiana .........................................21

2.3 Environmental Issues Associated with CKD ...............................................23

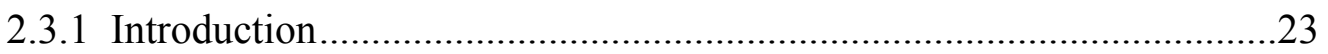

2.3.2 Regulatory History .............................................................................23

2.3.3 Standards for Protection of Air and Groundwater Resources.................25

2.3.4 Test Results of Trace Metals in the Leachate from Literature...........29 
CHAPTER 3 -- PROPERTIES AND UTILIZATION OF CEMENT KILN DUST.........32

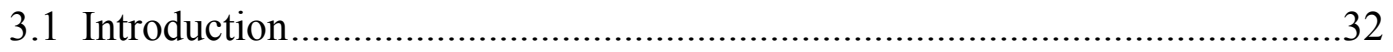

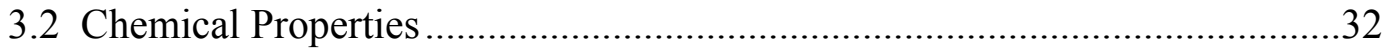

3.2.1 Chemical Composition of CKD and its Variability .............................32

3.2.2 Chemical and Physical Parameters to Define the Reactivity of CKD ...40

3.2.3 Loss on Ignition ............................................................................45

3.2.4 Mineralogical Composition and X-Ray Diffraction Patterns for CKD .46

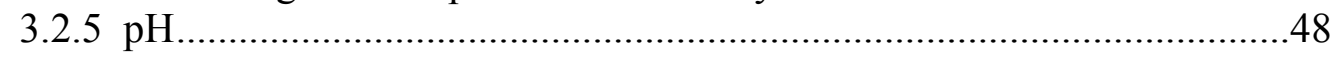

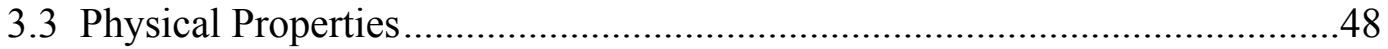

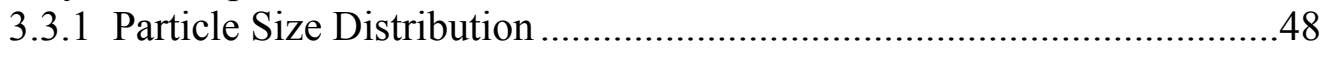

3.3.2 Specific Surface Area ................................................................51

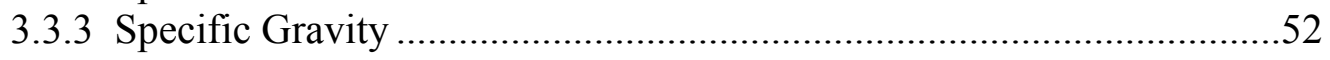

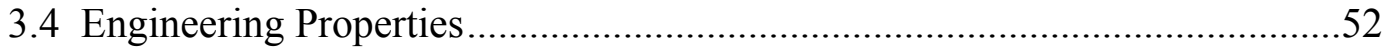

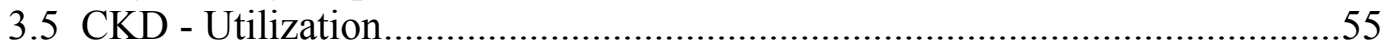

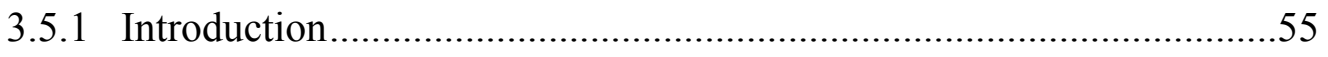

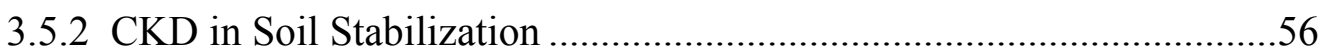

3.5.3 CKD in Controlled Low Strength Materials .........................................64

3.5.4 CKD in Highway Bases and Subbases ..............................................66

3.5.5 CKD in Blended Cements and Construction Products .........................67

3.5.6 CKD in Sludge Stabilization.........................................................67

3.5.7 CKD as an Activator for Pozzolans ..................................................68

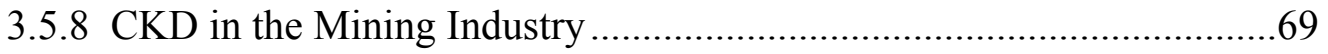

CHAPTER 4 -- CKD SOURCES AND SAMPLING OF LANDFILLED CKD.............70

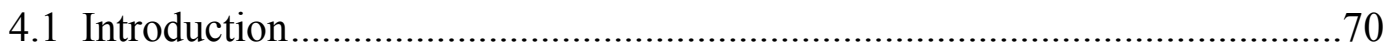

4.2 Mitchell Plant - General .................................................................... 70

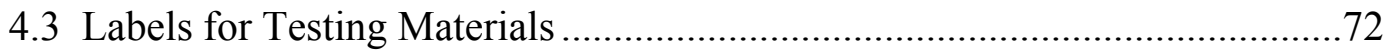

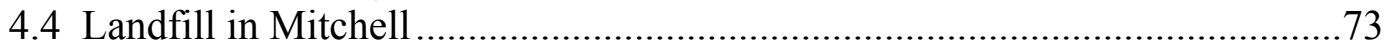

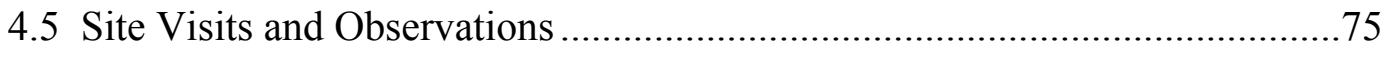

4.6 Landfill Investigation and CKD Sampling .......................................... 77

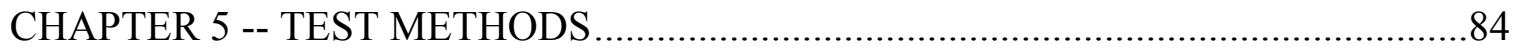

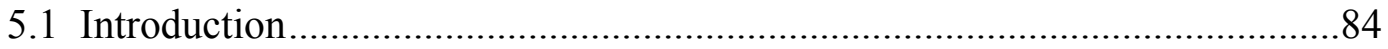

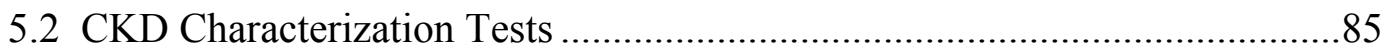

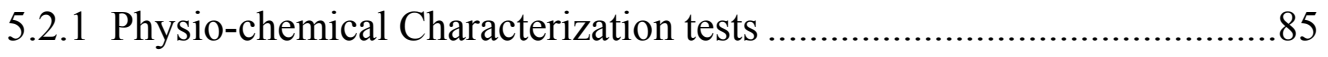

5.2.1.1 Chemical and Mineralogical Composition ..............................85

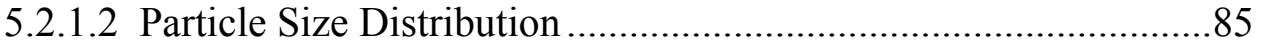

5.2.1.3 Microscopic Examination .....................................................8 86

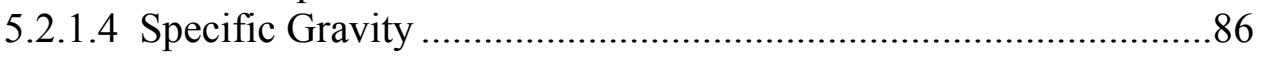

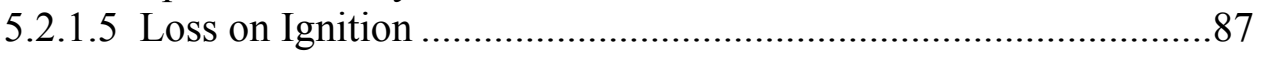

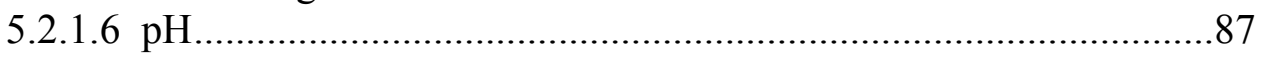

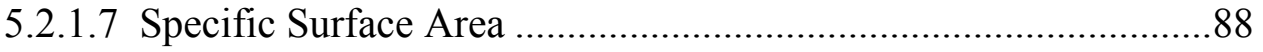


5.2.1.8 Bleeding .............................................................................. 91

5.2.2 Engineering Tests............................................................................91

5.2.2.1 Compressive Strength Tests on CKD Pastes .............................91

5.2.2.2 Compaction Behavior of CKD...............................................91

5.2.2.3 Unconfined Confined Compressive Strength of Compacted CKD .................................................................992

5.2.2.4 Hydraulic Conductivity of Compacted CKD.............................93

5.2.2.5 Compressibility .................................................................99

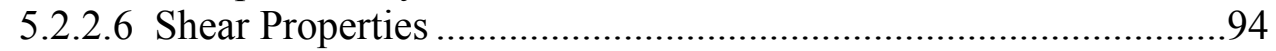

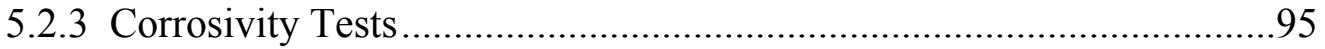

5.2.3.1 Electrical Resistivity Tests.....................................................95

5.2.3.2 Sulfate Content and Chloride Content .......................................96

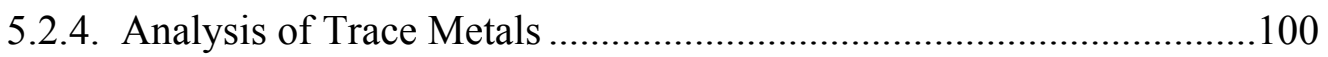

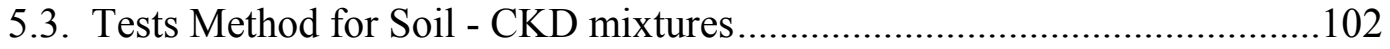

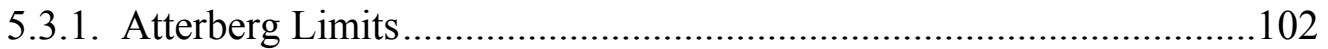

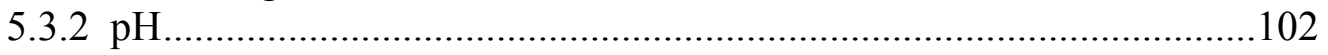

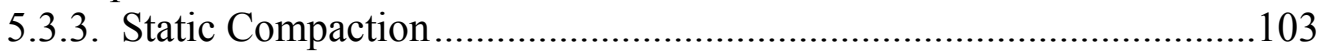

5.3.4. Unconfined Compression Tests .....................................................103

5.3.5. California Bearing Ratio (CBR) Test ..............................................104

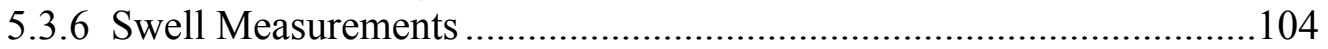

5.4 Test Methods for Controlled Low Strength Materials (CLSM) ...................107

5.4.1 Mixing Procedure.....................................................................10

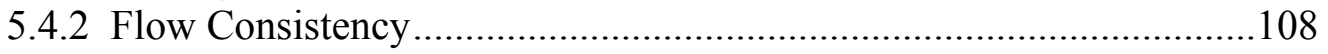

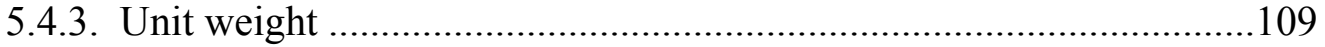

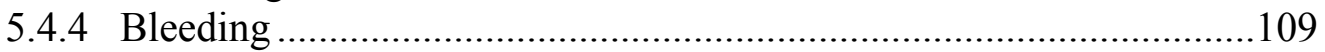

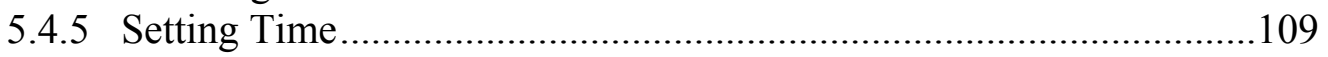

5.4.6 Unconfined Compressive strength ............................................110

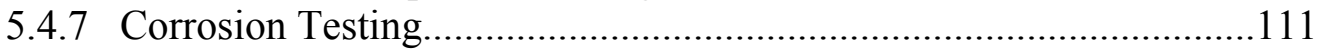

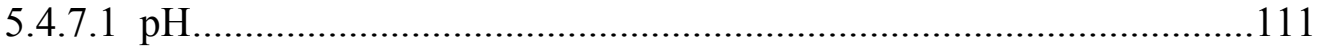

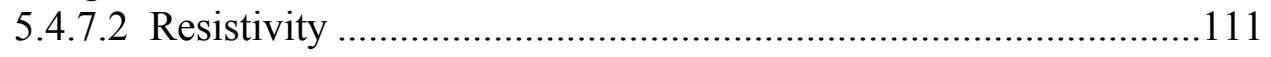

5.4.7.3 Mass Loss Test................................................................111

\section{CHAPTER 6 -- CHARACTERIZATION OF CKD AND IDENTIFICATION OF}

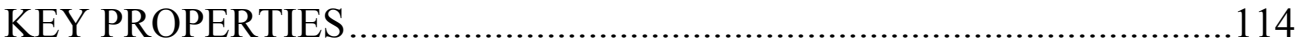

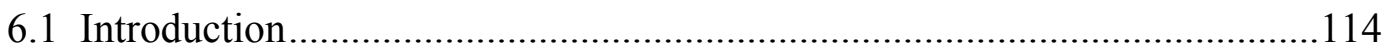

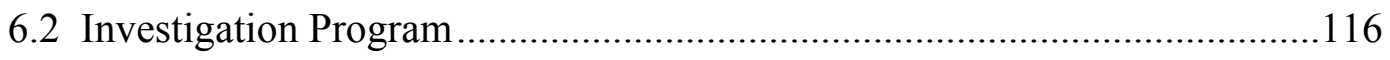

6.3 Test Results and Discussion..............................................................118

6.3.1 Physio - Chemical Properties........................................................119

6.3.1.1 Chemical and Mineralogical Composition ...............................119

6.3.1.2 Variation in Water Content, $\mathrm{pH}$ and LOI in Landfilled CKD ....122

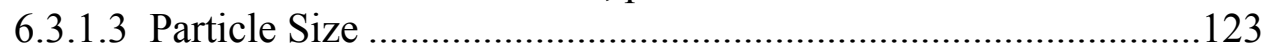

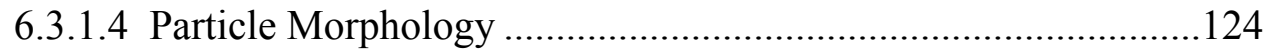

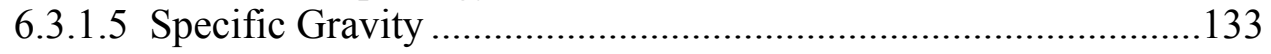


6.3.1.6 Specific Surface Area 133

6.3.1.7 Physio - Chemical Test: Conclusions ......................................134

6.3.2 Mechanical and Engineering Properties .........................................135

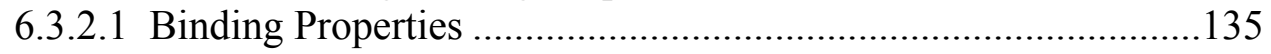

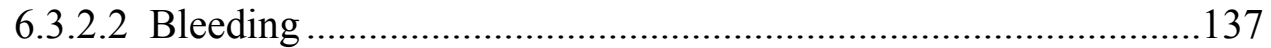

6.3.2.3 Moisture Density Relationship ............................................138

6.3.2.4 Unconfined Compressive Strength ..........................................141

6.3.2.5 Permeability and Drainage.......................................................144

6.3.2.6 CKD Compressibility (Dry Powder) ........................................145

6.3.2.7 Shear Properties (Dry Powder) ................................................147

6.3.2.8 Mechanical and Engineering Properties: Conclusions ...............151

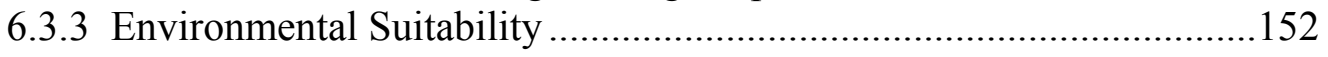

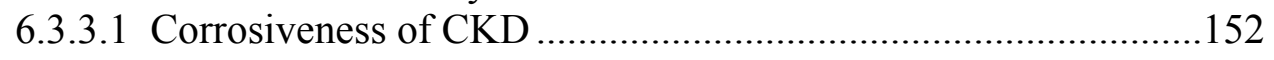

6.3.3.2 Analysis of Trace Metals .....................................................155

6.3.3.3 Environmental Suitability: Conclusions ..................................157

6.4 Dynamic Nature of Reactive By-Products..............................................159

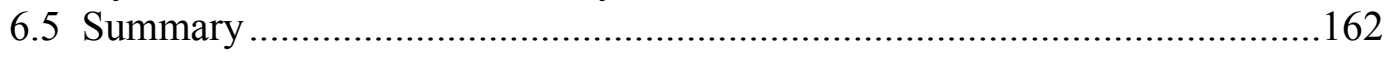

6.6 Key Properties and Potential Applications ............................................. 163

6.6.1 Soil Improvement and Treatment of Wet Sub-grades ........................164

6.6.2 Controlled Low Strength Materials (CLSM) ......................................165

6.6.3 Stabilization/Solidification of Water Based Sludge ..........................165

6.6.4 Compaction Grouting................................................................. 168

\section{CHAPTER 7-- SOIL TREATMENT USING FRESH AND LANDFILLED CEMENT}

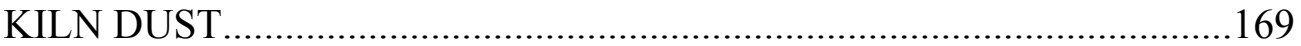

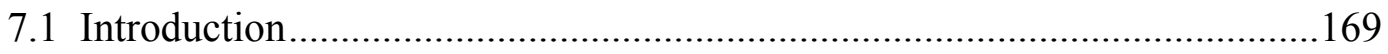

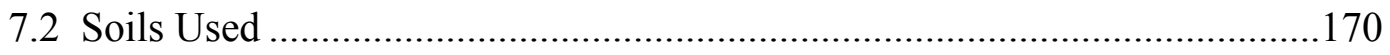

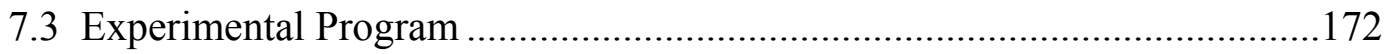

7. 4 Soil CKD Interaction- Rapid Ameliorating Effects.................................174

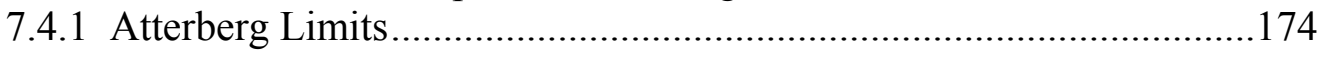

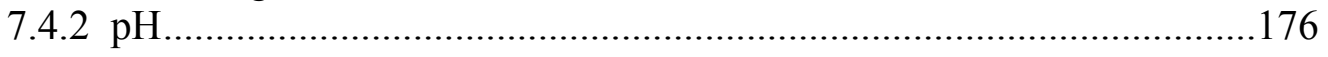

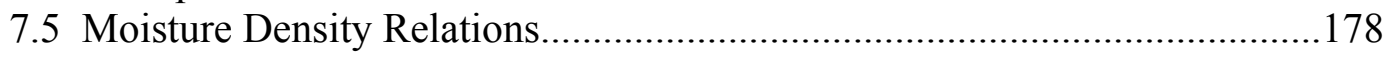

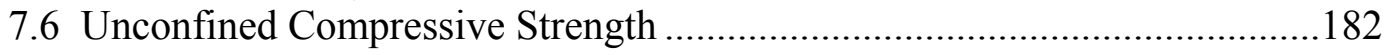

7.6.1 Phase I - Tests with Fresh I CKD.................................................182

7.6.2 Phase II - Tests with Fresh III CKD and Landfilled CKD .................184

7.6.2.1 Selected Additional Unconfined Compressive Strength Data for Soil

Treated with Fresh and Landfilled CKD .....................................186

7.7 CBR Results for Soaked and Unsoaked Specimens ................................191

7.8 Swelling Behavior.................................................................................193

7.8.1 Swelling Behavior from CBR Tests .............................................193

7.8.2 Long Term Swelling Behavior................................................... 195

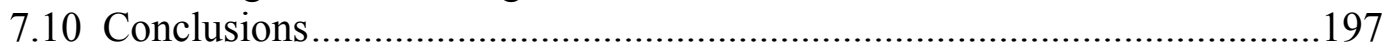


CHAPTER 8 -- CKD IN CONTROLLED LOW STRENGTH MATERIAL.................200

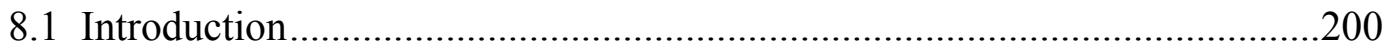

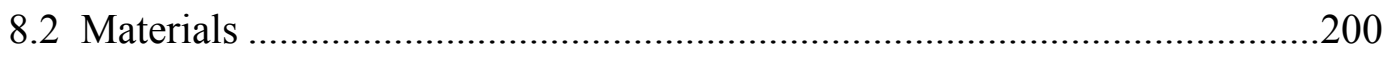

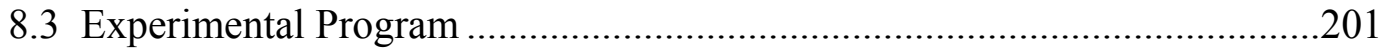

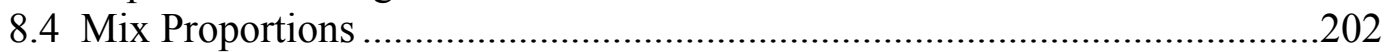

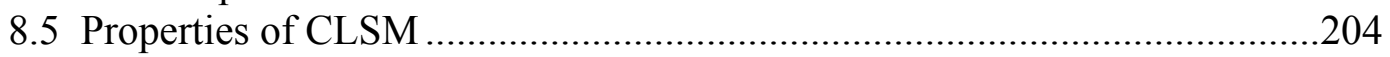

8.5.1 Properties of Fresh CLSM ....................................................204

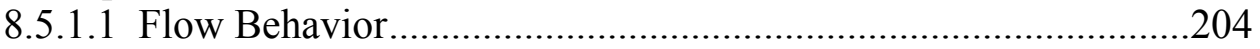

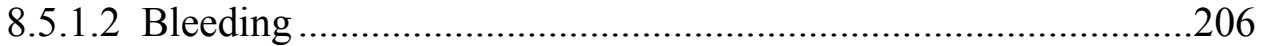

8.5.1.3 Unit Weight...................................................................20

8.5.1.4 Setting Time......................................................................207

8.6.2 Properties of Hardened CLSM..............................................................211

8.6.2.1 Unconfined Compressive Strength ........................................211

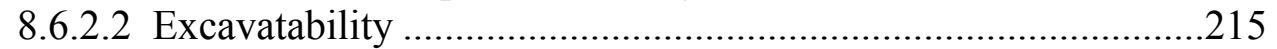

8.6.2.3 Corrosiveness ...........................................................................216

8.9 Advantages and Disadvantages of Using CKD in CLSM ..........................219

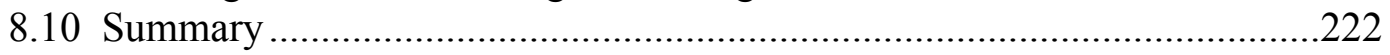

CHAPTER 9 -- CONCLUSIONS, SIGNIFICANCE AND RECOMMENDATIONS...224

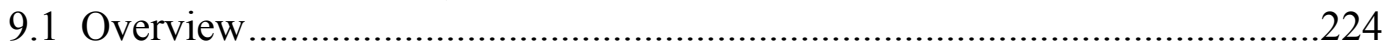

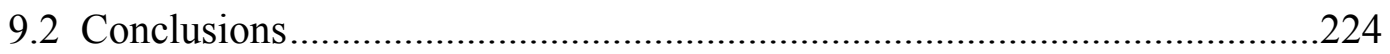

9.2.1 Conclusions from characterization study ......................................225

9.2.2 Conclusions on the use of the CKDs for soil improvement................231

9.2.3 Conclusions on the use of the CKDs in CLSMs ...............................2232

9.3 Significance and Impact of the Research Work ........................................2. 233

9.3 Recommendations for Future Research .................................................234

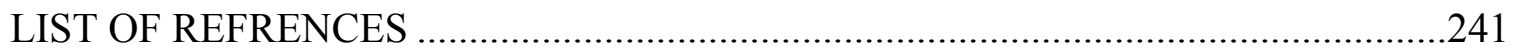

\section{APPENDICES}

Appendix A Heidelberger Technology Center Report on Free Lime Content ...............257

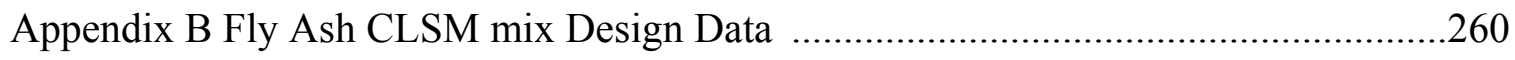




\section{LIST OF TABLES}

Table

Page

Table 2-1 Reactions occurring in the cement kiln at different temperature ranges (PCA, 1992 and Taylor, 1997)

Table 2-2 Production of cement kiln dusts from different plant operation types (Steuch, 1992, Kessler, 1995 and Muller, 1977) .16

Table 2-3 Typical costs associated with CKD disposal, \$/Short ton (Kessler, 1995) .......18

Table 2-4 Cement production in Indiana as of 2002 ..................................................22

Table 2-5 Summary of landfill design configuration (EPA, 1998) ...............................27

Table 2-6 Leachable (TCLP) metals in cement and CKD (PCA, 1992) ..........................30

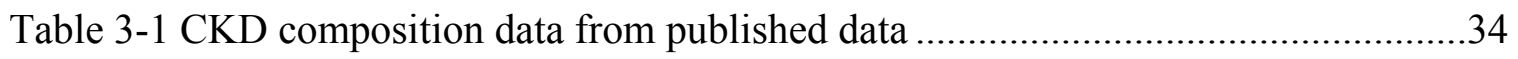

Table 3-2 Statistics on composition of fresh CKD based on 63 CKDs presented in

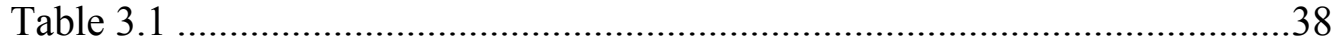

Table 3-3 Data for two stockpiled CKDs (Collins and Emery, 1983)...........................40

Table 3-4 Summary of CKDs and soils used and strength of treated soils (McCoy and Kriner, 1971)...................................................................43

Table 3-5 Average composition of cement kiln dust (Haynes and Kramer, 1982) ..........46

Table 3-6 Typical mineralogical compositions of selected CKDs (Muller, 1977 (from Bhatty, 1995))

Table 3-7 Effect of particle size on alkali content of CKD (European plants) (Corish and Coleman, 1995)...... .51

Table 3-8 CKDs used for compaction studies performed by Todres et al. (1992) ...........53

Table 3-9 Permeability values, $\mathrm{k}$ of compacted CKD sample (Todres et al., 1992) .........54

Table 3-10 Summary of soils and CKDs used by McCoy and Krinner (1971) (from Bhatty, 1995) .59

Table 3-11 Summary of soils and CKDs investigated by other researchers .60 
Table

Table 3-12 Atterberg limits and 7-day compressive strength of soil treated with CKD, lime and cement (McCoy and Kriner, 1971) (from Bhatty et al., 1996)

Table 6-1 Summary of experiments conducted in phase I.......................................117

Table 6-2 Summary of experiments conducted in phase II ........................................118

Table 6-3 Oxide composition of fresh and landfilled CKD tested ...............................120

Table 6-4 Specific surface area of fresh and landfilled CKD .....................................132

Table 6-5 Specific surface area of nine fly ashes

(Malhotra and Ramezanianpour, 1994) ......................................................133

Table 6-6 Compressive strength (in MPa) of pastes of fresh I CKD and cement ..........135

Table 6-7 Permeability values of fresh and landfilled CKD.....................................145

Table 6-8 Range in permeability values for soils (Mitchell, 1993) ..............................145

Table 6-9 Summary of specimen characteristics and peak friction angle from

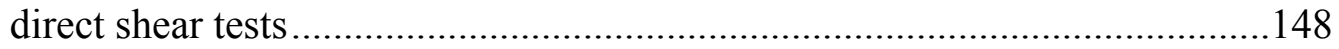

Table 6-10 Frictional characteristics of granular materials (Smith and Lohnes, 1984)...148

Table 6-11 Corrosivity parameters of fresh and landfilled CKD .................................153

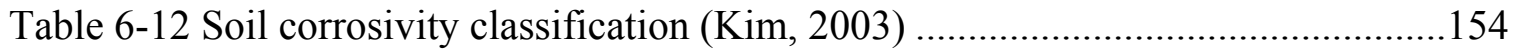

Table 6-13 Corrosivity parameters of Indiana bottom ashes (Ke and Lovell, 1992) ......154

Table 6-14 Leachable (TCLP) metals in CKD samples tested (mg/L).........................158

Table 6-15 Key difference in properties between fresh and landfilled CKD .................160

Table 6-16 Summary of key properties for fresh III and landfilled

CKD and potential applications.... 164

Table 7-1 Index properties and classification of soils used in the experimental program

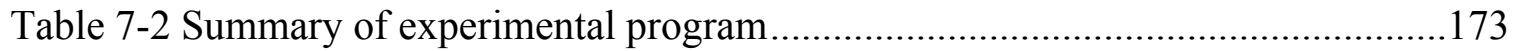

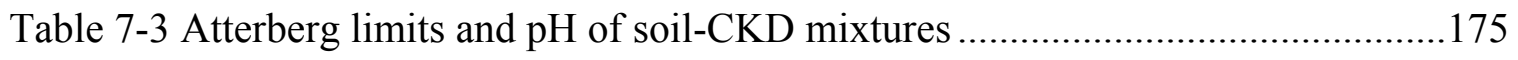

Table 7-4 Atterberg limits of soil S with fresh III CKD obtained at 0, 1, 3 and 7 days ..176

Table 7-5 pH values of soil, soil-CKD and soil-lime mixtures .177

Table 7-6 Optimum moisture content and maximum dry density of soil-CKD mixtures

Table 7-7 Unconfined compressive strength at optimum moisture content 183

Table 7-8 Unconfined compressive strength at optimum moisture content .185 
Table 7-9 Effect of CKD on unconfined compressive strength of "wet" soil 185

Table 7-10 CBR indices of specimens compacted at wet of OMC (CKD treated specimens cured in the humid room for 14 days before testing)

Table 7-11 CBR values of CKD treated soil compacted at OMC (no curing prior to testing)

Table 7-12 Maximum percentage vertical swell of tested specimens ...........................196

Table 8-1 Types and properties of materials used in the CLSM .................................201

Table 8-2 Mix proportions for the CLSM used ......................................................203

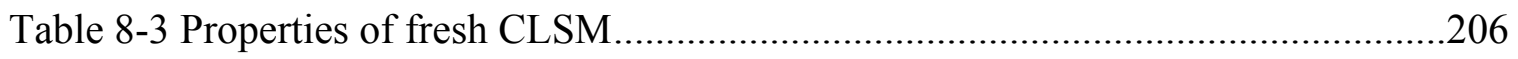

Table 8-4 Initial setting and walkability times from penetration resistance test ............210

Table 8-5 Properties of hardened CLSM …..............................................................213

Table 8-6 Strength requirements reported in the literature ......................................216

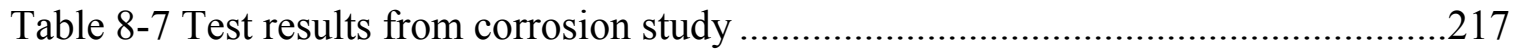

Table 8-8 Summary of flowable fill properties...........................................................221 


\section{LIST OF FIGURES}

Figure

Page

Figure 2-1 Diversion of solid waste from disposal via beneficial use (Schmitt, 2005)......9

Figure 2-2 Cement manufacturing process (Corish, 1995).....

Figure 2-3 Schematic diagram showing the phases present during the formation of portland cement clinker (Diamond, 2000)

Figure 2-4 Zones in a wet process kiln with typical gas and material temperature profile and collection of CKD (Bye, 1983) ................................................14

Figure 2-5 Location of cement plants in the US (www.cement.org)..............................19

Figure 2-6 Statistics of the cement consumption in the US (www.cement.org)...............19

Figure 2-7 Flow chart for gross CKD management practices in the US

(Kessler, 1995 and EPA, 1993) 20

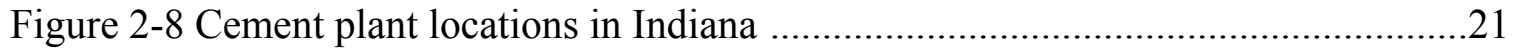

Figure 2-9 Annual portland cement production in the state of Indiana (Shaffer, 2004)....22

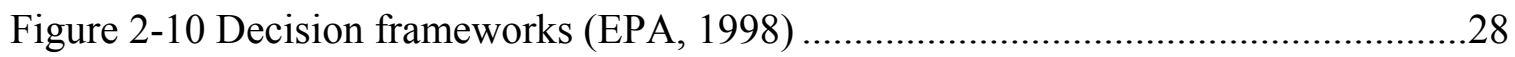

Figure 2-11 Comparisons of studies conducted in 1982 by Bureau of Mines and in 1992 by PCA.

Figure 3-1 Histograms representing the variation of (a) free lime and (b) LOI

Figure 3-2 Relationship between free lime and hydration modulus for the data given in

Table 3.1(Shaded band highlights the favorable range of HM).

Figure 3-3 Relationship between compressive strength of CKD-fly ash blends and TRO of CKDs (Collins and Emery, 1983).......................................................42

Figure 3-4 Variation of TRO with LOI for CKDs given in Table 3.1 ............................44

Figure 3-5 Variation of TRO with free lime for CKDs given in Table 3.1 ….................44

Figure 3-6 Variation of LOI with free lime (data from Table 3-1)...............................46

Figure 3-7 X-Ray diffraction for four CKDs (Konsta-Gdoutos and Shah, 2003) ............48

Figure 3-8 Examples of CKD particle size distributions from the literature ...................49 
Figure

Figure 3-9 Effect of kiln type and dust collection system on particle size distribution of CKD (Gdoutos and Shah, 2003)

Figure 3-10 Example of effect of kiln type CKD particle size distribution (all dusts collected using electrostatic precipitators) (Todres et al., 1992)....50

Figure 3-11 Typical compaction curves for fresh CKDs (Todres et al., 1992) .54

Figure 3-12 Variation in Atterberg limits of high plasticity clay with CKD addition (Zaman et al., 1992)

Figure 3-13 Variation in limits for different soils treated with different percentages of CKD (Miller and Azad, 2000)

Figure 4-1 Layout of the cement manufacturing process in the Lehigh plant in

Mitchell, IN (Tolliver, 2002) .72

Figure 4-2 Layout of CKD landfill and locations of borings......................................... 74

Figure 4-3 Views of the CKD landfill in Mitchell, IN ..............................................74

Figure 4-4 Borings in landfill are being performed using a simple auger boring-spiral type auger .... .79

Figure 4-5 Preparation for standard penetration test................................................. 79

Figure 4-6 Plastic sleeves with CKDs sample inside the split barrel sampler..................80

Figure 4-7 Final marked tube samples sealed at both ends and ready for shipping ..........80

Figure 4-8 SPT - N values and sample recovery as a function of depth for the three boreholes .81

Figure 4-9 Variation of SPT - N values with depth for the three boreholes ....................81

Figure 4-10 Conveying CKD from the landfill to the screener using a backhoe .82

Figure 4-11 Separation of lumps present in landfilled CKD during screening operation .83

Figure 4-12 Collection of screened CKD in the plastic bins ........................................83

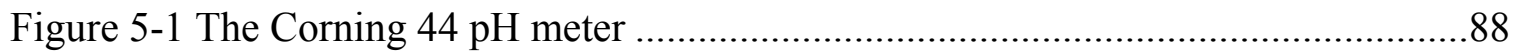

Figure 5-2 Procedure to eliminate bedding errors in unconfined compression tests .........93

Figure 5-3 Diagram showing the connection between the resistivity meter and electrodes .96

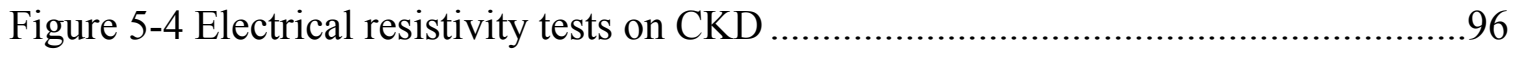

Figure 5-5 Figure showing a typical ion chromatograph........................................97

Figure 5-6 Basic components of an ion chromatography system .................................98 
Figure

Figure 5-7 The Dionex ion chromatograph

Figure 5-8 Layout showing the typical components of an inductively coupled plasma

spectrometer system

Figure 5-9 The plasma emission detector used for the present study

Figure 5-10 Schematic of the set up used for investigating the long term swelling behavior 106

Figure 5-11 Kitchen aid mixer used for preparing CLSM

Figure 5-12 Flow test

Figure 5-13 Coupons are suspended in cylindrical mold containing CLSM for corrosion testing

Figure 6-1 Steps involved in the development of reuse applications for waste by-product materials (Modified from Edil and Benson, 1998)

Figure 6.2 Samples used to determine oxide composition shown in Table 6-3 (shaded in black)

Figure 6-3 XRD pattern for fresh and landfilled CKD .121

Figure 6-4 Location of borehole samples and results of water content, LOI and $\mathrm{pH}$ tests.

Figure 6-5 Particle size distribution of fresh and landfilled CKD

Figure 6-6 Tube samples used to determine particle size distributions shown in Figure 6-5 (shaded in black)

Figure 6-7 SEM micrographs of fresh II and landfilled CKD 126

Figure 6-8 SEM micrographs of fresh III CKD. 127

Figure 6-9 SEM micrographs of sample G from boring B1 ....................................128

Figure 6-10 SEM micrographs of sample F from boring B2 ...................................129

Figure 6-11 SEM micrographs of sample B from boring B3 ....................................130

Figure 6-12 SEM micrographs of landfilled CKD ...............................................131

Figure 6-13 Average compressive strength of (a) cement and (b) CKD pastes .............136

Figure 6-14 Dimensional stability of cube samples made from different CKDs ...........137

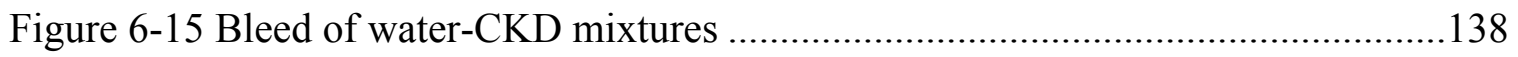

Figure 6-16 Moisture density relations of fresh and landfilled CKDs. 139 
Figure

Figure 6-17 Stress strain behavior of fresh and landfilled CKD in unconfined compression

Figure 6-18 Effect of compaction energy on the strength of fresh and landfilled CKD .142

Figure 6-19 Effect of mellowing on the unconfined behavior of compacted fresh III CKD (standard Proctor compacted samples)

Figure 6-20 One dimensional compression of fresh III and landfilled CKD ................146

Figure 6-21 Typical shear behavior of fresh III CKD

Figure 6-22 Typical shear behavior of landfilled CKD ............................................150

Figure 6-23 Corrosion of steel in water as a function of $\mathrm{pH}$ level (Bentur, 1997) ..........155

Figure 6-24 Tube samples used to determine heavy metal concentrations shown in Table 6-14 (shaded in black)

Figure 7-1 Moisture density relations for soil $\mathrm{G}$ treated with $0,8,15$ and $20 \%$ fresh I CKD

Figure 7-2 Moisture density relations for soil $\mathrm{W}$ treated with 0,8 , and $15 \%$ fresh I CKD

Figure 7-3 Moisture density relations for soil S treated with fresh III and landfilled CKD.

Figure 7-4 Stress-strain behavior of soil G treated with 8,15 \& $20 \%$ fresh I CKD (w 20\%)

Figure 7-5 Effect of percentage fresh III CKD on stress strain behavior

Figure 7-6 Effect of soil water content on stress strain behavior (soil S and with $20 \%$ fresh III CKD) 188

Figure 7-7 Effect of soil water content on stress strain behavior (soil S treated with $10 \%$ landfilled CKD) 188

Figure 7-8 Effect of $1 \%$ portland cement on soil treated with $10 \%$ fresh III

Figure 7-9 Effect of $1 \%$ cement on soil treated with $10 \%$ landfilled CKD $\left(\mathrm{w}_{\text {soil }} \sim \mathrm{OMC}\right)$

Figure 7-10 Effect of 1\% cement on soil treated with $10 \%$ landfilled CKD

$\left(\mathrm{w}_{\text {soil }}>\mathrm{OMC}\right)$

Figure 7-11 Swelling behavior of compacted CKD treated soil (soil S) specimens at $\mathrm{OMC}$

Figure 7-12 Swelling behavior of compacted CKD treated soil (soil S) specimens (cured for 14 days) at higher water content.... 
Figure

Figure 7-13 Effect of addition of Fresh I CKD and cement (PC) on the

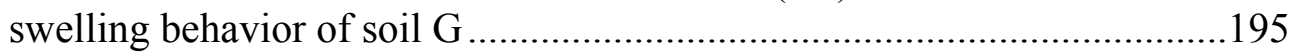

Figure 7-14 Results of long term swelling tests for soil S ......................................196

Figure 8-1 Particle size distribution of sand used .....................................................201

Figure 8-2 Flowability tests on LFA-CLSM and CKD-CLSM (HC-FCKD3)...............205

Figure 8-3 Setting curves for fresh CKD-CLSM......................................................208

Figure 8-4 Setting curves for landfilled CKD-CLSM ..............................................209

Figure 8-5 Setting curves for CLSM mixes with fly ash ........................................209

Figure 8-6 Steel coupons embedded in sand; a) before cleaning and b) after cleaning...218 


\section{LIST OF ABBREVATIONS AND NOTATIONS}

$\begin{array}{ll}\text { ACI } & \text { American Concrete Institute } \\ \text { APCA } & \text { American Portland Cement Alliance } \\ \text { ASTM } & \text { American Society for Testing and Materials } \\ \text { BET } & \text { Brunauer Emmett and Teller } \\ \text { CaO } & \text { Calcium Oxide } \\ \text { CBR } & \text { California Bearing Ratio } \\ \text { CFR } & \text { Code of Federal Regulations } \\ \text { CKD } & \text { Cement Kiln Dust } \\ \text { CKRC } & \text { Cement Kiln Recycling Coalition } \\ \text { CLSM } & \text { Controlled Low Strength Materials } \\ \text { cm } & \text { Centimeter } \\ \text { CO } & \text { Carbon dioxide } \\ \text { D } & \text { Diameter } \\ \text { D } & \text { Relative density } \\ \text { EPA } & \text { Environmental Protection Agency } \\ \text { FA } & \text { Fly ash } \\ \text { FHWA } & \text { Federal Highway Administration } \\ \text { g } & \text { Gram } \\ \text { Gs } & \text { Specific gravity } \\ \text { H } & \text { Height } \\ \text { HDPE } & \text { High Density Polyethylene } \\ \text { HM } & \text { Hydration Modulus } \\ \text { HWMU } & \text { Hazardous Waste Management Units } \\ \text { ICP } & \text { Inductively Coupled Plasma } \\ & \end{array}$




\begin{tabular}{|c|c|}
\hline INDOT & Indiana Department of Transportation \\
\hline $\mathrm{k}$ & Permeability \\
\hline $\mathrm{Kg}$ & Kilo gram \\
\hline $\mathrm{kN}$ & Kilo Newton \\
\hline $\mathrm{kPa}$ & Kilo Pascal \\
\hline 1 & Liter \\
\hline LL & Liquid limit \\
\hline LOI & Loss on ignition \\
\hline LVDT & Linear Variable Displacement Transducer \\
\hline $\mathrm{m}$ & Meter \\
\hline $\mathrm{mg}$ & Milligram \\
\hline MPa & Mega Pascal \\
\hline MSWLF & Municipal Solid Waste Landfills \\
\hline NPDES & National Pollution Discharge Elimination System \\
\hline $\mathrm{OMC}$ & Optimum Moisture Content \\
\hline OPC & Ordinary portland cement \\
\hline PCA & Portland Cement Association \\
\hline PI & Plasticity index \\
\hline PL & Plastic limit \\
\hline psi & Pound per square inch \\
\hline RCRA & Recycle Conservation and Recovery Act \\
\hline $\mathrm{RH}$ & Relative humidity \\
\hline RTC & Report to Congress \\
\hline SEM & Scanning electron microscope \\
\hline $\mathrm{SiO}_{2}$ & Silicon dioxide \\
\hline SD & Standard deviation \\
\hline SPT & Standard penetration test \\
\hline $\mathrm{S} / \mathrm{S}$ & Stabilization/solidification \\
\hline $\mathrm{T}$ & Temperature \\
\hline TCLP & Toxicity Characteristics Leaching Procedure \\
\hline
\end{tabular}




$\begin{array}{ll}\text { TGA } & \text { Thermo gravimetric analysis } \\ \text { TPH } & \text { Tons per hour } \\ \text { TPD } & \text { Tons per day } \\ \text { TRO } & \text { Total Reactive Oxide } \\ \text { UCS } & \text { Unconfined compressive strength } \\ \text { USCS } & \text { Unified soil classification system } \\ \text { w } & \text { Water content } \\ \text { XRD } & \text { X-Ray Diffraction } \\ \rho_{\mathrm{d}} & \text { Dry density } \\ \rho_{\mathrm{d} m a x} & \text { Maximum dry density } \\ \Phi & \text { Friction angle } \\ \mu \mathrm{m} & \text { Micron meter }\end{array}$




\section{CHAPTER 1 -- INTRODUCTION}

\subsection{Problem Statement}

The manufacture of portland cement is accompanied by the generation of large quantities of cement kiln dust (CKD), a by-product waste material. In the United States, more than four million tons of CKD that is unsuitable for recycling in the cement manufacturing process require disposal annually (Todres et al., 1992). Due to the large amounts of CKD produced, the costs associated with its disposal, and the continuous interest in seeking more cost effective construction materials, there has been great interest in finding applications for this industrial by-product. Researchers have investigated the re-use of CKD in various fields (e.g. as a soil fertilizer, as a stabilizer of waste water streams, as a partial replacement of soda in glass production, as an anti-stripping agent in asphalts, as a component of blended cements and masonry products [e.g. see Klemm, 1980 and Bhatty, 1995]).

So far most of the work performed has been limited to freshly generated CKD, i.e, the CKD immediately removed from the cement plant. The issue of reusing already landfilled material has, instead, been mostly unexplored. Landfilled CKD is available in significantly greater quantities than the fresh CKD, with accumulations of stockpiles estimated to be well in excess of 100 million tons in the US as of 1983 (Collins and Emery, 1983). While the recycling of landfilled material poses additional challenges associated with the variability in age, the exposure during storage to varying environmental conditions, and potential contamination, several considerations suggest that investigation of prospects of its industrial as well as non-industrial use is of great practical significance. In particular:

- there exist large quantities of this material that could be re-utilized; 
- mining of landfilled cement kiln dust would extend the life of existing landfills, and free disposal volume for wastes that cannot be easily reused;

- when the existing contaminant facility does not meet the requirements for permanent disposal, mining and re-use of the CKD would limit/avoid the costs associated with excavation and re-storage of the material;

- by making use of the landfilled material, large volume of traditional, "more precious" construction materials that are always at risk of being depleted may be conserved;

- the use on a large scale of landfilled CKD may lead to more cost effective solutions for the construction of roadways.

The commitment by the Indiana DOT to promoting and facilitating the use of waste materials in highway construction together with Lehigh Cement Company's need to address the disposal of newly generated CKD, as well as the management of the already landfilled CKD, promoted the study conducted at Purdue University.

In November 2000, Lehigh Cement Company and the Indiana DOT sponsored an exploratory investigation on the use of fresh cement kiln dust (CKD) generated from the Lehigh plant in Mitchell, Indiana, for soil stabilization. This preliminary research, conducted as part of the Joint Transportation Research Program (JTRP) yielded promising results (Santagata and Bobet, 2002) for the use of CKD in this capacity and as a result additional work funded by the Indiana DOT was initiated in August 2002. Additional funding was provided by Lehigh Cement Company with contribution from the Indiana Department of Commerce through an "Innovation grant". This second phase of the research was aimed, in particular, at evaluating the properties and potential for reuse of previously landfilled CKD obtained from a disposal site in the same Lehigh facility in Mitchell, IN. For comparison purposes the study also included extensive testing of the fresh CKD produced by the same plant. This report summarizes the work conducted in this second stage of the research. 


\subsection{Scope of Study}

The overall goal of this research study was to identify potential applications for the CKDs investigated based on a detailed characterization of the materials.

The specific objectives of the research can be summarized as follows:

1 Design a sampling program to collect CKD samples from the selected landfill (used by Lehigh Cement Company for disposal of the CKD from the adjacent Mitchell plant over a period of 12 years). At the same, time obtain samples of the fresh CKD from the same plant.

2 Establish the spatial variability in properties of landfilled CKD given that differences in age and in environmental conditions in which it has been stored may impose significant challenges to its use.

3 Compare the physio-chemical properties of the fresh and the landfilled material and evaluate the two materials with respect to other CKDs, based on published data.

4 Design a detailed laboratory testing program to establish the engineering properties of both fresh and landfilled CKD.

5 Evaluate the environmental hazardous potential of leachate residuals which might be released from fresh and landfilled CKD. Investigate the corrosiveness of CKD as it may sometimes be inevitable for CKD to come in contact with metals when it is used in construction.

6 Identify the salient properties of fresh and landfilled CKDs based on the detailed characterization tests.

7 Identify potential applications for these materials based on the favorable properties of CKD observed from the characterization tests.

8 Explore in detail the potential of using fresh and landfilled CKD in selected applications by relevant experimental methods. 


\subsection{Research Approach}

The objectives described above were pursued through an extensive laboratory experimental program which was articulated in three main phases: a) CKD sampling; b) CKD characterization; $c$ ) evaluation of CKDs for selected applications.

\subsubsection{CKD Sampling}

During this phase of research, two different CKDs from the Lehigh plant were investigated: "fresh" CKD obtained directly from the plant, and "landfilled" CKD obtained from the adjacent landfill used by Lehigh for CKD disposal for more than twelve years.

The fresh CKD was sampled on three different occasions. Based on the date of sampling, the fresh CKD is referenced in the following with a different Roman numeral (i.e. fresh I, II, and III). The results presented in this report pertain primarily to tests performed making use of the CKD (termed fresh II and fresh III) obtained during 2003.

The "landfilled CKD" was obtained in March 2003. Tube samples were obtained at three locations in the landfill to give insight into the spatial variability in properties of the landfilled CKD. In addition, bulk samples were obtained with a backhoe at an open front in the landfill where CKD was being mined for agricultural use.

\subsubsection{CKD Characterization}

Extensive characterization of the chemical, physical and engineering properties of the fresh and landfilled CKD was performed. This work was aimed at:

- comparing the characteristics of the fresh and landfilled CKDs;

- performing a preliminary evaluation of the variability of the landfilled CKD;

- assessing how the characteristics of the two CKDs (fresh and landfilled) compared to other CKDs based on published literature;

- isolating key characteristics of the two CKDs for purposes of identifying their potential re-use in construction related applications; 
- initiating a study on the potential impact of chemical alteration on the physiochemical and mechanical properties of a reactive by-product such as CKD when exposed to environment, as in a disposal site;

The properties evaluated in this phase included: chemical composition, free lime content, loss of ignition (LOI), mineralogical composition through XRD, specific gravity, particle size distribution, particle surface morphology (through SEM), specific surface area (nitrogen adsorption and Blaine fineness), compaction characteristics, permeability following compaction and binding properties. In addition to the above tests, the impact of particle morphology on the mechanical behavior of CKDs was assessed by studying the compressibility and frictional properties (via direct shear tests) on dry CKD powders. The environmental suitability of fresh and landfilled CKD was assessed by analyzing the leachable trace metals and corrosion characteristics.

\subsubsection{CKD Applications}

As a result of the characterization tests and additional preliminary engineering tests, it became evident that any reutilization of the CKDs had to exploit the following key properties of these materials: fineness, limited reactivity, high alkalinity and ability to absorb water. The following potential applications were identified:

- treatment of wet subgrades

- improvement of water logged areas

- controlled low strength fill mixtures (CLSM)

- sludge stabilization

- grouting mixtures

- anti-stripping agents in asphalt

Following interaction with members of the study advisory committee, it was decided that given the strong interest of INDOT in identifying cost-effective alternatives for subgrade treatment, this would be the first application investigated.

Investigation of the use of CKD for soil stabilization/modification relied on compaction and strength testing using a low plasticity Indiana clay (LL $=41.0 \%$, 
$\mathrm{PL}=18.4 \%$, clay fraction $=38 \%$ ) treated with $10-20 \%$ (by dry mass of soil) $\mathrm{CKD}$. The dosages of CKD were selected based on the results of previous experimental work and the combined use of CKD and portland cement was also considered. Tests were also performed to study the swelling behavior of CKD treated soil and also the rapid ameliorating effects (e.g. $\mathrm{pH}$, Atterberg limits) associated with the addition of CKD to soil.

To evaluate the viability of using the CKDs under investigation for controlled low strength mixtures, tests were conducted on mixes manufactured with either the fresh or the landfilled CKD. Three mixes each were manufactured with fresh and landfilled CKDs as the fine material. Additionally two mixes were prepared with CKDs in combination with fly ash. Two reference mixes with fly ash, representative of mixes employed in the state of Indiana were also prepared for comparison purposes. Properties measured in this phase were: flow behavior, setting time, bleeding, unit weight and unconfined compressive strength. Excavatability and walkability time were also estimated from these results. Model mass loss tests were conducted to compare the corrosiveness of CKDCLSM with fly ash-CLSM.

\subsection{Organization of the Report}

Chapter 2 summarizes the background on the generation, disposal and current management practices of CKD. The chapter also discusses the environmental issues associated with the storage and disposal of CKD.

Chapter 3 presents an extensive literature survey on the physio-chemical properties and utilization of CKD. A data base on the oxide composition of CKD from 63 sources published in the literature is presented and the data set is analyzed to establish the variability in properties of CKD.

The materials used in the investigation program are discussed in Chapter 4. The chapter presents in particular the field investigation and sampling procedures followed for collection of tube samples from the landfill.

Chapter 5 outlines the experimental program performed in this study. The experimental procedures are summarized in three sections. The first part discusses the 
experiments conducted to characterize the fresh and landfilled CKDs. The second and third sections illustrate the experiments performed to explore the application of CKD in soil stabilization/modification and in controlled low strength materials, respectively.

Chapter 6 summarizes the physio-chemical and engineering properties of the fresh and landfilled CKDs.

Chapter 7 summarizes all the test results obtained in the experimental work undertaken to evaluate the fresh and landfilled CKDs for soil treatment.

Chapter 8 presents the results of the laboratory investigation conducted to explore the potential of using fresh and landfilled CKD in controlled low strength materials (CLSM).

Chapter 9 presents the conclusions of this research work and provides recommendations for future work. 


\section{CHAPTER 2 -- CEMENT KILN DUST- GENERATION, DISPOSAL PRACTICE AND ENVIRONMENTAL REGULATIONS}

\subsection{Introduction}

"It is sometimes argued that waste materials are an avoidable problem; that new and improved technology, coupled with new strategies for reuse and recycling, will eliminate waste" (Glasser, 2000). Implementation of new technologies may help to reduce the quantity of waste generated in future; however production of some amount of waste is inevitable. According to the Environmental Protection Agency (EPA), American industrial facilities generate and dispose of approximately 7.6 billion tons of industrial solid waste each year (www.epa.gov). Most of these materials have been landfilled at considerable cost since the inception of modern environmental regulations in the late 1970s and early 1980s (Edil and Benson, 1998). Currently, as the volume of waste and by-product materials generated in our society and the cost of disposal become greater, there is increased pressure and incentive to recover and recycle these materials for use in secondary applications. Figure 2-1 shows the amount of solid waste diverted from disposal via beneficial use between 1994 and 2001. Environmental regulations are being modified to permit the re-use of these materials in a variety of applications to reduce the waste generated. The EPA's future mission is to establish a "zero waste" environment by recycling all materials back into nature or the market place in a manner that protects human health and the environment. The significance of recycling industrial waste has been recognized in regard to decreasing disposal costs, reduction of landfill space, natural resource conservation, reducing environmental hazards and efficient landfill utilization. In the last few decades researchers have been exploring alternate uses of byproduct and waste materials in engineering and construction applications which made mass application of these materials. For example, blast furnace slag, fly ash, bottom ash, boiler 
slag, reclaimed pavement material and many other industrial by-products have been or are in the process of being beneficially used as highway materials.

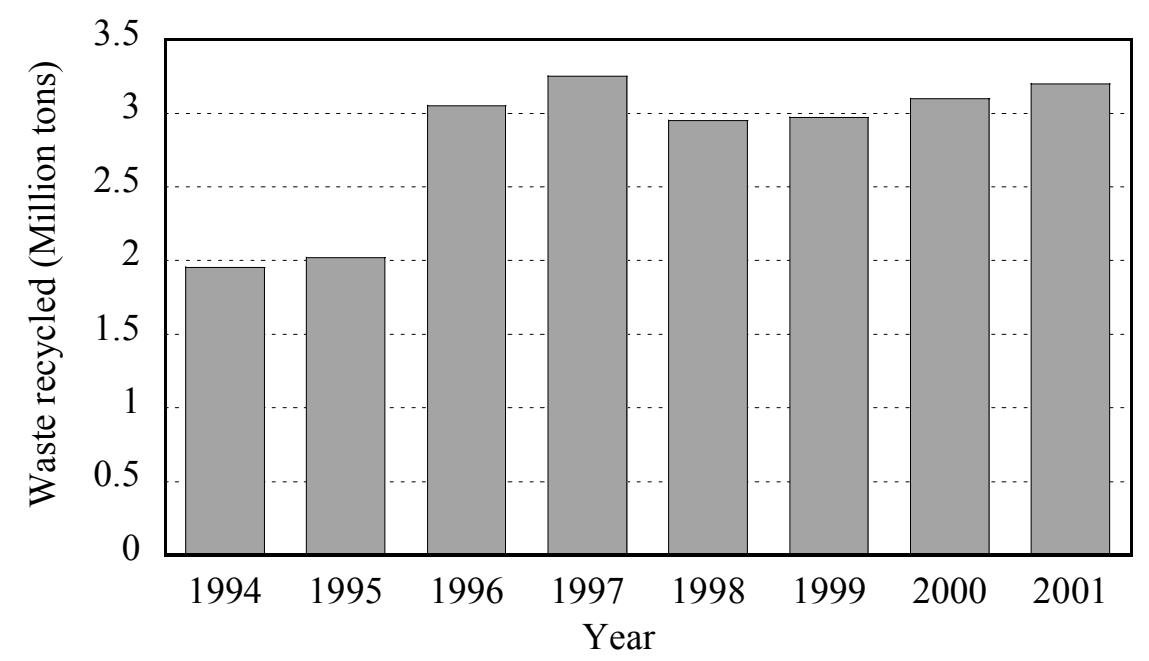

Figure 2-1 Diversion of solid waste from disposal via beneficial use (Schmitt, 2005)

The manufacture of portland cement is accompanied by the generation of large quantities of a waste material: cement kiln dust (CKD). Despite the improvements in process technology which have reduced the amounts of CKD produced, and despite the research that has gone into finding secondary applications for this material, considerable amounts of $\mathrm{CKD}$ continue to require disposal through stockpiling or landfilling every year. The generation of $\mathrm{CKD}$ is responsible for a significant financial loss to the cement industry in terms of the value of raw materials, processing, energy usage, dust collection and, above all, disposal and storage. In recent years, cement industries have demonstrated a keen interest in finding practical applications for CKD due to the quantity of CKD produced, the cost associated with its production and disposal in addition to the strong and strict environmental regulations on the management of CKD. Before discussing the issues related to disposal practice, characteristics, and applications of CKD, it is beneficial to understand the steps involved in the generation of CKD. 


\section{$\underline{2.2 \text { Overview of Cement Manufacturing and CKD Production }}$}

\subsubsection{Portland Cement and its Manufacturing Processes}

ASTM C 150 defines portland cement as "hydraulic cement produced by pulverizing clinkers consisting essentially of hydraulic calcium silicates, usually containing one or more forms of calcium sulfate as an inter-ground addition". According to PCA (1992) cement manufacturing is simply the conversion of calcium and silicon oxides into calcium silicates. Calcium silicates being its primary constituents, portland cement is produced by combining materials containing calcium oxide, silica, alumina and iron oxide at high temperatures around $1450^{\circ} \mathrm{C}$. The production of portland cement is generally a four step process: 1) acquisition of the raw materials 2) preparation of the raw materials; 3) pyroprocessing of the raw materials to form portland cement clinker; and 4) grinding of the clinker into portland cement. Figure 2-2 schematically illustrates the above steps.

The raw materials for cement manufacturing are a finely ground mixture of limestone and clay containing approximately $75 \%$ calcium carbonate, $15 \%$ silicon dioxide, $3 \%$ aluminum oxide, $2 \%$ iron oxide. Minor constituents, generally less than $5 \%$ by weight of the mixture, include magnesium, sulfur, sodium, and potassium (Taylor, 1997). There can be numerous other trace elements which generally total less than $1 \%$ of the mixture. Raw materials must be very intimately mixed before they are introduced into the kiln. Based on the preparation of the feed material prior to calcination, cement kilns are classified as either wet process cement kilns or dry process cement kilns. In wet process kilns which are generally simpler but less energy efficient, feed is prepared in the form of a slurry containing 30\% to $40 \%$ water (Mehta, 1993). Modern cement plants favor the dry process, which is more energy efficient than the wet process because the water used in the slurry must subsequently be evaporated before the clinkering operation. An efficient dry-kiln will consume only about $60 \%$ of the energy required to produce a ton of cement in a typical wet-process kiln (PCA, 1992). A further advancement in cement kiln technology is the preheater/precalciner kiln, where fuels are combusted in the 


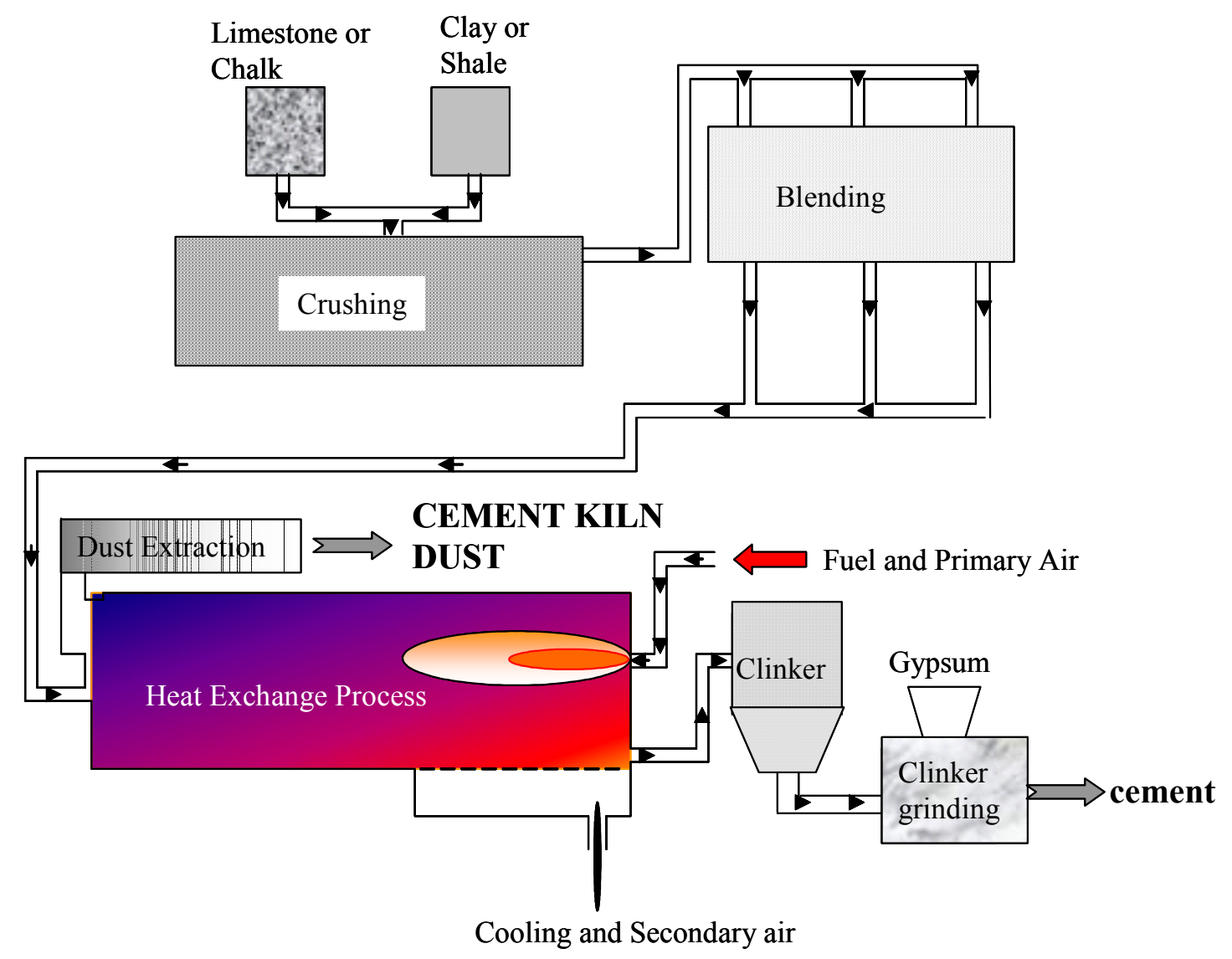

Figure 2-2 Cement manufacturing process (Corish, 1995)

preheater system just upstream of the rotary kiln. Here the moving raw material powder is dispersed in a stream of hot gas coming from the kiln. The initial heating to about $800^{\circ} \mathrm{C}$ is carried out in a preheater using the carbon dioxide $\left(\mathrm{CO}_{2}\right)$ evolved from the limestone and the hot combustion gases from the fuel. Lower grade fuels can be used in a precalciner kiln because the temperatures required for calcinations are much lower than the temperatures needed to fuse the minerals into clinker.

The well-homogenized raw materials are fed into the upper end of cylindrical rotary kilns, huge ovens that can range in size from 3.7 to $5.5 \mathrm{~m}$ in diameter, 46 to $183 \mathrm{~m}$ in length and rotate at 1-4 revolutions per minute. Typically the length to diameter ratio of kilns ranges from 30:1 to 40:1. The kiln is slightly inclined (3-4\%) and rotates about its longitudinal axis. As the raw mix travels down the kiln, it is gradually heated to 
$1450^{\circ} \mathrm{C}$ in the burning or clinkering zone. The raw materials are fed into the upper end of the kiln while fuels are burned in the lower end. Pulverized coal ash is the most commonly used fuel, though oil, natural gas and lignite are also used. The various reactions occurring along the kiln as the raw material moves along the kiln at different temperatures are summarized in Table 2-1. Successive reactions in different regions of the kiln produce hard pellets called clinker by partial fusion of raw materials, typically 3$20 \mathrm{~mm}$ in diameter, which when ground with gypsum and other additives produce the fine powder called portland cement. The chemistry of clinker formation is summarized in Figure 2-3. The clinker typically has a composition in the range of $67 \% \mathrm{CaO}, 22 \% \mathrm{SiO}_{2}$, $5 \% \mathrm{Al}_{2} \mathrm{O}_{3}, 3 \% \mathrm{Fe}_{2} \mathrm{O}_{3}$ and $3 \%$ of other components (Taylor, 1997).

Table 2-1 Reactions occurring in the cement kiln at different temperature ranges (PCA, 1992 and Taylor, 1997)

\begin{tabular}{ll}
\hline \multicolumn{1}{c}{ Temperature $\left({ }^{\circ} \mathbf{C}\right)$} & \multicolumn{1}{c}{ Process } \\
\hline \hline 100 & Evaporation of free water \\
500 and above & $\begin{array}{l}\text { Dehydroxylation of clay minerals } \\
\text { Crystallization of products of clay minerals } \\
\text { dehydroxylation } \\
\text { Re0 and above }\end{array}$ \\
$900-1200$ & $\begin{array}{l}\text { aluminosilicates } \\
\text { Beginning of liquid formation }\end{array}$ \\
$1250-1280$ & $\begin{array}{l}\text { Further liquid formation and completion of formation } \\
\text { of cement compounds }\end{array}$ \\
Above 1280 &
\end{tabular}

The pyroprocessed hydraulic material is composed of four major oxide phases: tricalcium silicate $\left(\mathrm{C}_{3} \mathrm{~S}\right) \quad(50-70 \%)$, dicalcium silicate $\left(\mathrm{C}_{2} \mathrm{~S}\right) \quad(15-30 \%)$, tricalcium aluminate $\left(\mathrm{C}_{3} \mathrm{~A}\right)(5-10 \%)$, and tetracalcium aluminoferrite $\left(\mathrm{C}_{4} \mathrm{AF}\right)(5-15 \%)$ (In cement 
chemistry notation, $\mathrm{C}=\mathrm{CaO}, \mathrm{S}=\mathrm{SiO}_{2}, \mathrm{~A}=\mathrm{Al}_{2} \mathrm{O}_{3}$ and $\mathrm{F}=\mathrm{Fe}_{2} \mathrm{O}_{3}$ ). Several other phases, such as alkali sulphates and calcium oxide, are normally present in minor amounts.

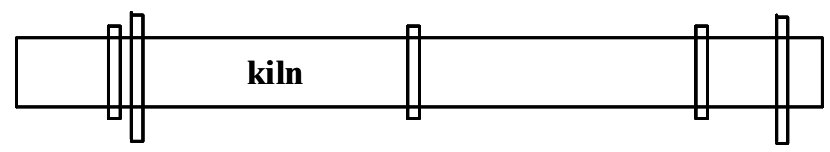

Preheater

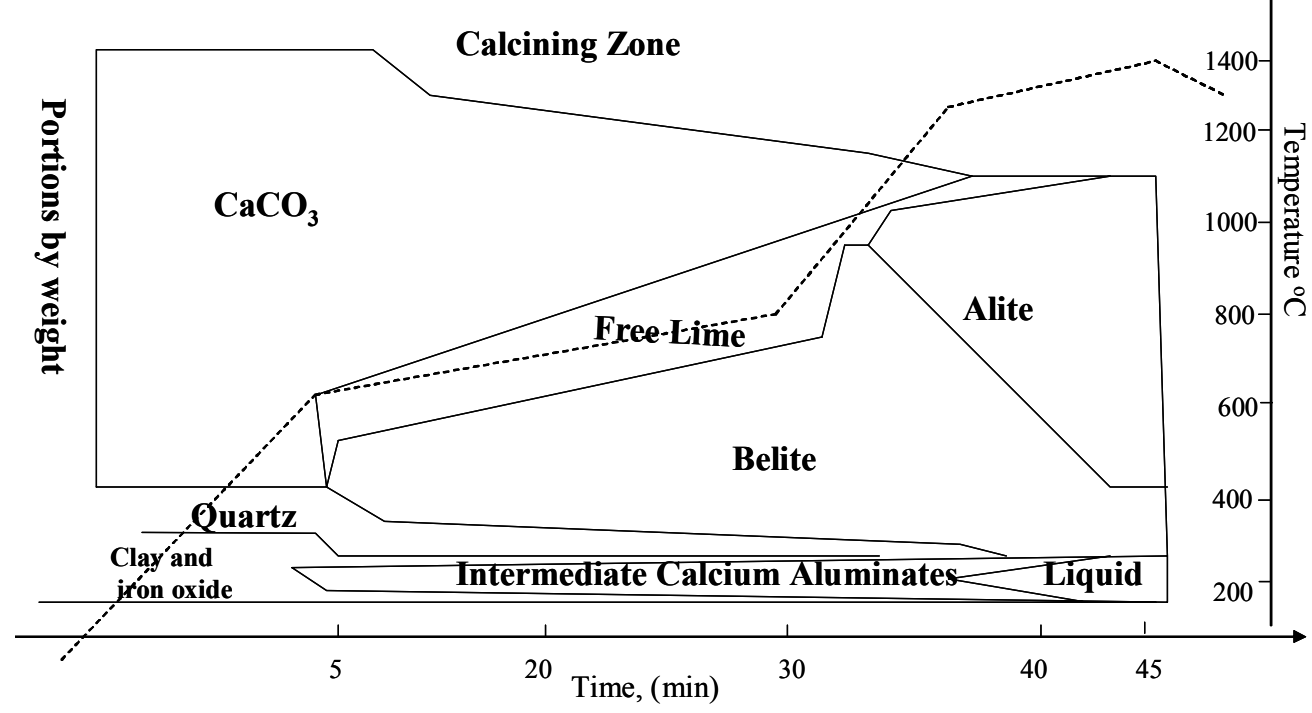

Figure 2-3 Schematic diagram showing the phases present during the formation of portland cement clinker (Diamond, 2000)

\subsubsection{Formation of Cement Kiln Dust}

As the kiln rotates the raw materials move slowly from the upper end to the lower end at a rate controlled by the slope and rotational speed of the kiln. In the hotter part of the kiln, potassium, sodium, chlorine and some other elements present in the raw materials or fuel are partially or wholly volatilized. These volatiles are not allowed to pass into the clinker. The oxygen for combustion of the fuel is provided by the rapid flow of air, which moves against the flow of raw material. The swift gas flow and continuous raw feed agitation are turbulent in nature and result in large quantities of particulate matter being entrained in the combustion gases. These combustion gases released from 
the fuels move up the kiln counter to the downward flow of raw materials as shown in Figure 2-4. The gas flow picks up partially burned raw materials and the volatilized materials, carrying them up the kiln. The entrained particulate matter (as well as various precipitates) constitutes cement kiln dust (CKD) and is subsequently removed from the kiln exhaust gases by air pollution control equipment. The nature and quantity of CKD produced strongly depends on the raw feed, fuel used, as well as on the design and operation of the cement kiln. Modern dry process kilns are equipped with an alkali bypass system which removes the volatilized alkali chlorides and sulfates from the CKD and hence facilitates its recycling back into the kiln. The quality and quantity of CKD generated is also affected by advancement in process technology like the introduction of a preheater system.

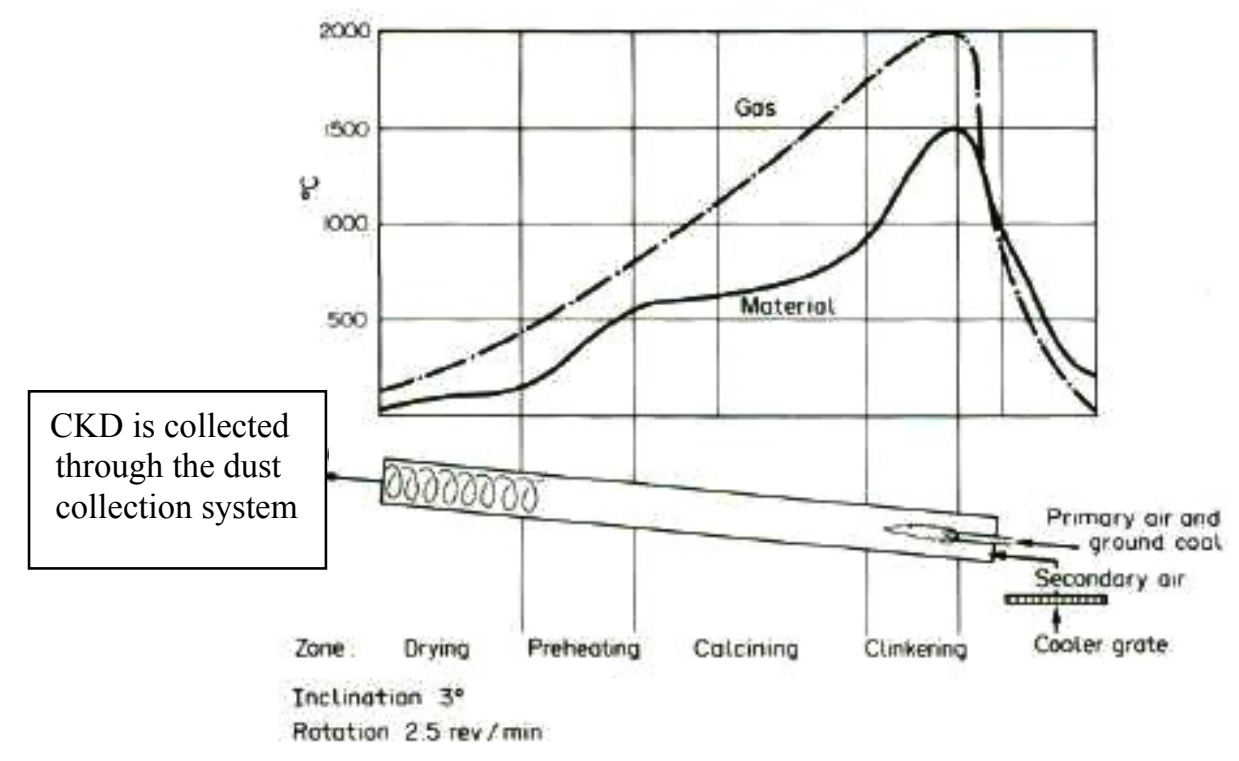

Figure 2-4 Zones in a wet process kiln with typical gas and material temperature profile and collection of CKD (Bye, 1983) 


\subsubsection{Cement Kiln Dust (CKD) - General}

Abeln et al. (1993) define CKD as a "fine particulate matter that consists of entrained particles of clinker, raw materials, and partially calcined raw materials". Cement industries generate millions of metric tons of cement kiln dust, as a measure to control product quality (low alkali clinker from high alkali raw materials) and to ensure uninterrupted operation of the plant (Kessler, 1995). Modern cement plants are equipped with provisions like suspension heaters which largely capture the dust (which is not removed by the dust collection system) before the gas escapes through the chimney. This dust depending on its composition (content of alkali, sulfates or chlorides) is recycled back into the kiln either by mixing it with the raw meal or with the fuel (insufflation). The major factor preventing return of more dust to the kilns is the high concentration of alkalis in the dust that would cause the alkali content of the clinker to exceed the allowable value, which in most of the United States is around $0.6 \%$. Additionally, the high concentrations of volatiles develop deposits on the walls of the kiln which can result in frequent shut down of the plant. Hence cement plants generate CKD as a means of removing volatile alkalis, chlorides and sulfates from the kiln system (Kessler, 1995).

The nature and amount of CKD can be significantly affected by the design, operation and materials used in a cement kiln. For example, a cement plant using raw materials, fuels low in alkalis (potassium and sodium), low chlorine and sulfur will generate lesser amounts of CKD. The CKD generated by intermittent bypass operation will typically have much higher levels of alkali, volatile metal salts, and oxides than CKD generated from a continuous bypass.

Although it is difficult to directly correlate in a quantitative manner dust generation and plant operation, the production of CKD strongly depends upon the type of process and design of gas velocities in the kiln (PCA, 1992). Other factors such as kiln performance and dust collection system also play vital roles. Since each kiln system markedly differs in the amount of dust contact and gas velocities, the quantity of CKD generated varies accordingly. According to Steuch (1992), the largest amount of dust is generated from long dry kilns in which the dust is stirred up by chains and the gas velocities are high. In contrast, in preheater kilns, feed loading is high and the resulting 
dust contact with kiln gases is short. Some of the wet kilns produce the lowest amount of dust, mainly because these kilns contain pebble-size dust agglomerates that are difficult to sweep away by the moving kiln gases. Thus the CKD generation is fairly low. Table 2-2 shows data reported in the literature on the percentage of CKD generated from each kiln operation type.

Table 2-2 Production of cement kiln dusts from different plant operation types (Steuch, 1992, Kessler, 1995 and Muller, 1977)

\begin{tabular}{lr|lc|lc}
\hline \multicolumn{2}{c|}{ Steuch, 1992 } & \multicolumn{2}{|c|}{ Kesseler, 1995 } & \multicolumn{2}{c}{ Muller, 1997 } \\
\hline $\begin{array}{l}\text { Kiln } \\
\text { operation }\end{array}$ & $\begin{array}{l}\text { Range of CKD } \\
\text { produced per } \\
\text { kiln feed (tons) }\end{array}$ & $\begin{array}{l}\text { Kiln } \\
\text { operation }\end{array}$ & $\begin{array}{l}\text { CKD production } \\
\text { (\% of clinker } \\
\text { produced) }\end{array}$ & $\begin{array}{l}\text { Kiln } \\
\text { operation }\end{array}$ & $\begin{array}{l}\text { Range of CKD } \\
\text { produced (\% of } \\
\text { clinker } \\
\text { produced) }\end{array}$ \\
\hline \hline Wet & $0.05-0.40$ & Wet & 11.5 & Wet & $10-25$ \\
Long dry & $0.25-0.40$ & Long dry & 10.5 & $\begin{array}{l}\text { Semi-dry/ } \\
\text { semi-wet }\end{array}$ & $0-3$ \\
Preheater & $0.10-0.15$ & $\begin{array}{l}\text { Preheater/ } \\
\text { precalciner }\end{array}$ & 4 & Dry & $7-15$ \\
\hline
\end{tabular}

Advancements in process design such as preheater systems and suspension heaters facilitates large scale recycling of CKD back into the kiln and have resulted in a significant reduction in the quantity of CKD generated per tons of clinker.

\subsubsection{CKD Collection System}

The devices most commonly used for collection of dust particulate emissions from cement kilns are cyclones, electrostatic precipitators or baghouses. Multiple cyclones are often used as the sole collection equipment for small capacity vertical kilns. For rotary kilns, the peak collection efficiency of cyclonic system ranges from 92 to $95 \%$, which is inadequate to meet current strict particulate emission standards. Electrostatic precipitators are most widely used for dust collection in the cement industry. The first 
electrostatic precipitator (Cottrell electrostatic precipitator) was installed at the Riverside Portland Cement industry in Crestmore, California in January, 1912 (Klemm, 1980). Electrostatic precipitators, which are normally capable of collection efficiencies of $99 \%$ or higher, operate by inducing an electrical charge in the area through which fuel gases flow and provide oppositely charged collection plates which attract the charged particles in the gas stream. These particles are attracted to and accumulate on the collection plates. Baghouses are structures containing a large number of fiberglass or cloth bags with a very fine mesh textures. They are multiple modular compartments with the capability of separating dust from different compartments. Baghouses reportedly achieve the highest consistent collection efficiency of all dust control system, sometimes approaching 99.9\% efficiency (Collins and Emery, 1983).

\subsubsection{Cost Associated with Generation of CKD}

Any plant that is wasting CKD experiences major costs associated with its generation and disposal. Table 2-3 outlines and compares typical costs associated with CKD generation and disposal.

Based on the volume of CKD generated, Schreiber and Riney (1995) calculated that the cost for disposal of CKD in designed landfill fall between $\$ 5$ and $\$ 14$ per ton. The costs associated with the generation and the management of CKD illustrate the importance of recycling the millions of tons of CKD produced every year by the cement manufacturing industry. 
Table 2-3 Typical costs associated with CKD disposal, \$/Short ton (Kessler, 1995)

\begin{tabular}{lccc}
\hline \multicolumn{1}{c}{ Description } & Low & Average & High \\
\hline \hline Raw Material Costs & 1.5 & 4 & 5.5 \\
Raw Feed Costs & & & \\
$\begin{array}{l}\text { Crushing, Conveying, } \\
\text { Drying and Grinding }\end{array}$ & 3.0 & 4.5 & 6.0 \\
$\begin{array}{l}\text { Fuel Costs } \\
\begin{array}{l}\text { Dust Collection and Sensible } \\
\text { heat }\end{array}\end{array}$ & 1.0 & 1.5 & 2.0 \\
$\begin{array}{l}\text { CKD Transport } \\
\text { Conveying, hauling and } \\
\text { Dedusting }\end{array}$ & 0.5 & 1.0 & 1.5 \\
$\begin{array}{l}\text { Landfill maintenance } \\
\begin{array}{l}\text { Monitoring, Pile } \\
\text { maintenances, and Closing }\end{array}\end{array}$ & 1.0 & 3.0 & 5.0 \\
$\begin{array}{l}\text { Total, \$/short ton of CKD } \\
\text { Landfilled }\end{array}$ & 7.0 & 14.0 & 20.0 \\
\hline
\end{tabular}

\subsubsection{CKD Generation Rates and Disposal Practice in United States}

Cement is one of the most widely used construction materials. In the United States, 38 companies operate 116 cement plants in 35 states (www.cement.org). The locations of cement plants are shown in Figure 2-5. Figure 2-6 shows the statistics of the cement consumption in the US for the past 22 years. Note that the cement consumption includes both domestic production as well as imports.

Generation of CKD is estimated at approximately 30 million tonnes worldwide per year (Dyer et al., 1999). While modern dust-collecting equipment is designed to 


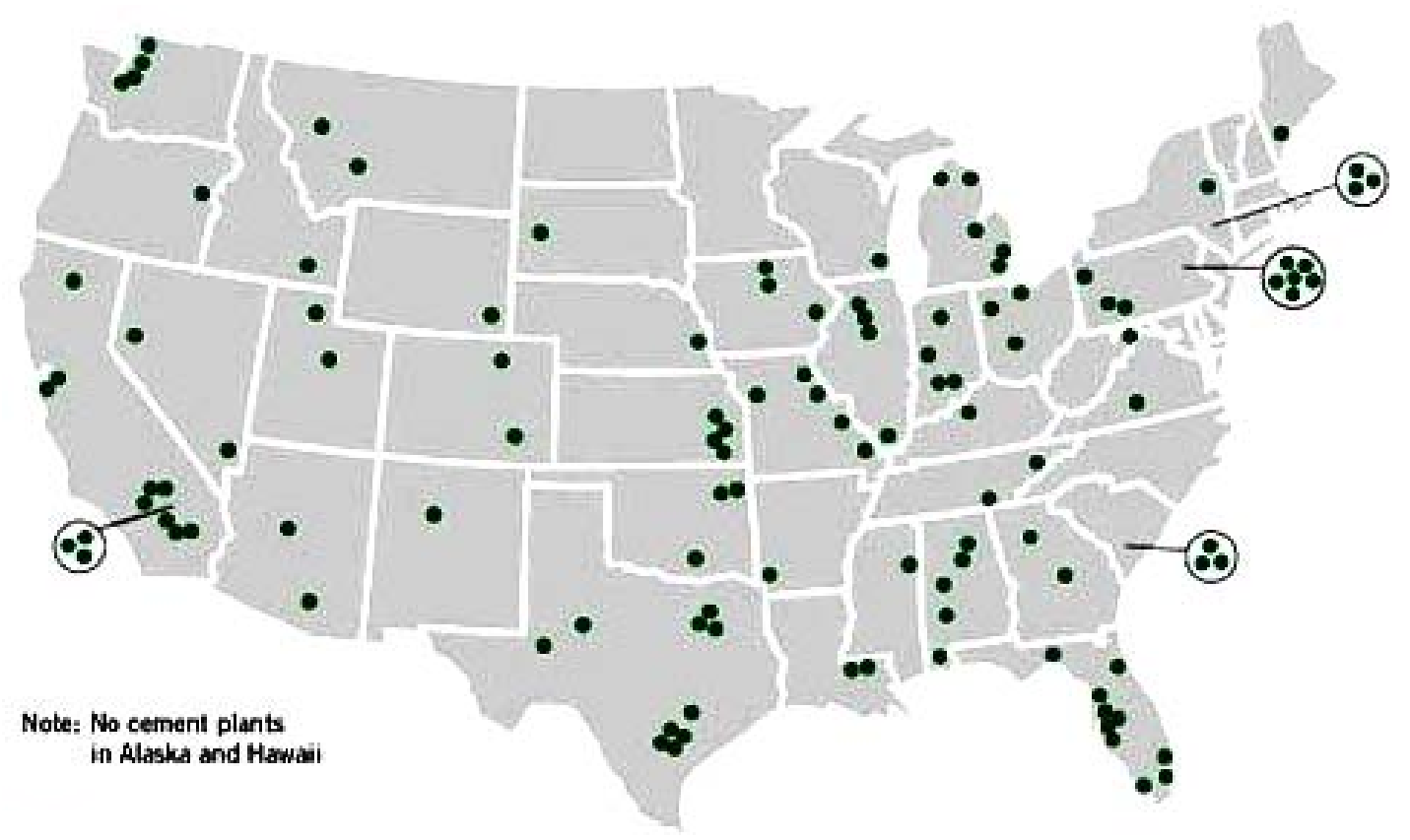

Figure 2-5 Location of cement plants in the US (www.cement.org)

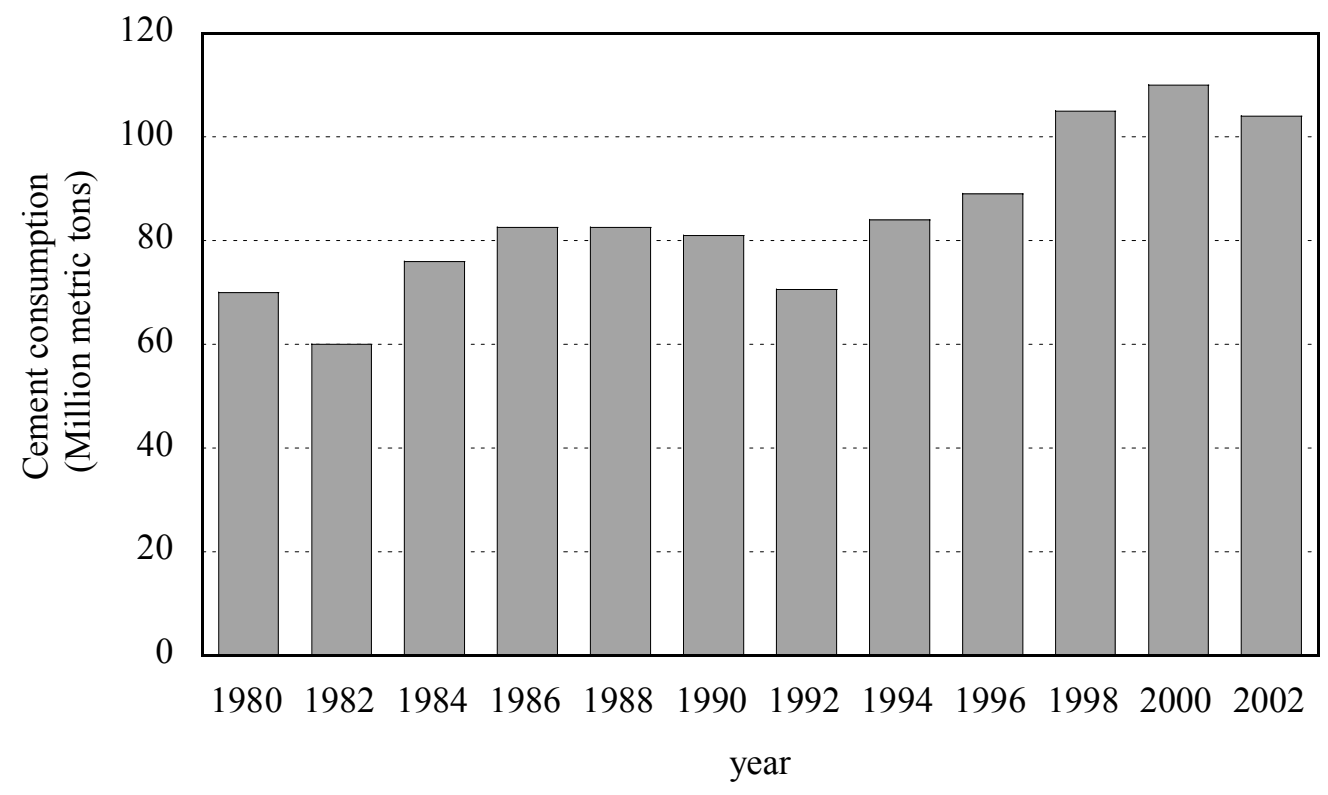

Figure 2-6 Statistics of the cement consumption in the US (www.cement.org) 
capture virtually all CKD, and much of this material can today be returned to the kiln, for various reasons, a significant portion, in some cases as much as 30\%-50\% of the captured dust, must be removed as industrial waste (Kessler, 1995; USEPA, 1998). Figure 2-7 illustrates the CKD management practices (Kessler, 1995; EPA, 1993). As a result, in the United States more than four million tons of CKD that are unsuitable for recycling in the cement manufacturing process, require disposal annually (Todres et al., 1992). This constitutes approximately $4.2 \%$ of the raw materials used by the cement industry (Nisbet, 1997).

Typically, CKD landfill units are non-engineered, unlined and uncovered landfills and piles located in abandoned quarries, retired portions of operating quarries or nearby ravines. The regulations and latest developments in the management of CKD are summarized in section 2.3. In 1993, the United States Environmental Pollution Agency (USEPA, 1993) estimated that of this material, 52\% was disposed of in landfills, 43\% percent in piles, and less than 5\% in ponds. The average piles were $15 \mathrm{~m}$ thick. Maximum reported thickness for CKD landfills and waste piles were $56.4 \mathrm{~m}$ and $34.6 \mathrm{~m}$, respectively.

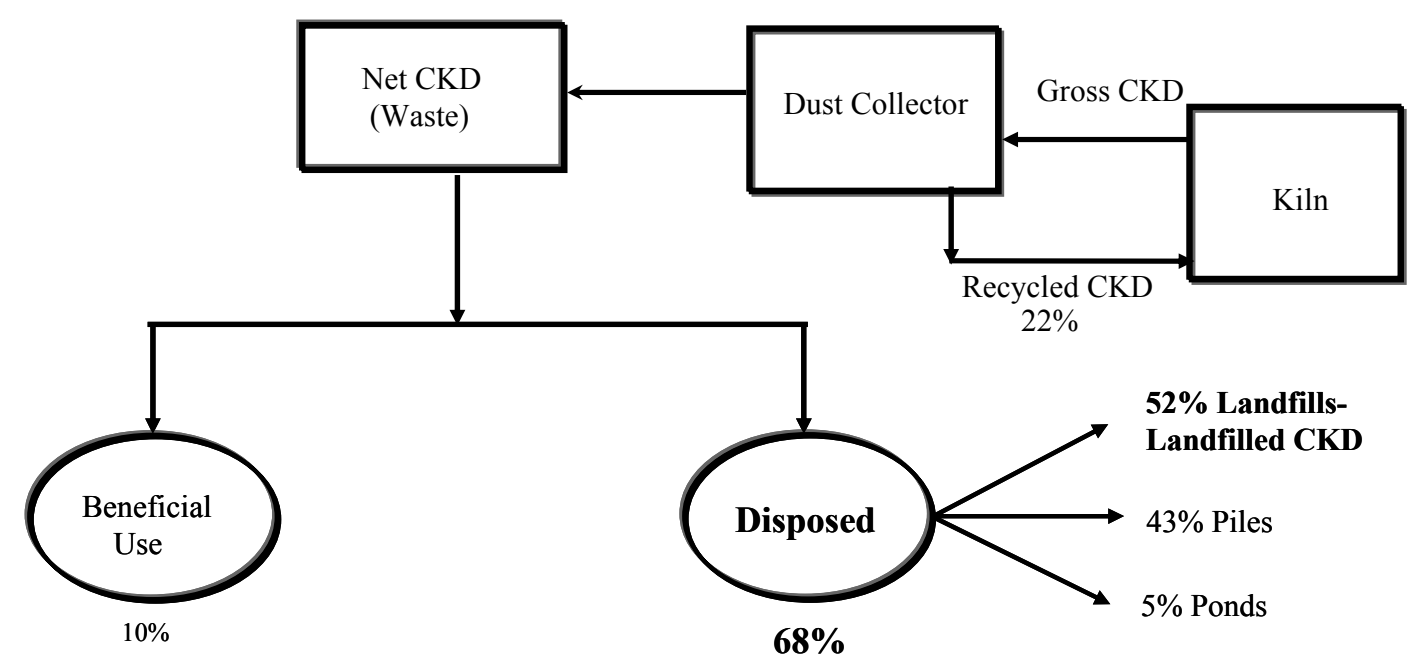

Figure 2-7 Flow chart for gross CKD management practices in the US (Kessler, 1995 and EPA, 1993) 


\subsubsection{Cement and CKD Generation in Indiana}

There are four cement production plants in the state of Indiana (Figure 2-8). Essroc Materials owns two plants, a wet processing plant in Logansport and a dry processing plant in Speed. As seen in Table 2-4, the cement production of the dry processing plant of the Essroc is significantly larger than that of the wet processing plant. Lone Star Industries, Inc uses a dry process accompanied by a precalciner. Figure 2-9 shows the annual cement production for the state of Indiana from 1995 to 2003. Due to an increase in demand and technological advances in processing there has been a steady increase in the annual cement production. The CKD production in the Lehigh cement plant is estimated at approximately 18,0000 metric tons per year (Tolliver, 2002).

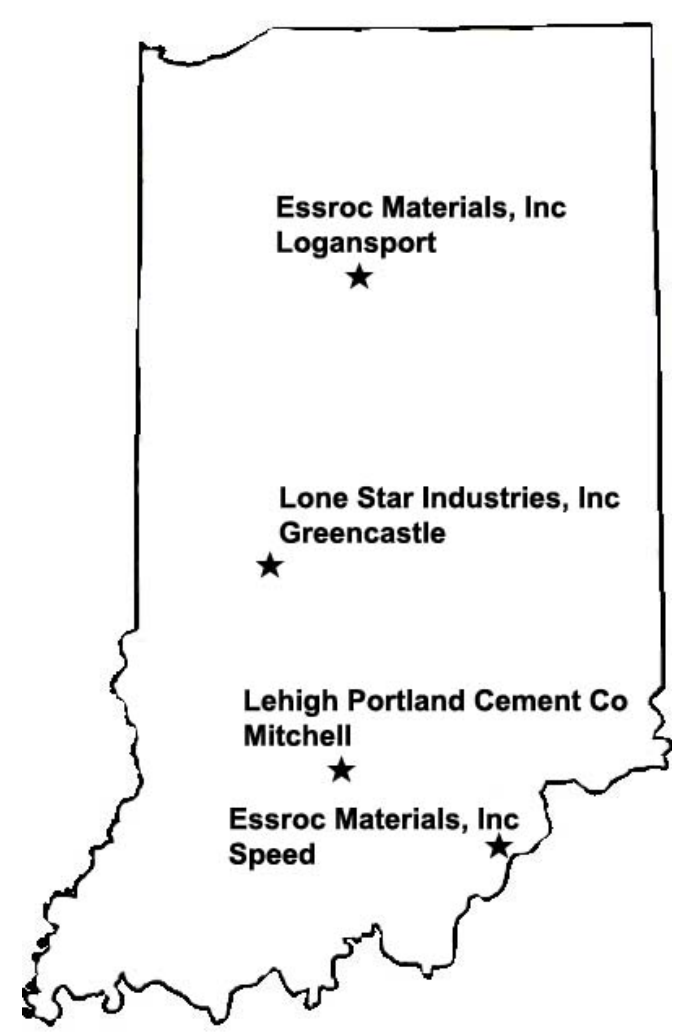

Figure 2-8 Cement plant locations in Indiana 
Table 2-4 Cement production in Indiana as of 2002 (www.lonestarind.com, www.essroc.com, wwww.lehighcement.com)

\begin{tabular}{|c|c|c|c|c|}
\hline Company & Location & $\begin{array}{l}\text { Types of cement } \\
\text { produced }\end{array}$ & $\begin{array}{c}\text { Type of } \\
\text { processing }\end{array}$ & $\begin{array}{c}\text { Cement Capacity } \\
\text { (tpy) }\end{array}$ \\
\hline $\begin{array}{l}\text { Essroc Materials } \\
\text { Inc. }\end{array}$ & Logansport, IN & $\begin{array}{l}\text { Types I, III and } \\
\text { Masonry }\end{array}$ & Wet & 430,000 \\
\hline $\begin{array}{l}\text { Essroc Materials } \\
\text { Inc. }\end{array}$ & Speed, IN & $\begin{array}{l}\text { Types I, IA, II, III } \\
\text { and Masonry }\end{array}$ & Dry & $1,150,000$ \\
\hline $\begin{array}{l}\text { Lehigh Portland } \\
\text { Cement Co. }\end{array}$ & Mitchell, IN & $\begin{array}{l}\text { Types I, II, III and } \\
\text { Masonry Cements }\end{array}$ & Dry (Precalciner) & 830,000 \\
\hline $\begin{array}{l}\text { Lone Star } \\
\text { Industries Inc. }\end{array}$ & Greencastle, IN & $\begin{array}{l}\text { Masonry Cements, } \\
\text { Type I, Type IA, } \\
\text { Type III }\end{array}$ & Dry (Precalciner) & $1,538,000$ \\
\hline
\end{tabular}

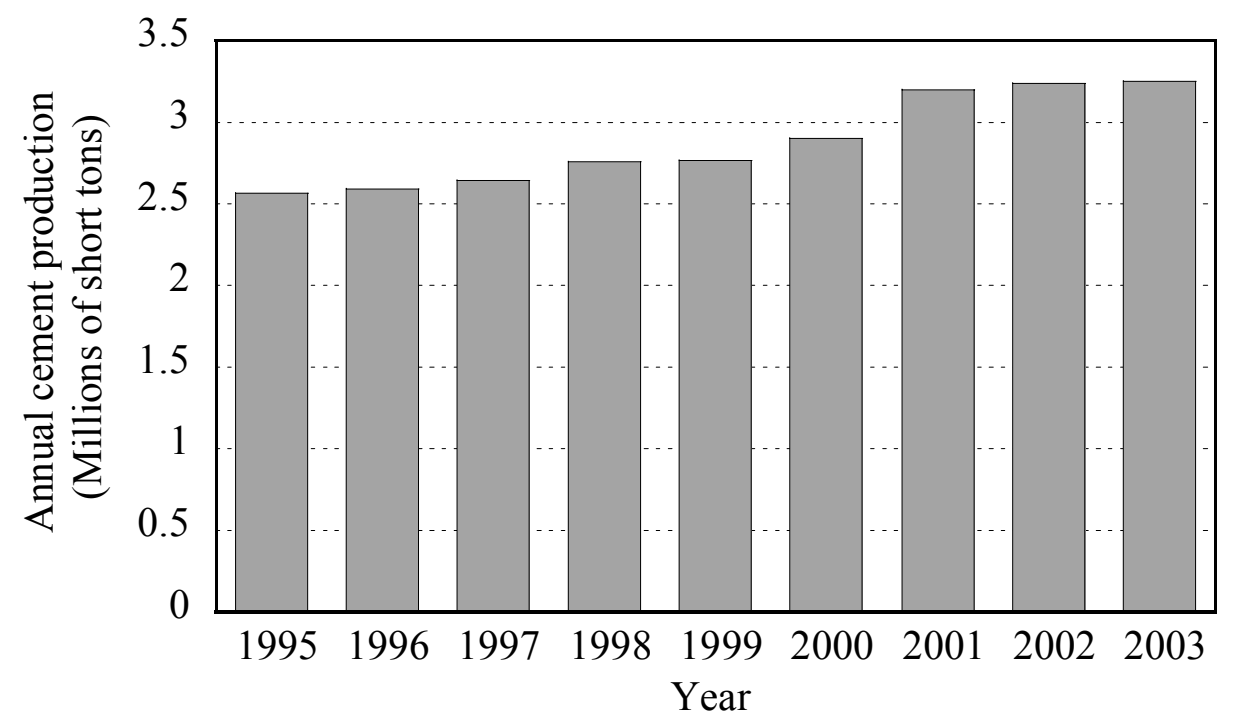

Figure 2-9 Annual portland cement production in the state of Indiana (Shaffer, 2004) 


\subsection{Environmental Issues Associated with CKD}

\subsubsection{Introduction}

The generation of cement kiln dust is not only accountable for a significant financial loss to the cement industry in-terms of raw materials and management of CKD, but also a source of environmental concerns. Greer and Matz (1996) define CKD management as a classic case of the transfer of a pollution problem from the air to the land, surface water or groundwater. Before the implementation of the Clean Air Act in the early 1970s, CKD was disposed of directly into the atmosphere without any control. Increased concern and awareness about air pollution constrained the discharge of CKD into the atmosphere to regulate future emissions and warranted the use of dust collection systems to protect the environment. As a result, CKD disposal practice shifted to dumping this waste into the open land or in a quarry, not into a designed landfill, with little thought being given to the environmental issues to be faced later. Today, the cement industry is faced with a rising problem of "storage" of the millions of tons of CKD that are collected each year. In addition to the fresh CKD, over the years considerable amounts of CKD has been landfilled or stockpiled and is available in significantly greater quantities than fresh CKD. More than 20 years ago, the CKD in these stockpiles was already estimated to be well in excess of 100 million tons in the U.S (Collins and Emery, 1983).

Over the past few years, regulatory agencies have conducted extensive studies on the issues associated with the "storage" of CKD. These have resulted in recommendations for cost-effective management standards and guidelines for the disposal of CKD that will avoid environmental impacts and extensive future remediation of the disposal sites. To date compliance with these guidelines has varied greatly from state to state.

\subsubsection{Regulatory History}

A brief account of the regulatory history of $\mathrm{CKD}$ provided here is taken from Greer and Matz (1196) and the EPA website (http://www.epa.gov/epaoswer/other/ckd/index.htm). Since 1980, cement kiln dust and 
certain other waste products have been temporarily excluded from otherwise applicable hazardous waste regulations under Subtitle $\mathrm{C}$ of the Resources Conservation and Recovery Act (RCRA) under the Bevill Amendment (RCRA Sec.3001(b)(3)). The provisions of the Bevill Amendment were included in implementing regulations of RCRA at 40 CFR 261.4. In this list of materials that were considered at the time to be high-volume but low-toxicity waste was CKD. RCRA requested that the Environmental Protection Agency study the current management practice of CKD and its adverse effects on human health and environment. The EPA was supposed to complete this study and submit a report to Congress (RTC) in 1983. The EPA failed to meet the deadline and finally submitted the RTC on December 30, 1993 after the Environmental Defense Fund filed suit against the EPA for missing the statutory deadline for the RTC. In March 1994, the American Portland Cement Alliance (APCA), the Cement Kiln Recycling Coalition (CKRC) and individual cement companies submitted extensive comments on the evidence and findings contained in the RTC. The EPA incorporated public comments in the report and held a series of public meetings in early 1994 before making any decisions on CKD management practices. After a long debate, in January 1995 the EPA announced the regulatory status of $\mathrm{CKD}$ management. The EPA decided that $\mathrm{CKD}$ required additional management controls to prevent damage to groundwater by controlling the release of waste CKD constituents to groundwater and potable water and to reduce health risks associated with dust problems. In a January 1995 announcement, it was stated that the requirements of the Clean Air Act, the Clean Water Act and the RCRA will be used in a tailored fashion to address the relevant pathways of potential releases while avoiding duplication among the existing regulatory programs. The EPA states that CKD does not typically exhibit the RCRA subtitle C hazardous waste characteristics; however the runoff that contacts $\mathrm{CKD}$ storage and waste piles has the potential to generate leachate containing hazardous characteristics.

The EPA's final decision has been criticized by some groups as constituting "Subtitle C Lite" regulation of CKD, and for failure to fully regulate the material as a full-fledged hazardous waste which should not escape RCRA regulation under the "derived from" rule that presently ensures the hazardous waste incinerator ash mist be 
treated as a hazardous waste. The critics contend that the EPA's decisions do not go far enough (EPA, 1998).

\subsubsection{Standards for Protection of Air and Groundwater Resources}

The disposal of CKD can bring about pollution problems not only to air but also to both surface water and groundwater. Considering the fine particle size of CKD, the EPA is suggesting the following steps to regulate the fugitive dust emission from CKD management and disposal operations (EPA, 1998):

- Compacting and periodic wetting of CKD managed in landfills

- On-site handling of CKD in closed, covered vehicles and conveyance devices

- Keeping cement kiln dust in enclosed tanks, containers, and buildings when temporarily stored for disposal or sale.

To regulate surface water pollution from CKD management and disposal the agency determined that the existing National Pollution Discharge Elimination System (NPDES) for water discharges would be sufficient. The EPA is proposing to ban disposal of CKD in units below the natural groundwater table and placing restrictions on the placement of CKD units in a 100-year floodplain, wetlands, fault areas, seismic impact zones and unstable areas including Karst terrains.

The proposed technical requirements for groundwater monitoring at CKD disposal units are based on those already promulgated under 40 CFR part 258 (for Municipal Solid Waste landfills( MSWLFs)) and 40 CFR part 264 (for Hazardous Waste Management Units (HWMU)). The EPA has evaluated a range of configurations for landfills to protect groundwater and these are summarized in Table 2-5. The EPA conducted a series of technical analyses to evaluate the various landfill design configurations against proposed performance standards. Later they recognized that it was necessary to develop a "one-size-fits-all" approach to fit all the CKD disposal sites through out the country because the cement manufacturing facilities are located in a wide range of climatic and hydrologic settings. Based on all of this analysis, the EPA concluded that the subtitle $\mathrm{D}$ default design would be adequate to control release of 
groundwater for all CKD landfill units including those in karsts areas with special precautions in areas of unstable ground such as landslides and sinkholes (40CFR 258.15). Based on the above conclusions, the EPA created a decision framework (Figure 2-10) to establish a rationale for deciding the type of groundwater controls required. The EPA's proposed standards for groundwater monitoring at CKD landfills include provisions for:

- Groundwater monitoring well design, construction and development

- Groundwater sampling and analysis requirements

- Statistical analysis of groundwater monitoring data

- Detection monitoring

- Assessment of corrective measures

- Selection of remedy 
Table 2-5 Summary of landfill design configuration (EPA, 1998)

\begin{tabular}{|c|c|c|c|c|c|}
\hline Design Variable & $\begin{array}{l}\text { Baseline CKD } \\
\text { Landfill }\end{array}$ & Modified CKD low & Modified CKD high & $\begin{array}{l}\text { Subtitle D (composite } \\
\text { Liner; leachate collection) }\end{array}$ & $\begin{array}{l}\text { Subtitle C (Double liner: } \\
\text { leachate collection) }\end{array}$ \\
\hline Cover layer & $\begin{array}{l}\text { Uncompacted CKD } \\
\text { (no cover) }\end{array}$ & $\begin{array}{l}0.5 \mathrm{ft} \text { top soil } \\
2 \mathrm{ft} \text { compacted CKD } \\
\left(\mathrm{k}=2 \times 10^{-5} \mathrm{~cm} / \mathrm{s}\right)\end{array}$ & $\begin{array}{l}1.0 \mathrm{ft} \text { top soil } \\
0.5 \mathrm{ft} \text { sand drainage layer- } \\
\left(\mathrm{k}=2 \times 10^{-3} \mathrm{~cm} / \mathrm{s}\right) \\
\text { Geotextile support fabric } \\
2 \mathrm{ft} \text { compacted CKD }\end{array}$ & $\begin{array}{l}0.5 \mathrm{ft} \text { top soil } \\
1.5 \mathrm{ft} \text { sand } \\
60 \mathrm{mil} \mathrm{HDPE} \text { geomembrane } \\
2 \mathrm{ft} \text { compacted soil cap }\end{array}$ & $\begin{array}{l}2 \mathrm{ft} \text { top soil } \\
1 \mathrm{ft} \text { sand } \\
30 \text { mil HDPE geomembrane } \\
2 \mathrm{ft} \text { compacted soil cap }\end{array}$ \\
\hline Liner layer & $\begin{array}{l}\text { Uncompacted CKD } \\
\text { (no liner) }\end{array}$ & $\begin{array}{l}\text { 4ft compacted CKD } \\
\left(\mathrm{k}=2 \times 10^{-5} \mathrm{~cm} / \mathrm{s}\right)\end{array}$ & $\begin{array}{l}\text { Geotextile filter fabric } \\
1 \mathrm{ft} \text { sand (leachate collection } \\
\text { layer ) } \\
\text { Geotextile support fabric } \\
4 \mathrm{ft} \text { compacted CKD }\end{array}$ & $\begin{array}{l}1 \mathrm{ft} \text { sand ( leachate } \\
\text { collection layer) } \\
60 \mathrm{mil} \mathrm{HDPE} \text { geomembrane } \\
2 \mathrm{ft} \text { clay }\end{array}$ & $\begin{array}{l}1 \mathrm{ft} \text { sand (leachate collection } \\
\text { layer) } \\
30 \mathrm{mil} \text { HDPE geomembrane } \\
1 \mathrm{ft} \text { sand (leachate detection } \\
\text { layer) } \\
30 \mathrm{mil} \mathrm{HDPE} \mathrm{geomembrane} \\
2 \mathrm{ft} \text { clay }\end{array}$ \\
\hline Slope of final Cover & NA & NA & 0.02 & 0.02 & 0.03 \\
\hline $\begin{array}{l}\text { Ground water } \\
\text { Monitoring }\end{array}$ & Yes & Yes & Yes & Yes & Yes \\
\hline Leachate Collection & No leachate collection & $\begin{array}{l}\text { No leachate } \\
\text { collection }\end{array}$ & Yes & Yes & Yes \\
\hline
\end{tabular}

Modified CKD low and Modified CKD high are two proposed CKD monofill landfill design configurations

$\mathrm{k}=$ Hydraulic conductivity

HDPE=High density polyethylene 


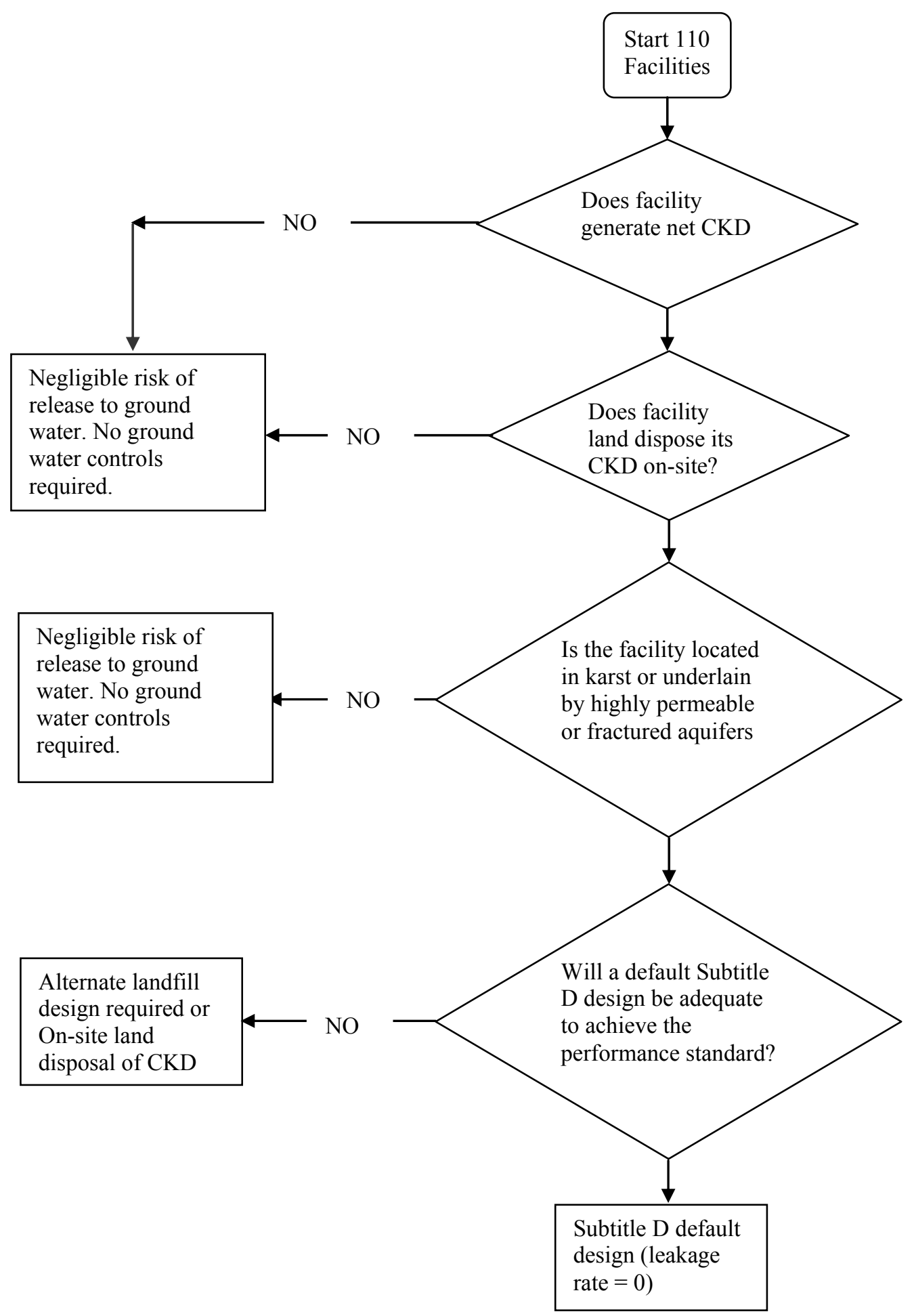

Figure 2-10 Decision frameworks (EPA, 1998) 


\subsubsection{Test Results of Trace Metals in the Leachate from Literature}

After the EPA placed regulations on the disposal of CKD, the U.S. Bureau of Mines in 1982 and Portland Cement Association (PCA) in 1992 conducted extensive studies evaluating the heavy metal concentrations in leachate from CKD to establish the hazardous waste potential of CKD generated in United States. Both of the studies determined the non hazardous nature of CKD by establishing the low level concentration of heavy metals in CKD leachate.

For the U.S Bureau of Mines Haynes and Kramer (1982) conducted an extensive study on the mineralogical and chemical composition of CKD and its hazardous waste potential. To assess the hazardous waste potential of CKD, toxicity tests were performed on 113 CKD samples from 102 plants in the United States, representing about $72 \%$ of the sites in operation which at that time routinely sent CKD waste to landfill. Based on these data, it was found that CKD did not meet the criteria for a hazardous waste under ignitability, corrosivity, reactivity, or toxicity. All but one sample were in total compliance (the non complying sample slightly exceeded the EPA toxicity test criterion for lead). Haynes and Kramer (1982) concluded that "Cement kiln dust is a large-volume material and a potential resource as a substitute for lime. Any environmental considerations are minor, as the results of this extensive survey show that US-CKD is not hazardous waste as defined by current regulations established under RCRA."

In 1992, PCA conducted a comprehensive study on trace metals for 79 plants in the United States and 10 plants in Canada using both conventional and waste derived fuels incorporating the use of cheap fuels in cement plants. In this study each CKD was tested for the eight RCRA metals: arsenic, barium, cadmium, chromium, lead, mercury, selenium and silver and additional four metals: antimony, beryllium, nickel and thallium. The average levels of trace metals found in the dust from the study are given in Table 26. All were found to be significantly below the regulatory limits. The study also evaluated the leachable trace metals according to the Environmental Protection Agency's Toxicity Characteristics Leaching Procedure (TCLP). With regard to TCLP tests on CKD, only one facility produced two CKD samples that exceeded the selenium limits and another facility produced two CKD samples that exceeded the lead limit. Relatively little CKD is 
discarded at these two plants and thus volatile metals accumulate in the recirculating CKD.

Table 2-6 Leachable (TCLP) metals in cement and CKD (PCA, 1992)

TCLP-Cement, $\mathrm{mg} / \mathrm{L}$

TCLP-CKD, mg/L

\begin{tabular}{|c|c|c|c|c|c|c|c|c|c|c|}
\hline Volatile & & No. & Min. & Max. & Average & No. & Min & Max & Average & $\begin{array}{l}\text { Ratio of Avg. } \\
\text { Cement/CKD,\% }\end{array}$ \\
\hline & Mercury & 32 & 0.0001 & 0.005 & 0.006 & 61 & 0.0002 & 0.0223 & 0.0018 & 30 \\
\hline & Selenium & 17 & 0.001 & 0.025 & 0.011 & 38 & 0.006 & 1.711 & 0.152 & 7 \\
\hline & Thalium & 16 & 0.002 & 0.028 & 0.01 & 84 & 0.01 & 4.5 & 0.38 & 3 \\
\hline & Cadmium & 29 & 0.003 & 0.0123 & 0.0019 & 24 & 0.0001 & 0.22 & 0.0288 & 7 \\
\hline & lead & 41 & 0.002 & 0.029 & 0.009 & 70 & 0.002 & 9.718 & 0.349 & 3 \\
\hline & Antimony & 7 & 0.003 & 0.063 & NM & 25 & 0.003 & 0.031 & 0.012 & NM \\
\hline & Silver & 93 & 0.003 & 0.12 & 0.07 & 95 & 0.03 & 0.17 & 0.07 & 100 \\
\hline & Arsenic & 19 & 0.005 & 0.084 & 0.027 & 26 & 0.003 & 0.636 & 0.066 & 41 \\
\hline & Nickel & 8 & 0.06 & 0.17 & NM & 19 & 0.06 & 0.32 & 0.13 & NM \\
\hline & Barium & 92 & 0.49 & 4.27 & 1.35 & 90 & 0.12 & 9.19 & 1.04 & 130 \\
\hline & Berylium & 61 & 0.0001 & 0.003 & 0.0005 & 42 & 0.0001 & 0.0029 & 0.0004 & 125 \\
\hline & Chromium & 92 & 0.07 & 1.54 & 0.54 & 78 & 0.01 & 1.29 & 0.1 & 540 \\
\hline
\end{tabular}

- Excludes non-detectable values

- NM indicates average not meaningful because of large number of non-detectable values

PCA compared their data with the results of the 1982 study and found that the concentrations of the investigated metals in CKD were reasonably consistent between the two studies. This study reflected the effect of changes in the manufacturing process, raw materials, fuels and testing procedures that had occurred between 1982 and 1992. Figure 2-11 compares both sets of data. Bars indicate the range of values from high to low; circles show average concentration. (Non-detectable metals are excluded) (PCA, 1992)

PCA noted that the consistency between the two data sets was remarkable considering the changes that had taken place in raw materials, fuels, and technology. 


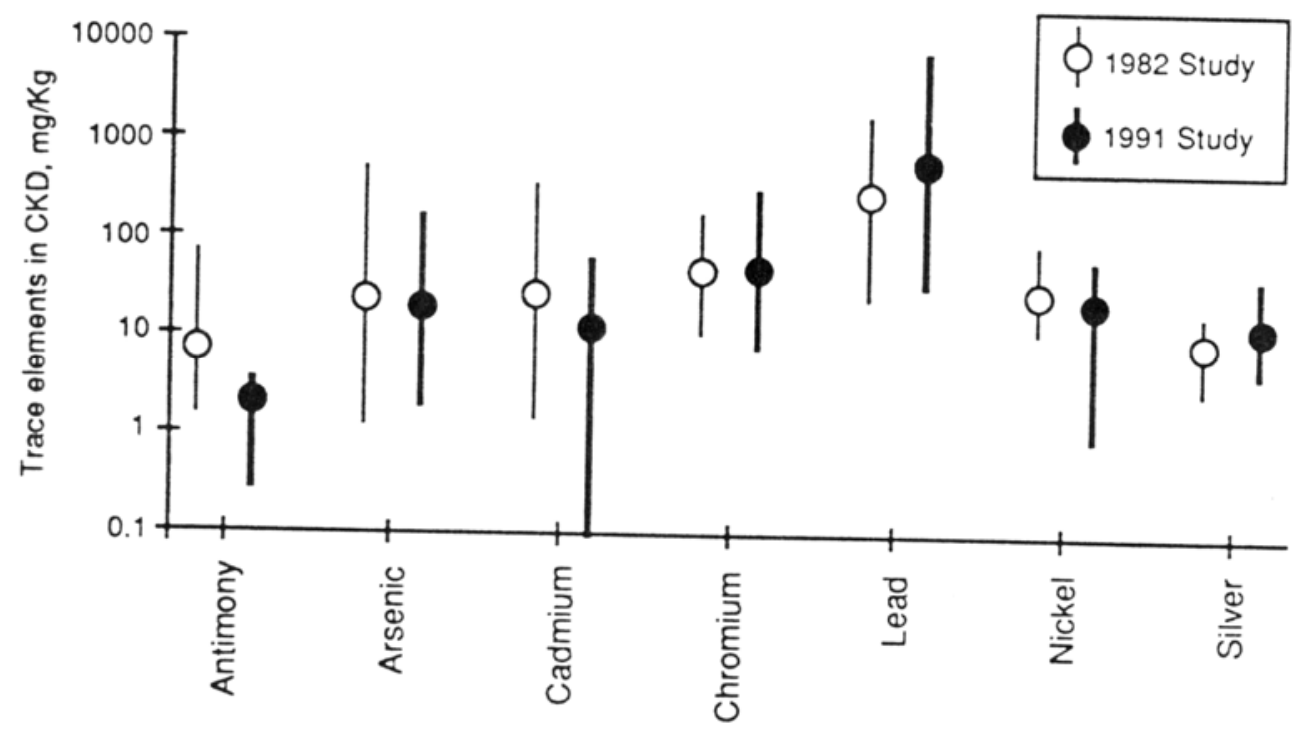

Figure 2-11 Comparisons of studies conducted in 1982 by Bureau of Mines and in 1992 by PCA.

PCA concluded that the single most important parameter in determining the level of trace metals in CKD is the degree of recirculation of CKD in the kiln system.

In the case of cement kiln dust, significant amounts of hazardous metals also end up in the cement product. Even higher metal levels may occur in the future. If CKD is regulated as a hazardous waste, kiln operators can be expected to recycle more CKD in an effort to avoid disposal costs. A portion of the metals found in recycled CKD will invariably wind up in the cement product.

Nevertheless, similar exploratory environmental issues/problems were encountered with the use of other "waste" materials in the past. For example, on the environmental issues associated with the beneficial use of fly ash, a by-product of thermal power plants, as a construction material Lewis commented that "environmental hazards, real or purely speculative, must be solved or fly ash use may never reach its full potential" (Lewis, 1976). Today fly ash is one of the most extensively used industrial byproducts as a construction material. On similar line it is hoped that issues associated with the use of CKD will be deciphered with time. 


\section{CHAPTER 3 -- PROPERTIES AND UTILIZATION OF CEMENT KILN DUST}

\section{$\underline{3.1 \text { Introduction }}$}

The previous chapter provided background information on the generation of CKD and also briefly addressed the environmental issues associated with its disposal and storage. This chapter provides a summary of the physio-chemical and engineering properties of this by-product material and discusses the applications reported in the literature, with focus on those pertaining to the construction industry. As part of this research an extensive literature review was performed and the data (oxide composition and physical properties) for a large number of CKDs were compiled. A specific goal of this chapter is to use this database to highlight the variability in properties that CKD typically displays, as a result of differences in kiln type, process technology, fuel type and dust collection system. This variability currently appears to represent one of the major barriers to a more widespread use of CKD as a construction material.

\subsection{Chemical Properties}

\subsubsection{Chemical Composition of CKD and its Variability}

In general, CKD "is a particulate matter that is collected from kiln exhaust gases and consists of entrained particles of clinker, raw materials, partially calcined raw materials, and fuel ash enriched with alkali sulfates, halides and other volatiles" (Abeln et al., 1993). Though the chemical composition of ordinary portland cement from most parts of the world is found to be remarkably consistent, and despite the fact that CKD is derived from the same raw materials as portland clinker, significant variation in chemical composition and physical characteristics has been observed for CKDs obtained from different plants. This variability can be ascribed to differences in the type of kiln operations, the dust collection facility (e.g., dusts collected from the alkali bypass of precalciner kilns have been observed to be typically coarser, more calcined, and 
concentrated with alkali volatiles (Klemm,1980)); the location within the system where the dust is collected, and the fuel used (e.g., dusts from gas-or oil-fired kilns have been reported to contain higher proportions of soluble alkalis as compared to those from coal fired kilns (Klemm, 1980)). Collins and Emery (1983) have also reported that there are often significant differences between total and separated dust collected, with the finer dust particles usually having a higher concentration of sulfates and alkalis and a lower free lime content.

To assess the variability in the chemical composition of fresh CKD, oxide data for 63 different CKDs (58 from plants located in the US) documented in the literature were compiled and are summarized in Table 3-1. In conjunction with the oxide data, the table also reports values of the hydration modulus (HM) and the total reactive oxide (TRO) content which will be discussed in Section 3.2.2. It may be noted that the samples represent CKDs from different kiln types and operations, fuel type(s) and dust collection systems and for the most part (58 out of the total 63) pertain to plants located in the United States. The average percentages of the main oxides present in these CKDs, as well as of the loss on ignition (LOI) and the free lime content (not available for all datasets), are shown in Table 3.2. While $\mathrm{CaO}$ and $\mathrm{SiO}_{2}$ are the major constituents for all CKDs, the data indicates a large range in variation for all the oxides, as well as for the LOI and the free lime content. All the free lime and LOI data are also summarized in the histograms presented in Figures 3-1a and 1b. These figures show that the majority of the CKDs have low free lime content ( $<5 \%$ for 27 out of 63 , with 13 of these having less than $1 \%$ ), and a LOI in the $20-35 \%$ range.

Compared to portland cement, CKDs on the average are typically characterized by higher alkali content, in particular potassium (the high alkali content is one of the reasons for removing the dust), and by higher sulfur content. 
Table 3-1 CKD composition data from published data

\begin{tabular}{|c|c|c|c|c|c|c|c|c|c|c|c|c|c|c|}
\hline No & & $\mathrm{CaO}$ & $\mathrm{SiO}_{2}$ & $\mathrm{Al}_{2} \mathrm{O}_{3}$ & $\mathrm{Fe}_{2} \mathrm{O}_{3}$ & MgO & $\mathrm{SO}_{3}$ & $\mathrm{Na}_{2} \mathrm{O}$ & $\mathbf{K}_{2} \mathbf{O}$ & LOI & FreeCaO & $\begin{array}{c}\text { Total } \\
\text { Alkali }^{+} \\
\end{array}$ & TRO & HМ \\
\hline & $O P C$ & 64.00 & 22.00 & 5.00 & 3.00 & 1.00 & 3.00 & $<1$ & $<<1$ & 1.00 & 2.00 & & & \\
\hline 1 & Al-Jabri et al. (2002) $* * *$ & 59.26 & 15.84 & 3.45 & 2.98 & 2.11 & 2.00 & 0.60 & 2.99 & 9.67 & NA & 2.57 & 48.11 & 2.66 \\
\hline 2 & Baghadi et al. (1995) & 40.31 & 13.46 & 3.86 & 2.09 & 1.76 & 5.48 & 4.01 & 2.15 & 33.04 & NA & 5.42 & 2.87 & 2.08 \\
\hline 3 & Collins \& Emery (1983) & 37.90 & 8.85 & 2.98 & 1.51 & 1.15 & 11.74 & 0.36 & 7.94 & 27.50 & 0.00 & 5.58 & 3.25 & 2.84 \\
\hline 4 & Collins \& Emery (1983) & 57.10 & 9.70 & 4.18 & 0.24 & 1.81 & 2.67 & 0.00 & 0.22 & 21.10 & 16.00 & 0.14 & 37.59 & 4.04 \\
\hline 5 & Collins \& Emery (1983) & 25.80 & 9.71 & 2.21 & 1.77 & 1.13 & 17.40 & 1.35 & 15.30 & 19.50 & 0.20 & 11.42 & - & 1.88 \\
\hline 6 & Collins \& Emery (1983) & 49.70 & 13.20 & 3.24 & 1.48 & 1.73 & 3.02 & 0.40 & 4.03 & 18.70 & 21.30 & 3.05 & 28.30 & 2.77 \\
\hline 7 & Collins \& Emery (1983) & 40.80 & 13.30 & 4.85 & 2.26 & 1.02 & 6.24 & 0.27 & 2.90 & 25.60 & 2.20 & 2.18 & 13.05 & 2.00 \\
\hline 8 & Collins \& Emery (1983) & 34.60 & 15.10 & 4.24 & 2.06 & 1.83 & 8.64 & 0.58 & 7.05 & 22.90 & 0.30 & 5.22 & 5.90 & 1.62 \\
\hline 9 & Collins \& Emery (1983) & 41.10 & 15.20 & 3.92 & 2.19 & 1.30 & 13.76 & 0.20 & 3.39 & 11.70 & 13.15 & 2.43 & 27.11 & 1.93 \\
\hline 10 & Collins \& Emery (1983) & 39.60 & 17.60 & 4.42 & 2.04 & 2.04 & 3.75 & 0.20 & 2.60 & 26.60 & 0.00 & 1.91 & 12.24 & 1.65 \\
\hline 11 & Collins \& Emery (1983) & 19.40 & 22.40 & 10.00 & 4.06 & 0.64 & 10.14 & 1.34 & 14.10 & 13.20 & 0.20 & 10.62 & - & 0.53 \\
\hline 12 & Collins \& Emery (1983) & 38.30 & 13.20 & 4.61 & 2.32 & 2.49 & 6.74 & 0.15 & 3.96 & 25.30 & 3.30 & 2.76 & 11.38 & 1.89 \\
\hline 13 & Collins \& Emery (1983) & 44.50 & 17.10 & 4.84 & 1.97 & 1.15 & 3.82 & 0.27 & 2.91 & 22.80 & 4.10 & 2.18 & 19.67 & 1.93 \\
\hline 14 & Collins \& Emery (1983) & 39.10 & 15.40 & 2.93 & 2.13 & 2.63 & 8.56 & 0.55 & 3.52 & 22.80 & 3.72 & 2.87 & 14.86 & 1.87 \\
\hline 15 & Collins \& Emery (1983) & 37.20 & 12.50 & 4.18 & 1.51 & 2.02 & 6.79 & 0.68 & 4.70 & 27.30 & 0.30 & 3.77 & 6.54 & 1.99 \\
\hline 16 & Collins \& Emery (1983) & 38.00 & 15.30 & 4.25 & 1.83 & 0.91 & 7.94 & 0.32 & 7.30 & 19.60 & 2.30 & 5.12 & 11.69 & 1.86 \\
\hline 17 & Collins \& Emery (1983) & 41.90 & 16.20 & 4.11 & 2.39 & 1.64 & 4.79 & 0.34 & 3.22 & 22.90 & 1.70 & 2.46 & 17.08 & 1.91 \\
\hline 18 & Collins \& Emery (1983) & 39.40 & 17.70 & 4.07 & 2.84 & 0.92 & 3.47 & 1.20 & 3.90 & 22.70 & 1.10 & 3.77 & 12.52 & 1.74 \\
\hline
\end{tabular}

Oxide values expressed in \% by mass of cement 
Table 3-1 (cont.) CKD composition data from published data

\begin{tabular}{|c|c|c|c|c|c|c|c|c|c|c|c|c|c|c|}
\hline No & & $\mathrm{CaO}$ & $\mathrm{SiO}_{2}$ & $\mathrm{Al}_{2} \mathrm{O}_{3}$ & $\mathrm{Fe}_{2} \mathrm{O}_{3}$ & MgO & $\mathrm{SO}_{3}$ & $\mathrm{Na}_{2} \mathrm{O}$ & $\mathbf{K}_{2} \mathbf{O}$ & LOI & FreeCaO & $\begin{array}{c}\text { Total } \\
\text { Alkali }^{+}\end{array}$ & TRO & HМ \\
\hline 19 & Collins \& Emery (1983) & 41.60 & 20.00 & 5.76 & 2.46 & 2.22 & 6.69 & 0.41 & 3.76 & 12.70 & 4.20 & 2.88 & 26.95 & 1.49 \\
\hline 20 & Collins \& Emery (1983) & 45.90 & 11.90 & 2.92 & 2.04 & 1.39 & 6.24 & 0.07 & 1.54 & 28.20 & 4.80 & 1.08 & 17.48 & 2.83 \\
\hline 21 & Collins \& Emery (1983) & 44.40 & 12.00 & 3.13 & 1.27 & 1.66 & 3.30 & 0.08 & 2.86 & 31.80 & 0.40 & 1.96 & 11.32 & 2.64 \\
\hline 22 & Collins \& Emery (1983) & 45.20 & 16.80 & 3.88 & 2.11 & 1.37 & 3.72 & 0.18 & 1.78 & 23.20 & 6.70 & 1.35 & 21.41 & 2.05 \\
\hline 23 & Collins \& Emery (1983) & 37.40 & 15.20 & 4.75 & 2.78 & 1.96 & 6.37 & 0.48 & 5.03 & 24.00 & 1.20 & 3.79 & 9.85 & 1.71 \\
\hline 24 & Collins \& Emery (1983) & 26.80 & 13.00 & 4.50 & 2.04 & 0.54 & 16.93 & 1.47 & 12.40 & 13.50 & 1.20 & 9.63 & - & 1.49 \\
\hline 25 & Collins \& Emery (1983) & 47.60 & 9.91 & 3.08 & 1.21 & 1.33 & 2.92 & 0.11 & 1.08 & 31.60 & 4.20 & 0.82 & 16.14 & 3.32 \\
\hline 26 & Collins \& Emery (1983) & 45.50 & 14.00 & 3.39 & 1.26 & 1.16 & 2.40 & 0.28 & 2.50 & 28.40 & 4.80 & 1.93 & 15.48 & 2.45 \\
\hline 27 & Collins \& Emery (1983) & 42.90 & 14.90 & 4.62 & 2.31 & 0.89 & 5.54 & 0.14 & 3.16 & 22.20 & 4.30 & 2.22 & 18.29 & 2.10 \\
\hline 28 & Collins \& Emery (1983) & 42.50 & 14.30 & 3.34 & 1.82 & 2.09 & 3.10 & 0.44 & 5.21 & 23.80 & 7.80 & 3.87 & 15.14 & 2.15 \\
\hline 29 & Collins \& Emery (1983) & 47.50 & 14.30 & 3.03 & 1.93 & 1.20 & 3.20 & 0.30 & 2.02 & 24.10 & 9.10 & 1.63 & 22.28 & 2.56 \\
\hline 30 & Collins \& Emery (1983) & 43.00 & 16.00 & 3.97 & 2.20 & 3.28 & 2.15 & 0.28 & 2.09 & 27.10 & NA & 1.66 & 16.81 & 1.85 \\
\hline 31 & Dyer et al. (1999) $* * * *$ & 34.30 & 34.30 & 3.50 & 2.00 & 0.80 & 11.40 & 1.20 & 8.20 & NA & NA & 6.60 & - & 0.86 \\
\hline 32 & Dyer et al. (1999) $* * * *$ & 34.80 & 12.20 & 3.20 & 1.80 & 0.90 & 10.60 & 1.60 & 7.50 & NA & NA & 6.54 & - & 2.02 \\
\hline 33 & El-Awady \& Sami (1997) & 43.90 & 21.80 & 7.10 & 4.71 & 2.50 & - & 6.25 & 6.10 & NA & NA & 10.26 & - & 1.31 \\
\hline 34 & Gdoutos \& Shah (2003) & 48.60 & 8.96 & 10.31 & 2.21 & 3.14 & 7.23 & 0.54 & 6.81 & 17.92 & 26.90 & 5.02 & 26.47 & 2.26 \\
\hline 35 & Gdoutos \& Shah (2003) & 50.20 & 11.50 & 4.68 & 2.04 & 1.34 & 16.70 & 1.02 & 5.86 & 9.56 & NA & 4.87 & 35.11 & 2.76 \\
\hline 36 & Gdoutos \& Shah (2003) & 56.99 & 14.67 & 5.06 & 3.46 & 1.04 & 8.45 & 0.60 & 6.07 & 15.10 & 8.00 & 4.59 & 36.26 & 2.46 \\
\hline 37 & Gdoutos \& Shah (2003) & 45.50 & 15.70 & 5.06 & 2.58 & 2.33 & 5.68 & 0.89 & 5.33 & 25.50 & 5.10 & 4.40 & 16.11 & 1.95 \\
\hline
\end{tabular}

Oxide values expressed in $\%$ by mass of cement 
Table 3-1 (cont.) CKD composition data from published data

\begin{tabular}{|c|c|c|c|c|c|c|c|c|c|c|c|c|c|c|}
\hline No & & $\mathrm{CaO}$ & $\mathrm{SiO}_{2}$ & $\mathrm{Al}_{2} \mathrm{O}_{3}$ & $\mathrm{Fe}_{2} \mathrm{O}_{3}$ & MgO & $\mathrm{SO}_{3}$ & $\mathrm{Na}_{2} \mathrm{O}$ & $\mathbf{K}_{2} \mathbf{O}$ & LOI & FreeCaO & $\begin{array}{c}\text { Total } \\
\text { Alkali }^{+} \\
\end{array}$ & TRO & HМ \\
\hline 38 & Kumar et al. (2002) ** & 47.80 & 11.40 & 3.00 & 2.10 & 0.70 & 1.80 & 0.30 & 1.30 & 30.60 & NA & 1.16 & 16.30 & 2.90 \\
\hline 39 & McCoy \& Kriner (1971) & 42.70 & 11.00 & 5.10 & 0.86 & 1.60 & 2.20 & 0.35 & 2.80 & 33.60 & 0.50 & 2.19 & 7.55 & 2.52 \\
\hline 40 & McCoy \& Kriner (1971) & 57.30 & 12.30 & 4.00 & 1.60 & 3.10 & 2.00 & 0.49 & 7.20 & 11.60 & 14.30 & 5.23 & 41.11 & 3.20 \\
\hline 41 & McCoy \& Kriner (1971) & 51.30 & 17.30 & 6.30 & 1.80 & 3.50 & 7.90 & 0.65 & 6.00 & 5.80 & 26.60 & 4.60 & 42.35 & 2.02 \\
\hline 42 & McCoy \& Kriner (1971) & 49.70 & 18.30 & 8.30 & 1.80 & 1.50 & 8.40 & 0.40 & 3.00 & 8.40 & 15.70 & 2.37 & 39.40 & 1.75 \\
\hline 43 & McCoy \& Kriner (1971) & 50.90 & 18.40 & 3.60 & 6.00 & 1.30 & 8.90 & 0.43 & 3.40 & 6.60 & 14.60 & 2.67 & 41.77 & 1.82 \\
\hline 44 & McCoy \& Kriner (1971) & 48.60 & 19.30 & 6.80 & 6.00 & 2.60 & 6.60 & 0.47 & 3.00 & 6.00 & 7.80 & 2.44 & 41.73 & 1.51 \\
\hline 45 & McCoy \& Kriner (1971) & 47.70 & 19.70 & 6.50 & 3.10 & 1.10 & 10.43 & 0.66 & 4.80 & 4.20 & 10.00 & 3.82 & 39.14 & 1.63 \\
\hline 46 & McCoy \& Kriner (1971) & 25.80 & 32.30 & 10.50 & 3.10 & 1.80 & 0.43 & 0.54 & 1.60 & 23.60 & 0.00 & 1.59 & 1.86 & 0.56 \\
\hline 47 & Miller et al. (2003) & 42.50 & 11.90 & 4.70 & 1.80 & 1.40 & 7.30 & - & - & 25.80 & NA & - & - & 2.31 \\
\hline 48 & Miller et al. (2003) & 44.10 & 13.80 & 4.10 & 1.50 & 1.40 & 3.00 & 0.40 & 1.60 & 29.10 & NA & 1.45 & 14.40 & 2.27 \\
\hline 49 & Miller et al. (2003) & 52.80 & 16.00 & 3.60 & 2.30 & 2.20 & 6.00 & 0.30 & 3.50 & 17.50 & NA & 2.60 & 33.70 & 2.41 \\
\hline 50 & Miller et al. (2003) & 46.30 & 15.30 & 4.70 & 1.70 & 1.40 & 2.00 & 0.20 & 1.70 & 27.90 & NA & 1.32 & 17.90 & 2.13 \\
\hline 51 & Miller et al. (2003) & 48.40 & 15.10 & 3.90 & 2.00 & 1.40 & 4.50 & 0.20 & 2.50 & 22.10 & NA & 1.85 & 25.00 & 2.30 \\
\hline 52 & Miller \& Azad (2000) & 43.50 & 15.90 & 3.43 & 1.90 & 1.64 & 1.62 & 0.30 & 2.94 & 25.20 & NA & 2.23 & 16.70 & 2.05 \\
\hline 53 & Nisbet (1997) & 43.80 & 12.90 & 3.00 & 2.40 & 1.10 & 1.10 & 0.07 & 0.39 & 34.90 & NA & 0.33 & 9.54 & 2.39 \\
\hline 54 & Nisbet (1997) & 38.60 & 19.20 & 6.40 & 2.70 & 2.60 & 0.21 & 0.08 & 1.88 & 26.10 & NA & 1.32 & 13.14 & 1.36 \\
\hline 55 & Salem \& Ragai (2000) * & 51.07 & 14.37 & 3.97 & 4.49 & 2.40 & 4.43 & 1.55 & 1.20 & 18.85 & NA & 2.34 & 31.87 & 2.24 \\
\hline
\end{tabular}

Oxide values expressed in $\%$ by mass of cement 
Table 3-1 (cont.) CKD composition data from published data

\begin{tabular}{|c|c|c|c|c|c|c|c|c|c|c|c|c|c|c|}
\hline No & & $\mathrm{CaO}$ & $\mathrm{SiO}_{2}$ & $\mathbf{A l}_{2} \mathbf{O}_{3}$ & $\mathrm{Fe}_{2} \mathrm{O}_{3}$ & MgO & $\mathrm{SO}_{3}$ & $\mathrm{Na}_{2} \mathrm{O}$ & $\mathbf{K}_{2} \mathbf{O}$ & LOI & FreeCaO & $\begin{array}{c}\text { Total } \\
\text { Alkali }^{+}\end{array}$ & TRO & HM \\
\hline 56 & Sayah (1993) & 41.70 & 14.40 & 4.10 & 1.40 & 1.50 & 5.00 & 0.34 & 1.90 & 28.00 & NA & 1.59 & 12.96 & 2.10 \\
\hline 57 & Shoaib et al. (1999) & 49.75 & 11.95 & 1.12 & 2.45 & 1.86 & 6.35 & 3.87 & 2.66 & 17.92 & NA & 5.62 & 27.16 & 3.21 \\
\hline 58 & Todres et al. (1992) & 44.91 & 9.64 & 3.39 & 1.10 & 1.29 & 6.74 & 0.27 & 2.40 & 30.24 & 0.52 & 1.85 & 13.29 & 3.18 \\
\hline 59 & Todres et al. (1992) & 41.01 & 15.02 & 3.85 & 1.88 & 1.47 & 6.27 & 0.74 & 2.57 & 25.78 & 0.85 & 2.43 & 13.39 & 1.98 \\
\hline 60 & Todres et al. (1992) & 61.28 & 15.23 & 3.07 & 2.00 & 2.13 & 8.67 & 0.34 & 2.51 & 4.48 & 27.18 & 1.99 & 56.08 & 3.02 \\
\hline 61 & Udoeyo \& Hyee (2002) * & 52.72 & 2.16 & 1.09 & 0.54 & 0.68 & 0.02 & 0.26 & 0.11 & 42.39 & NA & 0.33 & 10.64 & 13.91 \\
\hline 62 & Wang et al. (2002) & 56.99 & 17.67 & 5.06 & 2.75 & 0.91 & 6.55 & 0.30 & 3.43 & 8.00 & NA & 2.56 & 46.17 & 2.24 \\
\hline 63 & Zaman et al (1992) & 41.65 & 14.43 & 4.05 & 1.43 & 1.51 & 4.95 & 0.34 & 1.86 & 28.04 & NA & 1.56 & 12.92 & 2.09 \\
\hline
\end{tabular}

Oxide values expressed in \% by mass of cement

* Plant located in Egypt

** Plant located in India

*** Plant located in the UK

**** Plant located in Oman

All other plants are located in the US

+ Total alkali is the equivalent sodium alkali which is equal to $\mathrm{Na}_{2} \mathrm{O}+0.65 \mathrm{~K}_{2} \mathrm{O}$ 
Table 3-2 Statistics on composition of fresh CKD based on 63 CKDs presented in Table 3.1

\begin{tabular}{|c|c|c|c|c|c|c|c|c|c|c|c|c|c|}
\hline & $\mathrm{CaO}$ & $\mathrm{SiO}_{2}$ & $\mathbf{A l}_{2} \mathbf{O}_{3}$ & $\mathrm{Fe}_{2} \mathrm{O}_{3}$ & MgO & $\mathrm{SO}_{3}$ & $\mathrm{Na}_{2} \mathrm{O}$ & $\mathbf{K}_{2} \mathbf{O}$ & LOI & $\begin{array}{l}\text { Free } \\
\mathrm{CaO} \\
\end{array}$ & $\begin{array}{r}\text { Total } \\
\text { Alkali } \\
\end{array}$ & TRO & HM \\
\hline Mean & 43.99 & 15.05 & 4.43 & 2.23 & 1.64 & 6.02 & 0.69 & 4.00 & 21.57 & 6.75 & 3.32 & 21.49 & 2.33 \\
\hline SD & 8.01 & 4.74 & 1.82 & 1.04 & 0.68 & 3.93 & 1.02 & 3.01 & 8.50 & 7.83 & 2.44 & 12.97 & 1.61 \\
\hline $\operatorname{COV}(\%)$ & 18 & 31 & 41 & 47 & 41 & 65 & 147 & 75 & 39 & 116 & 74 & 60 & 69 \\
\hline Max & .28 & 34.30 & 10.50 & 6.00 & 3.50 & 17.40 & 6.25 & 15.30 & 42.39 & 27.18 & 11.42 & 56.08 & 13.91 \\
\hline Min & 19.40 & 2.16 & 1.09 & 0.24 & 0.54 & 0.02 & 0.00 & 0.11 & 4.20 & 0.00 & 0.14 & 1.86 & 0.53 \\
\hline
\end{tabular}

Oxide values expressed in \% by mass of cement 

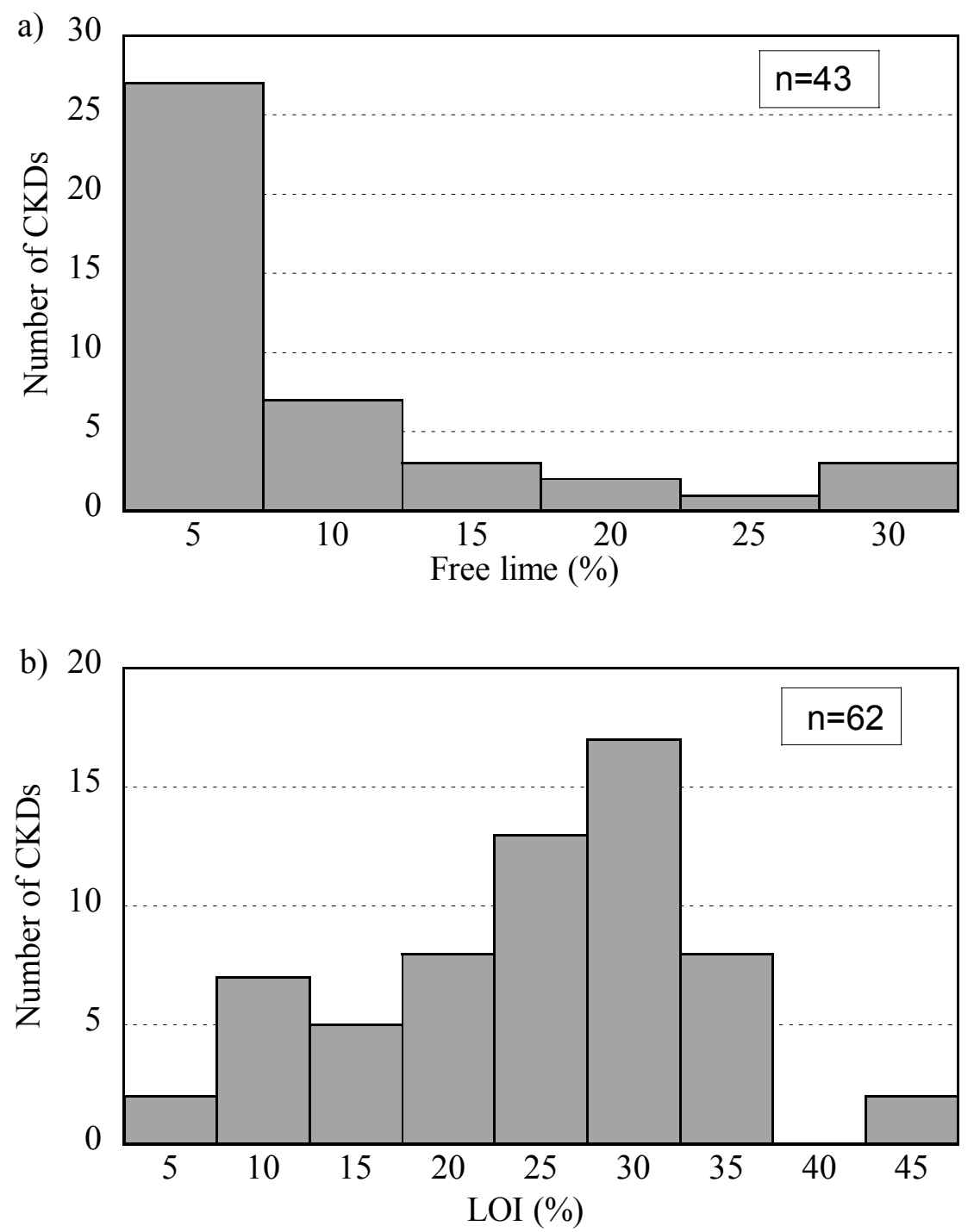

Figure 3-1 Histograms representing the variation of (a) free lime and (b) LOI

Oxide data for the only two stockpiled CKDs which were found in the literature are shown in Table 3-3 (Collins and Emery, 1983). These CKDs are characterized by a LOI at the high end of the range reported for the fresh material and by the absence of free lime. In Addition, the alkali percentages are also lower than the typical values found in fresh CKDs. This is the result of the fact that once CKD is exposed to moisture, the alkali sulfates are likely to go into solution. Free lime and some cementitious phases, if present, may undergo hydration or carbonation. Thus stockpiled CKD may contain some 
prehydrated or carbonated lime and hydrated cementitious phase which all may contribute to high LOI.

Table 3-3 Data for two stockpiled CKDs (Collins and Emery, 1983)

\begin{tabular}{|c|c|c|c|c|c|c|c|c|c|c|c|c|}
\hline $\mathrm{CaO}$ & $\mathrm{SiO}_{2}$ & $\mathrm{Al}_{2} \mathbf{O}_{3}$ & $\mathrm{Fe}_{2} \mathrm{O}_{3}$ & MgO & $\mathrm{SO}_{3}$ & $\mathrm{Na}_{2} \mathrm{O}$ & $\mathbf{K}_{2} \mathbf{O}$ & LOI & $\begin{array}{l}\text { Free } \\
\mathrm{CaO}\end{array}$ & $\begin{array}{c}\text { Total } \\
\text { Alkali }\end{array}$ & TRO & HM \\
\hline 31.40 & 111.00 & 3.18 & 2.16 & 0.97 & $\overline{8.24}$ & 0.13 & 1.65 & 40.40 & 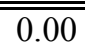 & 1.22 & - & 2.07 \\
\hline 44.20 & 11.90 & 3.24 & 1.45 & 1.73 & 2.40 & 0.27 & 2.92 & 30.20 & 0.00 & 2.19 & 12.54 & 2.62 \\
\hline
\end{tabular}

Overall, the data examined above indicate that there exists no "average" cement kiln dust, and that each CKD source should be considered as having its own unique properties. The variability in the composition of $\mathrm{CKD}$, and in particular the large range in variation in free lime content, highlight the importance of fully characterizing a particular CKD before recommending it for use as a construction material.

\subsubsection{Chemical and Physical Parameters to Define the Reactivity of CKD}

It is accepted that the reactivity of any binding material, including $\mathrm{CKD}$, is a function of its overall physical and chemical make up. While overall the reactions and products associated with the interaction of CKD with water are not completely understood, and are likely to vary depending on the particular CKD under consideration, there have been efforts to identify some simple parameters that can be used to predict the reactivity of $\mathrm{CKD}$, based on its oxide composition. Two empirical parameters that have been proposed are the Hydration Modulus, HM (Kamon and Nontananandh, 1991) and the Total Reactive Oxide content, TRO (Collins and Emery, 1983).

Kamon and Nontananandh (1991) defined the hydration modulus as:

$\mathrm{HM}=\mathrm{CaO} /\left(\mathrm{SiO}_{2}+\mathrm{Al}_{2} \mathrm{O}_{3}+\mathrm{Fe}_{2} \mathrm{O}_{3}\right)$ where $\mathrm{CaO}, \mathrm{SiO}_{2}$, etc, are expressed as percentage values. 
Using alite $(\mathrm{HM} \sim 1.7)$ and belite (HM 2.4), the most common cementitious phases present in portland cement, as references they suggested that for a CKD to be characterized as reactive, the HM should lie between 1.7 and 2.4. Based on tests conducted with two fresh CKDs with hydration modulus 2.05 and 2.3 (free lime content is not provided), Miller et al. (2003) reported a good correlation between the HM and the effectiveness of the CKD in stabilizing three oils (Soils employed are CH, CL and ML as per USCS). Since cementitious phases in the form of alite and belite are rarely found in $\mathrm{CKD}$, and given that free lime is likely the most significant source of reactivity in $\mathrm{CKD}$, the literature data summarized in Table 3.1 were analyzed to establish the correlation, if any, between free lime content and HM. The data for all the CKDs in Table 3.1 for which the free lime content was known are plotted in Figure 3-2. The shaded band in the figure highlights the "favorable" range of HM recommended by Kamon and Nontananandh (1991). The figure demonstrates that there is no direct correlation between free lime content and HM. CKDs with practically no free lime have values of HM falling within the limits set by Kamon and Nontananandh (1991). One of the stockpiled CKDs (\#1LF) shown in Table 3.1 with a HM value of 2.07 also support this observation. Conversely, CKDs with free lime content values as high as $27 \%$ are observed to have HM outside the recommended range (e.g. \# 60 in Table 3.1). Overall, these observations suggest that the validity of the HM as an indicator of the reactivity of the CKD is debatable.

Collins and Emery (1983) performed a study to determine the effectiveness of replacing kiln dusts (both CKD and lime kiln dust) in lime-fly ash aggregate road base system, and introduced a second parameter, the total reactive oxide content (TRO), as an indicator of the reactivity of CKD (note that the basis for the definition for TRO is not reported). The TRO is defined as:

$\mathrm{TRO}=(\mathrm{CaO}+\mathrm{MgO}-\mathrm{LOI})-\left(\mathrm{K}_{2} \mathrm{O}+\mathrm{Na}_{2} \mathrm{O}\right)$ where $\mathrm{CaO}, \mathrm{MgO}, \mathrm{K}_{2} \mathrm{O}, \mathrm{Na}_{2} \mathrm{O}$ and LOI are expressed as percentage values (note that the use of the equation is not recommended by the authors for a total alkali content greater than $6 \%$ ).

For over 20 CKDs with TRO ranging between $13 \%$ and 37\%, Collins and Emery (1983) showed a good correlation between the TRO and the seven day 


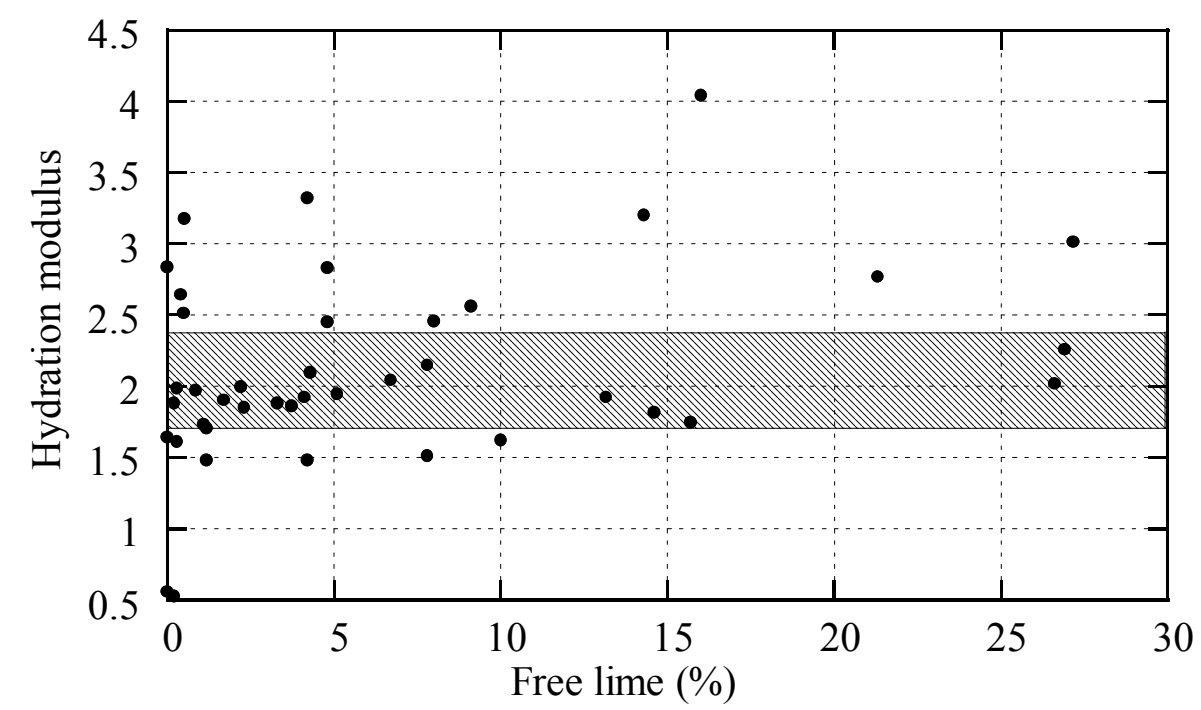

Figure 3-2 Relationship between free lime and hydration modulus for the data given in Table 3.1(Shaded band highlights the favorable range of $\mathrm{HM}$ )

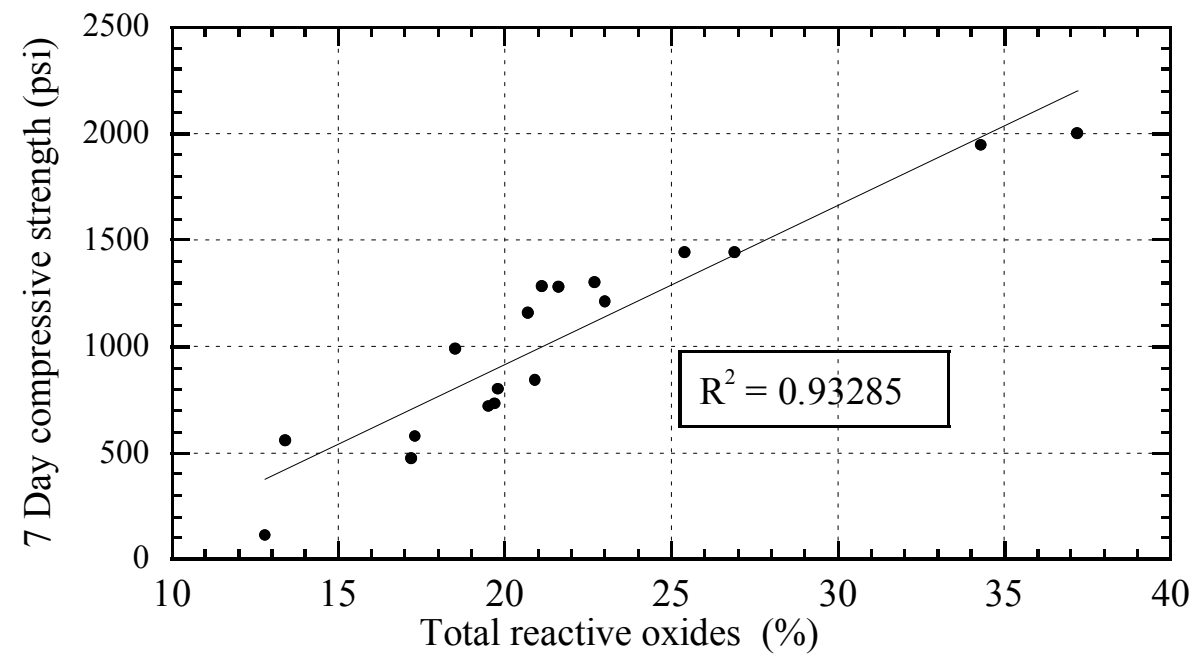

Figure 3-3 Relationship between compressive strength of CKD-fly ash blends and TRO of CKDs (Collins and Emery, 1983) 
compressive strength of CKD-fly ash 2:1 blends (Figure 3-3). Based on this study they proposed that the higher the TRO of a CKD, the greater the potential contribution of the CKD in terms of strength development. Figure 3-3 shows the relationship between the 7day compressive strength obtained and the TRO of the CKDs used.

Bhatty et al. (1996) performed a comparison between the TRO and the strength development in CKD stabilized soils using data from the study performed by McCoy and Kriner (1971) on the use of CKD in soil stabilization. The oxide composition of these CKDs are available in Table 3.1 (A, B, C, D, E and F refer to \#42, \#43, \#40, \#44, \#46 and \#45 respectively in the table). Table 3-4 shows the values of the TRO calculated by Bhatty et al. (1996) for the six CKDs included in the study, with the values of 7-day compressive strength for the soil-CKD mixtures reported by McCoy and Kriner (1971). These data show no correlation between strength developed and the TRO. In fact the CKD (C) with the highest TRO yields the lowest strength. It should be however noted that the relationship between TRO and compressive strength for CKD stabilized soil and CKD-fly ash blends need not be expected to be the same as both involve different mechanisms.

Table 3-4 Summary of CKDs and soils used and strength of treated soils (McCoy and Kriner, 1971)

\begin{tabular}{cccccc}
\cline { 3 - 5 } & \multicolumn{2}{c}{ CKD } & & & \\
\hline & Free lime, \% & TRO,\% & $\begin{array}{c}\text { Optimum } \\
\text { moisture } \\
\text { content (\%) }\end{array}$ & $\begin{array}{c}\text { Maximum dry } \\
\text { density (g/ce) }\end{array}$ & MPa Strength, \\
\hline \hline A & 15.57 & 46.20 & 21.90 & 2.01 & 2.83 \\
B & 14.60 & 49.43 & 20 & 2.05 & 2.93 \\
C & 14.30 & 56.49 & 20.6 & 2.04 & 2.01 \\
D & 7.80 & 48.67 & 20.1 & 1.99 & 2.21 \\
E & traces & 6.14 & 22.6 & 1.93 & 2.28 \\
F & 10.00 & 50.06 & 21.1 & 1.98 & 4.01 \\
\hline
\end{tabular}


As done for the HM (Table 3-1 and Figure 3-2), the TRO was calculated for all CKDs presented in Table 3-1 and plotted versus the free lime content and LOI (Figure 34 and Figure 3-5). As reflected by the correlation coefficient, there is a clear correlation between TRO and free lime content. These data support the hypothesis by Collins and Emery (1983) that a higher total reactive oxide signifies a CKD with more reactive phases.

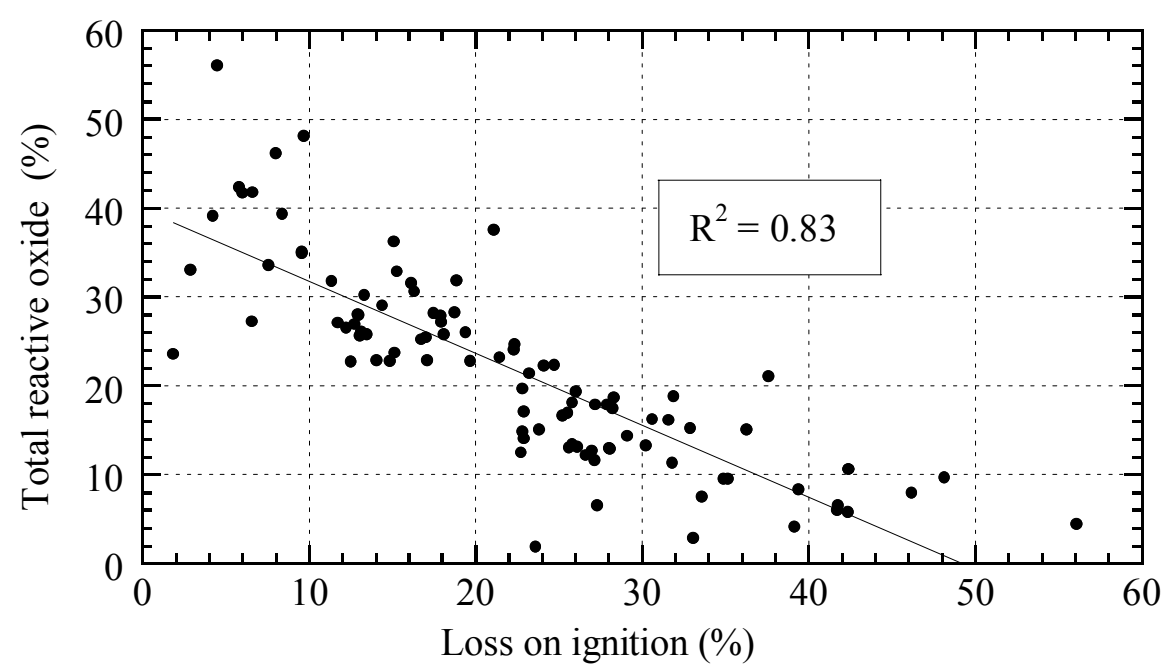

Figure 3-4 Variation of TRO with LOI for CKDs given in Table 3.1

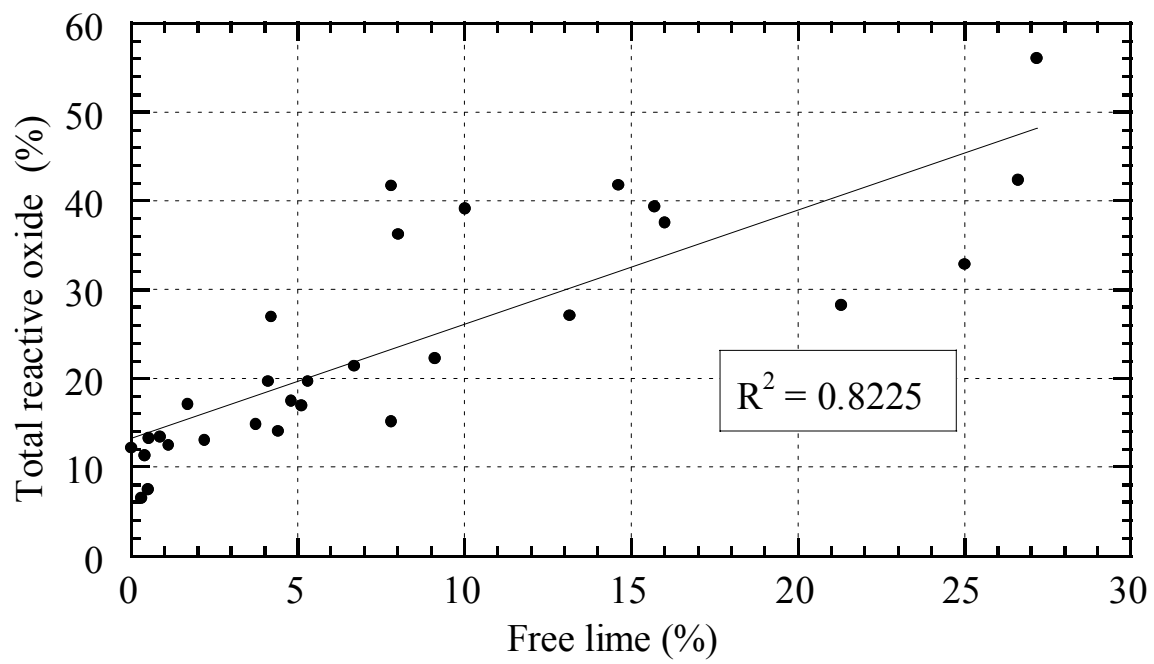

Figure 3-5 Variation of TRO with free lime for CKDs given in Table 3.1 


\subsubsection{Loss on Ignition}

In CKD the loss on ignition (LOI), i.e., the loss in mass associated with heating to $\sim 950^{\circ} \mathrm{C}$, is contributed by chemically bound water, $\mathrm{CO}_{2}$ and noncarbonated carbon (Haynes et al.,1995). The sources of noncarbonated carbon in CKD are the unburned clinker or the fuel oil.

Thermo gravimetric analysis (TGA) can be used to identify the exact contributions of each of these compounds. Haynes et al. (1995) analyzed 113 fresh CKD samples, fresh CKD samples from 102 plants by TGA and showed that the chemically bound water is typically low in $\mathrm{CKD}$, ranging from 0.4 to $3.8 \%$. The $\mathrm{CO}_{2}$ content ranged from 4.4 to $34.4 \%$ and free noncarbonated carbon varied from 0.01 to $1.83 \%$. Hence the LOI of CKD is primarily contributed by the $\mathrm{CaCO}_{3}$ that undergoes de-carbonation when ignited.

Bhatty et al. (1996) suggests that high LOIs typically are an indication of high carbonate and low free lime. McCoy and Kriner (1971) reported that soil treated with low LOI and high free lime CKD provided promising results in terms of strength.

As observed from Table 3-1 and the data summarized in the histogram (Figure 31b) the majority of the CKDs have a LOI in the 20-35\% range. The LOI shows significant variation, depending on the plant operation. For example Todres et al. (1992) compared CKDs from three different kiln types and observed that the CKDs from long wet and long dry kilns had LOI significantly greater (25\% and 30\%, respectively) than that measured on CKD obtained from an alkali bypass system (LOI 4.0\%). LOI values of landfilled CKDs are generally higher compared to the parent fresh CKD. When the CKD is exposed to the atmosphere the free lime and any other cementitious phases present, commonly undergo hydration and carbonation. Also evaporation of moisture from an open stock pile may result in the formation of gypsum and alkali hydroxides (Bhatty, 1996). Each of these compounds will contribute to higher values of the LOI.

The CKD data from Table 3-1 were analyzed to evaluate the relation between $\mathrm{LOI}$ and free $\mathrm{CaO}$ content (Figure 3-6). Despite the significant scatter, the data presented in Figure 3-6 suggest a trend (shaded area) of decreasing LOI with increasing free lime 
content (see for example that all CKDs with low free lime are characterized by relatively high values of the LOI).

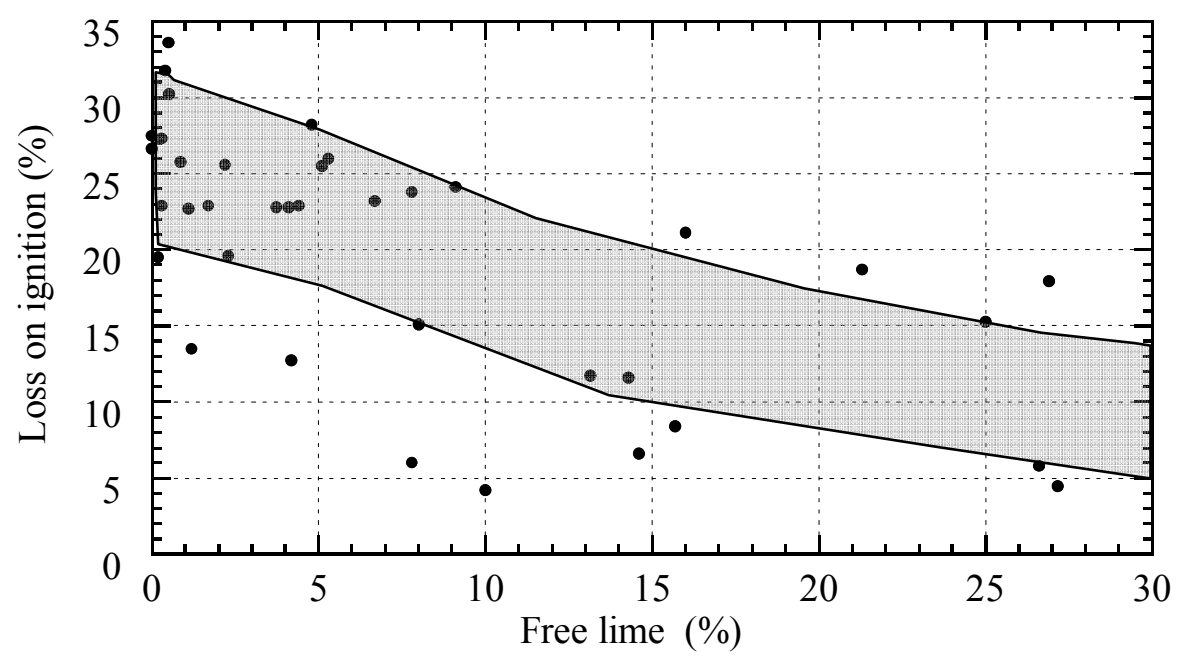

Figure 3-6 Variation of LOI with free lime (data from Table 3-1)

\subsubsection{Mineralogical Composition and X-Ray Diffraction Patterns for CKD}

The most extensive study on the mineralogical composition of CKD was performed by Haynes and Kramer (1982) who analyzed 113 CKD samples from 102 plants located in the US. They observed that the major constituents of CKD are calcite, and, to a lesser degree, lime, anhydrite, quartz and dolomite; based on these data, they reported the average phase composition for CKD shown in Table 3-5.

Table 3-5 Average composition of cement kiln dust (Haynes and Kramer, 1982)

\begin{tabular}{ccccccccccccc}
\hline Constituent & $\mathrm{CaCO}_{3}$ & $\mathrm{SiO}_{2}$ & $\mathbf{C a O}$ & $\mathrm{K}_{2} \mathrm{SO}_{4}$ & $\mathrm{Fe}_{2} \mathrm{O}_{3}$ & $\mathrm{KCl}$ & $\mathbf{M g O}$ & $\mathrm{Na}_{2} \mathrm{SO}_{4}$ & $\mathrm{CaSO}_{4}$ & $\mathrm{Al}_{2} \mathrm{O}_{3}$ & $\mathrm{KF}$ & Others \\
\hline \hline \% by weight & 55.5 & 13.6 & 8.1 & 5.9 & 2.1 & 1.4 & 1.3 & 1.3 & 5.2 & 4.5 & 0.4 & 0.7 \\
\hline
\end{tabular}


In another study (Muller, 1977), nearly 100 European CKDs were investigated. Table 3-6 summarizes the mineralogical composition of each of the four major components of the dusts.

Table 3-6 Typical mineralogical compositions of selected CKDs (Muller, 1977 (from Bhatty, 1995))

\begin{tabular}{ll}
\hline CKD Component & Mineralogical Composition \\
\hline \hline Unreacted raw feed & $\begin{array}{l}\text { Carbonates,Quartz,Others (clay } \\
\text { minerals, Fe/Al oxides) }\end{array}$ \\
$\begin{array}{l}\text { Partially calcined feed and } \\
\text { clinker dust }\end{array}$ & $\begin{array}{l}\text { Decomposed raw feed Clinker minerals } \\
\text { Intermediate phases }\end{array}$ \\
Free lime & $\mathrm{CaO}, \mathrm{Ca}(\mathrm{OH})_{2}$ \\
$\begin{array}{l}\text { Alkali salts and other volatile } \\
\text { compounds }\end{array}$ & $\mathrm{KCl}, 2 \mathrm{NaCl},\left(\mathrm{K} / \mathrm{Na}_{2}\right) \mathrm{SO}_{4}, \mathrm{Ca} \mathrm{SO}_{4}$ \\
\hline
\end{tabular}

Additional data on the mineralogical composition of CKD have been reported for example by Baghdadi (1990) and Konsta-Gdoutos and Shah (2003). The X-ray diffraction pattern for a CKD produced by Arabian Cement Co. reported by Baghdadi (1990) showed calcium carbonate (calcite) as the predominant constituent. KonstaGdoutos and Shah (2003) conducted X-ray diffraction studies on several CKDs to study the hydration and properties of novel blended cements based on cement kiln dust and blast furnace slag. The CKD samples identified as E, P, A, and X, were representative of various plant operating conditions affecting dust composition and reactivity, such as the feed raw materials, kiln type, and dust collection systems. The plant configuration and mode of CKD collection are summarized in Figure 3-9 in section 3.3.1. Results from the XRD analysis of the four CKD samples are as shown in Figure 3-7. Calcite was identified as the prevailing phase in all four samples. 


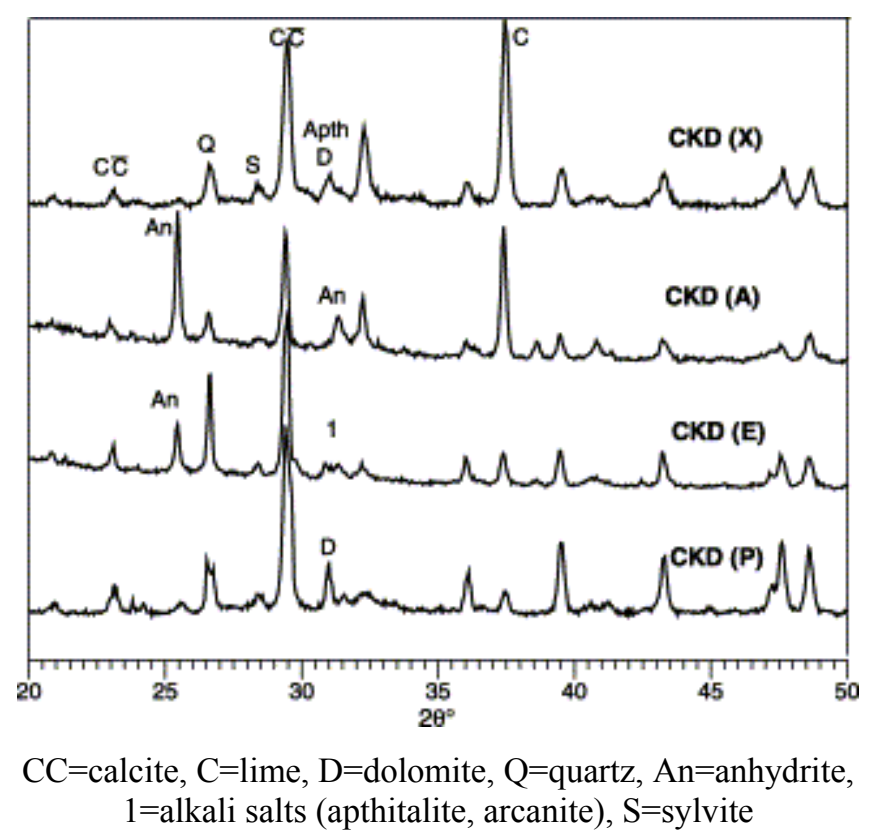

Figure 3-7 X-Ray diffraction for four CKDs (Konsta-Gdoutos and Shah, 2003)

\section{$3.2 .5 \mathrm{pH}$}

The chemical composition of CKD shows that it contains significant amounts of alkalis, which are considered to be caustic. As a result the $\mathrm{pH}$ of a CKD-water mixture is typically about 12.0 or greater. For example, Miller et al. (2003) reported pH values of 12.48 and 12.65 for two fresh CKDs.

\section{$\underline{3.3 \text { Physical Properties }}$}

\subsubsection{Particle Size Distribution}

An important physical characteristic of CKD is its particle size distribution. As $\mathrm{CKD}$ is a waste product that is collected from the exhaust gas stream, it is a very fine, powdery material of relatively uniform particle size. PCA (1992) reported that CKD typically has a mass median particle diameter of $10 \mu \mathrm{m}$ even though the raw materials are much larger in mean diameter. Data from the literature show that the particle size distribution of CKD depends on the process technology, method of dust collection, chemical composition of CKD, alkali content. 
The particle size analysis of CKD is typically carried out using some form of sedimentation test based on Stokes' law. Figure 3-8 shows a selection of results collected from the literature that illustrate the range in particle size of this material (all data derived from sedimentation analysis in water). Typical curves for ordinary portland cement and two microcements (Santagata and Collepardi, 1998) are also plotted for comparison purposes. As seen in the figure, the various fresh CKDs show significant variation in the mean particle size $\left(\mathrm{D}_{50}=2.8 \mu \mathrm{m}\right.$ to $\left.55 \mu \mathrm{m}\right)$, as well as in the gradation $\left(\mathrm{C}_{\mathrm{u}}=5-25\right)$. For the most part, these values straddle the data for ordinary portland cement, and are greater than those reported for microcements. The particle size of the only two landfilled CKDs (Collins and Emery, 1983) for which the author was able to find data in the literature (note that one of these was first ground) indicates that this material is somewhat coarser and better "graded" than the fresh CKDs.

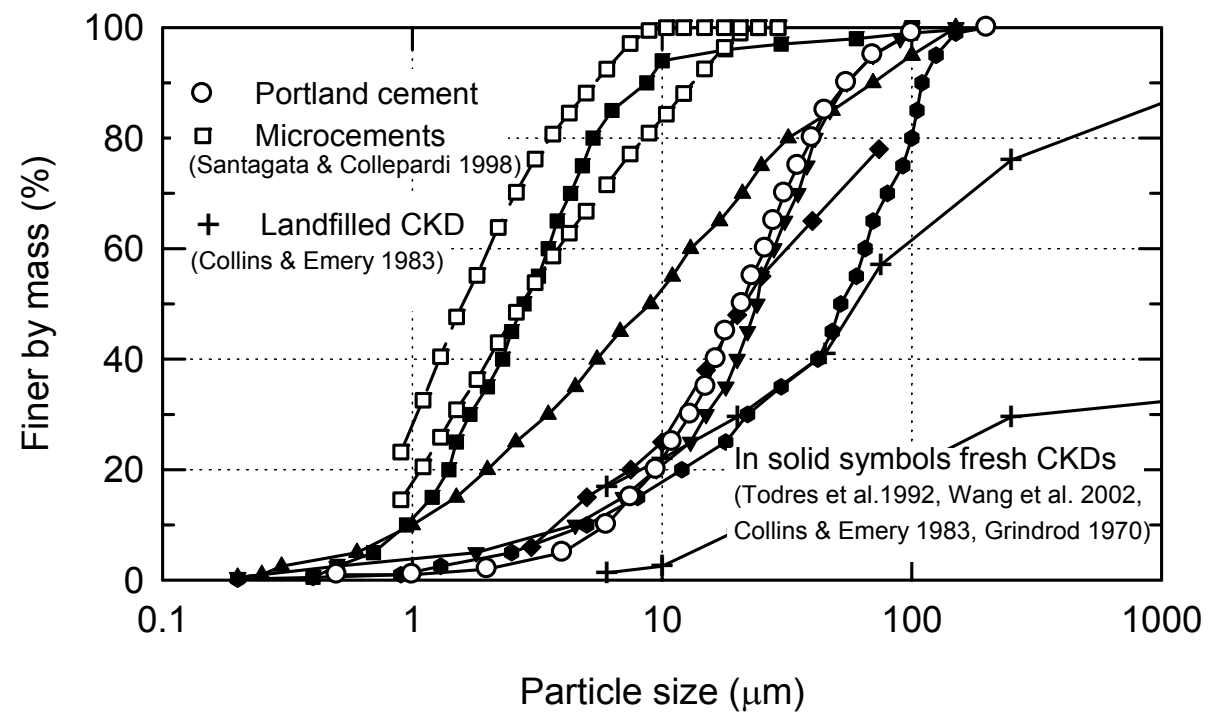

Figure 3-8 Examples of CKD particle size distributions from the literature 


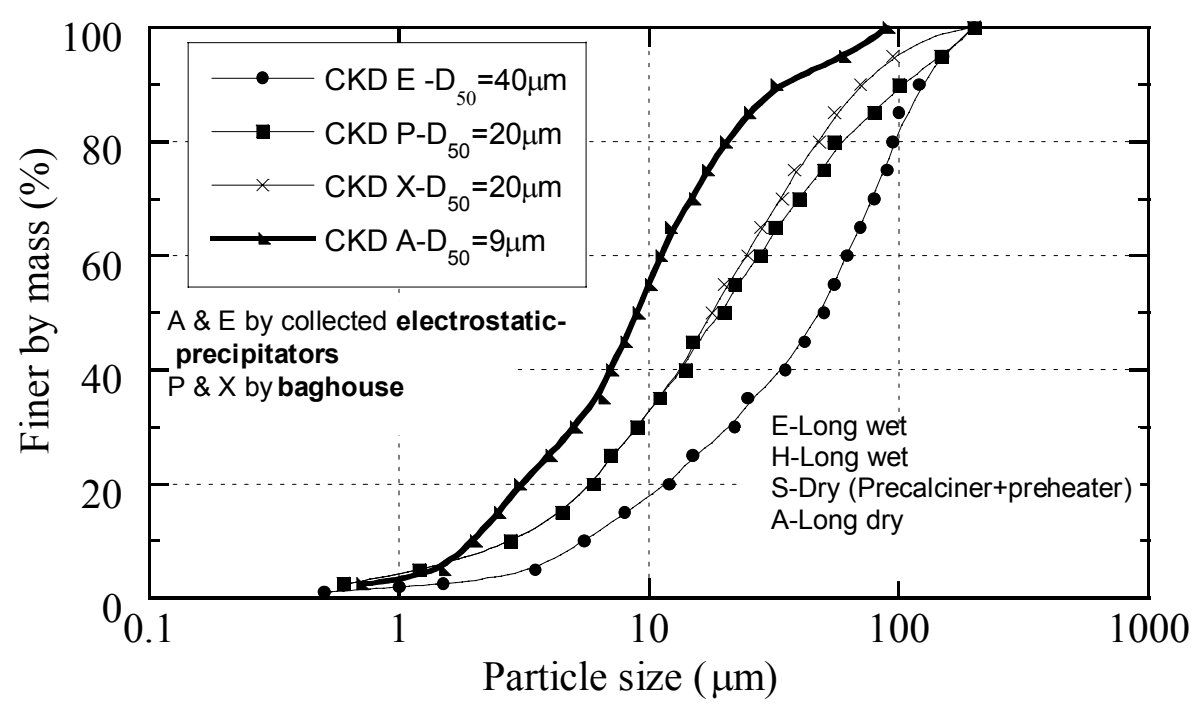

Figure 3-9 Effect of kiln type and dust collection system on particle size distribution of CKD (Gdoutos and Shah, 2003)

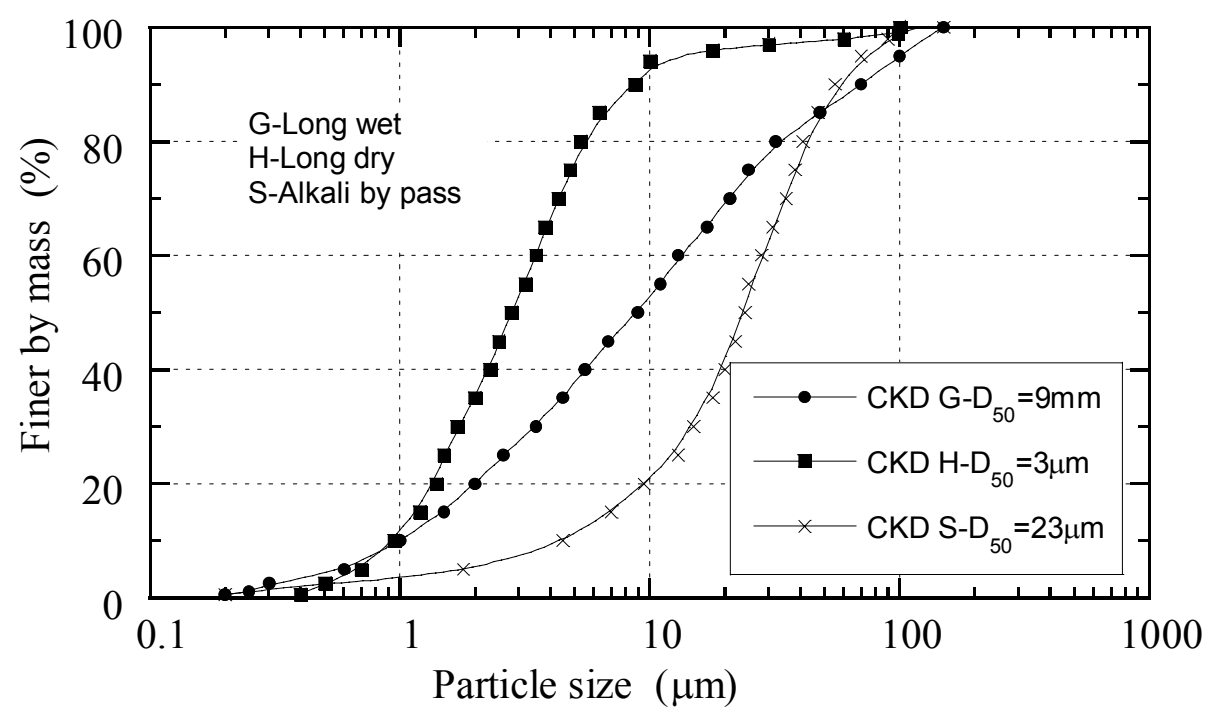

Figure 3-10 Example of effect of kiln type CKD particle size distribution (all dusts collected using electrostatic precipitators) (Todres et al., 1992) 
The particle size of CKD depends greatly on the type of kiln system used. This is illustrated in Figure 3-9 and Figure 3-10 which show the results of particle size analyses performed at the Construction Technology Laboratories Inc. (CTL) (Todres et.al., 1992) and at Northwestern University (Gdoutos and Shah, 2003) on CKDs representing different plant operations. The figures indicate that the dusts collected from dry kilns are finer than those from wet and semi-wet/semi-dry kilns.

Corish and Coleman (1995) reported that there typically are significant variations in the alkali concentration depending on the particle size fraction. Table 3-7 indicates the tendency for the percentage of potassium to increase significantly in the finer fraction of CKD, suggesting that the alkali concentration may be higher in finer CKDs. Collins and Emery (1983) have also reported that there are often significant differences between total and separated dust collected, with the finer dust particles usually having a higher concentration of sulfates and alkalis, and a lower free lime content.

Table 3-7 Effect of particle size on alkali content of CKD (European plants) (Corish and Coleman, 1995)

\begin{tabular}{cccc}
\hline Size Micons & Mass, $\%$ & $\mathbf{N a}_{\mathbf{2}} \mathbf{O}, \mathbf{\%}$ & $\mathbf{K}_{\mathbf{2}} \mathbf{O}, \mathbf{\%}$ \\
\hline \hline $46-68$ & 0.3 & 0.3 & 3.6 \\
$34-48$ & 0.4 & 0.3 & 3.5 \\
$24-34$ & 0.7 & 0.4 & 4.5 \\
$17-24$ & 1.8 & 0.4 & 5.1 \\
$12-17$ & 5.1 & 0.4 & 5.2 \\
$6-12$ & 27.3 & 0.3 & 5.4 \\
$0-6$ & 64.4 & 0.4 & 10.7 \\
\hline
\end{tabular}

\subsubsection{Specific Surface Area}

Blaine fineness values for CKD reported in the literature vary between 2300 and $14000 \mathrm{~cm}^{2} / \mathrm{g}$ (e.g., McCoy and Kriner, 1971; Collins and Emery, 1983; Baghdadi, 1990; 
Konsta-Gdoutos and Shah, 2003) and are consistently above typical values for ordinary portland cement ( $\left.\sim 3000-5000 \mathrm{~cm}^{2} / \mathrm{g}\right)$ suggesting that in the case of CKD, particle texture and morphology may play a significant role. In an extensive study on the stabilization effects of CKD, McCoy and Kriner (1971) found that calcined CKD has lower fineness $\left(2290 \mathrm{~cm}^{2} / \mathrm{g}\right)$ than undercalcined CKD $\left(9370 \mathrm{~cm}^{2} / \mathrm{g}\right)$.

Malhotra and Ramezanianpour (1994) reported that the specific surface areas of fly ash are a function of the raw material and method of dust collection. For example, fly ash collected from modern electrostatic precipitators generally has a higher specific surface area compared to dust collected by cyclones. Considering the variability in the raw materials, process technology, fuel used, dust collection methods associated with the generation of $\mathrm{CKD}$, this observation is likely to apply also to CKD.

\subsubsection{Specific Gravity}

The measured specific gravity of a particulate material is affected by the chemistry and structure of the individual particles. For similar chemical composition, the particles with solid structure tend to have greater specific gravity than particles with hollow and porous structure (Huang, 1990). The specific gravity of CKD is typically in the range of 2.6-2.8 (Baghdadi, 1990), less than that of portland cement (Gs 3.15).

\subsection{Engineering Properties}

The discussion presented so far in this chapter focused on the physio-chemical properties of CKD. Considerable research has already been performed in this regard to prove the inter dependence of oxide composition and physical properties of CKD with the process technology, raw materials, fuel used and dust collection system. However, little effort has been paid to understand the mechanical and engineering properties of this material. To the author's knowledge, the only published data in the literature on the mechanical properties of CKD is by Todres et al. (1992), which focused on the compaction behavior and permeability following compaction of CKD from three sources. The following section summarizes the test results from Todres et al. study. 
Todres et al. (1992) used the standard Proctor test to investigate the compaction behavior of three fresh CKDs. Physio-chemical properties of these CKDs are discussed earlier (see Table 3-1 for oxide composition \# 58, 59 \& 60 and Figure 3.10 for the particle size distributions). Table 3-8 summarizes some of the key physio-chemical characteristics of the CKD used and highlights how the dusts vary both in terms of particle size, and more importantly, the percentage free lime (which ranges from $0.52 \%$ to $27.18 \%$ ).

Table 3-8 CKDs used for compaction studies performed by Todres et al. (1992)

\begin{tabular}{clcccc}
\hline CKD & Kiln System & $\begin{array}{c}\text { Mean Size } \\
\boldsymbol{\mu m}\end{array}$ & $\begin{array}{c}\text { Uniformity } \\
\text { Coefficient }\end{array}$ & LOI, \% & Free lime, \% \\
\hline \hline Dust G & $\begin{array}{l}\text { Long wet } \\
\text { rotary kiln }\end{array}$ & 9.3 & 25 & 25.78 & 0.85 \\
Dust H & $\begin{array}{l}\text { Long dry } \\
\text { rotary kiln }\end{array}$ & 3 & 5 & 30.24 & 0.52 \\
& $\begin{array}{l}\text { Alkali bapass } \\
\text { with } \\
\text { Dust }\end{array}$ & 22.2 & 15.55 & 4.45 & 27.18 \\
\hline
\end{tabular}

Todres et al. (1992) had performed the standard Proctor tests following overnight tempering of the CKDs in a humid room at $23^{\circ} \mathrm{C}$ and $100 \%$ relative humidity. Figure 311 shows the compaction curves obtained for these three CKDs. The figure show that the CKDs investigated respond to compaction in a manner similar to that observed for most fine grained soil, i.e., the dry density increases with water content up to a maximum and then decreases with further increase in water content.

Along with the compaction tests described in the previous section, Todres et al. (1992) conducted permeability tests on CKD specimens compacted to different densities directly inside the permeameter molds. The measured values of the hydraulic 
conductivity k, obtained from these tests are presented in Table 3-9. For compacted CKD low permeability values could be achieved by increasing the compaction effort.

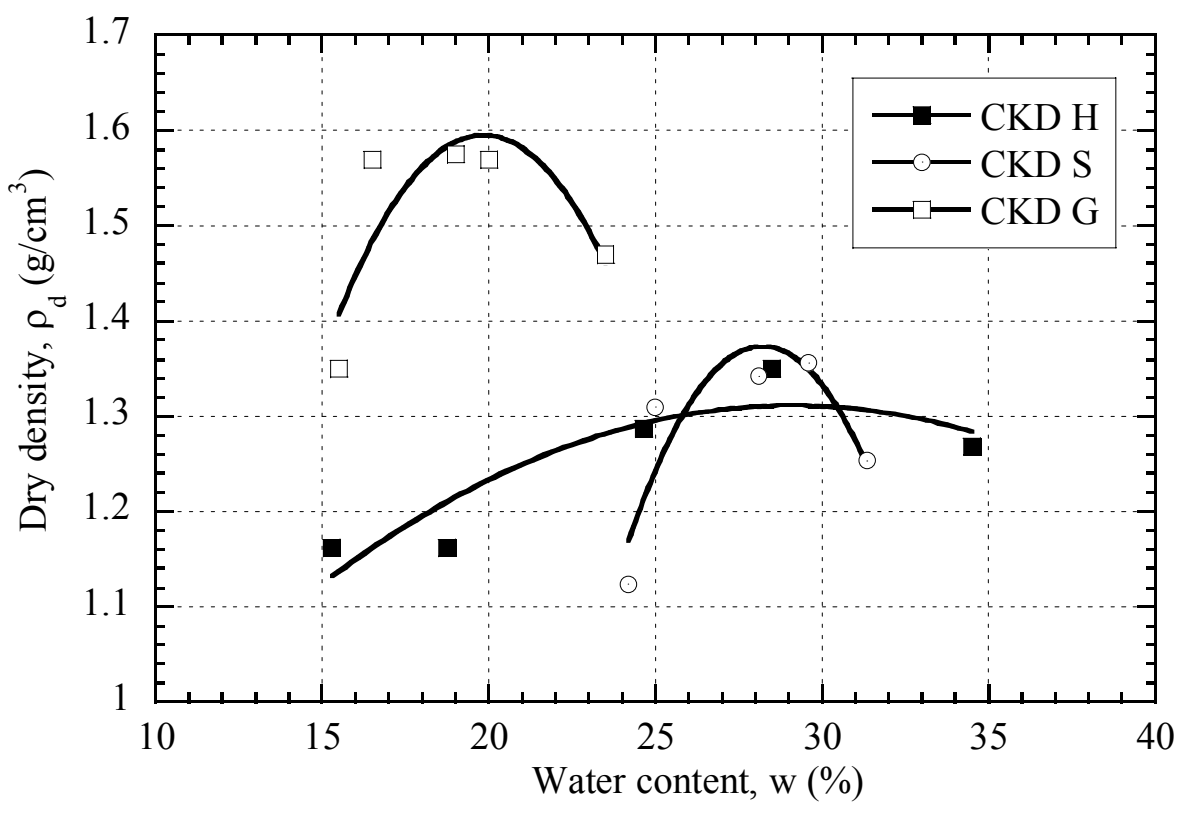

Figure 3-11 Typical compaction curves for fresh CKDs (Todres et al., 1992)

Table 3-9 Permeability values, $\mathrm{k}$ of compacted CKD sample (Todres et al., 1992)

\begin{tabular}{ccccccc}
\hline \multirow{2}{*}{$\mathbf{C K D}$} & \multicolumn{2}{c}{ Light compaction } & \multicolumn{2}{c}{ Medium compaction } & \multicolumn{2}{c}{ Heavy compaction } \\
\cline { 2 - 7 } & $\begin{array}{c}\text { Density, } \\
\mathbf{g} / \mathbf{c c}\end{array}$ & $\mathbf{k}, \mathbf{c m} / \mathbf{s}$ & $\begin{array}{c}\text { Density, } \\
\mathbf{g} / \mathbf{c c}\end{array}$ & $\mathbf{k}, \mathbf{c m} / \mathbf{s}$ & $\begin{array}{c}\text { Density, } \\
\mathbf{g} / \mathbf{c c}\end{array}$ & $\mathbf{k}, \mathbf{c m} / \mathbf{s}$ \\
\hline \hline $\mathbf{G}$ & 1.386 & $1.5 \times 10^{-3}$ & 1.501 & $7.6 \times 10^{-6}$ & 1.733 & $1.5 \times 10^{-10}$ \\
$\mathbf{H}$ & 1.221 & $3.0 \times 10^{-3}$ & 1.33 & $7.0 \times 10^{-6}$ & 1.418 & $4.9 \times 10^{-8}$ \\
$\mathbf{S}$ & 1.243 & $5.1 \times 10^{-4}$ & 1.3 & $2.1 \times 10^{-5}$ & 1.349 & $1.6 \times 10^{-6}$ \\
\hline
\end{tabular}




\subsection{CKD-Utilization}

\subsubsection{Introduction}

As discussed in chapter 2 , it is not practically possible for a cement plant to achieve 100 percent recycling of CKD. Landfilling continues to be the typically adopted mode of "storage" of CKD to accommodate the increased production of CKD. The cement industry has a keen interest in finding practical applications for fresh CKD due to the quantities produced, the cost associated with the disposal and the strict environmental regulations for management and disposal of CKD. In addition to decreasing disposal costs, and freeing precious landfill space, the re-utilization of CKD provides the opportunity to save higher quality natural materials and overall to make progress towards the $100 \%$ recycling scenario advocated by the EPA.

The first commercial use of CKD was reported in 1912. CKD from Riverside Portland Cement Company in Crestmore, California was used as a potassium rich fertilizer for citrus and other crops. During World War I, due to a shortage of sodium nitrate used to produce potassium nitrate for explosives, CKD was used for extraction of potassium (Klemm, 1983).

Since then, researchers have investigated the reuse of CKD in a number of fields (e.g., as a soil fertilizer, as a stabilizer of waste water streams, as a partial replacement of soda in glass production, as an anti-stripping agent in asphalts, and as component of blended cements and masonry products (Klemm, 1980 and Bhatty, 1995)). However, as with other industrial waste materials, due to the large volumes of materials involved in highway construction, there has, and continues to be, great interest in exploring the viability of using CKD in partial substitution of traditional construction materials. In particular, a number of researchers have investigated the use of CKD for subgrade stabilization/modification (e.g. McCoy and Kriner, 1971; Zaman and Sayah, 1992; Baghdadi et al., 1995; Bhatty et al., 1996; Miller and Azad, 2000; Miller et al., 2003). A few of the other listed applications for CKD are for stabilization of contaminated soils and sludge (MacKay and Emery, 1994), as filler in asphalts (Zhu, Zaman and Laguros, 1999), as a partial additive to produce blended cements for concrete construction (Wang et al., 2002; Shoaib et al., 2000 and Kurdi et al., 1996). Additionally, ASTM D 5050 lists 
a few potential applications for CKD (e.g. soil stabilization, solidification and stabilization of waste materials and agricultural lime). It may be noted that so far, most of the work performed has been limited to freshly generated CKD while the issue of reusing already landfilled material, available in significantly greater quantities, has been mostly unexplored.

While much work has been done in trying to identify large scale applications for CKD, there are clear "barriers" to the widespread utilization of CKD as a construction material. Some of these "barriers" have been encountered in the past with other industrial by-products, including concerns over the environmental impact and regulatory issues, the perception of the new material as "experimental", and economic related concerns associated with special design and construction considerations, additional training required for the design and construction teams.

Also in the case of CKDs, there are specific additional concerns that are associated with the variability in properties of this material. It was illustrated in Section 3.2.1 that there exists no "average" CKD, and that physical and chemical properties of CKD vary markedly from plant to plant, depending upon the feed raw materials, type of kiln operation, dust collection facility, and the fuel used. As a result, the re-utilization of CKD is likely to be best considered on a plant by-plant basis.

In addition, the fineness of CKD is likely to represent a concern in many geotechnical applications due to the inferior properties and construction difficulties (e.g., compaction and dust control) that typically characterize similarly graded geomaterials.

As with any other industrial by-product, before CKD can be considered as a practical alternative to other construction materials, issues including environmental stability, field verification, and long term performance have to be clearly addressed.

\subsubsection{CKD in Soil Stabilization}

Chemical admixtures, in particular lime and cement, have been extensively used in both shallow and deep stabilization of soils, in order to improve properties such as strength and stiffness. Although several studies have been undertaken to investigate the use of CKD as an alternative to these traditional materials for treating both clays and 
sands, there remain many fundamental questions regarding its effectiveness as a soil stabilizer. In part this is a result of the fact that the CKDs used in these studies have chemical and physical properties varying over a very wide range (e.g. LOI ranging between $6 \%$ and 4\%; and free lime from traces to 27\%). Tables 13-10 and Table 13-11 summarize the published research performed on the use of CKD for soil stabilization.

The first investigation of CKD for soil stabilization was reported by McCoy and Kriner (1971), who employed CKDs with different free lime contents and soils of different plasticity (Table 3-10). The results were compared to those obtained with hydrated lime and type portland cement, and it was concluded that the use of CKD with appropriate composition at adequate addition levels was promising for stabilizing soils. CKDs with high free lime and low LOI provided, in fact, a 7-day compressive strength comparable to that measured on soil-cement mixtures and significantly higher than that of hydrated lime-soil mixtures. It was also noted that the presence of high alkali content in the CKD adversely affected the compressive strength.

Later research included work with kaolinite and bentonite (Baghdadi, 1990); an expansive clay (Zaman et al., 1992); dune sand (Baghdadi et al., 1995); and extensive work by Miller and co-workers with several soils (Miller and Azad, 2000 and Miller et al., 2003). These studies testify the potential of using CKD for soil stabilization, albeit at dosages (8-30\%) substantially greater than those used for other admixtures (unfortunately the chemical and physical characteristics of the CKDs used are not always documented). For example, for a CKD with 5.3\% free lime and $\mathrm{LOI}=26 \%$, considerable improvement in the strength of kaolinite (e.g., for 16\% CKD the 28-day UCS increased 5 times) and a reduction in the PI of the bentonite (more marked with increasing CKD \%) were reported by Baghdadi (1990). Similar effects on strength (although not as marked) and plasticity are reported by Zaman et al.(1992) for a highly expansive clay and a CKD with LOI $=28 \%$. Testing on different soils discussed in Miller and Azad (2000) indicates more effective stabilization in the case of low PI soils and a correlation between the $\mathrm{pH}$ response of soil-CKD mixtures and the effectiveness of the treatment.

Peethamparan et al. (2006) performed an experimental study to investigate the effectiveness of CKD for stabilizing kaolinite clay. The Two CKDs used have free lime 
content of 13.85 and $5.32 \%$ and LOI of 14.22 and $29.63 \%$ respectively. The percentage CKD varied from 8 to $25 \%$ by dry weight of clay. They reported that the strength of CKD treated kaolinite clay is proportional to the CKD content and also to the free lime content. For example, for a CKD with $13.85 \%$ free lime and LOI $=14.22 \%$, considerable improvement in the strength of kaolinite is observed (e.g. for 15\% CKD the 7-day UCS increased 6 times). Also for a CKD with higher free lime content (13.85\%), the increase in compressive strength at 7 days is twice that of the CKD with lower free lime (5.32\%).

Field experience on subgrade modification/stabilization with CKD is at this time still quite limited. The Oklahoma DOT performed a field evaluation of CKD treated subgrades in 2000 (Miller et al., 2003) The results of this investigation, which involved treatment of a sandy lean clay (PI 15-30\%) with three different CKDs, confirmed laboratory observations (the significant improvement in properties that can be obtained using CKD, but also the great variability in stabilization results depending on the type of CKD used), and highlighted a number of issues relevant to construction (e.g. the problem posed by wind blown CKD). Additional field work, as well as laboratory tests with different CKDs (LOI ranging between 22 and 29\%) on shale-sand mixtures (Miller et al., 2003), showed that CKD can perform better than free lime, and indicated better performance for the lower LOI CKD.

Overall the results documented in the literature indicate that, due to wide variation in the physical and chemical properties of CKD, general conclusions on its validity as a soil stabilizer cannot be drawn. Moreover, the investigations conducted so far have been limited to comparative experimental investigations and the mechanisms responsible for the improved behavior remain unclear. These factors have essentially to date prevented a more extensive use of CKD in soil stabilization. 
Table 3-10 Summary of soils and CKDs used by McCoy and Krinner (1971)

(from Bhatty, 1995)

\begin{tabular}{|c|c|c|c|c|c|c|c|c|}
\hline \multirow[t]{2}{*}{ Additives } & \multicolumn{3}{|c|}{ Properties of CKD used } & \multirow{2}{*}{\begin{tabular}{|c|}
$\begin{array}{c}\text { Additives } \\
\text { used in } \\
\text { percentage of } \\
\text { dry soil }\end{array}$ \\
\\
\\
10.0
\end{tabular}} & \multirow{2}{*}{$\begin{array}{c}\text { Soil Type } \\
\text { Clayey A-6-A-7 }\end{array}$} & \multirow{2}{*}{$\begin{array}{c}\text { OMC (\%) } \\
\\
\end{array}$} & \multirow{2}{*}{$\begin{array}{c}\boldsymbol{\rho}_{\mathrm{d} \max },(\mathbf{g} / \mathbf{c c}) \\
2.01\end{array}$} & \multirow{2}{*}{\begin{tabular}{|c|}
$\begin{array}{c}\text { day UCS } \\
\text { (MPa) }\end{array}$ \\
\end{tabular}} \\
\hline & $\begin{array}{l}\text { Free lime } \\
(\%)\end{array}$ & LOI (\%) & $\begin{array}{l}\text { Total } \\
\text { alkali (\%) }\end{array}$ & & & & & \\
\hline $\begin{array}{c}\text { CKD A } \\
\text { CKD B } \\
\text { CKD C } \\
\text { CKD D } \\
\text { Type I PC } \\
\text { Lime }\end{array}$ & $\begin{array}{c}15.7 \\
14.6 \\
14.3 \\
7.8\end{array}$ & $\begin{array}{c}8.4 \\
6.6 \\
11.6 \\
6\end{array}$ & $\begin{array}{l}2.35 \\
2.64 \\
5.17 \\
2.42\end{array}$ & $\begin{array}{c}10.0 \\
10.0 \\
10.0 \\
10.0 \\
8.0\end{array}$ & $\begin{array}{l}\text { Clayey A-6-A-7 } \\
\text { Clayey A-6-A-7 } \\
\text { Clayey A-6-A-7 } \\
\text { Clayey A-6-A-7 } \\
\text { Clayey A-6-A-7 } \\
\text { Clayey A-6-A-7 }\end{array}$ & $\begin{array}{c}21.9 \\
20 \\
20.6 \\
20.1 \\
24.1 \\
24.6\end{array}$ & $\begin{array}{l}2.01 \\
2.05 \\
2.04 \\
1.99 \\
1.97 \\
1.98\end{array}$ & $\begin{array}{c}2.8 \\
2.9 \\
2 \\
2.2 \\
3.2 \\
1.0\end{array}$ \\
\hline $\begin{array}{c}\text { CKD E } \\
\text { CKD F } \\
\text { Type I PC }\end{array}$ & $\begin{array}{c}\text { Traces } \\
10\end{array}$ & $\begin{array}{c}23.6 \\
4.2\end{array}$ & & $\begin{array}{c}10.0 \\
10.0 \\
8.0\end{array}$ & & $\begin{array}{l}22.6 \\
21.1 \\
20.5\end{array}$ & $\begin{array}{l}1.93 \\
1.98 \\
1.92\end{array}$ & $\begin{array}{l}2.28 \\
4.01 \\
5.35\end{array}$ \\
\hline $\begin{array}{c}\text { None } \\
\text { CKD H } \\
\text { CKD H } \\
\text { CKD L } \\
\text { Type I PC } \\
\text { Type I PC }\end{array}$ & $\begin{array}{c}26.6 \\
26.6 \\
0.5\end{array}$ & $\begin{array}{c}5.8 \\
5.8 \\
33.6\end{array}$ & $\begin{array}{l}4.6 \\
4.6 \\
2.2\end{array}$ & $\begin{array}{l}3.0 \\
5.0 \\
5.0 \\
3.0 \\
5.0\end{array}$ & $\begin{array}{l}\text { Silty ( } 40 \% \text { silt, } \\
54 \% \text {,clay, } 4 \% \text { sand) }\end{array}$ & & & $\begin{array}{c}0.4 \\
0.59 \\
0.69 \\
\\
0.68 \\
1.1\end{array}$ \\
\hline $\begin{array}{c}\text { None } \\
\text { CKD H } \\
\text { CKD H } \\
\text { Type I PC } \\
\text { Type I PC }\end{array}$ & $\begin{array}{l}26.6 \\
26.6\end{array}$ & $\begin{array}{l}5.8 \\
5.8\end{array}$ & & $\begin{array}{l}3.0 \\
5.0 \\
3.0 \\
5.0\end{array}$ & $\begin{array}{l}\text { Clayey ( } 73 \% \text { Clay, } \\
23 \% \text { silt, } 1 \% \text { sand) }\end{array}$ & & & $\begin{array}{c}0.37 \\
0.73 \\
1.12 \\
0.79 \\
1.2\end{array}$ \\
\hline $\begin{array}{c}\text { None } \\
\text { CKD H } \\
\text { CKD H } \\
\text { Type I PC } \\
\text { Type I PC } \\
\text { Lime } \\
\text { Lime }\end{array}$ & $\begin{array}{l}26.6 \\
26.6\end{array}$ & $\begin{array}{l}5.8 \\
5.8\end{array}$ & & $\begin{array}{l}3.0 \\
5.0 \\
3.0 \\
5.0 \\
3.0 \\
5.0\end{array}$ & $\begin{array}{l}\text { Sandy }(20 \% \text { Sand, } \\
52 \% \text { silt, } 28 \% \text { clay }\end{array}$ & & & $\begin{array}{c}0.26 \\
0.72 \\
0.97 \\
1.01 \\
1.63 \\
0.9 \\
1.21\end{array}$ \\
\hline
\end{tabular}


Table 3-11 Summary of soils and CKDs investigated by other researchers

\begin{tabular}{|c|c|c|c|c|}
\hline Author & \multicolumn{2}{|c|}{ Properties of CKD } & $\begin{array}{l}\text { CKD used (by } \\
\% \text { of dry soil) }\end{array}$ & Soil Type \\
\hline \multirow[b]{2}{*}{$\begin{array}{l}\text { Napierala (1983) (From } \\
\text { Bhatty et al., 1996) }\end{array}$} & \begin{tabular}{|l|} 
Free lime \\
$(\%)$
\end{tabular} & LOI (\%) & & \multirow[b]{2}{*}{ Sandy soils } \\
\hline & 5.9 & - & 15.0 & \\
\hline $\begin{array}{l}\text { Baghdadi and } \\
\text { Rahman(1990) }\end{array}$ & & & $30-70$ & Siliceous Dune Sand \\
\hline Baghdadi et al. (1995) & - & 33.04 & $15-50$ & Dune Sand (SP) $\rho_{\mathrm{d} \max }=1.52 \mathrm{~g} / \mathrm{cc}$ and $\mathrm{OMC}=22.5 \%$ \\
\hline Baghdadi (1990) & 5.33 & 26 & - & $\begin{array}{l}\text { Processed and pure kaolinite }\left(\mathrm{G}_{\mathrm{s}}=2.62, \mathrm{LL}=40 \%, \mathrm{PI}=9 \%\right) \text {. } \\
\text { Commercially available bentonite }(\mathrm{LL}=513 \%)\end{array}$ \\
\hline $\begin{array}{l}\text { Zaman and Sayah } \\
\text { (1992) }\end{array}$ & - & 28 & $5-40$ & $\begin{array}{l}\text { Expansive clay }\left(\mathrm{LL}=99 \%, \mathrm{PI}=64 \%, \mathrm{OMC}=32.7 \%, \rho_{\mathrm{dmax}}\right. \\
=1.37 \mathrm{~g} / \mathrm{cc})\end{array}$ \\
\hline Miller and Azad (2000) & - & $22.1-29.1$ & $\begin{array}{l}15-40 \text { (Depends } \\
\text { on the type of } \\
\text { soil) }\end{array}$ & $\begin{array}{l}\text { Natural soils from Oklahom: } \mathrm{CH}(\mathrm{LL}=55 \%, \mathrm{PI}=40 \% \\
\left.\mathrm{OMC} 23.3 \%, \rho_{\mathrm{dmax}}=1.59 \mathrm{~g} / \mathrm{cc}\right) ; \mathrm{CL}(\mathrm{LL}=48 \%, \mathrm{PI}=33 \% \text {, } \\
\left.\mathrm{OMC}=16 \%, \rho_{\mathrm{dmax}}=1.75 \mathrm{~g} / \mathrm{cc}\right) ; \text { and } \mathrm{ML}(\mathrm{LL}=23 \%, \mathrm{PI}= \\
\left.6 \%, \mathrm{OMC}=14 \%, \rho_{\mathrm{d}}=1.86 \% \mathrm{~g} / \mathrm{cc}\right)\end{array}$ \\
\hline Miller et al. (2003) & - & $22.1-29.1$ & - & $\begin{array}{l}\text { Soil 1: CL }(\mathrm{LL}=48 \%, \mathrm{PI}=30 \%, \mathrm{OMC}=18.9 \%, \\
\rho_{\mathrm{dmax}}=1.7 \mathrm{~g} / \mathrm{cc}, \text { Soil } 2: \mathrm{CL}(\mathrm{LL}=45 \%, \mathrm{PI}=24 \%, \\
\mathrm{OMC}=16.0 \%, \rho_{\mathrm{d}}=1.71 \mathrm{~g} / \mathrm{cc}, \text { Soil-3: sand: SP-SM } \\
\left(\mathrm{OMC}=16.5 \% \text { and } \rho_{\mathrm{dmax}}=1.72 \mathrm{~g} / \mathrm{cc}\right) .\end{array}$ \\
\hline
\end{tabular}


One of the most noticeable phenomena that are mentioned in almost every article on lime, fly ash or CKD stabilization is the ability of the binder to change the plasticity characteristics of the soil. It has been shown by many researchers that the addition of CKD to moderately plastic to highly plastic soil generally causes an immediate increase in plastic limit and reduction in plasticity index (McCoy and Kriner, 1971; Baghdadi, 1990; Zaman et.al., 1992; Miller and Azad, 2000). However note that in the literature trends of both increasing and decreasing liquid limit with CKD percentage are reported depending on the soil used (Zaman et.al., 1992; Miller and Azad, 2000; Santagata and Bonet, 2002).

Table 3-12 summarizes the test results of McCoy and Kriner (1971) from which we observe that the liquid limit generally increased with the addition of CKD except for one case (a decrease in LL by $2 \%$ for silty soil with the addition of $5 \%$ CKD with low free lime content). The PL of the neat soil increased with the addition of CKD. As observed for LL, the addition of CKD with low free lime content caused a reduction in PL of the neat soil. The PI being a composite property, the increase in LL and decrease in PL caused a reduction in PI of the treated soils. Zaman et al. (1992) studied the effect of CKD (free lime content of CKD employed was not reported) on highly plastic clayey soil and found that the liquid limit generally decreased, while the plastic limit sharply increased with the increase in amount of CKD (Figure 3-12). Figure 3-13 shows the results of Atterberg limits from the study conducted by Miller and Azad (2000) the addition of various percentages of CKD on three different soils. Soils 1, 2 and 3 are classified as $\mathrm{CH}, \mathrm{CL}$ and $\mathrm{ML}$ respectively. The properties of the CKD used are listed are Table 3-1 (CKD \#52). From the figure, it can be seen that for all the three soils tested the LL increased dramatically with the addition of CKD. There is a substantial reduction in PI occurred with modest amounts of CKD for soils 1 and 2. However for soil 3 the there is not much change in PI with the addition of CKD. This could be due to increase in both LL and PL with the addition of CKD. Miller and Azad concluded that the treatment of soil with CKD reduces the PI of moderate to high plastic soils. 
Table 3-12 Atterberg limits and 7-day compressive strength of soil treated with CKD, lime and cement (McCoy and Kriner, 1971) (from Bhatty et al., 1996)

\begin{tabular}{llccc}
\hline Soil & Additive & $\begin{array}{c}\text { Liquid } \\
\text { Limit(\%) }\end{array}$ & $\begin{array}{c}\text { Plastic } \\
\text { Limit (\%) }\end{array}$ & $\begin{array}{c}\text { Plasticity } \\
\text { Index (\%) }\end{array}$ \\
\hline \hline Silty (40\% silt, & None & 63 & 30 & 33 \\
54\%,clay, & CKD H (3\%) & 63 & 36 & 27 \\
4\% sand) & CKD H (5\%) & 61 & 42 & 19 \\
& CKD L (5\%) & 66 & 25 & 41 \\
& & 62 & 21 & 41 \\
Clayey (73\% Clay, & None & 65 & 29 & 36 \\
23\% silt, & CKD H (3\%) & 64 & 34 & 30 \\
1\% sand) & CKD L (5\%) & 68 & 20 & 48 \\
& None & 43 & 23 & 20 \\
\hline Sandy (20\% Sand, & CKD H (3\%) & 45 & 33 & 12 \\
52\%silt, & CKD H (5\%) & 47 & 38 & 9 \\
28\%clay & CKD L (5\%) & 48 & 19 & 29 \\
\hline
\end{tabular}

$\mathrm{H}$ denotes CKD with high lime (26.6\%) and moderate alkali content (4.6\%) and L denotes CKD with low lime $(0.5 \%)$ and low alkali $2.2 \%$. Alkali content is the equivalent alkali content.

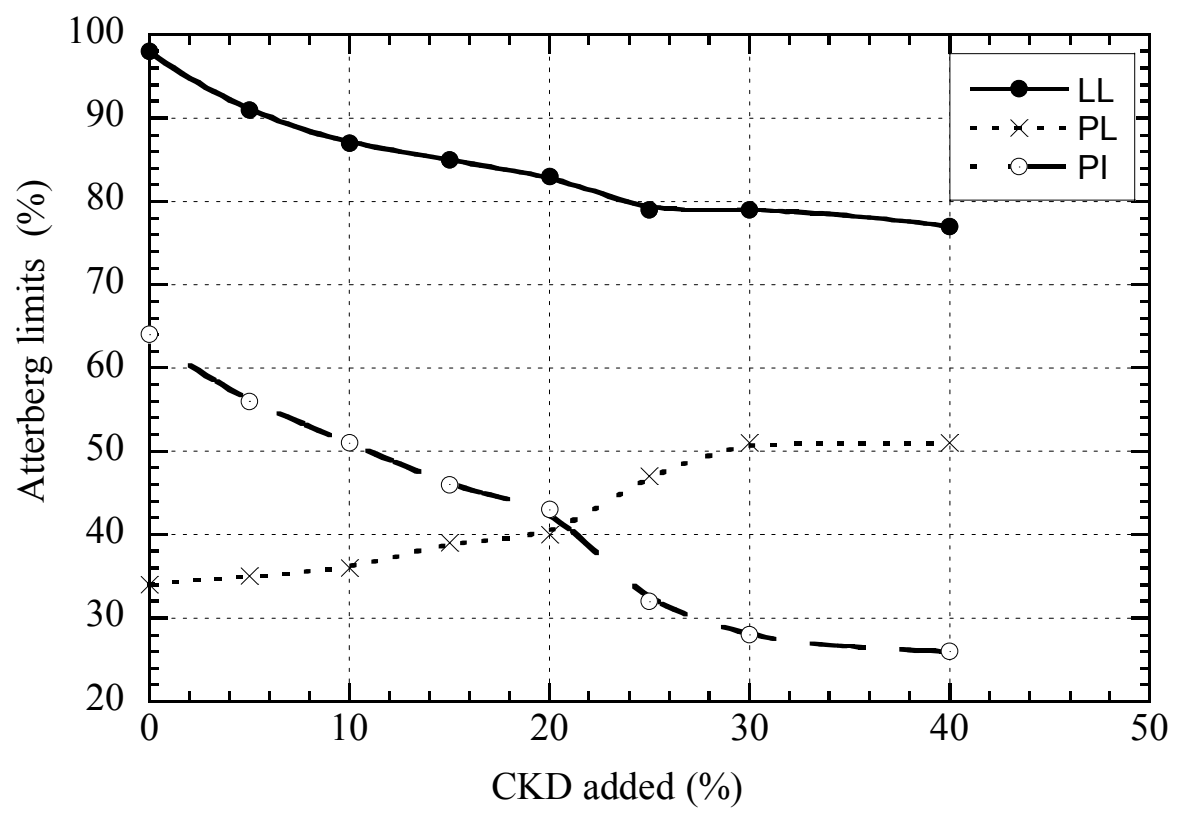

Figure 3-12 Variation in Atterberg limits of high plasticity clay with CKD addition (Zaman et al., 1992) 

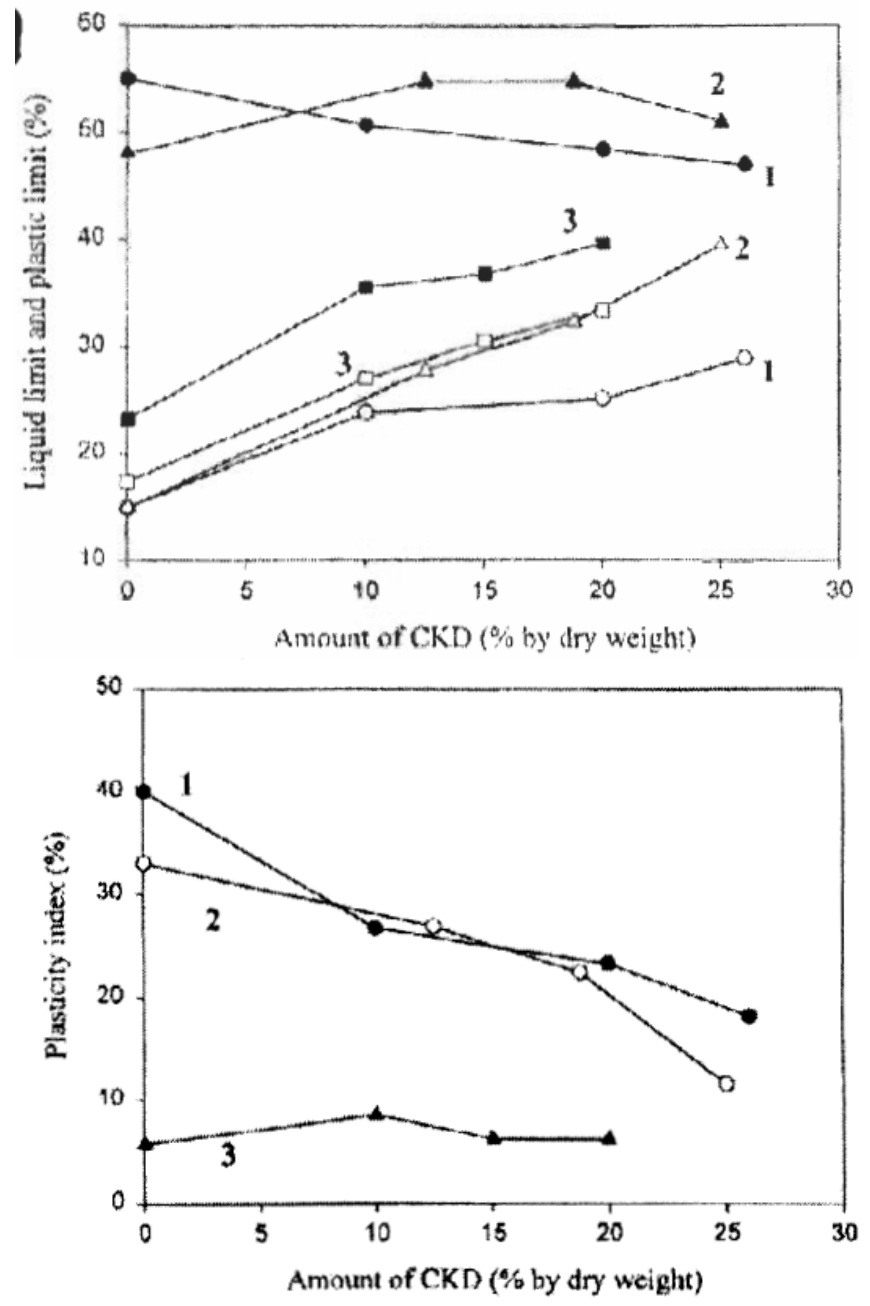

Figure 3-13 Variation in limits for different soils treated with different percentages of CKD (Miller and Azad, 2000)

In general, the plasticity characteristics of soil have been dramatically modified by the addition of CKD. The increase or decreases in limits are not only dependent on the type of soil treated but also on the chemical composition (primarily the free lime content) of CKD. 


\subsubsection{CKD in Controlled Low Strength Materials}

The American Concrete Institute (ACI) Committee 229 defines controlled lowstrength material (CLSM) as "a self-compacting, cementitious material used primarily as backfill in lieu of compacted fill" (ACI 1994). CLSM is, as defined by ASTM, "a mixture of soil, cementitious materials, water, and sometimes admixtures that harden into material with a higher strength than the soil but less than $8270 \mathrm{kPa}$ (1200 psi)". In general, CLSM describes a fill technology that is used in place of compacted backfill and that contains cement, fly ash, fine aggregate, water and sometimes chemical admixtures, mixed in varying proportions to meet the requirements of strength and flowability. In 1984, ACI established a technical committee (ACI committee 229) on CLSMs which is accountable for developing and reporting information on these materials. The recent adoption of new ASTM test methods for CLSM (ASTM D 4832, ASTM D 5971, ASTM D 6023, ASTM D 6024 and ASTM D 6103) has helped increase the knowledge on the material and provide guidance on its testing and requirements.

The first use of CLSM in the U.S was reported in 1964 for the Canadian River Aqueduct Project in northwestern Texas. The estimated U.S. market for CLSM of all types was estimated at approximately 10 million cubic yards in 1997 (Crouch and Gamble, 1997).

In all applications, the primary property of CLSMs is their flowability/self leveling nature. CLSMs require no compaction and are therefore ideal for use in tight and restricted-access areas where placing and compacting soil or granular fill is difficult or even impossible. The consistency of flowable fills used in geotechnical applications is similar to that of a lean grout or slurry, yet several hours after placement the material hardens enough to support traffic loads without settlement.

CLSM is generally used in nonstructural applications below grade for which low strengths are desired. In these cases, the ultimate strength of the CLSM is intended to be no greater than that of the surrounding soil. ASTM standards, various researchers and ready mixed concrete companies have reported various strength requirements for CLSM. The recommendations for a minimum strength are intended to ensure that the CLSM has adequate bearing capacity and does not deform excessively under load. Maximum 
strength recommendations (which typically vary anywhere between 345 and $690 \mathrm{kPa}$ at 28 days) ensure that CLSM can be removed with conventional excavating equipment.

There have been significant efforts in utilizing various industrial by-products in CLSM. One of the most commonly used by products in CLSMs is fly-ash that is found to improve flowability and reduce segregation and bleeding. It is estimated that about $2 \%$ of fly ash produced ( $\sim 27$ million metric tons per year) is employed in CLSM.

Despite the limitations placed on fly ash used for conventional concrete, it has been demonstrated that CLSM can be successfully produced using a wide variety of fly ash types and sources, including high-carbon fly ash that is not permitted in concrete (due to its high water demand that significantly increases the need for chemical admixtures). For example, Mullarky (1998) reported the use of fly ash with LOI as high as $20 \%$ in CLSM.

In addition to fly ash, researchers have successfully used bottom ash in CLSM as the fine aggregate (Naik et al., 1998). Foundry sand, a by-product of the metal casting industry, has been studied and used successfully in CLSM and its use has increased in recent years (Bhatt, 1996; Tikalsky et al., 2000). In addition to these materials, waste materials like asphalt dust, quarry waste (Katz and Kovler, 2004), high fines limestone screening (Crouch and Gamble, 1997) and recycled glass (Ohlheiser, 1998) have also been successfully evaluated, at least in the laboratory.

Recently, researchers have started investigating the feasibility of using CKD as one of the component in CLSM. Al-Jabri et al. (2002) conducted a preliminary study on the use of one CKD (with LOI=9.67\%) in CLSM in replacement of cement. The two mixes tested by these authors (one with $249 \mathrm{~kg} / \mathrm{m}^{3}$ of CKD and $47 \mathrm{~kg} / \mathrm{m}^{3}$ of cement; the other with only $296 \mathrm{~kg} / \mathrm{m}^{3}$ of CKD) both showed satisfactory strength at 28 days (2735 $\mathrm{kPa}$ and $1045 \mathrm{kPa}$ respectively). It was concluded that CKD with good cementing properties could be used as a partial or full substitute for cement in flowable fill.

Pierce et al. (2003) investigated the combined use of CKD (LOI $=25.1 \%)$ and fly ash at different ratios in CLSM. This study involved evaluation of both the fluid and hardened state properties of the CLSM, and comparison to the results obtained with fly ash. The results showed that high flowability and relatively rapid setting time could be 
achieved with CKD-CLSM mixtures. Additionally, the 28-day compressive strength was observed to increase with CKD-fly ash ratio (for CKD: $F A=1: 12,1: 6$, and 1:1 the average 28 day compressive strength was 45, 71 and $356 \mathrm{kPa}$ ). Overall it was observed that by varying the amounts of $\mathrm{CKD}$, fly ash and water, it was possible to create a selfconsolidating material with a wide range of hardened and fluid state properties for field applications.

More recently, Katz and Kovler (2004) compared the properties of CLSM mixes using different waste materials like fly ash, CKD (no LOI, chemical composition or free lime data reported), dust from asphalt quarry, bottom ash and quarry waste. The results of this study indicated that CKD-CLSMs were characterized by higher water demand, lower bleeding, higher shrinkage and higher setting time compared to the fly ash-CLSM. In terms of strength the CKD and fly ash based CLSMs showed comparable results.

\subsubsection{CKD in Highway Bases and Subbases}

Collins (1983) carried out an extensive study in order to determine the effectiveness of substituting CKD for hydrated lime in lime fly ash-aggregate road base mixtures. 33 CKD samples were selected for the study: 17 from wet process plants and 16 from dry process plants (see Table 3-1 for details on the CKDs). Optimum ratios for CKD-fly ash combinations were determined on the basis of the strength developed in test cylinders. CKD - fly ash control mixes were prepared with a typical class F bituminous coal fly ash. These were compared with a control mix consisting of one part by weight of commercial high calcium hydrated lime and four parts by weight of the same fly ash. Only 11 of the 45 kiln dusts exhibited lower 7-day strengths than the lime-fly ash control mix. In terms of long term strength development similar results were reported for both the kiln dust-fly ash mixes and the lime-fly ash aggregate. Most CKD - fly ash aggregate mixtures were found to be dimensionally stable over extended periods, regardless of whether samples were submerged or cured in a moist room. Volume changes were found to be generally negligible or comparable in magnitude to those measured on conventional lime fly ash mixtures. Considerable volumetric expansion was documented for mixtures manufactured with CKD with high sulfate content $(10 \%$ or greater). CKD-fly ash 
aggregate test mixes showed excellent freeze-thaw durability, except for two mixes in which high sulfate, high alkali cement kiln samples were used. In general, the study concluded that CKDs having a sulfate content greater than or equal to $10 \%$ should not be considered or should be used with utmost caution in a pozzolanic base system.

\subsubsection{CKD in Blended Cements and Construction Products}

A great deal of work has been carried out on the use of CKD in blended cements (e.g., Bhatty, 1983, 1986; Sanduo, 1986; Daughterty and Funnell, 1983; Klemm, 1980). These studies investigated the effect of the CKD addition on workability, setting time and strength development. In addition, the potential for alkali-aggregate reaction (ASR) deriving from the high alkali content of CKD has also been investigated (e.g. Bhatty and Klemm (1980) suggested that the potential of ASR may be reduced by the addition of slag or fly ash). The use of CKD in concrete blocks has been reported by Wills (1983) and Chen and $\mathrm{Lu}$ (1989). Wills substituted up to 60\% CKD for portland cement in producing concrete blocks of adequate strength under different curing conditions.

Hydrated CKD has been successfully evaluated as an anti-stripping agent in hot mix asphaltic concrete (Klemm, 1993).

\subsubsection{CKD in Sludge Stabilization}

Stabilization/solidification (S/S) of waste (solid or liquid) or contaminated soil in general is the process of reducing the mobility of hazardous substances and contaminants in the waste through both physical and chemical means by the use of additives so as to yield a product or material suitable for land disposal or for other beneficial uses. Sludge is generally stabilized using common cementitious (portland cement, slag cement, hydrated lime), pozzolanic (fly ash, silica fume), or byproduct (cement kiln dust, lime kiln dust) materials (MacKay and Emery, 1992). The cementitious products stabilize the sludge not only by providing a $\mathrm{pH}$ band at which the solubility of metal hydroxides is minimized (thus reducing the mobility of heavy metals) but also by producing a final integral stabilized product. Additionally, the high $\mathrm{pH}$ creates an environment that is not conducive to the survival of microorganisms. Consequently, the sludge will not putrefy 
and create odors. The dosage of stabilizer depends on the type of sludge and its solid concentration.

According to Adaska et al.(1992), the candidacy for CKD in S/S primarily depends on its reactivity and for successful utilization of CKD thorough testing of the material for its suitability to treat specific wastes is required. Considering the variability in properties of CKD the application of CKD in S/S will vary depending on the characteristics of the CKD. Limited research is reported on the use of CKD in sludge stabilization (Angelbeck et al., 1989; MacKay and Emery, 1992; Burnham, 1988; Burnham et al., 1992). While most of the work has primarily focused on the microbiological aspects of the stabilization process, no research, to the author's knowledge, has been carried out on the physio-chemical and engineering properties of the CKD treated waste.

\subsubsection{CKD as an Activator for Pozzolans}

Studies have been carried out on the use of CKD as an activator for "latent pozzolanic materials" (Sprouse, 1984; Akin, 1995; Xu, 1995; Gdoutos et al., 2003). Latent hydraulic materials develop pozzolanic activity and act as hydraulic cements once their glass network disintegrates when attacked by $\mathrm{OH}^{-}$ions. The solubility of $\mathrm{Si}, \mathrm{Ca}, \mathrm{Al}$ and $\mathrm{Mg}$ are functions of $\mathrm{pH}$. At a $\mathrm{pH}$ lower than 11.5, the equilibrium solubility of silica is low and slag does not dissolve. As a result, more $\mathrm{Ca}^{2+}$ and $\mathrm{Mg}^{2+}$ enter into the solution and an impermeable aluminosilicate coating covers the surfaces of the slag grains inhibiting further hydration. Hence, a chemical activator is required for further hydration of slag. Activators generally include all alkali hydroxides and salts, with the least soluble salts being the most effective. The high alkali and sulfate content make CKD a potential candidate as an activator for pozzalanic materials.

Gdoutos et al. (2003) conducted a series of experiments on the interaction of CKD with slag in order to explore the feasibility and approaches for developing a new generation of more durable CKD-activated slag blends and found that $\mathrm{CKD}$ can be successfully utilized to activate blast furnace slag. CKD concrete, with good overall performance in terms of setting time and mechanical properties, can be produced with 
CKDs covering a wide range of chemical composition and fineness and can essentially be regarded as a future alternative material to OPC.

\subsubsection{CKD in the Mining Industry}

Studies by the U.S. Bureau of Mines (Haynes and Kramer, 1982) have documented the use of CKD as partial hydraulic filler for backfilling coal mine shafts and tunnels. This application can potentially use large quantities of CKD. 


\section{CHAPTER 4 -- CKD SOURCES AND SAMPLING OF LANDFILLED CKD}

\subsection{Introduction}

The CKDs for the present investigation were collected from the Mitchell, Indiana plant of Lehigh Portland Cement Company. At this plant Type I-II, IA, III cements and $\mathrm{M}$ and $\mathrm{N}$ masonry type cements are produced. The plant produces approximately 800,000 short tons of finished product per year, making it the third largest in the State of Indiana. A brief description of the cement manufacturing process practiced at the Lehigh plant is given in the following section. Prior to 2001, an estimated 30,000 metric tons of CKD per year were generated and disposed of in a non designed landfill adjacent to the plant. Since 2001, due to a change in the air pollution control for the two kilns, the generation of CKD has decreased to an estimated 18,000 metric tons per year. This material is currently being placed into the new CKD disposal landfill which is designed as per solid waste regulations (Solid Waste Facility Permit No.47-5 issued by the Indiana Department of Environmental Management, Office of Land Quality, August 1999). The landfilled CKD for the present study was collected from the older landfill. This chapter summarizes the sampling operations performed to collect the CKD samples used in the investigation.

\subsection{Mitchell Plant - General}

The cement plant has its raw material quarry adjacent to the plant. The limestone is blasted about every two weeks at the rate of 50,000 tons/shot. The rock is crushed from a diameter $1 \mathrm{~m}$ or less down to $2 \mathrm{~cm}$. The crushed rock is sent to the storage building at the plant at 550 tons per hour (TPH) using conveyor belts totaling about one mile in length. The storage building holds about 40,000 tons of crushed stone. Other raw materials like shale (alumina), sand (silica), and pyrite (iron) are purchased and are delivered to the plant. All four raw materials are ground by two dry ball mills at a rate of 
about 90 TPH each. The raw feed is pumped to blending silos (which hold about 750 tons each). This feed is drawn from the bottom of the blending silos and pumped to reblending silos which also hold 750 tons each. The feed is then pumped to kiln feed bins in the kiln department. Figure 4-1 shows the layout of the complete cement manufacturing process in Mitchell-plant.

There are three kilns operating in the plant. Two of them are $122 \mathrm{~m}$ long and 3.5 $\mathrm{m}$ diameter having capacities of 750 tons per day (TPD) and the third kiln is $35.5 \mathrm{~m}$ long and $3.5 \times 4 \mathrm{~m}$ (single stage preheater). The raw mix is burnt at a temperature of $2750^{\circ} \mathrm{F}$. At this stage, carbon dioxide is burned off in an endothermic reaction, feed is melted, and the four major components of portland cement are formed. Kilns burn about 5TPH each of pulverized coal for fuel (3 to 5 million BTU/ton clinker). Clinker is formed at this stage and is cooled with air. The hot air is recaptured and is used to sustain the burning process. The clinker is sent to the finishing department and is either sent to storage, to the roll process, or directly to the mills. Finish mills grind between 16 and $30 \mathrm{TPH}$, depending on fineness. Gypsum (calcium sulfate) is added at this stage to retard setting time. The Blaine fineness of cement generated ranges from $3500 \mathrm{~cm}^{2} / \mathrm{g}$ to $7000 \mathrm{~cm}^{2} / \mathrm{g}$. Finished cement is then sent to one of 30 silos with capacities of 2500 tons each. The collection of $\mathrm{CKD}$ occurs through electrostatic precipitators. 


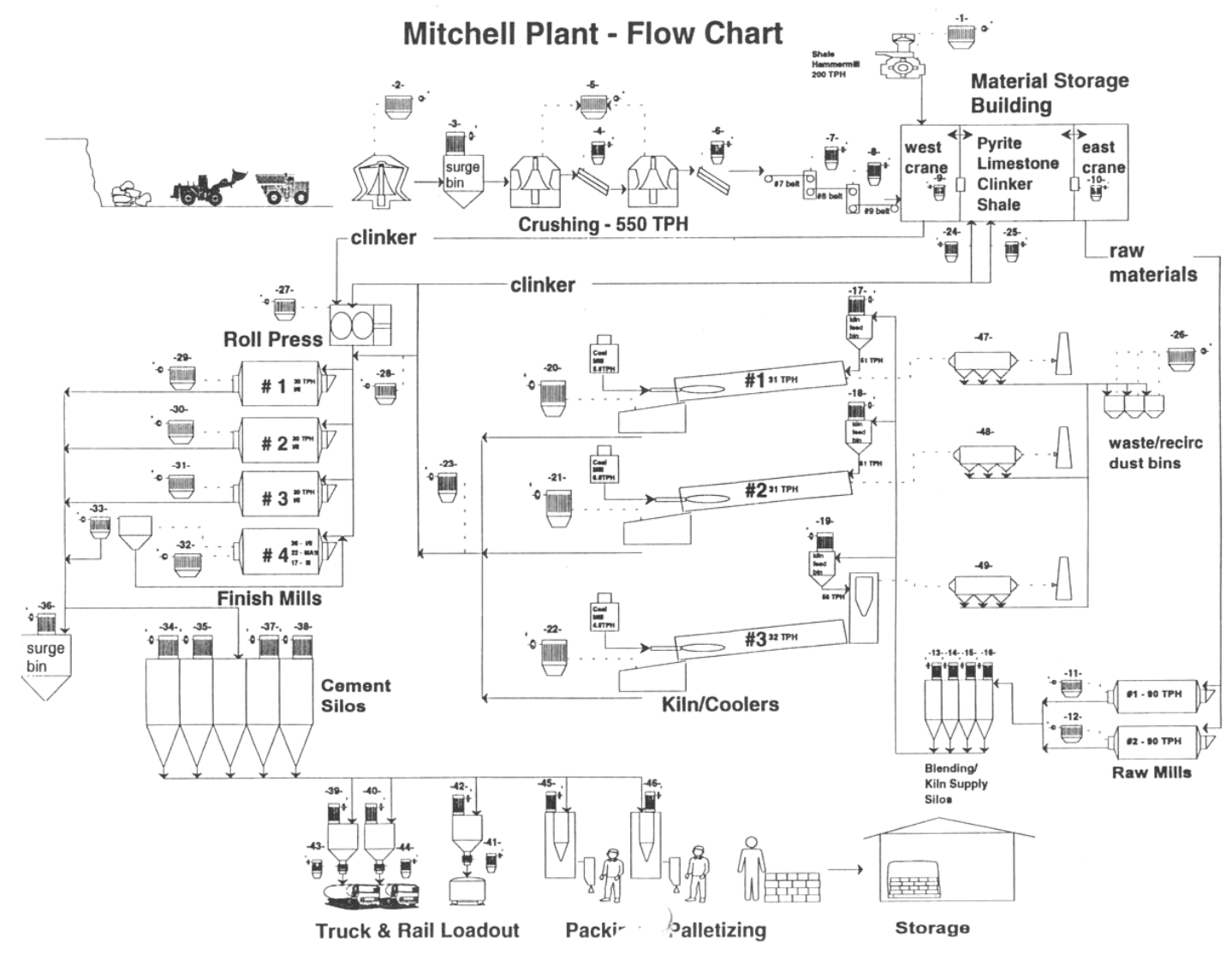

Figure 4-1 Layout of the cement manufacturing process in the Lehigh plant in Mitchell, IN (Tolliver, 2002)

\subsection{Labels for Testing Materials}

For the present investigation two types of CKDs were used. The first CKD, hereafter referred to as "fresh CKD" was obtained directly from the manufacturer's outlet at three separate instances. These different samples are referred to in the following as fresh I (November 2000), fresh II (March 2003) and fresh III CKD (July 2003). Note that changes in the processing technology were implemented in the period between the first and the other two sampling operations. Initially, it was believed that these changes had only impacted the quantity of CKD produced but had not significantly affected the "quality" of the CKD. As documented in Chapter 6 (characterization of fresh CKDs), it is 
established that the implementation of process technology considerably impacts the quality of CKD produced.

The second CKD, termed "landfilled CKD", was obtained in March 2003 from the landfill in proximity to the plant, which had been used for a duration of about 12 years (from 1987 to 1999) for the disposal of all CKD produced. As discussed in detail in the following section, from the year 2000 the CKD produced is being disposed into a new landfill facility adjacent to the plant. Hence fresh I CKD (CKD produced before the implementation of the change in process technology) in general represents the parent material for the landfilled CKD. Sampling of the landfilled CKD was conducted out at three locations in the landfill to provide an insight into the spatial variability of the landfilled CKD. Details of the sampling operations carried out to collect these tube samples of CKD are provided in the following sections. Larger quantities of CKD than those that could be obtained from the tubes samples were necessary for the engineering tests. As a result, bulk samples were collected in large bins from the face of the landfill where "mining" operations were underway. This material, also sampled in March 2003, is referred to as "landfilled" CKD.

\subsection{Landfill in Mitchell}

The disposal facility used by the Lehigh Portland Cement Company for over twelve years (from 1987 to the end of 1999) to dispose of cement kiln dust is located in Mitchell, Indiana. The Mitchell landfill extends over a surface of twelve acres, and currently contains approximately 450,000 tons of cement kiln dust available for mining. Figure 4-2 shows a plan of this disposal facility. Mining of the CKD (primarily for use as agricultural lime) has been ongoing at the landfill for several years. These operations have been conducted in proximity to the access road of the landfill (see Figure 4-2) where the material is excavated with a backhoe and then fed into a screener. A significant amount of material has been removed through this process from the front of the landfill, creating a vertical cut 5-6.5 m high, and a two-level terrain (See Figure 4-3).

The landfill is a monofill with only dry CKD deposited there. It was filled in 3 to $4.5 \mathrm{~m}$ layers, which were compacted and covered with coarse aggregate to improve the 
stability of the fill and allow transit of vehicles and equipment necessary to place subsequent layers of the material. In contrast with other sites (e.g. Lehigh's new disposal facility opened in 2000), no moisture conditioning of the CKD was performed during placement of the CKD. However, exposure to the environment (drying, wetting, freeze/thaw cycles etc.) has created non uniform conditions in the waste "deposit", as highlighted in Figure 4-3.

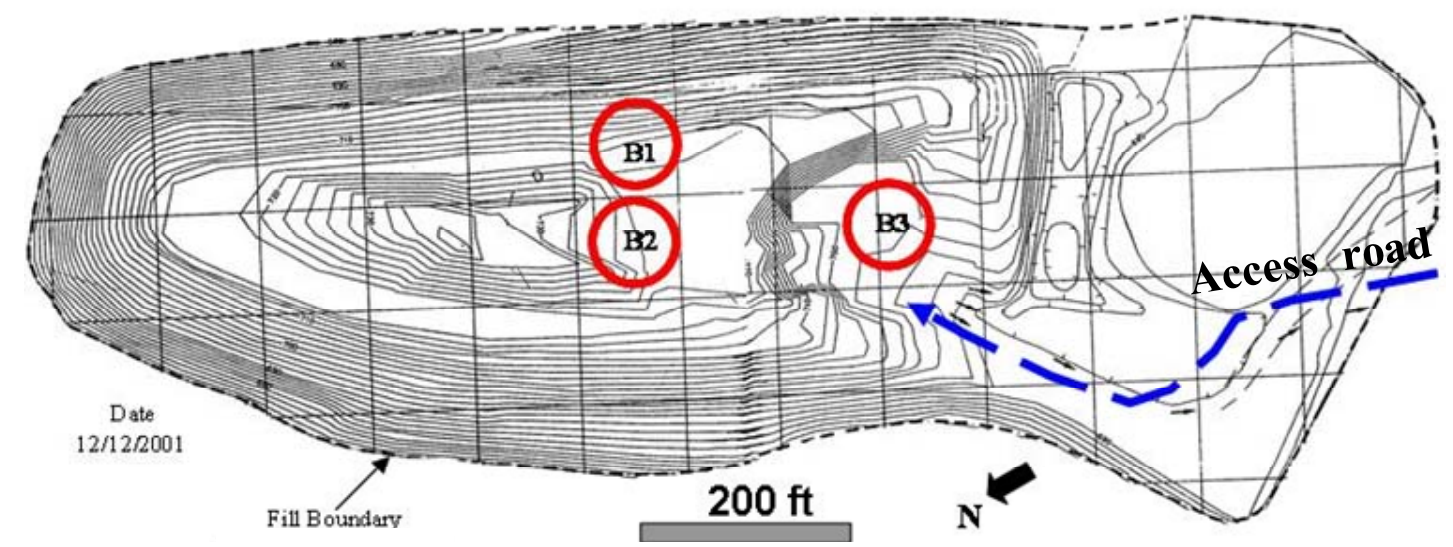

Note: The contour interval is $2 \mathrm{ft}$

Figure 4-2 Layout of CKD landfill and locations of borings
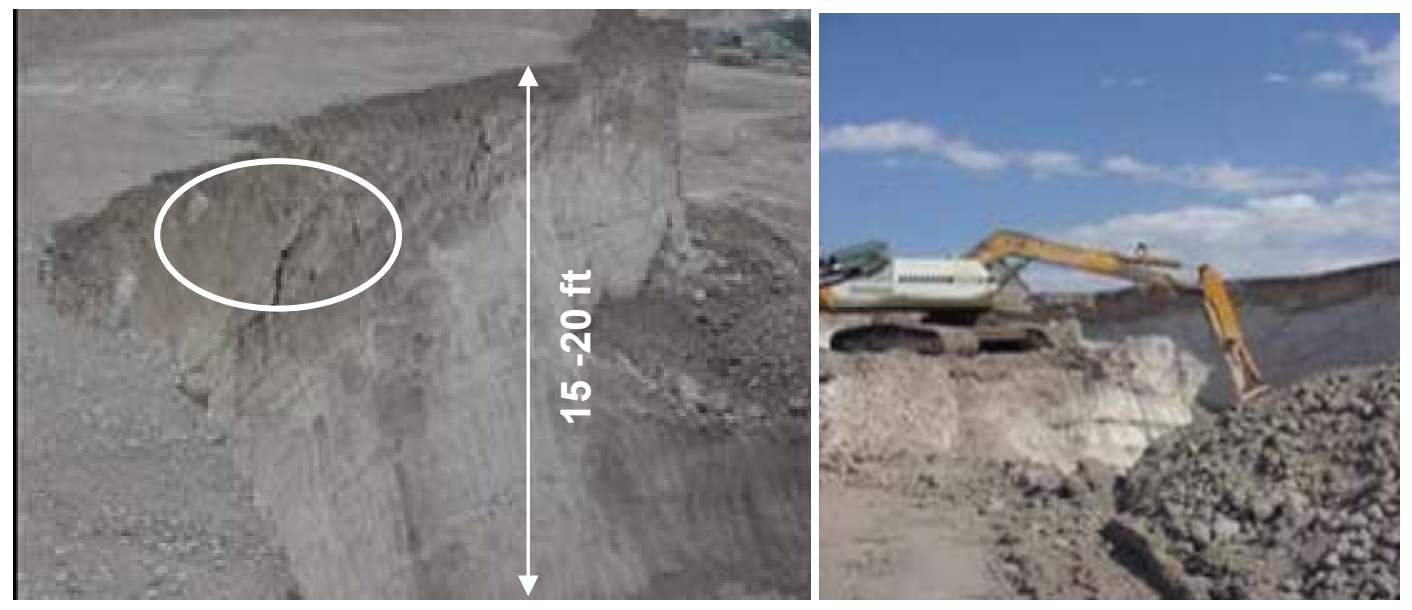

Figure 4-3 Views of the CKD landfill in Mitchell, IN 
The Mitchell landfill was selected to conduct the present study for the following reasons:

1. It is a monofill facility, i.e. it contains exclusively CKD. This not only facilitates interpretation of the results, but also does not require prescreening of the waste.

2. The material "stored" there is significant in age and the data gathered are expected to highlight the effects of aging on the characteristics of cement kiln dust

3. A permit has already been obtained for marketing and distribution of this material under Land Application Regulations, and thus implementation of the findings could occur after a short delay.

4. Preliminary characterization tests conducted on fresh CKD obtained from the Mitchell plant indicated that its physical and chemical properties fall within ranges typically reported for most CKD's. As a result, the conclusions drawn from the proposed work have the potential of being extended to CKDs manufactured by other plants.

Unfortunately, the Lehigh Cement Company has no record of the properties of the fresh cement dust prior to disposal in the landfill. Also, there is no documentation of the disposal operations that would allow identification of the best locations for sampling and possibly "dating" of the various layers.

\section{5 Site Visits and Observations}

The research group from Purdue University performed a first visit to the Lehigh plant and the CKD landfill in Mitchell, Indiana on November 8, 2002 to obtain information necessary to plan the sampling program and to collect some samples for a preliminary study. The visit started with a tour of the entire cement plant. During that time all operations involved in cement manufacturing, starting from crushing of the raw material to shipping of the final product were observed and explained by the Lehigh personnel. More importantly, this visit represented the first opportunity to view the CKD landfill facility containing the material to be evaluated in the research project, obtain 
direct information on disposal practices at the site and collect limited samples for preliminary testing. Some key observations made at this time included the following:

- The extent of the landfill appeared significantly greater than what had previously been thought. In particular, it appeared that the "deposit" could be as thick as $15 \mathrm{~m}$.

- It was noted that direct access to various points of the landfill was possible, and hence it was anticipated that sampling at different locations could be easily performed.

- An open vertical cut approximately 4.5-6 m high, created by mining operations, and extending over a front of $60 \mathrm{~m}$ or more was observed. This suggested that the material present might have some "cohesive" characteristics.

- Some variability in the coloration of the CKD (ranging from white to dark gray and brown) along the open faces, which was attributed to "weathering" effects was observed. However, it was also noted that once the superficial material was removed the CKD appeared uniform, at least to the naked eye.

- Most importantly it was noted that the deposit exhibited "soil like" characteristics and hence it was concluded that sampling at depth could be best conducted using a push in tube technique, rather than rock coring methods, as was previously anticipated.

Small samples for preliminary testing were also gathered at the vertical front of the mined area. Based on these samples, the water content of the CKD was estimated at approximately $25 \%$.

Based on the above observations it was decided that sampling would include:

- Tube samples to $12-15 \mathrm{~m}$ obtained at 2-3 locations to establish the variability in the chemical and physical properties of the waste throughout the deposit.

- Bin samples obtained at the mining front that would be used for the engineering tests.

The second visit to the landfill was on March 20, 2003. At that time extensive sampling of the landfill was performed, as described in the following section. 


\subsection{Landfill Investigation and CKD Sampling}

Given that one of the main objectives of this research work was to evaluate the spatial variability in the characteristics of the landfilled CKD, it was decided to obtain samples that would reflect different ages as well as different "storage" conditions of the material. As a result, a crucial phase of the CKD sampling work was to identify sampling locations within the landfill that reflected the different ages and different conditions under which the CKD has been "stored". Before designing a sampling layout or location of boreholes, the information recorded during the first site visit, and the site lay-out of the landfill area were carefully examined to reconstruct as closely as possible the age and the storage conditions for the landfilled CKD. Ultimately, sampling locations and the number of samples were limited by the accessibility of the boring equipment to the landfill, the maximum boring depth available with the equipment and the cost of the operation.

As shown Figure 4-2 and Figure 4-3, the landfill area is accessible because of the ongoing mining operations and the main entrance to the landfill is from the eastern side. Three borings were conducted. Two boreholes (B1 \& B2) were located on the upper level of the landfill and the third borehole (B3) was located in the lower level in proximity to the bottom of the vertical cut described earlier (Figure 4-3). Unfortunately given that no precise records of the disposal had been kept, the CKD at any given location could not be in any way "dated". On the higher level, sampling was conducted as close to the middle of the landfill as possible. Access of the boring equipment ultimately limited the selection of the borehole locations. For example, no samples could be obtained on the west side of the landfill.

Sampling/boring was carried out on March 20, 2003, by M/S.Alt \& Witzig Engineering from Indianapolis, and was supervised by the research team from Purdue University and Mr. Toby Knott of Lehigh Cement Company. Sampling operations began early in the morning and ended at around five o'clock in the evening. The borings were performed using a simple hollow stem auger (Figure 4-4). The samples were obtained by using a split-barrel sampler equipped with a plastic sleeve $(\sim 0.6 \mathrm{~m}$ long and $\sim 5 \mathrm{~cm}$ diameter), which was advanced inside a hollow auger (Figure 4-5). Samples were collected every $1.5 \mathrm{~m}$ up to a depth of approximately $15 \mathrm{~m}$. After the tubes were 
recovered the plastic sleeves were recovered, sealed at both ends and labeled (Figure 47). The standard penetration test (SPT) was carried out at regular intervals to gain additional insight into the uniformity of the deposit. Figure 4-4 to Figure 4-7 illustrate some of the operations associated with boring and sampling.

The tube samples were transported to the Geotechnical Testing laboratory at Purdue University immediately following sampling. Testing to establish the spatial variability in the properties of landfilled CKD was conducted thereafter.

Figure 4-8 summarizes the location of the "tube samples" (dark gray boxes indicated by a capital letter) collected and includes the sample recovery $(\mathrm{R})$ as well as the blow count $(\mathrm{N})$. Nine to ten samples were obtained at each borehole. While all the sleeves were of the same length, the recovery varied from $25-100 \%$. Overall, throughout most of the deposit the CKD was powdery in nature, making the recovery quite poor. This was particularly the case close to the surface where the material was very dry, uniform in color and "powdery", and in some case more than $2 / 3$ of the sample was lost. At greater depths it was possible to collect a "full" sample and thus obtain more material for testing. At greater depths the recovery was almost hundred percent and the CKD appeared darker and more moist. The variation of field SPT- N value with borehole depth is shown in Figure 4-9 The $\mathrm{N}$ value from the SPT measured about 5 to 7 at shallow depths and increased 25 to 50 at greater depths. The higher SPT value at greater depths may be a result of the effect of the greater overburden pressure (the values plotted in Figure 4-8 and Figure 4-9 are the original field values) and/or of cementitious reactions occurring in the CKD over the years. 


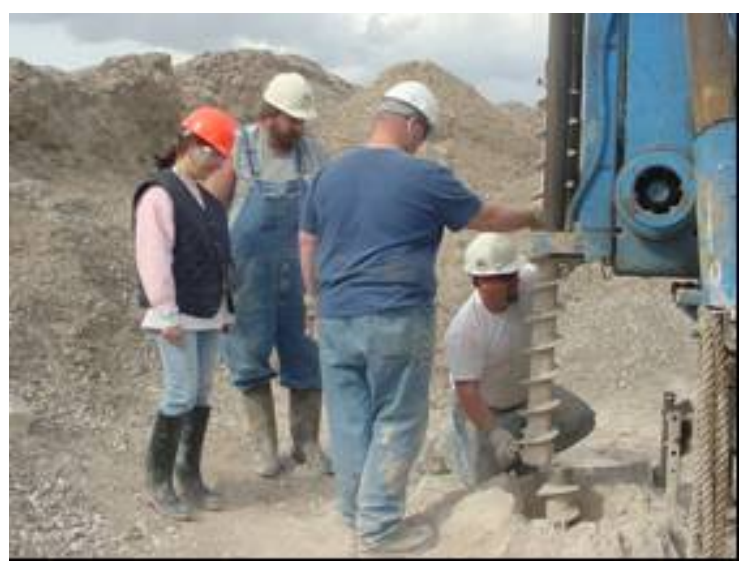

Figure 4-4 Borings in landfill are being performed using a simple auger boring-spiral type auger

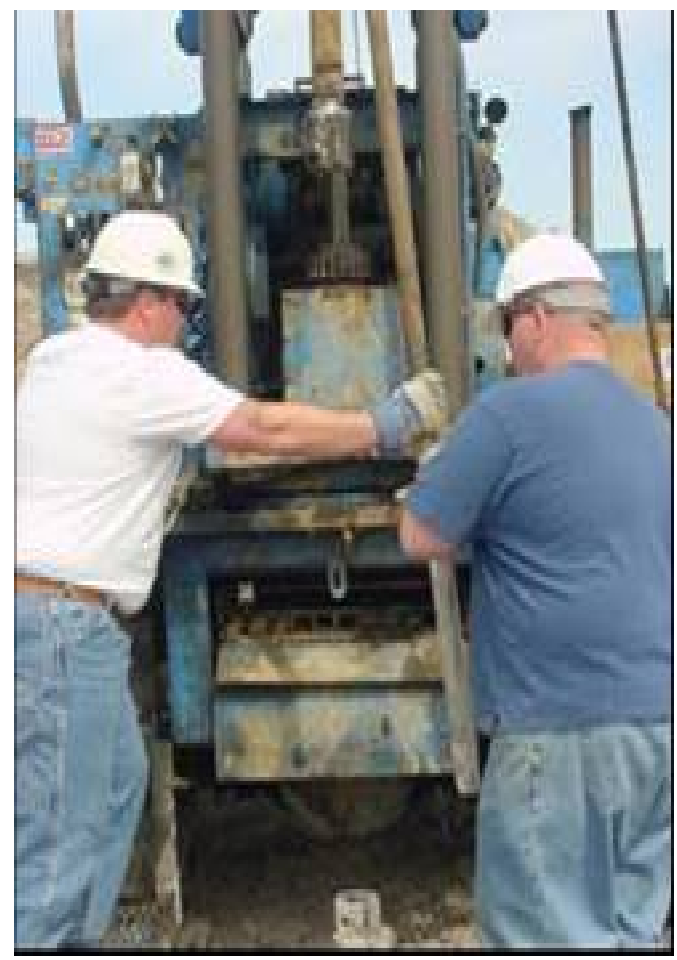

Figure 4-5 Preparation for standard penetration test 


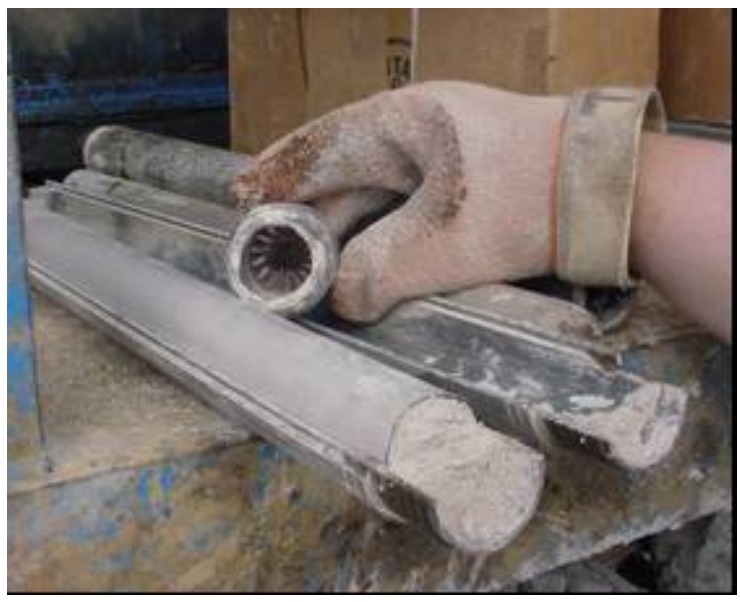

Figure 4-6 Plastic sleeves with CKDs sample inside the split barrel sampler

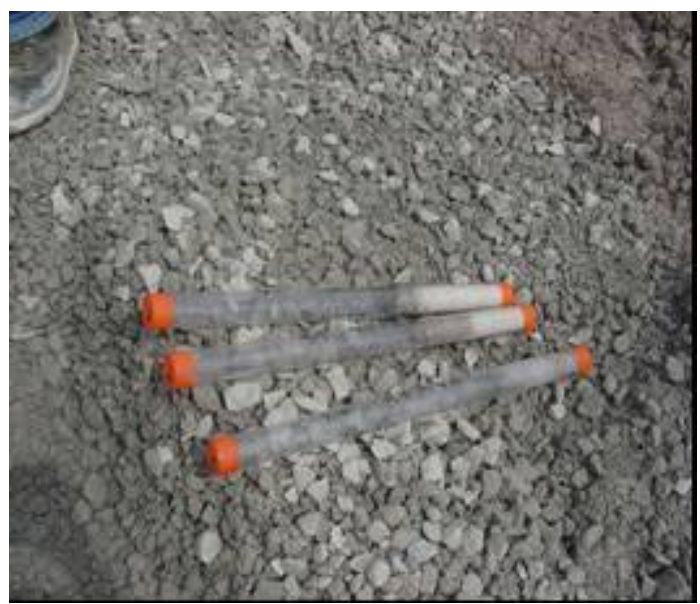

Figure 4-7 Final marked tube samples sealed at both ends and ready for shipping 


\begin{tabular}{|c|c|c|c|c|c|c|c|c|}
\hline B B1 & & & 口E & & & & & \\
\hline & $N$ & & & $N$ & & & & $\Gamma^{0}$ \\
\hline$A E$ & 5 & 20 & AF & 4 & 20 & & & \\
\hline$B=$ & 5 & 20 & B & 3 & 20 & & & \\
\hline$c=$ & 6 & 40 & $c$ & 7 & 65 & & & -5 \\
\hline $\mathrm{DE}$ & 7 & 70 & $D$ & 6 & 80 & $\Delta B^{\prime}$ & & \\
\hline $\mathrm{E}=$ & & 70 & $E$ & 11 & 50 & & $\neg \underline{N R}$ & \\
\hline $\mathrm{F}$ & 15 & 100 & $\mathrm{~F}$ & 14 & 100 & & 8 & \\
\hline $\mathrm{G}$ & & 75 & $\mathrm{G}$ & 22 & 100 & A & 1120 & \\
\hline $\mathrm{H}$ & 35 & 50 & $\mathrm{H}$ & 31 & 85 & $B E$ & 1235 & \\
\hline 1 & & 65 & & & & $c E$ & - 950 & \\
\hline $\mathrm{J} \square$ & 501 & 100 & I & 50 & 20 & $D E$ & 1580 & \\
\hline & & & & & & $E$ & 1820 & \\
\hline & & & & & & $F=$ & $\begin{array}{ll}26 & 20\end{array}$ & \\
\hline$=\mathrm{S}$ & PT b & low & coun & & & $G F$ & 34100 & \\
\hline & ampl & & & & & $\mathrm{H} E$ & 38100 & \\
\hline & & & & & & $1 \sqsubset$ & $\exists 50100$ & \\
\hline
\end{tabular}

Figure 4-8 SPT - N values and sample recovery as a function of depth for the three boreholes

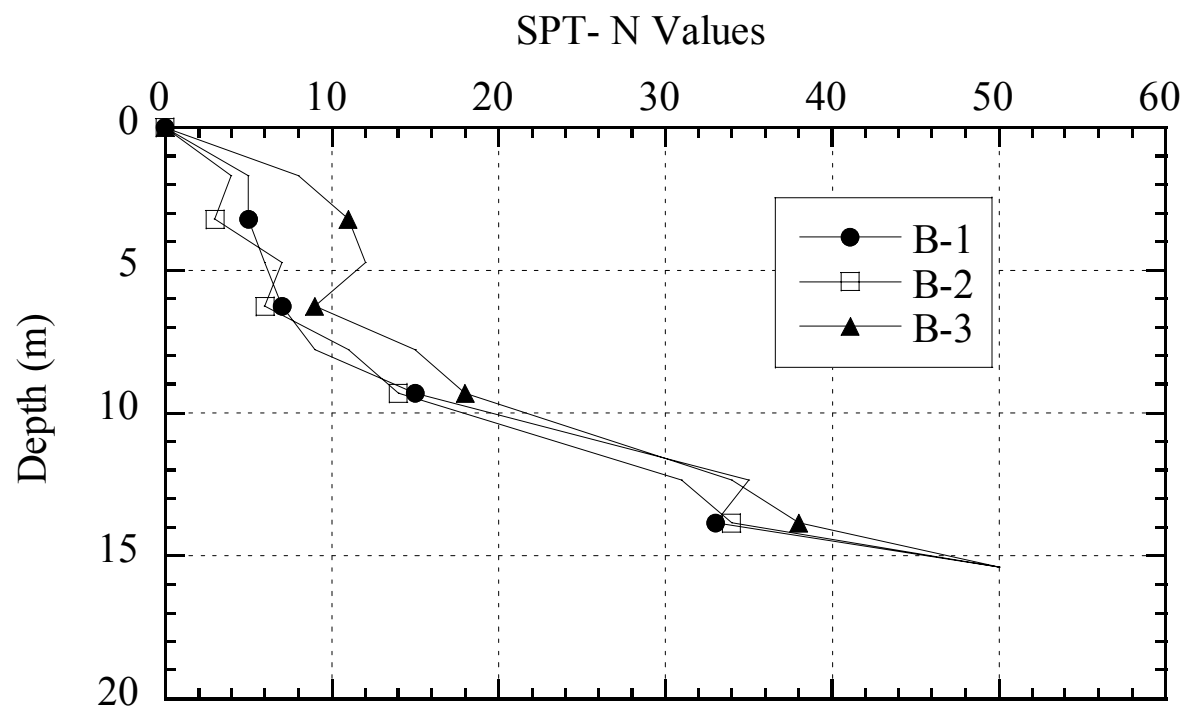

Figure 4-9 Variation of SPT - N values with depth for the three boreholes 
With the equipment available at the time of sampling, the boreholes could advance only up to a depth of $15 \mathrm{~m}$. In both boreholes B1 and B2 this prevented samples to reach the natural soil underlying the CKD. In contrast, in the case of borehole B-3 the underlying natural soil could be reached at this depth. Note that the "surface" elevation of this borehole is approximately $4.5-6.0 \mathrm{~m}$ lower than that of the other two. Overall this suggests that the depth of the CKD fill may be greater than $21 \mathrm{~m}$ throughout the majority of the facility.

In addition to the tube samples, auger cuttings were also collected at regular intervals. Samples of CKD were also collected from the landfill near the vertical cut where mining operations were in progress. Two bins of screened CKD and two containers of unscreened CKD were collected from the mining area. Only the screened CKD was used in this research work. The figures (Figure 4-10 to Figure 4-12) that follow, illustrate the steps associated with the collection of screened CKD. The CKD from the landfill was conveyed onto the screener using a backhoe as shown in Figure 410. During screening any large pieces of CKD or any external materials present were removed (Figure 4-11). After the screening, the CKD was collected in large plastic containers as shown in Figure 4-12.

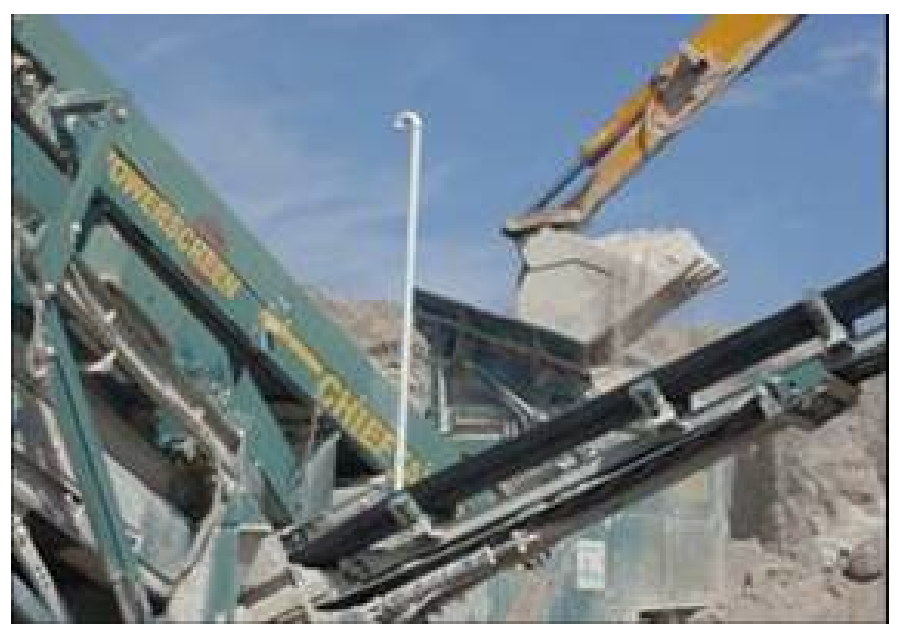

Figure 4-10 Conveying CKD from the landfill to the screener using a backhoe 


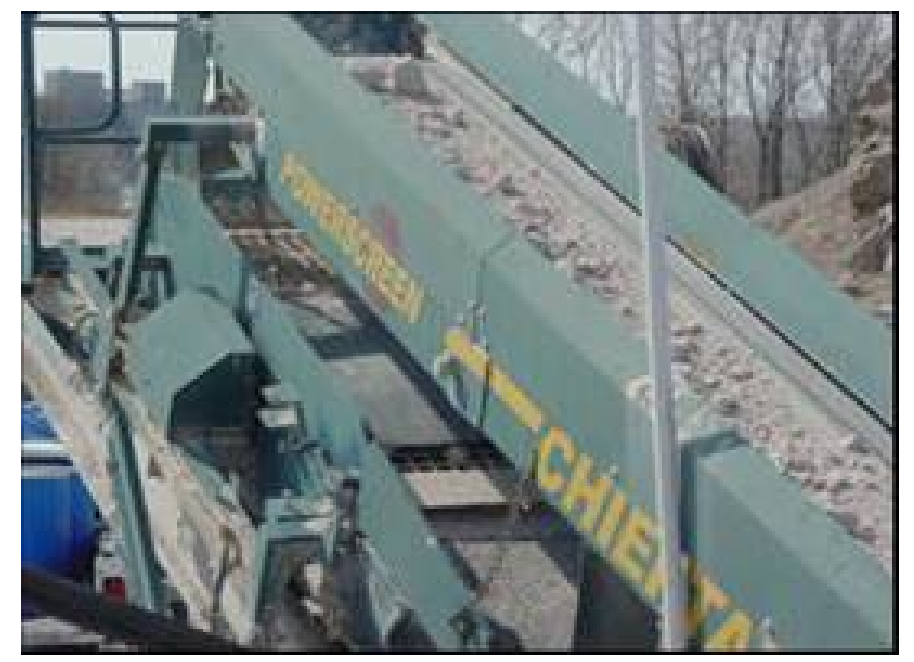

Figure 4-11 Separation of lumps present in landfilled CKD during screening operation

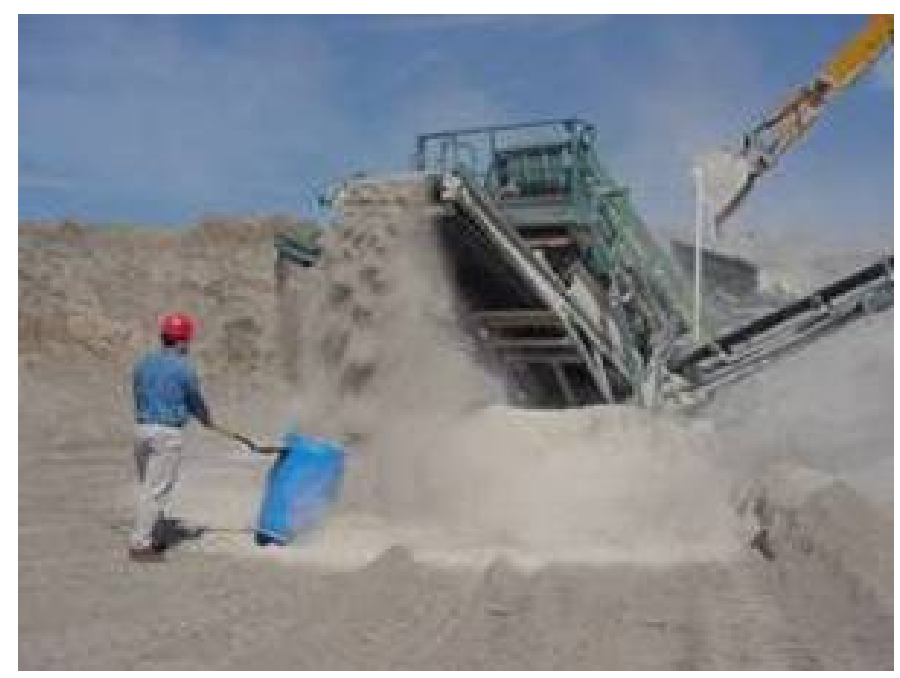

Figure 4-12 Collection of screened CKD in the plastic bins 


\section{CHAPTER 5 -- TEST METHODS}

\subsection{Introduction}

This chapter summarizes the laboratory testing procedures followed in the research work. The laboratory experimental program was divided in two main phases. In the first phase, experiments were primarily targeted at characterizing the fresh and landfilled CKD to identify their key properties. This work involved the application of experimental methods typically involved in characterizing soils, as well as others "borrowed" and, when necessary, adapted from those used for cement and fly ash. As the primary focus in this stage was on the identification of the key physio-chemical and engineering properties of the CKDs under investigation, tests were also conducted to establish the environmental impact of using CKD by identifying and quantifying the heavy metals present in the CKD leachate and the corrosiveness of CKD.

The second phase of experimental work was aimed at evaluating the CKD for use in two applications: soil stabilization/modification and flowable fills (i.e., controlled low strength materials).

Reflecting the above described organization of the experimental work, the present chapter is structured into three main sections aimed at illustrating: a) the characterization tests b) the test methods employed for evaluating the suitability of the CKDs for soil improvement/modification, and c) the test methods used for assessing the CKDs to manufacture flowable fills. 


\subsection{CKD Characterization Tests}

\subsubsection{Physio-chemical Characterization tests}

\subsubsection{Chemical and Mineralogical Composition}

The oxide composition of all CKDs was determined at the Heidelberg Technology Center in Doraville, GA using the following procedure: 1.5 grams of ignited sample were fused each at $1100^{\circ} \mathrm{C}$ with 7.5 grams of a lithium flux made up of $67 \%$ lithium tetraborate $\left(\mathrm{Li}_{2} \mathrm{~B}_{4} \mathrm{O}_{7}\right)$ and $33 \%$ lithium metaborate $\left(\mathrm{LiBO}_{2}\right)$. These fused beads were analyzed with a sequential wavelength-dispersive X-Ray Spectrophotometer manufactured by Philips (model \# PW-2400), using a calibration curve prepared with similar (matrix-matching) materials.

X-Ray diffraction analyses were carried out using a Siemens D-500 diffractometer using copper radiation in the Materials laboratory of the School of Civil Engineering at Purdue University. Prior to preparation of the XRD powder sample, the CKD was sieved through a No. 200 sieve. The landfilled CKD was oven dried before testing. Interpretation of the X-Ray patterns for the presence of crystalline components was carried out by the usual methods, involving assignment of each of the peaks present to one (or sometime more than one) of the crystalline phases which may be present. The samples were step-scanned from 2 to $60^{\circ}$ " $2 \theta^{\prime}$ " using a $0.5^{\circ} 2 \theta$ increment and 2 -s count time.

\subsubsection{Particle Size Distribution}

The gradation of CKD was determined following ASTM D 422-02 (Standard Test Method for Particle-Size Analysis of Soils), which is designed for soils. Particle size distribution of select samples of the fresh and landfilled CKD were obtained employing the hydrometer test in water with sodium hexametaphosphate as a dispersing agent. Grindrod (1968) performed an extensive study on the methods for determining the particle size of portland cement and cement-related materials (including CKD) and reported that the particle size of CKD can be analyzed in an aqueous medium. 


\subsubsection{Microscopic Examination}

CKD samples were subjected to microscopic examination in order to characterize their particle shape, angularity, surface texture etc. The preliminary examination was performed with the use of a scanning electron microscope (Model No. ASPEX LLC, Personal SEM) in the Materials Laboratory of the School of Civil Engineering at Purdue University. The CKD powder was mounted on the sample holder using double faced copper tape. The specimens were coated using an approximately $6 \mathrm{~nm}$-thick coating of gold-palladium alloy, deposited in a sputter coater. The images were captured on photomicrographs in addition to digitized files. The micrographs were made at magnifications permitting observation of features of a number of particles at one time, typically approximately $1500 \mathrm{X}$ to $3000 \mathrm{X}$.

Additional images were obtained using a 'FEI Nova-Nano SEM' field emission scanning electron microscope (available in Purdue's Life Science microscopy facility) using the Helix detector in low vacuum mode and immersion. CKD samples were mounted with double stick tape and sputter-coated with AuPd prior to imaging. The micrographs were made at magnifications permitting observation of features of a number of particles at one time, from 5000X to $15000 \mathrm{X}$.

\subsubsection{Specific Gravity}

The specific gravity of CKD was determined by means of a Le Chatelier flask as described by ASTM C 188-95 (Standard Test Method for Density of Hydraulic Cement). This is a standard test method that is specified for fly ash as well as cement. The method involves determining the weight of the sample using an analytical balance. The sample is then introduced in the flask and the apparent solid volume of particles in the sample determined by measuring the amount of fluid (kerosene) that is displaced by the particles. Some difficulties are encountered in using this method for CKD, as, given its high fineness; CKD tends to stick to the sides of the long neck of the flask when it is being transferred. Hence, a plastic funnel with a long stem was used to introduce the CKD into the flask and the flask was placed on a vibrating table. The funnel was weighed before and after the experiment to account for any CKD sticking to the side of the funnel and the 
difference in mass was subtracted from the initial mass of CKD used for calculating the specific gravity. The landfilled CKD was oven dried before conducting the test.

\subsubsection{Loss on Ignition}

Measurement of the loss on ignition of all the samples of fresh and landfilled CKD was carried out at Purdue University according to ASTM C 114-03 (Standard Test Method for Chemical Analysis of Hydraulic Cement). In this test a sample of about $2 \mathrm{~g}$ is allowed to dry in an oven at $105-110^{\circ} \mathrm{C}$ until a constant mass is obtained, and then ignited in a muffle furnace at a temperature of $900 \pm 50^{\circ} \mathrm{C}$ for about $2 \mathrm{hrs}$ to remove all residual carbon and/or organic materials present. The ignited sample is then cooled to room temperature and weighed. The loss on ignition (LOI) is given by the loss in mass with respect to the oven-dry mass, and typically expressed as a percentage. In the case of CKD the LOI serves as an approximate indication of the carbon content.

Independent measurements of the LOI were conducted at the Heidelberg technology Center in Doraville, GA on the samples used for the chemical analyses. These measurements made use of a thermogravimetric analyzer (Leco(r) TGA-601) in which up to 19 different samples (maximum sample size $=5$ grams) can be loaded in ceramic crucibles placed in a carrousel. The samples are slowly ramped up to $107{ }^{\circ} \mathrm{C}$ under a nitrogen atmosphere. All crucibles rotated and re-weighed (automatically) after each revolution. The process is continued until all samples achieve constant weight. Thereafter, the TGA-601 ramps up to $950{ }^{\circ} \mathrm{C}$ under an oxygen atmosphere while all crucibles rotate and get re-weighed after each revolution. Again, the process continues until all samples achieve a constant weight. The instrument monitor displays both the moisture content and the value of the ignited residue (i.e., the ash) from which the LOI can be calculated.

\section{$\underline{5.2 .1 .6 \mathrm{pH}}$}

$\mathrm{pH}$ is a useful parameter in determining the solubility of compounds and the mobility of ions. $\mathrm{pH}$ of the CKDs investigated was determined using a Corning $44 \mathrm{pH}$ 
meter (Figure 5-1), a pH glass electrode and a calomel (reference) electrode as per ASTM D 4792-01 (Standard Test Method for pH of Soils).

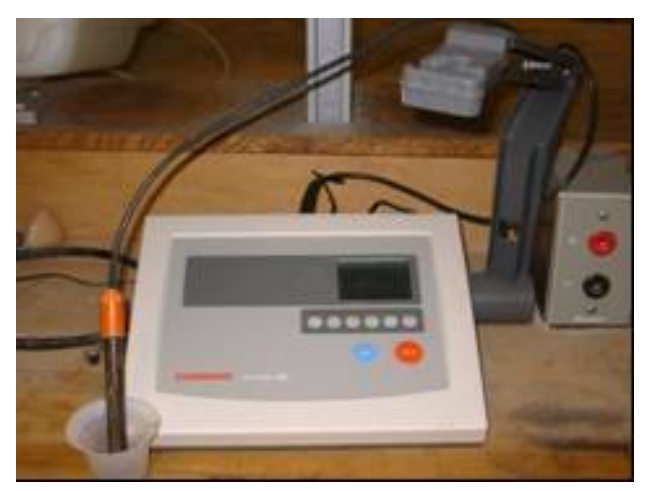

Figure 5-1 The Corning $44 \mathrm{pH}$ Meter

The $\mathrm{pH}$ of CKD is generally around 12 . As per the standard, at least two standard buffer solutions spanning the soil $\mathrm{pH}$ to be measured are required. In this research three standard buffer solutions with $\mathrm{pHs}$ of $7,10,12.5$ were used to calibrate the $\mathrm{pH}$ meter. For pH 7 and 10, commercially available standard buffer solutions were employed. The buffer calcium hydroxide solution of $\mathrm{pH} 12.5$ was prepared in the laboratory following the procedure described in Bates et al. (1956).

For measurement of the $\mathrm{pH}$, about $10 \mathrm{~g}$ of the CKD were mixed with $10 \mathrm{ml}$ of deionized water. This slurry was stirred with a glass rod until a uniform consistency was achieved. The $\mathrm{pH}$ was measured immediately after mixing, as well as after a one hour delay. After each measurement, to minimize errors in the subsequent measurements, the $\mathrm{pH}$ electrodes were retracted from the CKD slurry and their surface carefully cleaned using deionized water.

\subsubsection{Specific Surface Area}

The specific surface area of fine powder materials like, fly ash and cement kiln dust are typically measured by the Blaine air-permeability method or by the BET 
(Brunauer, Emmett and Teller) nitrogen adsorption method. These two methods can yield different values for surface area for the same material tested under the same conditions, as the underlying fundamental principles are different. The specific surface area is usually expressed as total surface area in square centimeter per gram of the powder. Along with the testing procedures, a brief description of the working principles of these two methods are summarized in this section.

\subsection{Blaine Air-Permeability Method}

The air permeability method is based on the principle that the resistance to the flow of a fluid, such as air, through a bed of compacted powder is proportional to the surface area of the powder. Thus, measurement of the resistance to flow provides a means of estimating specific surface area.

The fineness of fresh and landfilled CKD was measured following ASTM C 20400 (Standard Test Method for Fineness of Hydraulic Cement by Air-Permeability Apparatus) using the Blaine-air permeability apparatus available in the Materials Laboratory of the School of Civil Engineering, at Purdue University. The Blaine airpermeability method was originally developed for determining the surface area of portland cement. However, the standard suggests that the test method can be also used for determining the fineness of materials other than portland cement. The mass of CKD required to make the test bed in the permeability cell was decided based on the thumb pressure as specified in the standard. The landfilled CKD was oven dried at $110^{\circ} \mathrm{C}$ before conducting the test.

\subsubsection{2 $\mathrm{N}_{2}$ Adsorption}

The BET $\mathrm{N}_{2}$ adsorption method for the determination of specific surface area of powder is based an extension of the theory developed by Langmuir for type I chemical adsorption. BET makes use of an experimental determination of the number of molecules of the adsorbing gas (adsorbate, e.g. $\mathrm{N}_{2}$ gas) required to form a monomolecular layer on the surface of the solid substrate (the adsorbent, e.g. CKD powder) despite the fact that 
exactly one monolayer is never formed. The surface area is the product of the number of molecules in a completed monolayer and the effective cross sectional area of an adsorbate molecule.

In this method the amount of adsorbed nitrogen (adsorbate) is measured as a function of the applied vapor pressure. This provides the adsorption isotherm (a plot of pressure versus weight of gas adsorbed at constant temperature). The total surface area $\left(\mathrm{S}_{\mathrm{t}}\right)$ is calculated by using the equation developed by Langmuir.

$$
S_{t}=\frac{W_{m} \times \bar{N} \times A}{\bar{M}}
$$

where

$\mathrm{W}_{\mathrm{m}}$ is the weight of adsorbate required to make a perfect mono layer (see below),

$$
\bar{N} \text { is Avogadro's number, }
$$

$A$ is the area of one molecule the adsorbate (16.2 square Angstroms for $\mathrm{N}_{2}$

gas),

$\bar{M}$ is the molecular weight of the adsorbate.

$\mathrm{W}_{\mathrm{m}}$, the weight of nitrogen gas required to form the monolayer is determined from the slope and intercept of the BET plot. The BET plot (a plot of $1 /\left(\mathrm{W}\left(\mathrm{P}_{0}-\mathrm{P}\right)-1\right)$ versus $\mathrm{P} / \mathrm{P}_{0}$ where $\mathrm{W}$ is the weight of adsorbate, $\mathrm{P}$ is the equilibrium pressure and $\mathrm{P}_{0}$ is adsorbate saturated equilibrium vapor pressure) yields a straight line typically in the range of $0.05 \leq \mathrm{P} / \mathrm{P}_{0} \leq 0.35$. The specific surface area is obtained by dividing the total area by the sample mass. A detailed derivation of the above equation for determination of the specific surface area is provided by Lowell and Shields (1984).

The test was performed in the Materials Laboratory of the School of Civil Engineering, Purdue University, using Quantasorb, manufactured by Quantachrome Corporation employing nitrogen as the adsorbate. 


\subsubsection{Bleeding}

Bleeding tests on fresh and landfilled CKD pastes were conducted at Purdue University as per ASTM C 940-98a (Standard Test Method for Expansion and Bleeding of Freshly Mixed Grouts for Preplaced Aggregate Concrete in the Laboratory). CKD samples were mixed with water as per ASTM C 305-99 (Standard Practice for Mechanical Mixing of Hydraulic Cement Paste and Mortars of Plastic Consistency) in the standard laboratory mixer (Hobart Mixer) at various water CKD ratios. The percentage of bleeding was calculated on a volumetric basis. The tests were conducted on pastes having water-CKD ratio between 0.75 and 1.75 .

\subsubsection{Engineering Tests}

\subsubsection{Compressive Strength Tests on CKD Pastes}

Compression tests on cubes ( 2 in $x$ 2in $x$ 2in) of CKD pastes were performed to quantify the binding properties of the CKD. Specimens were prepared at a water-CKD ratio of 0.5 . For comparison purposes specimens were prepared at the same water-cement ratio (0.5) employing Type 1 portland cement. Three cubic specimens were tested at various curing time ranging from 1 to 56 days. The specimens were cured inside the molds in a humid room for $24 \mathrm{hrs}$, and then stored in the fog room, up to the testing time.

The compression tests were performed employing a 60,000 lb capacity computer controlled Static Universal Testing Machine, employing a constant loading rate of 500 lbs/minutes.

\subsubsection{Compaction Behavior of CKD}

Compaction tests were performed on fresh and landfilled CKD samples following ASTM D-698-00 (Standard Test Method for Laboratory Compaction Characteristics of Soils Using Standard Effort $\left(12,400 \mathrm{ft}-\mathrm{lbf} / \mathrm{ft}^{3}\left[600 \mathrm{kN}-\mathrm{m} / \mathrm{m}^{3}\right]\right)$, using a 4 inch diameter mold. Prior to compaction the CKD was mixed with water to produce the desired water content by hand-mixing. In consideration of the potential reactivity of the fresh $\mathrm{CKD}$, for this material alone compaction tests were carried both immediately after mixing the CKD with water, as well as after allowing the CKD-water mix to temper overnight in the 
humid room at R.H. $>98 \%$ and $\mathrm{T}=20^{\circ} \mathrm{C}$ protected by plastic wrap to avoid evaporation. Specimens for water content measurements were taken immediately after mixing the CKD with water, and after removing the soil from the humid room (in the case of tempering). Additionally, a determination of the water content was performed on the material trimmed off from the compaction mold at the end of compaction.

\subsubsection{Unconfined Confined Compressive Strength of Compacted CKD}

Unconfined compression tests were carried out on compacted fresh and landfilled CKD samples as per ASTM D 2166-00 (Standard Test Method for Unconfined Compressive Strength of Cohesive Soils). The specimens were prepared employing the Harvard Miniature compaction method (ASTM-D 4609-01) to meet the aspect ratio requirement of 2:1. The kneading energy (number of blows) was calibrated to standard proctor compaction energy to prepare samples with Proctor density at any given target water content. Considering the limited reactivity of $\mathrm{CKD}$, the majority of the compression tests were performed immediately after compacting the specimen, i.e., without any curing. Tests were conducted using a strain controlled load frame apparatus, employing a constant strain rate of approximately 80-90\%/hr. Measurements of the axial load and strain were performed employing a $1000 \mathrm{lbs}$ capacity shear beam load cell and a LVDT mounted on the top platen. The axial load and axial displacement were recorded using a computerized data acquisition system.

Tests were also conducted to determine the effect of compaction energy by compacting the samples at different energy levels. A limited number of unconfined compression tests were also conducted on Proctor size specimens. Note that due to the geometry of the Proctor specimens (which does not meet the 2:1 aspect ratio) the values of strength obtained from these specimens should be viewed as strength indexes, rather than as a true measure of the actual compressive strength of the compacted CKD.

Owing to the position of the LVDT, the measured stress strain curves are affected by initial bedding errors. As a result, the stress strain curves typically display an initial concave portion in which the measured axial strain increases with minor increase in the 
stress. Figure 5-2 shows how all the curves included under the test results sections in subsequent chapters, were corrected to remove such bedding errors.
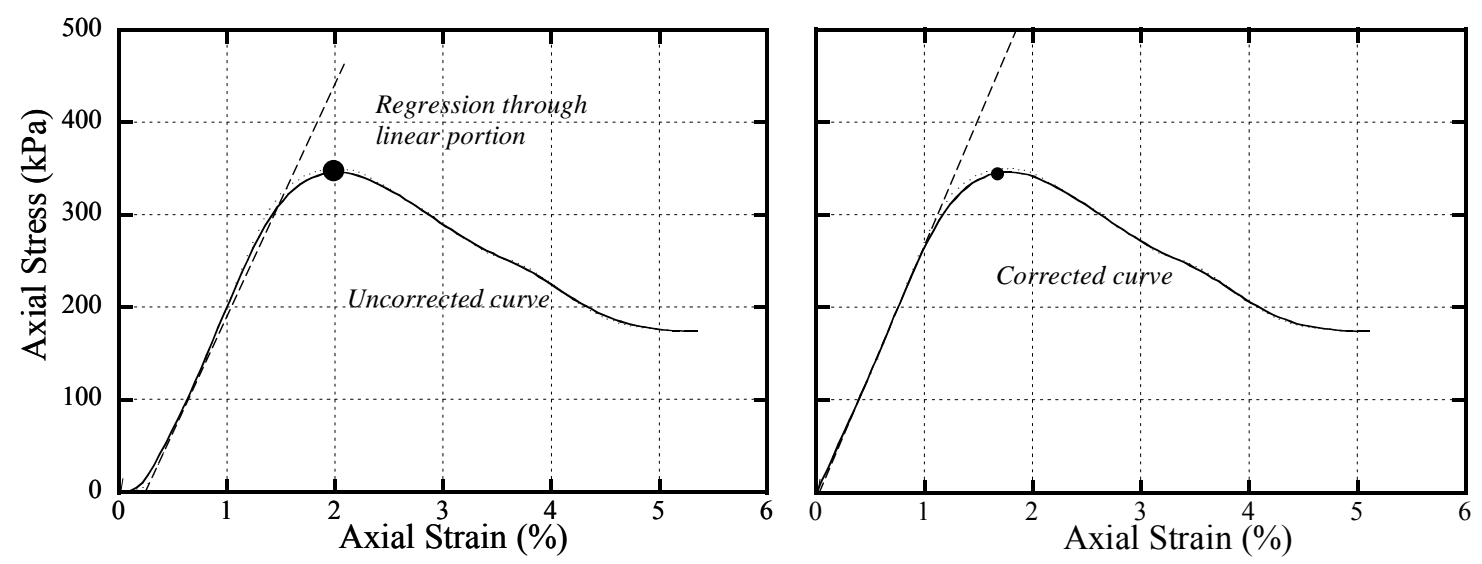

Figure 5-2 Procedure to eliminate bedding errors in unconfined compression tests

\subsubsection{Hydraulic Conductivity of Compacted CKD}

The permeability of both fresh and landfilled CKD samples was measured using a fixed-wall permeameter. The samples were prepared in the standard proctor compaction mold as per ASTM D 698 (Standard Proctor procedure). The side of the mold was greased with a thin layer of vacuum grease to ensure contact between the compacted CKD sample and the mold. The permeability test was carried out as per ASTM D 243400 (Standard Test Method for Permeability of Granular soil (Constant Head Method)) which is typically used for granular soils.

Determination of the hydraulic conductivity was performed using both the constant head and the falling head methods. In both cases an upward low gradient (approximately one) was initially applied to saturate the specimen from the bottom up. This upward gradient was intended to produce a plug type flow which is more effective in displacing the air from the voids. In the case of fresh CKD, the specimen took a very long time to saturate under this low gradient. Hence the gradient was gradually raised 
approximately to a value of 11 after one day. Measurements of the hydraulic conductivity were initiated after a steady state flow was established from the top drain tube.

Measurements of the hydraulic conductivity test using the constant head method were repeated using at least five different gradients ( $\mathrm{i}=11$ to 15$)$ and several measurements were taken for each gradient.

\subsubsection{Compressibility}

One dimensional compression tests were performed on the dry CKD powders (the landfilled $\mathrm{CKD}$ had an average water content of $\sim 18 \%$ and had to be oven dried at $110^{\circ} \mathrm{C}$ ). Specimens were prepared in a rigid wall cell (diameter $=63.5 \mathrm{~mm}$; height $=$ $25.4 \mathrm{~mm}$ ) in three equal layers by applying a small static stress, and then loaded up to a vertical stress of $60-100 \mathrm{MPa}$.

\subsubsection{Shear Properties}

Investigation of the shear strength properties of the powders in their dry state was conducted employing the direct shear apparatus, a device commonly employed to measure the frictional characteristics of soils. The device employed includes a specimen chamber $63.2 \mathrm{~mm}$ in diameter and $33.8 \mathrm{~mm}$ in height; a lever system for application of the normal load; a motor that controls the relative displacement of the two half boxes forming the specimen chamber; and sensors and a data acquisition unit for measuring the relative displacement of the two half boxes, the horizontal load and the change in height of the specimen during shear.

Tests were performed on the CKDs in their dry state, after sieving through a $75 \mu \mathrm{m}$ sieve to minimize the presence of particle aggregates. The internal friction angle was measured for a different initial dry density of the specimens over applied normal stresses ranging between 33-200 $\mathrm{kPa}$. The specimens were all prepared in three layers using a small funnel. The density of the specimens was controlled through the application of a static stress on each layer. 


\subsubsection{Corrosivity Tests}

The corrosiveness of CKD was studied based on the following electrochemical parameters: $\mathrm{pH}$, electrical resistivity, soluble chloride content and soluble sulfate content. The $\mathrm{pH}$ of CKD was measured using a Corning $\mathrm{pH}$ meter- 44 as discussed earlier. Measurements of the other two parameters are summarized below.

\subsubsection{Electrical Resistivity Tests}

The electrical resistivity test is a simple method employed in evaluating the corrosiveness of a material and has been widely used for the evaluation of soil corrosivity. ASTM G 57-2001 (Standard Test Method for Field Measurement of Soil Resistivity Using the Wenner Four-Electrode Method) describes the testing procedure for measuring the resistivity of a soil sample. A Nilsson Model 400 solid state 4-pin soil resistance meter was employed to measure the electrical resistivity of the compacted CKD samples. It consists of a Plexiglas box (2.5" wide by 9.0"long by 1.5 " deep) which holds the soil, four electrodes (manufactured by MC Miller Co.) and an electrical resistivity meter (Nilsson Model 400, Manufactured by Nilsson Electrical Laboratory Inc.). The four terminal, (null balancing ohmmeter) can measure resistance values ranging from $0.01 \mathrm{ohm}$ to 1.1 mega ohms.

The CKD was mixed with water near to its optimum water content and was compacted in layers in the soil box by tamping with an iron rod to approximate its maximum dry density. The inner and outer electrodes were connected to the resistivity meter as shown in the layout diagram (Figure 5-3). When all the connections between the inner and outer electrodes and resistivity meter were completed, the resistivity was read from the meter in ohm-centimeters. Figure 5-4 shows the experimental setup. Following the resistivity measurements on the as-compacted CKD samples, the soil box was immersed in deionized water for 24 hours and the resistivity of the saturated sample was then measured. 


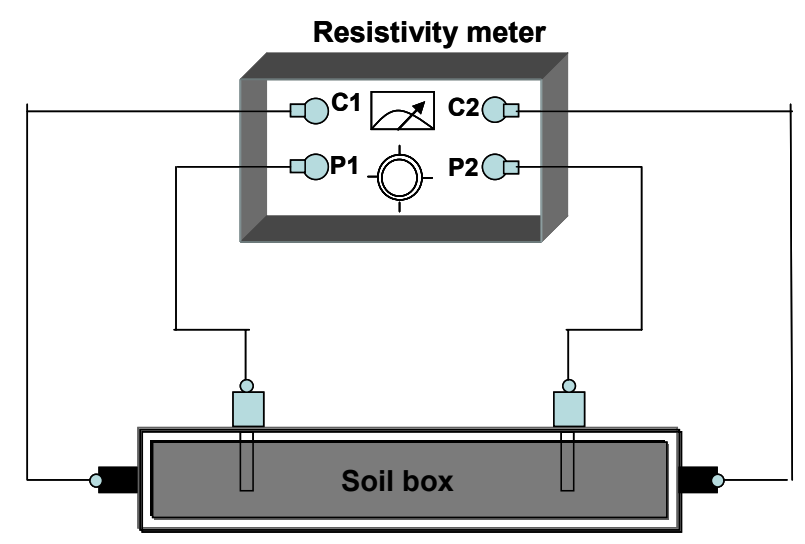

Figure 5-3 Diagram showing the connection between the resistivity meter and electrodes

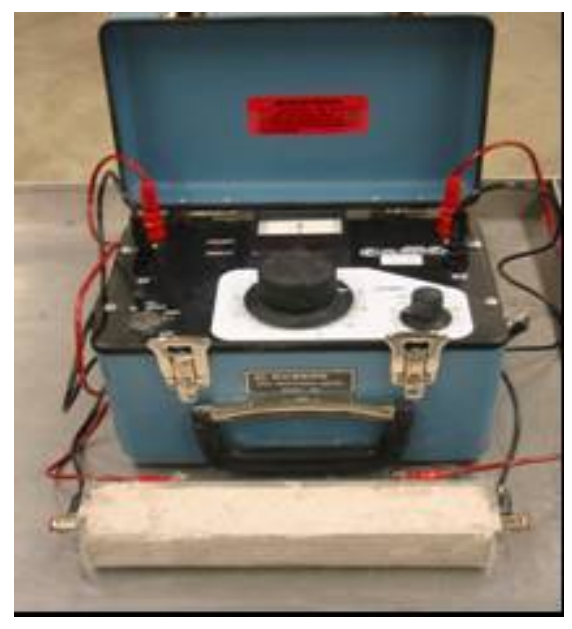

Figure 5-4 Electrical resistivity tests on CKD

\subsubsection{Sulfate Content and Chloride Content}

Measurement of the concentration of water soluble sulfates and chlorides present in CKD was performed in accordance with AASHTO T 290 (1999). Instead of employing the titration procedure suggested in the code, the ions present in the analyte where quantified by using an ion-chromatograph.

Ion chromatography (IC) is an analytical technique for the separation and determination of ionic solutes in water. Ion chromatography uses ion-exchange resins or polymers (ammonium type cation) to separate ions based on their interaction with the resin. The analyte and an eluent (carbonates and bicarbonates of sodium) are allowed to 
pass through the ion exchange column. When only the pure eluent is flowing through the column the positive centers present on the resin surface attract the negatively charged bicarbonate and carbonate ions in the eluent. But as the anions contained in the analyte sample begin to enter the column, these anions, which are also attracted to the polymer surface, may replace (i.e., they exchange with) the bicarbonate and carbonate ions adhering to the polymer surface. The analyte anions and the eluent anions compete with each other for the positive centers on the polymer surface. As a result of these interactions a rather complex equilibrium is set up as the analyte is carried through the column by the eluent.

The qualitative identification of the unknown ions present in the analyte is achieved based on the retention time of individual ions. The key to such identification rests on the fact that under a fixed set of analytical conditions (type of analytical column packing and concentration of eluent electrolytes) a given anion will always take the same amount of time to travel through the analytical column. Figure 5-5 shows a typical chromatograph. The ions are quantified based on the area under the chromatogram peak as concentration and area are generally linearly related.

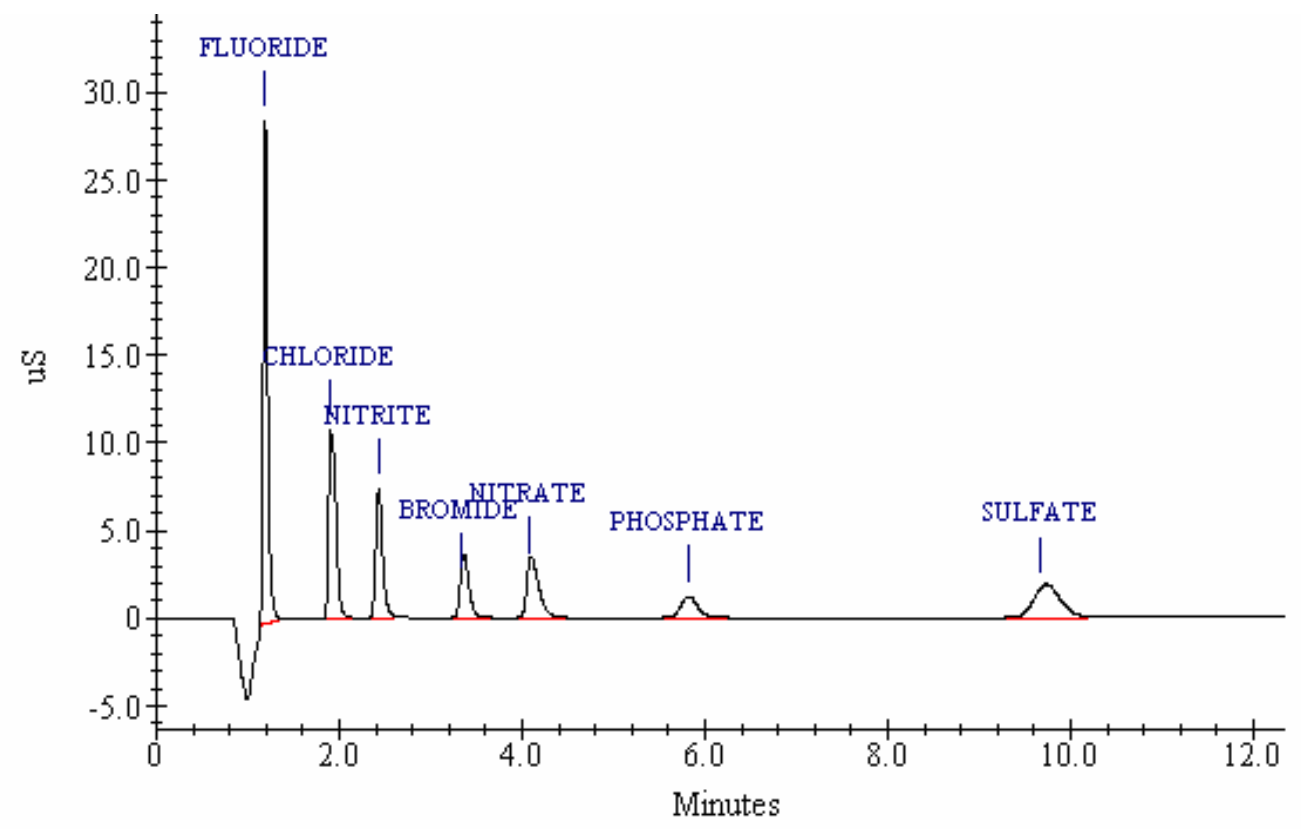

Figure 5-5 Figure showing a typical ion chromatograph 
Figure 5-6 shows a schematic of the basic components of an ion chromatography apparatus. Detection of anions using ion chromatography follows five steps: injection, separation, suppression, detection and recording. The sample is injected into the system using the autosampler. The eluent followed by the analyte are injected into the ion exchange column. The suppressor column effectively removes the carbonates and bicarbonates present in the solution coming from the exchange column to increase the sensitivity of the measurements by the detector. After separation, the anions flow through a conductivity detector which measures the conductance of the solution passing through it. These signals appear on a computer screen as distinctive patterns or peaks that can be identified (Figure 5-5). The detector response is calibrated with external standards of known concentration thus allowing detection and quantification of the analytes.

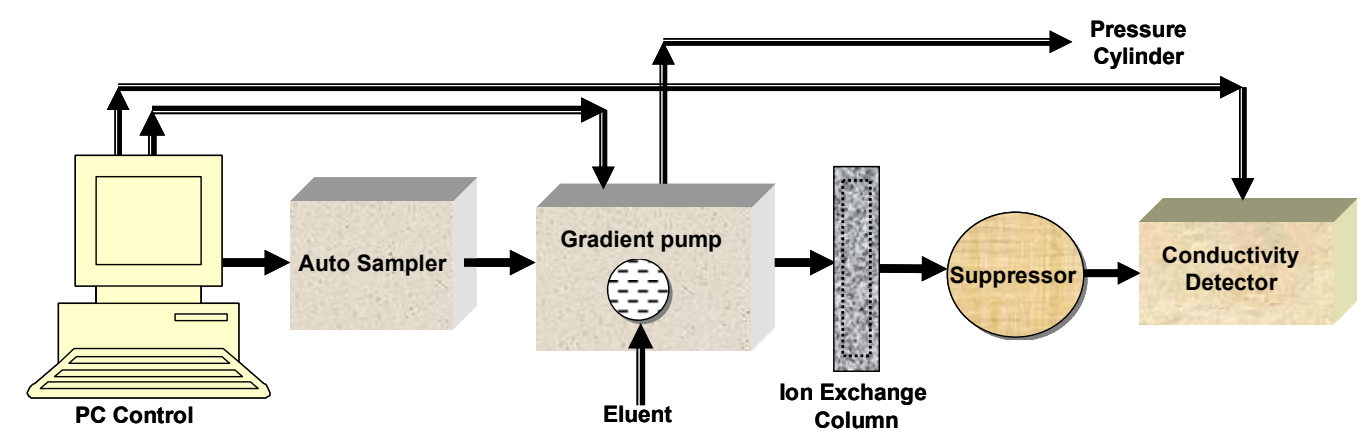

Figure 5-6 Basic components of an ion chromatography system 


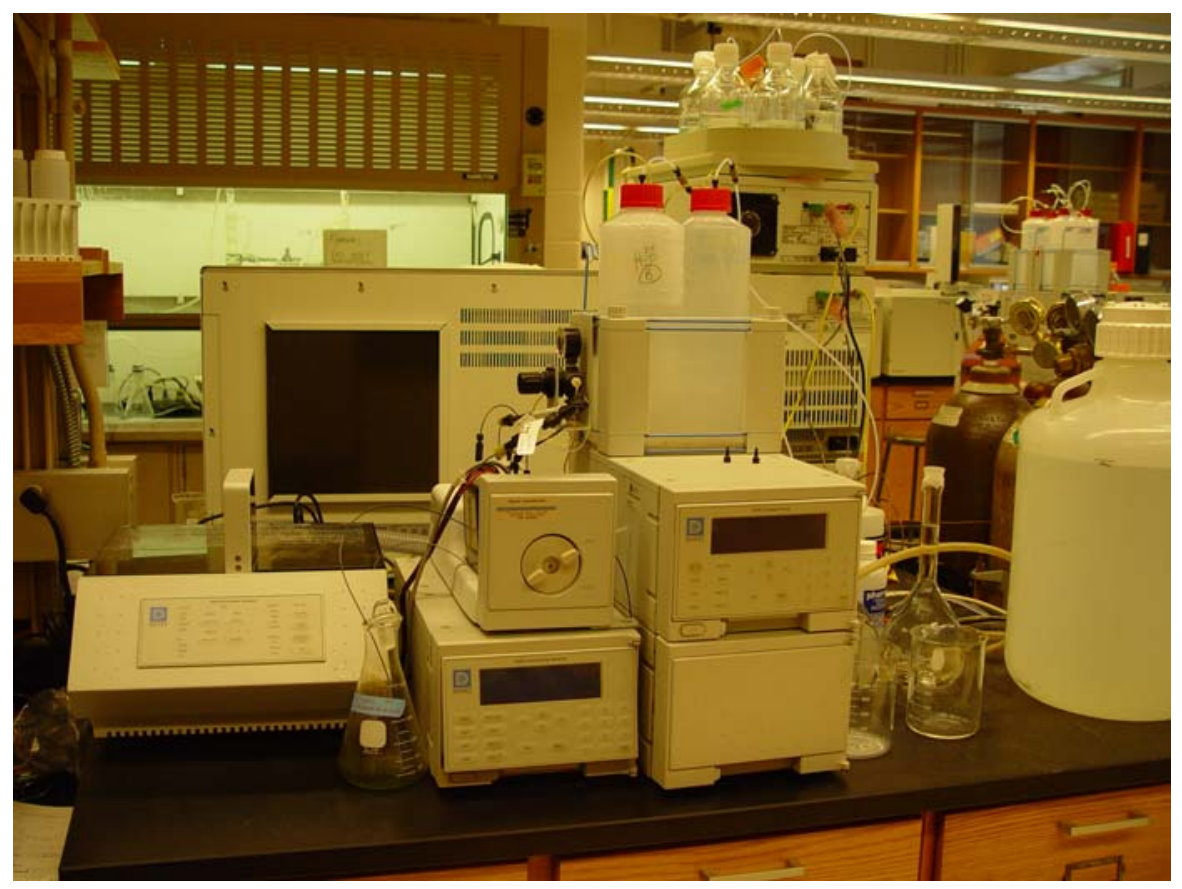

Figure 5-7 The Dionex ion chromatograph

Figure 5-7 shows the ion chromatograph used for the present study, manufactured by Dionex, and located in the Environmental Laboratory of the School of Civil Engineering, Purdue University. The eluent used in the tests is $10 \mathrm{mM} \mathrm{CO}_{3}{ }^{2-}$ and $\mathrm{HCO}_{3}{ }^{-}$. The analyte for the experiment was prepared by mixing about $100 \mathrm{~g}$ of the representative CKD sample and $300 \mathrm{ml}$ of de-ionized water in a 500ml flask. The CKD-water mixture was mechanically shaken over night. The mixture was allowed to settle and the supernatant free of solid phase was collected for testing purposes. This solution was again centrifuged (for 10 minutes at $4000 \mathrm{rpm}$ ) to eliminate any solid particles, which can cause blockages and considerably reduce the lifetime of the column(s).

The equipment was calibrated with standard solutions containing precise amounts of chloride and sulfate ions $(25,50$ and $100 \mathrm{ppm})$. The analyte samples were labeled and placed in the ion chromatography auto-sampler. The equipment starts the detection and quantification of the ions present in the samples after they are loaded into the autosampler and their identification data are entered into the data acquisition system. 


\subsubsection{Analysis of Trace Metals}

All "leachable" trace metals present in fresh, landfilled and selected tube samples were measured with an inductively coupled plasma (ICP) optical emission spectrophotometer in the Environmental Engineering Laboratory, Purdue University. ICP is a technique for elemental analysis which is applicable to most elements over a wide range of concentrations. It is based on the principle that atoms in the plasma emit light (photons) with characteristic wavelengths for each element. This light is recorded by one or more optical spectrometers. Thus the technique provides a quantitative analysis of the original sample. The most common sample delivery system consists of a peristaltic pump and capillary tube to deliver a constant flow of analyte liquid into a nebulizer. The nebulizer converts the analyte liquid into droplets. The largest droplets drop into a drain in the bottom of a spray chamber and the finest droplets are carried by gas into the IC plasma.

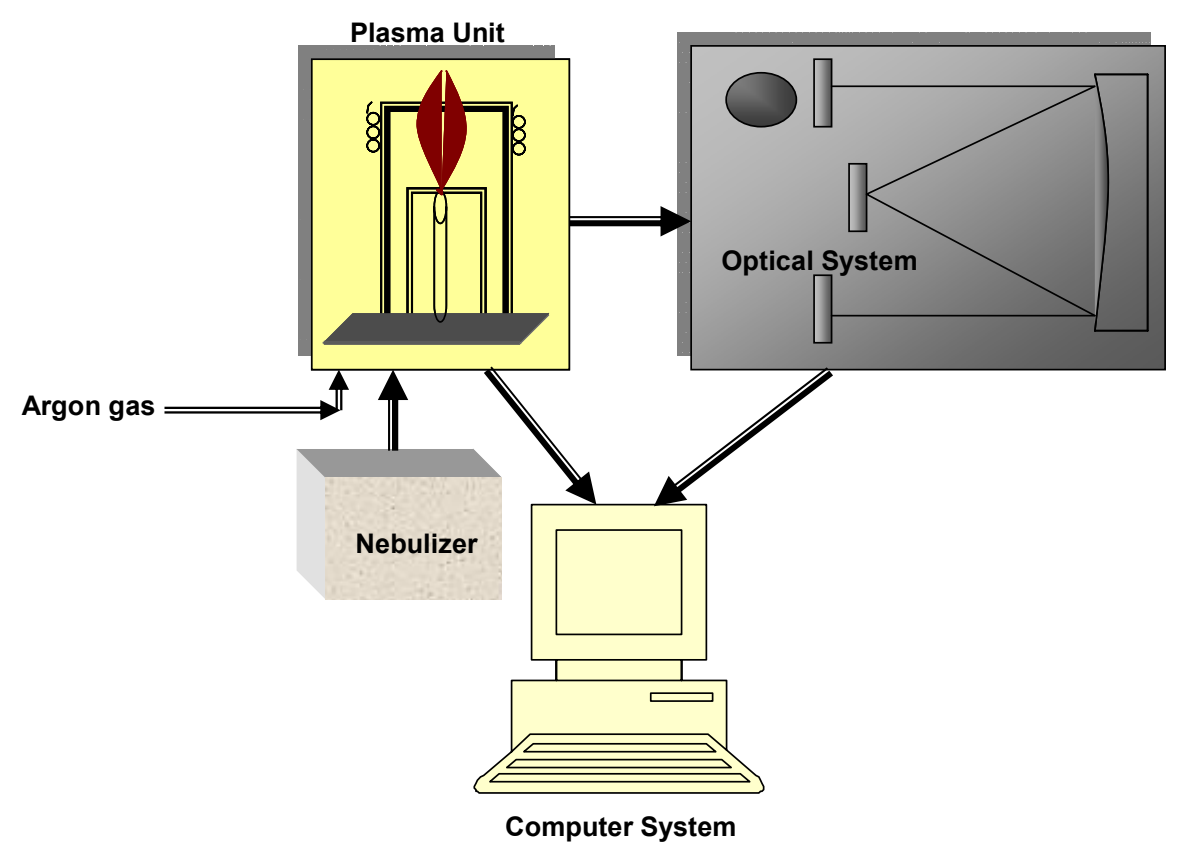

Figure 5-8 Layout showing the typical components of an inductively coupled plasma spectrometer system 
The amount of leachable metals in each sample was evaluated using the U.S. Environmental Protection Agency (EPA) Toxicity Characteristic Leaching Procedure (TCLP) (Sharma and Lewis, 1994). About $4 \mathrm{~g}$ (dry mass) of CKD were blended with 100 $\mathrm{g}$ of nano-pure water-acetic acid $(\mathrm{pH} \sim 5)$ to achieve a liquid to solid ratio of approximately 25 . The 'acetic acid' option was considered to be a worst-case leaching scenario. The solid-liquid mixtures were mechanically shaken for a period of 24 hours, and then allowed to rest so that the solids would settle. The top aliquot was centrifuged for 10 minutes at $4000 \mathrm{rpm}$ and was transferred to a new sample tube. Two to three drops of trace metal grade nitric acid were added to each tube. The samples were analyzed using ICP for seven RCRA metals (arsenic, barium, cadmium, chromium, lead, mercury and selenium) regulated in 40CFR261.24 under Resources Conservation and Recovery Act (RCRA). Silver is also included in the RCRA list, but was not quantified in the present study. The samples were also analyzed for aluminum, iron, manganese, nickel and zinc.

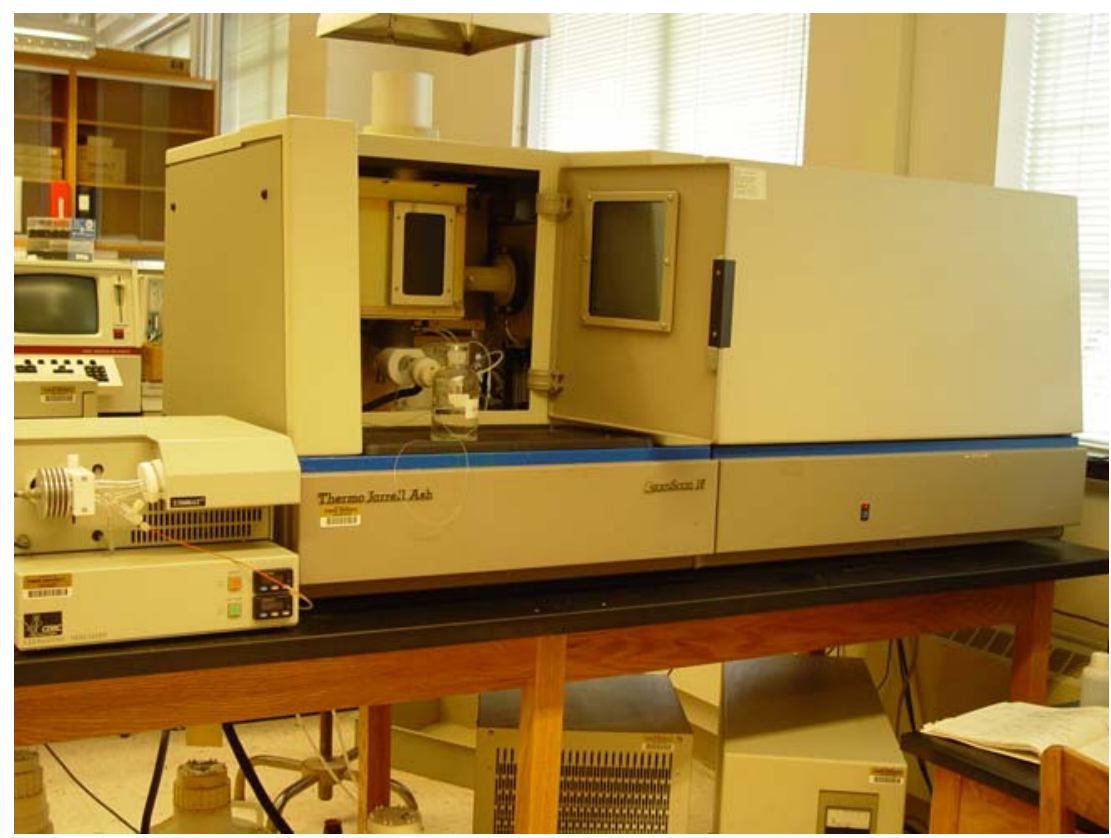

Figure 5-9 The plasma emission detector used for the present study 
Figure 5-9 shows the Thermo Jarrell Ash ATOMSCAN 25 plasma emission spectrometer used for the present study. The host computer system controls collection of the integrated charge information at each channel and converts this value into concentration units. Before conducting the tests on analytes, the ICP was calibrated using standard solutions containing known amounts of the metals of interest. The results reported are based on five analyses for each reading, with 45 seconds sample purging between samples.

\section{$\underline{5.3}$ Test Methods for Soil-CKD mixtures}

\subsubsection{Atterberg Limits}

Determination of the liquid and plastic limits was performed on soil CKD mixtures obtained by mixing soil with different percentages of CKD. The soil was mixed with water to reach a consistency of 15 blows or less and then put in the humid room to temper overnight. At the same time a specimen was placed in the oven for water content determination to calculate the appropriate amount of CKD (by weight) to be added. The following day, prior to adding the CKD, some of the soil was removed to determine reference limits for the neat soil. The CKD was then added and a first set of limits $(\mathrm{t}=0$ days) was determined for the mixed soil. Determination of the limits followed the same procedures typically used for neat soil, following a wet to dry procedure. After completing the tests, sufficient water was added to bring the mixture back to a 10-15 blow consistency. The soil was then stored in the humid room until the following testing time. Limits were determined after 1, 3 and 7 days.

\section{$5.3 .2 \mathrm{pH}$}

The $\mathrm{pH}$ of CKD-soil mixtures was determined following the ASTM 6276-99 (Standard Test Method for Using pH to Estimate the Soil-Lime Proportion Requirement for Soil Stabilization) method, which involves mixing the soil CKD mixture with pure water at a 1:5 ratio, periodically shaking the samples, then measuring the $\mathrm{pH}$ using a $\mathrm{pH}$ meter after one hour. The test is proposed for pure soil-lime mixtures whose $\mathrm{pH}$ is primarily due to calcium hydroxide which plays a key role in soil modification. The $\mathrm{pH}$ of soil-CKD mixtures can result from various other alkalis present in $\mathrm{CKD}$. Though the 
test procedure is not recommended for additives with high alkali content like CKD, the $\mathrm{pH}$ response of soil-CKD mixtures determined by this method has been successfully used by other authors (e.g., Miller and Azad, 2000) as an indication of the potential effectiveness of CKD for soil stabilization.

\subsubsection{Static Compaction}

For all tests, in order to reduce the scatter in the data, the soil was mixed with water to produce the desired water content and allowed to temper overnight in the humid room at R.H. $>98 \%$ and $\mathrm{T}=20^{\circ} \mathrm{C}$ protected by plastic wrap to avoid evaporation. The next day the soil was mixed with an appropriate amount of additive and compacted immediately to avoid any time delay. In addition to the water content measurements taken immediately prior to adding the CKD, specimens for water content measurements were taken following the mixing process, and on the soil shaved off from the compaction mold at the end of compaction. Compaction was carried out as per ASTM 698-00 (Standard Test Method for Laboratory Compaction Characteristics of Soils Using Standard Effort (12,400 ft-lbf/ft3 (600 kN-m/m3))).

\subsubsection{Unconfined Compression Tests}

All unconfined compression tests conducted on soil-CKD mixes were performed on specimens compacted using the proctor procedure. Following compaction, the specimens were maintained in the compaction mold for 24 hours completely covered in plastic wrap. At the end of this period the specimens were demolded and stored wrapped in plastic wrap in the humid room of the geotechnical laboratory $\left(\mathrm{T}=20^{\circ} \mathrm{C}, \mathrm{R} . \mathrm{H} .>98 \%\right)$. UCC tests were conducted on the compacted specimen as per ASTM 2166. Note that due to the geometry of the Proctor specimens (which does not meet a $2 / 1 \mathrm{H} / \mathrm{D}$ ratio) the values reported should be viewed as strength indexes, rather than as a true measure of the actual compressive strength of the compacted soil.

Tests were conducted using a strain controlled load frame apparatus, employing a constant strain rate of approximately $50-60 \% / \mathrm{hr}$. Measurement of axial load and axial strain was conducted using the same procedure described in Section 5.2.2.3. The 
corrections were applied to eliminate the bedding errors on the stress-strain curves as explained in Section 5.2.2.3.

\subsubsection{California Bearing Ratio (CBR) Test}

The California Bearing Ratio tests were performed on neat soil and CKD treated soil following the testing procedures outlined in Bowles (1986) and also by ASTM D 1883. The soil/CKD mixtures were prepared similar to the procedure outlined in section 5.3.3. Specimens were compacted at the desired water content in the CBR mold in 3 layers applying 56 blows per layer. Two identical specimens were typically prepared. A CBR test was conducted on one of the specimens immediately after compaction under a surcharge of approximately $6.7 \mathrm{~kg}$, corresponding to a stress of $\sim 3.6 \mathrm{kN} / \mathrm{m}^{2}$ (dry CBR). The second specimen was soaked in its mold for a period of 96 hours under the same surcharge. During the soaking phase, swelling of the specimen was monitored employing a LVDT connected to a computerized data acquisition system. The CBR penetration test was conducted on this second specimen at the end of the soaking period to obtain a CBR value for the specimen in saturated conditions (wet CBR). All CBR tests were conducted using a strain controlled load frame apparatus using a displacement rate of $1.3 \mathrm{~mm} / \mathrm{min}$. Load and depth of penetration of the plunger were recorded using a $2000 \mathrm{lb}$ capacity shear beam load cell and a LVDT connected to the laboratory's data acquisition system.

Following the same procedure, tests were also conducted on samples obtained by compacting soil CKD mixtures. For these materials CBR tests were also in some cases performed after 14 days of curing in the mold in the humid room $\left(\mathrm{T}=20^{\circ} \mathrm{C}, \mathrm{R} . \mathrm{H} .>98 \%\right)$.

\subsubsection{Swell Measurements}

In addition to the data gathered from the soaking phase preceding the CBR tests on the "wet" specimens, information on the swelling behavior of soil treated with CKD was derived from longer term swelling tests performed using a test setup which is a modified version of the "sand bath" test employed by Mitchell and Dermatas (1992) to perform early investigations on the interaction between sulfate-rich soils and lime. The photos in Figure 5-10 highlight the main features of the setup. Soil-CKD specimens, 
approximately $3.5 \mathrm{~cm}$ in diameter and $7 \mathrm{~cm}$ in height, were compacted using the Harvard miniature compaction method and were placed in plastic cylindrical molds $(D=7.5 \mathrm{~cm}$, $\mathrm{H}=15 \mathrm{~cm}$ ) over a $5 \mathrm{~cm}$ layer of Ottawa sand (carefully prepared to ensure a horizontal surface). The volume around the specimens was filled with additional sand, to a height corresponding to the top of the specimen. A $2.5 \mathrm{~cm}$ tall stainless steel top cap ( $\sim 96 \mathrm{~g})$ was placed on top of the specimen, while a second annular shaped cap was placed on top of the sand. After saturating the sand with water, the plastic cylindrical molds were immediately placed in a Plexiglas box, containing a frame for anchoring the LVDTs required to measure the vertical strain. The box was located inside an environmental chamber manufactured with styrofoam. Recordings of the vertical displacement and of the temperature were taken at regular intervals (every 12 hours) making use of the data acquisition system available in the geotechnical laboratory.

Using the above described procedure, swell measurements were conducted on both on soil-CKD mixtures as well as on control specimens made of soil alone, all prepared at the same water content. Measurements were conducted for almost thirty days and water was added every third day. Duplicate specimens were prepared for each of the testing mixtures under investigation. The swell data reported represent the average data from these two specimens. 


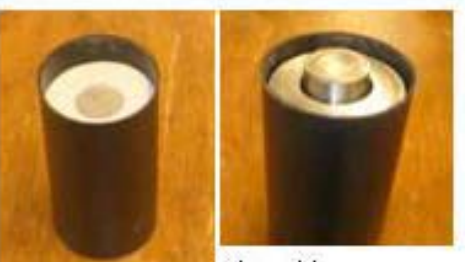

a) b)

Specimen inside sand bath

a) Without surcharge

b) With two surcharge caps

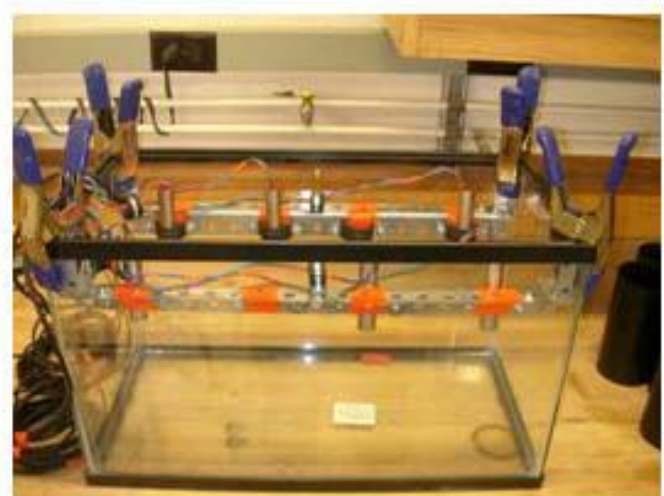

Plexiglas box and frame for LVDTs

Overall view of specimens inside environmental chamber
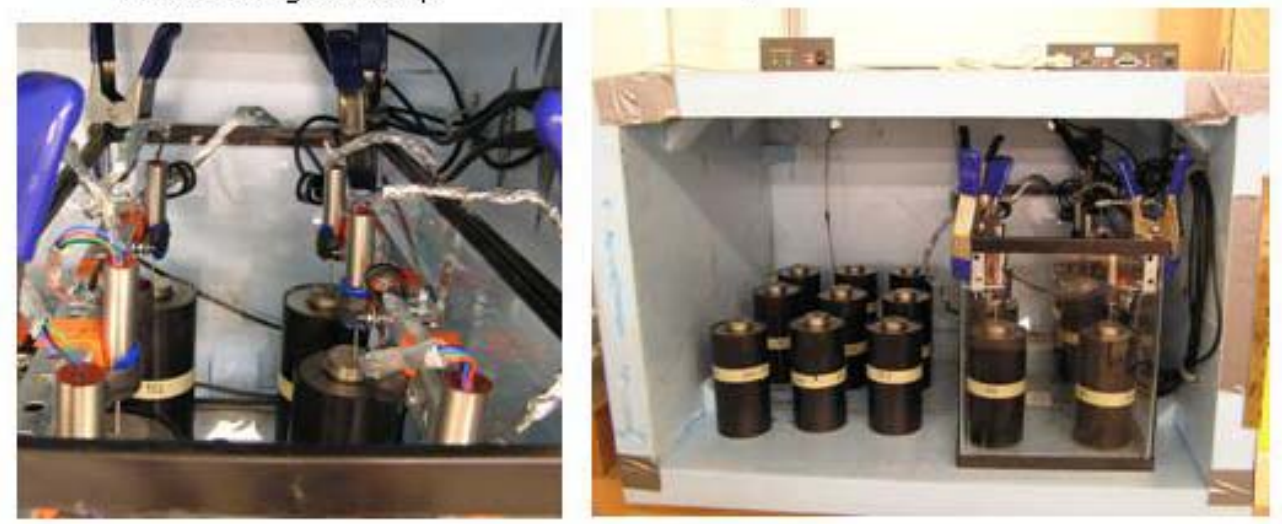

Figure 5-10 Schematic of the set up used for investigating the long term swelling behavior 


\subsection{Test Methods for Controlled Low Strength Materials (CLSM)}

\subsubsection{Mixing Procedure}

For all the mixes used, initial trial mixing was performed to determine the approximate amount of water needed to obtained the target flow of 8 inches specified by ASTM D 6103-04 (Standard Test Method for Flow Consistency of Controlled Low Strength Material (CLSM)). After determining the exact amount of water required to meet this flow consistency, actual mixes were prepared to perform the experiments with the following procedure. The required amounts of dry ingredients were weighed and were first mixed with approximately half the required water for 3 minutes. A rest period of 2 minutes followed, during which the sides of the mixer were carefully cleaned to incorporate all the material in the mix. The remaining water was then added and mixing continued for additional 3 minutes. Immediately after mixing, the flow measurements were taken. If the flow was less than the required amount, a small amount of additional water was added. The mixture was mixed for anther one minute to get a homogeneous mix. Small amount of mixes were prepared using a 3 liter Kitchen Aid mixer available in the Geotechnical Laboratory of the School of Civil Engineering at Purdue University. When greater volumes were required (e.g. for the strength and setting tests) a larger capacity mixer HOBART from in Materials Laboratory of the School of Civil Engineering at Purdue University was employed.

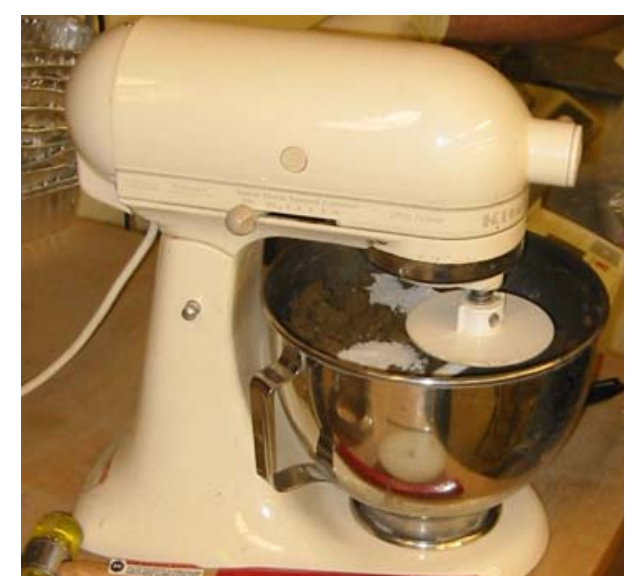

Figure 5-11 Kitchen aid mixer used for preparing CLSM 


\subsubsection{Flow Consistency}

The flow consistency of the flowable fill mixtures investigated in this research was measured following ASTM D 6103 (Standard Test Method for Flow Consistency of Controlled Low Strength Material (CLSM). The objective of this test is to determine the amount of water required for the mix to display the flow consistency required in flowable fills. This method makes use of a straight open ended plastic cylinder having height of $150 \mathrm{~mm}$ and diameter of $75 \mathrm{~mm}$. After dampening its internal wall, the cylinder is placed on a smooth clean glass plate. Immediately after the mixture is prepared it is poured into the cylinder. After filling filled, the cylinder is raised and the mixture is allowed to flow (Figure 5-12). If it flows to occupy a patty of 8-9 in, the mixture is considered to have acceptable flow properties. If not, more water is added and the measurement is repeated after one additional minute of mixing.
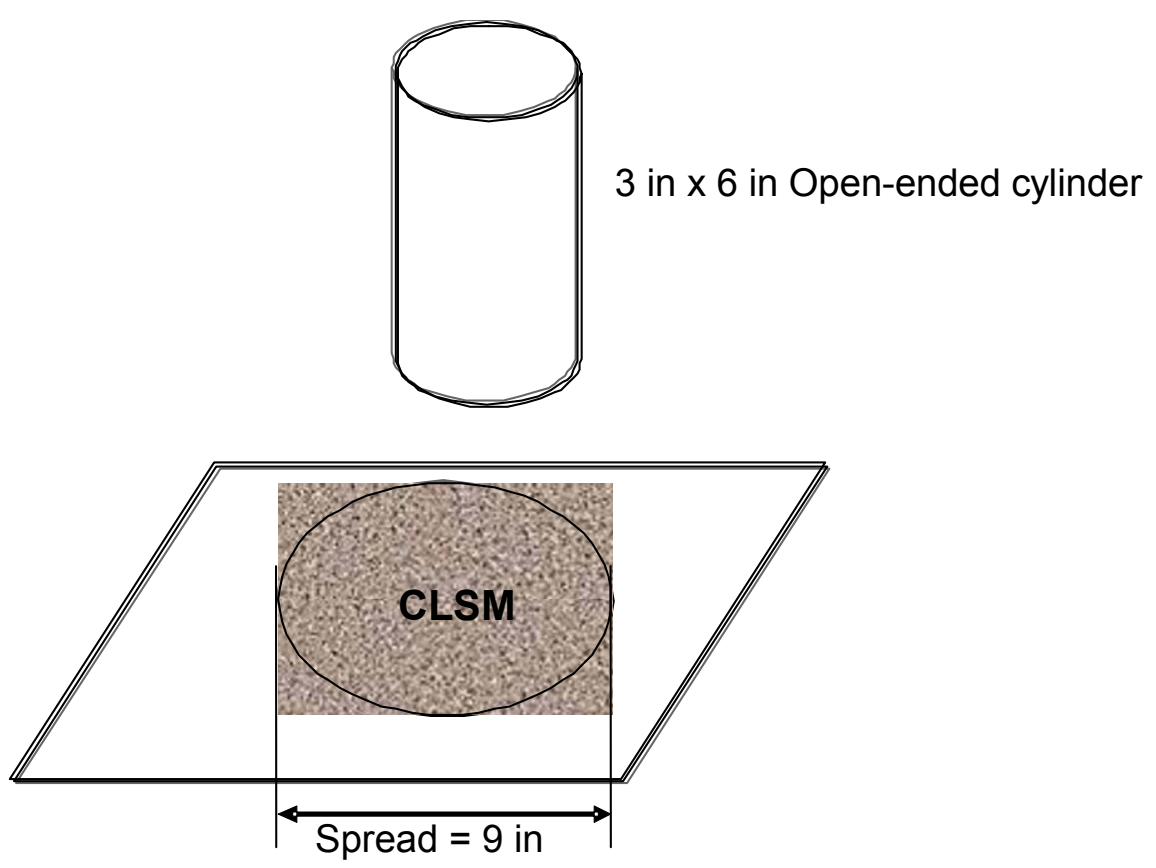

Figure 5-12 Flow test 


\subsubsection{Unit weight}

The Unit weight of the fresh mixtures was measured as per ASTM D 6023-96 (Standard Test Method for Unit Weight, Yield, Cement Content and Air Content (Gravimetric) of Controlled Low Strength Material (CLSM)). A $400 \mathrm{~cm}^{3}$ water tight copper cylindrical container was used for the measurements. The unit weight was calculated following the standard.

\subsubsection{Bleeding}

Volume stability of the all mixes was measured by bleeding tests, conducted as per ASTM C-940-98a (Standard Test Method for Expansion and Bleeding of Freshly Mixed Grouts for Preplaced Aggregate Concrete in the Laboratory). This test involves pouring the mixture immediately after mixing into a $1000 \mathrm{ml}$ graduated cylinder. The cylinder is placed on a level surface free of any vibrations and the volume of the clean bleed water, released after a period of about 3 to 4 hours, is measured. During this period the cylinder is covered with a plastic sheet to avoid any loss by evaporation. Bleeding is expressed as the percentage of the volume of free water released by the mix to the total volume of the sample taken at the beginning of the test. A minimum of two measurements were taken for each batch.

\subsubsection{Setting Time}

The setting time was measured using the penetration resistance test described in ASTM C 403 (Standard Test Method for Time of Setting of Concrete Mixtures by Penetration Resistance). In this test the resistance (in pounds) to the penetration of a cylindrical needle in the CLSM mixture is measured. This value divided by the cross sectional area of the tip of the needle is taken as the penetration resistance. Needles of different diameters are available and the choice depends on the strength of the material to be tested. Freshly mixed CLSM was poured in a plastic container and covered to prevent evaporation loss. Penetration resistance readings were taken with time varying up to three days depending on the strength of the material. No drainage of water was permitted 
during this test. Any free bleeding water was removed before each measurement of the penetration resistance.

In the field, a flowable fill is considered to have set if it can support foot traffic. Bhatt (1996) found that the penetration resistance necessary to ensure walkability on the CLSM is about $450 \mathrm{kPa}(65 \mathrm{psi})$. The time necessary to attain this penetration resistance is defined as walkable time. The time dependent setting behavior obtained by the penetration resistance test was used to derive the time required to develop a $450 \mathrm{kPa}$ penetration resistance.

\subsubsection{Unconfined Compressive strength}

The unconfined compressive strength of CLSM specimens was determined using cylindrical specimens, $75 \mathrm{~mm}$ in diameter and $150 \mathrm{~mm}$ in height, cast in PVC molds.

To facilitate easy removal of the CLSM specimens from the mold, prior to casting the specimens, the PVC cylinders were cut from top to bottom along the side. The cylinder was then wrapped with electrical tape to close the cut. The inside of the molds was lightly coated with mineral oil before pouring in the flowable fill mix, to avoid sticking of the mix to the mold. The mix was poured into the mold and slightly tapped with a metallic rod to remove entrapped air. The mold was left under observation for ten to fifteen minutes and additional mix was added to compensate subsidence, if any. The surface was then leveled. Immediately after casting, the cylinders were placed in the humid room $\left(\mathrm{T}=20^{\circ} \mathrm{C}\right.$ and $\left.\mathrm{RH}>98 \%\right)$ for 3 to 4 days before demolding the specimens. The specimens were then transferred to the fog room located in the Materials Laboratory and stored there protected with a plastic sheet until the day of testing. On that day, specimens were allowed to air dry for about 6 hours. The top surface of the specimen was cleaned with a wire brush to flatten the surface by removing all loose particles. No capping was provided. Considering the lower strength of specimens they were tested in the displacement controlled machine available in the Geotechnical Laboratory. The strain rate was applied such that the specimen was failed in no less than 2 minutes as per ASTM D 4832 (Standard Test Method for Penetration and Testing of Controlled Low Strength Material (CLSM) Test Cylinders). A strain rate of around $0.4-0.5 \mathrm{~mm} / \mathrm{min}$ was found to 
be adequate to meet this requirement. The load was applied until the specimen failed and the maximum load carried by the specimen during the test, was recorded. The specimens were tested at various curing times ranging from 1 to 90 days.

\subsubsection{Corrosion Testing}

The corrosiveness of CLSM was investigated by measuring $\mathrm{pH}$ and resistivity. Additionally, a mass loss test on steel coupons buried in CLSM was also performed.

\section{$\underline{5.4 .7 .1 \mathrm{pH}}$}

The $\mathrm{pH}$ of the fresh mix was measured using a Corning $\mathrm{pH}$ meter 44 immediately after being mixed.

\subsubsection{Resistivity}

Resistivity of the CLSM mixes was measured immediately after mixing using the procedures and apparatus described in section 5.2.3.1.

\subsubsection{Mass Loss Test}

A model mass loss test was conducted by the procedure adopted by Abelleria et al. (1998) using 1018 steel coupons $26 \mathrm{~mm}$ x13 mm x3 mm in size. The coupons were cut yielding edges perfectly smooth and a $6 \mathrm{~mm}$ diameter hole was made at the top edge. Prior to testing the coupons were rubbed with sandpaper to remove any rust, cleaned in hexane solution, and finally dried as per ASTM G1-03 (Standard Practice for Preparing, Cleaning, Cleaning, and Evaluating Corrosion Test Specimens). They were then weighed using a highly sensitive balance (sensitivity up to four digits) and placed in a desiccator to avoid any direct exposure to atmosphere.

Two coupons were suspended by a thin nylon wire inside a plastic cylinder mold $(\mathrm{D}=100, \mathrm{H}=200 \mathrm{~mm}$ ) approximately $25 \mathrm{~mm}$ apart, and $\sim 6 \mathrm{~cm}$ from the top of the cylinder (Figure 5-13). 


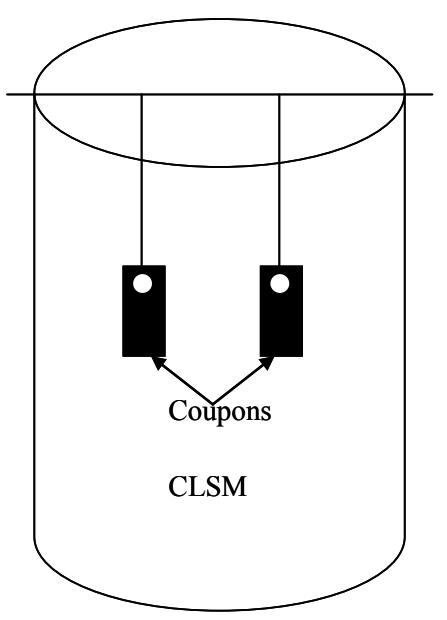

Figure 5-13 Coupons are suspended in cylindrical mold containing CLSM for corrosion testing

Following preparation, the CLSM mixture was carefully poured into the cylinder. Extra precautions were taken to limit movement of the coupons. The specimens were then transferred to the humid room and allowed to cure in the mold for three days prior to demolding. Each cylinder was then placed in a plastic container and covered with concrete sand. Four reference coupons were also placed in containers holding sand alone.

Tap water was added to all the containers until the water level was approximately $1 \mathrm{~cm}$ above the surface of sand. The containers were stored at room temperature in the Geotechnical Laboratory. The water was allowed to evaporate until the level fell below the buried coupons. Additional water was then added to bring the water back to the original level. The cycle was repeated for the duration of the test to simulate wetting/drying cycles. All coupons including the control specimens buried in sand were removed from the CLSM cylinders after six months. They were then cleaned and weighed according to ASTM G1, to determine the mass loss.

The average corrosion rates for the metal coupons ( $\mu \mathrm{m} /$ year) were calculated using the following formula:

Corrosion rate $=(\mathrm{K} \times \mathrm{W}) /(\mathrm{A} \times \mathrm{T} \times \mathrm{D})$

where: 
$\mathrm{K}=\mathrm{a}$ constant $\left(8.76 \times 10^{7}\right)$

$\mathrm{W}=$ mass loss in grams

$A=$ total surface area of the coupons in $\mathrm{cm}^{2}$

$\mathrm{T}=$ time of exposure in hours

$\mathrm{D}=$ density of steel in $\mathrm{g} / \mathrm{cc}$

The tests were conducted using CLSM manufactured with fresh CKD, landfilled CKD and fly ash. 


\section{CHAPTER 6 -- CHARACTERIZATION OF CKD AND IDENTIFICATION OF KEY PROPERTIES}

\subsection{Introduction}

There are number of issues associated with the development of reuse applications for a waste by-product material. Figure 6-1 illustrates the steps associated with this process. The first and critical step in the process aimed at isolating potential applications for an industrial by-product material is the careful and thorough characterization of the material, based on which the key properties can be identified. This is the case particularly for materials, such as CKD, that have found to date only limited applications. With a few exceptions, previous investigations on the re-use of CKD have focused on one particular application (e.g., soil stabilization), and thus have placed emphasis exclusively on the specific properties relevant to this application (e.g., free lime content in the case of soil stabilization and alkali content as an activator for slag in concrete). To the authors' knowledge, no comprehensive study has been conducted so far to characterize CKD in a broader way, as an engineering material.

This chapter presents the results of a comprehensive experimental study of the physico-chemical and engineering properties of fresh and landfilled CKD obtained from an Indiana plant.

This work was carried out in two phases. The first phase of the experimental work was aimed at:

a) performing a preliminary evaluation of the variability in characteristics of the landfilled CKD, based on a limited set of properties (water content, loss on ignition, $\mathrm{pH}$ and a limited number of chemical analyses);

b) comparing basic properties of the fresh and the landfilled CKD; and

c) evaluating the two types of materials with respect to other CKDs, based on published data. 
In the second phase of the study, testing focused on:

a) evaluating some key engineering properties of the CKDs; and

b) assessing the hazardous nature of the fresh and landfilled CKDs.

Overall, the study was finalized at identifying the key properties of the CKDs investigated that could be exploited in a large scale application.

Details on the tests conducted in the two phases of the experimental work are discussed in section 6.2 which describes in detail the testing program. The subsequent sections (6.3.1-6.3.3) summarize the results of the characterization study. In addition to the physio-chemical and engineering properties, the chapter discusses the corrosiveness and environmental hazardous potential of both fresh and landfilled CKD. When CKD is used in construction applications, it is inevitable that it will come in contact with metals, and thus an understanding of its corrosiveness appears to be of great practical significance. Similarly, it seems imperative that the hazardous potential of any material that is re-introduced into the environment needs to be well understood. In this study the hazardous waste potential of CKD was evaluated on the basis of heavy metal concentration present in the CKD leachate.

Special emphasis is placed throughout the chapter on highlighting differences between the CKDs tested. The differences between the various samples of fresh CKD underline the significant impact that differences in the operations of a cement plant can have on the characteristics of the CKD produced. On the other hand, the dissimilarity in the results between fresh and landfilled CKD emphasizes the changes to the properties of CKD that can occur due to long term exposure of this material to the environment.

The chapter concludes with a discussion on the potential applications for fresh and landfilled CKD that appear to be more promising based on the results of the characterization study. 


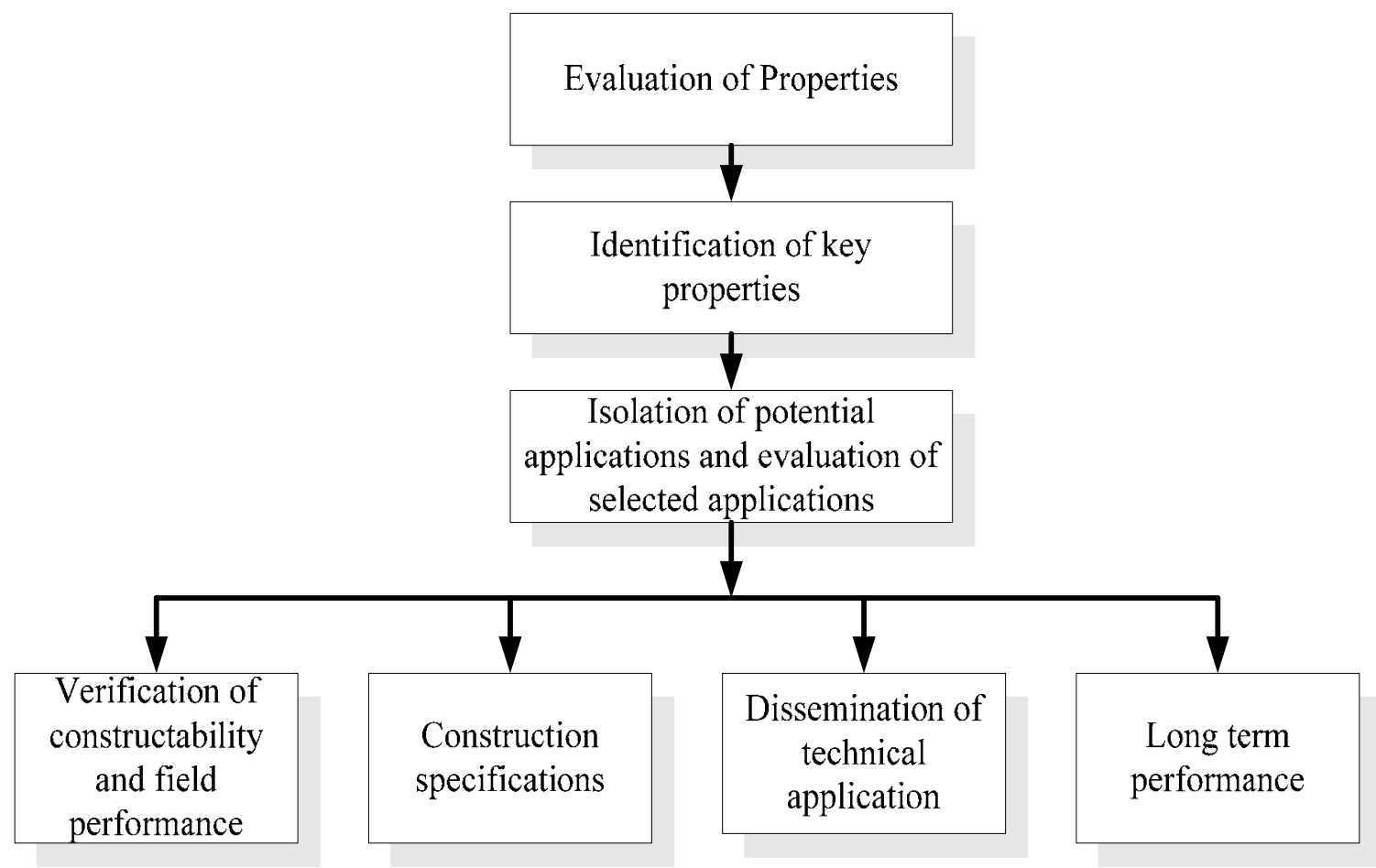

Figure 6-1 Steps involved in the development of reuse applications for waste by-product materials (Modified from Edil and Benson, 1998)

\subsection{Investigation Program}

As discussed in the previous section, the laboratory investigation for characterizing the fresh and landfilled CKD was conducted in two phases. Table 6-1 summarizes the tests conducted and the samples used in the first phase of the work. In this table B1, B2 and B3 refer to the three borings conducted in the landfill.

While testing involved all three samples of fresh CKD obtained from the Lehigh plant, the work presented here made use primarily of the CKD produced after 2002, i.e. after changes had been implemented to the plant (fresh II and III). Data for the previous CKD (fresh I), collected during the proposal stage of this project (2000), was used primarily for comparison purposes. See Chapter 4 for an in depth discussion of the sampling phases. 
As shown in Table 6-1, the properties evaluated included chemical (oxide) composition, mineralogy, morphology and particle size distribution, specific gravity, specific surface, water content, LOI and $\mathrm{pH}$. While chemical and mineralogical analyses and particle size distribution and specific gravity were limited to a small number of the field samples (which are identified by the letter A, B,C, D,E,F,G and I. See Figure 6-2 for the location of the "tube samples" within the boreholes B1, B2 and B3), measurements of the "natural water content", the $\mathrm{pH}$ and the LOI were performed on all tube samples immediately after the tubes were received in Purdue's Geotechnical Laboratory. These characteristics are compared and evaluated with respect to other CKDs, based on published data in section 6.3.1.2.

Table 6-1 Summary of experiments conducted in phase I

\begin{tabular}{|c|c|c|c|c|c|}
\hline & Fresh & Landfilled & B-1 & B-2 & B-3 \\
\hline Chemical composition & $\mid \mathrm{II}$ & - & $\mathrm{F}$ & $\mathrm{C}, \mathrm{F}, \mathrm{I}$ & $\mathrm{B}, \mathrm{D}$ \\
\hline Free lime content & II & - & \multicolumn{3}{|c|}{ Composite sample for each } \\
\hline Mineralogy (XRD) & $\mathrm{I}, \mathrm{II}, \mathrm{III}$ & $\mathbf{X}$ & - & - & - \\
\hline Water content, LOI, $\mathrm{pH}$ & I, II,III & 凶> & All & All & All \\
\hline Specific gravity & I, II,III & 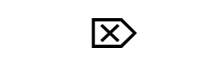 & $\mathrm{F}$ & $\mathrm{D}$ & \\
\hline Particle size & I, II,III & 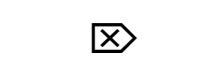 & $\mathrm{E}$ & $\mathrm{D}, \mathrm{I}$ & $\mathrm{I}$ \\
\hline Morphology (SEM) & II,III & 区 & G & $\mathrm{F}$ & A \\
\hline Specific surface area & III & 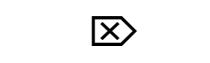 & - & - & - \\
\hline
\end{tabular}

Testing was accomplished in the second phase of investigation to differentiate the engineering properties of fresh and landfilled CKD. The environmental hazardous potential and corrosiveness of both the fresh and the landfilled CKDs were also studied. Based on the consistent characteristics of the landfilled material found in the first phase of the investigation, the bulk samples collected from the mining front of the landfill were 
used in the second phase of the investigation to represent the landfilled material. Table 62 summarizes the testing program for this phase.

Table 6-2 Summary of experiments conducted in phase II

\begin{tabular}{|c|c|c|c|}
\hline & Fresh CKD & $\begin{array}{c}\text { Landfilled } \\
\text { CKD }\end{array}$ & $\begin{array}{l}\text { ASTM/Other } \\
\text { standards }\end{array}$ \\
\hline Binding properties & $\mathrm{I}, \mathrm{II}, \mathrm{III}$ & $\bar{X}$ & C 305 \\
\hline Bleeding properties & III & 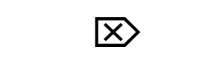 & C 940 \\
\hline Moisture density relations & I,II,III & $凶$ & D 698 \\
\hline Unconfined compressive strength & III & 凶> & D 2166 \\
\hline Permeability & III & 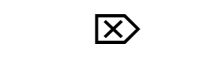 & D 2434 \\
\hline Compressibility (Dry powder) & III & 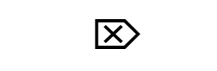 & \\
\hline Shear Properties (Dry powder) & III & $\mathbf{x}$ & \\
\hline \multicolumn{4}{|l|}{ Properties relevant to corrosion } \\
\hline Electrical resistivity & II & 区 & G 57 \\
\hline $\mathrm{pH}$ & $I, I I, I I I$ & 凶> & D 4972 \\
\hline Sulfate content & II & 区 & AASHTO 290 \\
\hline Chloride content & III & 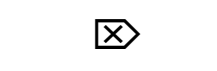 & AASHTO 290 \\
\hline Leachable metals $^{*}$ & I,III & 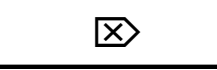 & TCLP \\
\hline
\end{tabular}

${ }^{*}$ Heavy metal concentration were also determined for selected tube samples (B1-B, B1-I, B2-C, B2-F, B3-A \& B3-I).

\subsection{Test Results and Discussion}

The test results from the characterization tests are discussed in sections 6.3.16.3.3. The first two sections illustrate the physio-chemical properties and mechanical and engineering properties of the fresh and landfilled CKDs, while section 6.3.3 presents the test results from the environmental assessment tests. 


\subsubsection{Physio - Chemical Properties}

\subsubsection{Chemical and Mineralogical Composition}

The chemical composition of fresh and landfilled CKD is summarized in Table 63. The table includes the data for the samples of fresh CKD (I, II and III) as well as the results for select number of tube samples from the landfill. The table also includes mean and standard deviation (SD) values for the tube samples, which were selected to provide an insight into the variability of the oxide composition within the landfill. Figure 6-2 shows the location of samples (shaded in black) employed for the oxide composition determination. In general the results appear quite consistent, with no major difference between the fresh and the landfilled material. $\mathrm{CaO}$ and $\mathrm{SiO}_{2}$ are the two major oxides present in both CKDs. The values of the LOI vary within a limited range, and are at the higher end of the data reported in the literature (see Table 3.1 in Chapter 3). The data in Table 6-3 also indicates a $\mathrm{SiO}_{2}$ percentage and alkali content at the low end of the range reported in the literature as well as low free lime content. As a result, and particularly due to the high level of LOI, the values of the total reactive oxide (TRO) fall below the average from the literature. Measurements of the free lime conducted on composite samples obtained by combining CKD from select samples from each of the borings indicate values less than $1 \%$, at the low end of the values reported in the literature.

Representative XRD patterns for both the fresh and the landfilled CKDs are shown in Figure 6-3. The results indicate that calcite and silica are the major components in both the fresh and the landfilled CKD. The peaks of ettringite, resulting from the hydration reactions occurred in the field, were identified in the landfilled material. No other major minerals could be identified. While determination of the free lime was not conducted for fresh I, X-ray diffraction isolated the peaks of this compound and historic data (APPENDIX A) from the manufacturer indicated a free lime content for this material in the $2-6 \%$ range. For fresh II and fresh III CKDs instead only traces of free lime were found from the chemical analyses, and no peaks for this compound were identified in the X-ray diffraction pattern (Figure 6-3). This appears to be the result of the plant changes implemented in 2002 (see Chapter 4), which resulted in a more efficient manufacturing process. The difference in free lime content of CKD produced before the 
implementation of plant modifications (2-6\%) and after the modification (traces) is significant. As expected, the landfilled material also showed only traces of free lime, which, if present at the time of disposal, would have likely reacted or carbonated during the extended "storage" time.

Table 6-3 Oxide composition of fresh and landfilled CKD tested

\begin{tabular}{cccccccccccc}
\hline Sample & Fresh I & Fresh II & Fresh III & B1-F & B2-C & B2-F & B2-I & B3-B & B3-D & mean & SD \\
\hline \hline $\mathbf{C a O}$ & 50.4 & 45.93 & 44.9 & 42.96 & 53.19 & 46.3 & 44.59 & 42.14 & 44.54 & 46.15 & 3.98 \\
$\mathbf{S i O}_{2}$ & N.A & 9.3 & 10.5 & 7.62 & 8.7 & 7.82 & 7.99 & 7.1 & 12.37 & 8.8 & 1.91 \\
$\mathbf{A l}_{\mathbf{2}} \mathbf{O}_{3}$ & 2.66 & 3.20 & 3.49 & 2.50 & 2.87 & 2.66 & 2.56 & 2.43 & 2.82 & 2.67 & 0.18 \\
$\mathbf{F e}_{2} \mathbf{O}_{3}$ & 1.09 & 1.06 & 1.32 & 0.96 & 1.11 & 1.05 & 1.11 & 1.00 & 1.57 & 1.17 & 0.22 \\
$\mathbf{M g O}$ & 0.70 & 1.11 & 1 & 0.83 & 1.02 & 0.88 & 0.91 & 0.99 & 1.93 & 1.14 & 0.41 \\
$\mathbf{S O} \mathbf{O}_{\mathbf{3}}$ & 3.50 & 2.30 & 1.89 & 4.62 & 4.92 & 3.76 & 4.12 & 4.17 & 2.59 & 3.91 & 0.81 \\
$\mathbf{N a}_{\mathbf{2}} \mathbf{O}$ & 0.18 & 0.13 & 0.16 & 0.30 & 0.23 & 0.12 & 0.08 & 0.23 & 0.11 & 0.15 & 0.09 \\
$\mathbf{K}_{\mathbf{2}} \mathbf{O}$ & 2.16 & 1.22 & 1.45 & 2.14 & 2.39 & 1.43 & 1.39 & 2.32 & 1.19 & 1.74 & 0.53 \\
$\mathbf{L O I}$ & 33.62 & 33.30 & 34.98 & 33.86 & 33.00 & 33.64 & 34.80 & 34.10 & 33.16 & 33.74 & 0.65 \\
Tot.Alkali & 1.60 & 0.93 & 1.11 & 1.71 & 1.80 & 1.06 & 0.99 & 1.76 & 0.89 & 1.34 & 0.41 \\
TRO & 15.14 & 12.36 & 9.31 & 7.49 & 18.95 & 11.99 & 9.24 & 6.49 & 12.00 & 11.66 & 4.36 \\
$\mathbf{H M}$ & & 3.39 & 2.93 & 3.87 & 4.19 & 4.01 & 3.82 & 4.00 & 2.66 & 3.74 & 0.55 \\
\hline
\end{tabular}

Notes: Total alkali is the total alkali content in sodium equivalent

Oxide values expressed in \% by mass;

Mean and SD (standard deviation) pertain to tube samples only

$\mathrm{pH}$ measurements were conducted on all samples of CKD collected. The average $\mathrm{pH}$ value of the field samples was approximately 12, falling between the value measured for fresh I $(\mathrm{pH} \sim 12)$ and those obtained from the other two fresh samples $(\mathrm{pH} 11.5)$. Further discussion on the variability in $\mathrm{pH}$ in the landfill is provided in the following section. 


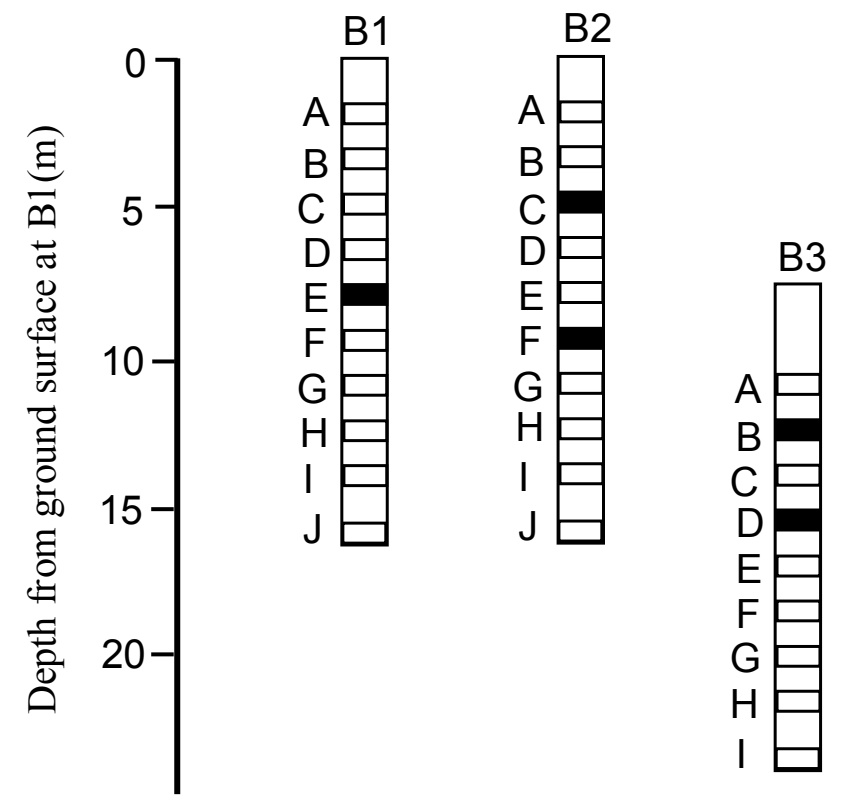

Figure 6.2 Samples used to determine oxide composition shown in Table 6-3 (shaded in black)

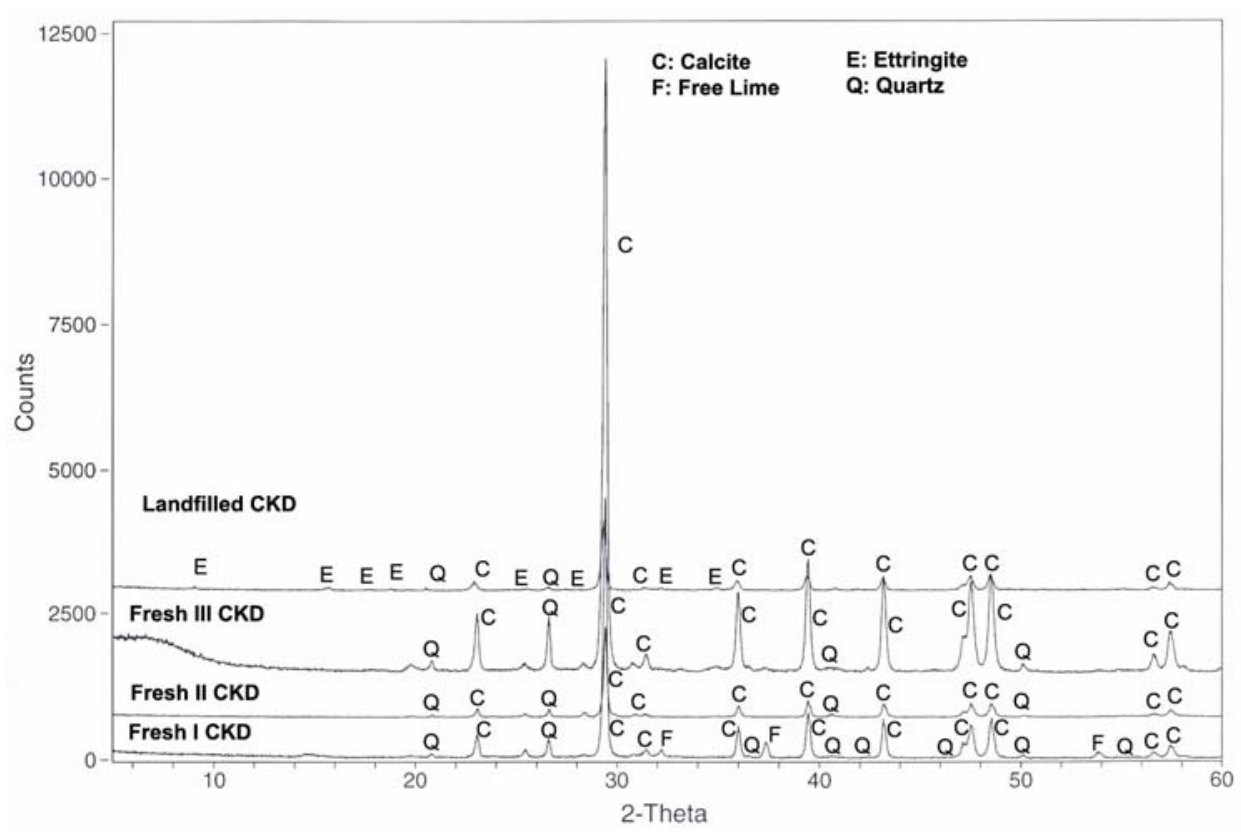

Figure 6-3 XRD pattern for fresh and landfilled CKD 


\subsubsection{Variation in Water Content, $\mathrm{pH}$ and LOI in Landfilled CKD}

While chemical and mineralogical analyses were limited to a small number of the field samples, measurements of the "natural water content", the $\mathrm{pH}$ and the LOI were performed on all tube samples immediately after the tubes were received in the Geotechnical Laboratory. These test results which were intended to provide some assessment of the variability of the landfilled CKD are presented in Figure 6-4.

The water content data show significant variation, from nearly $0 \%$ to about $65 \%$ for the deeper samples obtained from boring B3.

The values of the LOI are quite consistent for all the tube samples $(33.57 \pm 1.44)$, with no correlation with water content, and as discussed above, at the high end of those reported in the literature. Despite the long exposure to the atmosphere of the landfilled material, there is no significant difference in this parameter between the tube samples and the fresh CKD (LOI=33.62, 33.30 and 34.98 for fresh I, II and III, respectively).

The $\mathrm{pH}$ data also appears quite consistent (Average $=12.0 \pm 0.7$ ).
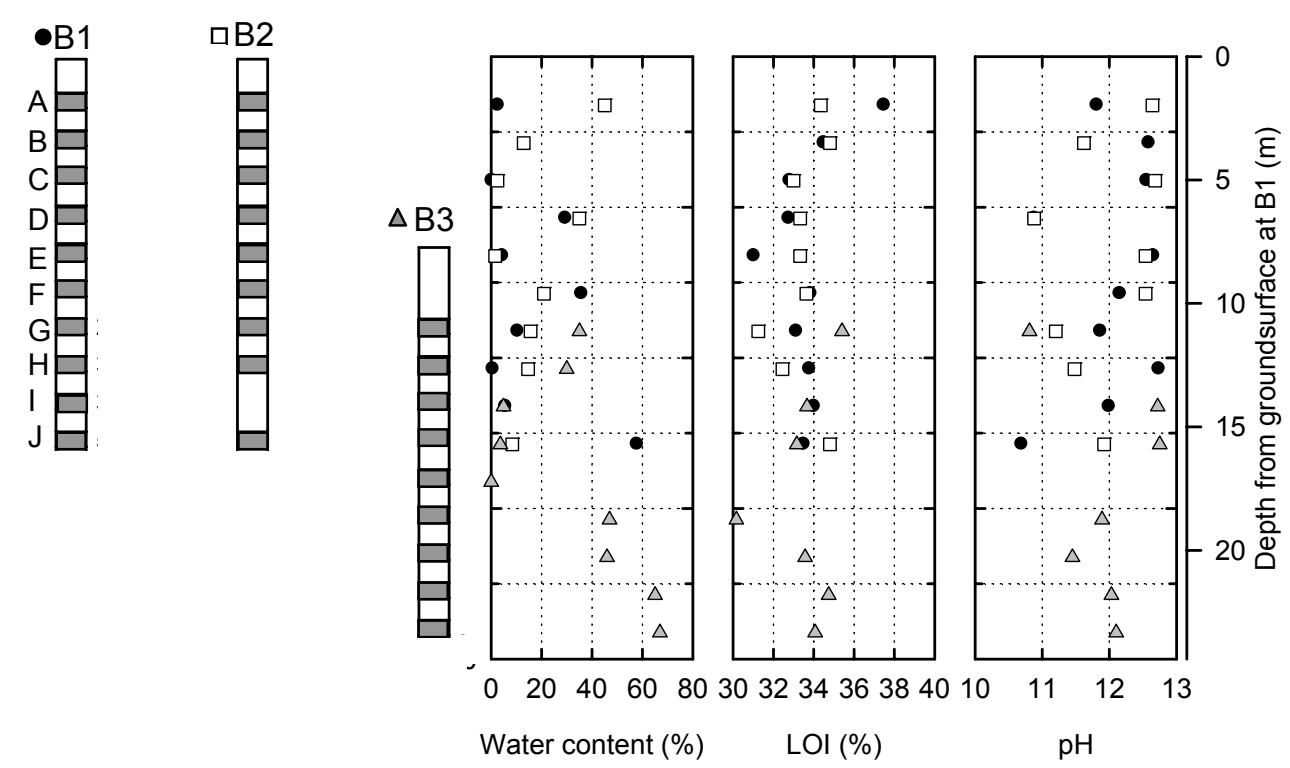

Figure 6-4 Location of borehole samples and results of water content, LOI and $\mathrm{pH}$ tests 


\subsubsection{Particle Size}

The particle size distribution of select samples (Figure 6-6) of the fresh and landfilled CKD were obtained employing the hydrometer test in water with sodium hexametaphosphate as a dispersing agent. Figure 6-5 shows the results obtained. Also shown is the range in particle size reported in the literature for other CKDs (see Chapter 3 section 3.3.1).

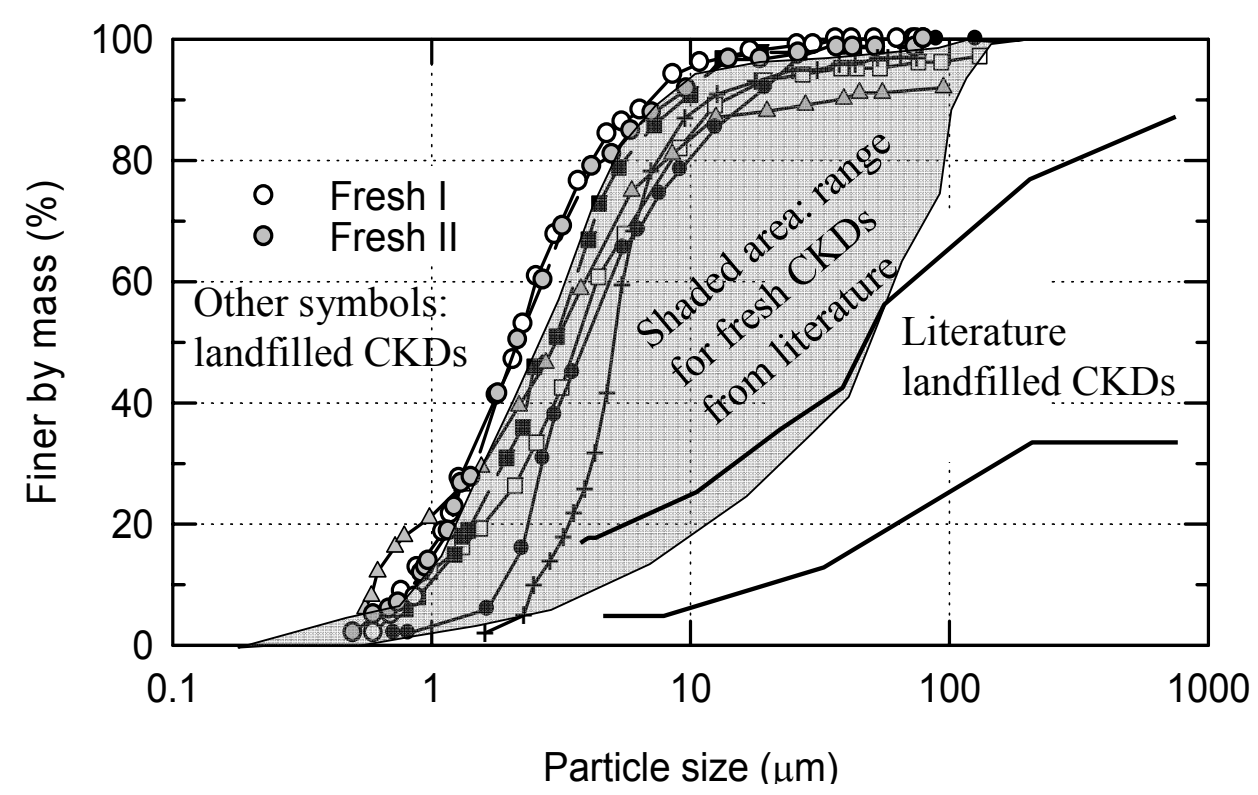

Figure 6-5 Particle size distribution of fresh and landfilled CKD

Figure 6-5 shows that the fresh material obtained from the Lehigh plant is characterized by a mean particle size of about $2 \mu \mathrm{m}$ and by $95 \%$ finer than $7 \mu \mathrm{m}$, making this CKD finer than any of those reported in the literature. The consistency in particle size distribution between fresh I CKD and fresh II CKD suggests that modifications to the plant did not affect the particle size. The results for the five tube samples of landfilled CKD tested show some sample to sample variability. While this material is somewhat coarser $\left(\mathrm{D}_{50} \sim 3-5 \mu \mathrm{m}\right)$ than the fresh CKD (this is an expected result which may derive from changes in microstructure occurring as a result of chemical reactions [e.g. 
hydration], or contamination from other materials, and has been reported for both stockpiled fly ash [McLaren and DiGioia, 1987] and another landfilled CKD [Collins and Emery, 1983]), overall all the data for the landfilled CKD fall at the low end of the range obtained from the literature.

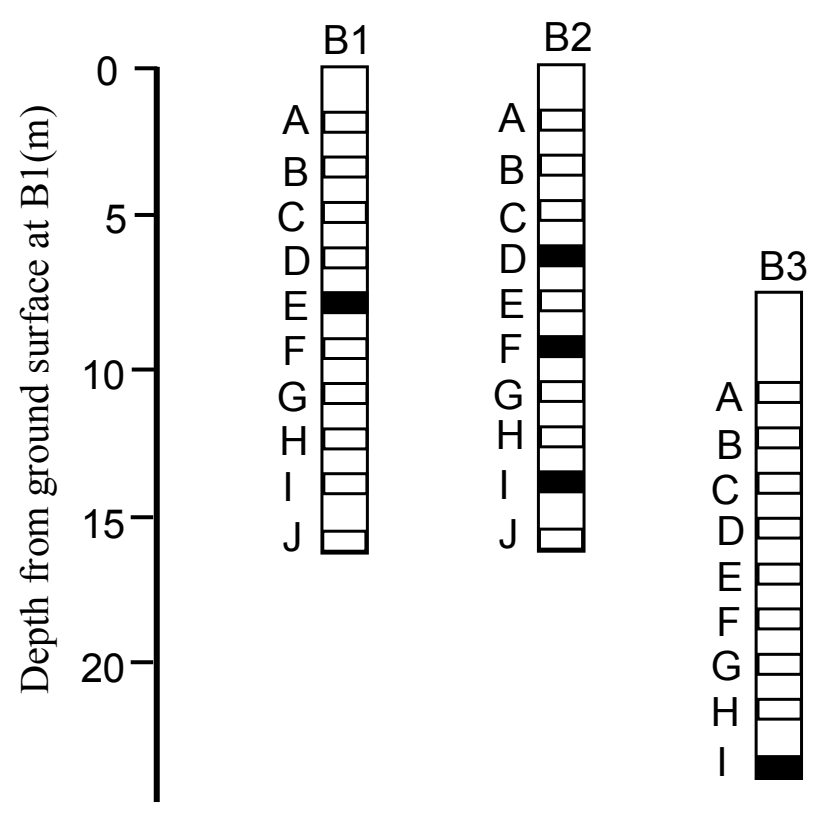

Figure 6-6 Tube samples used to determine particle size distributions shown in Figure 6-5 (shaded in black)

\subsubsection{Particle Morphology}

Insight into further differences between the fresh and the landfilled CKD was provided by examination of the micrographs obtained using a scanning electron microscope (SEM). Figure 6-7 shows the micrographs for particle and particle agglomerates for fresh II and landfilled CKD from the preliminary investigation on morphological studies conducted using a personal SEM. Figures 6-8 to 6-12 show the representative micrographs of the two CKDs (fresh III and landfilled CKD) from a detailed investigation performed with a more sophisticated FEI Nova-Nano SEM. For 
landfilled CKD observations were made on one sample obtained from each of the three borings (Figures 6-9 through Figure 6-11) as well as from CKD gathered at the landfill mining front (Figure 6-12).

The images indicate that there exist significant morphological differences between the two CKDs. Fresh CKD particles are irregularly shaped and have a fairly smooth surface. The landfilled material, on the other hand, shows clear evidence of chemical alteration resulting from extended exposure to the environment. The presence of reaction products, some in the form of elongated crystals, and a more networked structure markedly distinguish it from the fresh material. Consistently with the results of the XRD analysis, ettringite and calcite crystals are observed in the landfilled material.

It is to be noted that microanalysis using EDX (Energy Dispersive X-Ray) was not performed on the particles to identify the chemical composition. An in-depth SEM examination with EDX application is necessary for the identification of the minerals present in the landfilled CKD. 

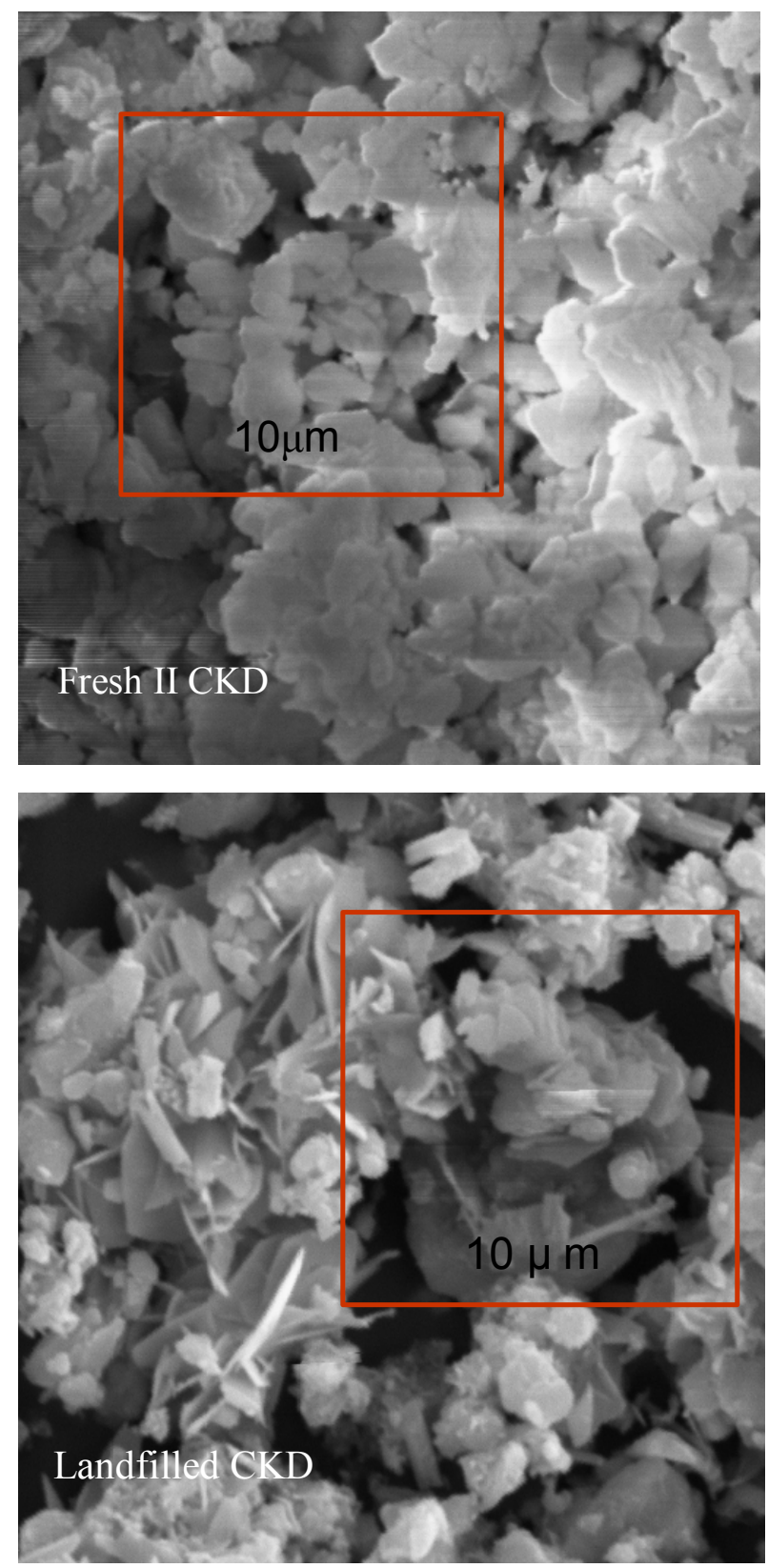

Figure 6-7 SEM micrographs of fresh II and landfilled CKD 

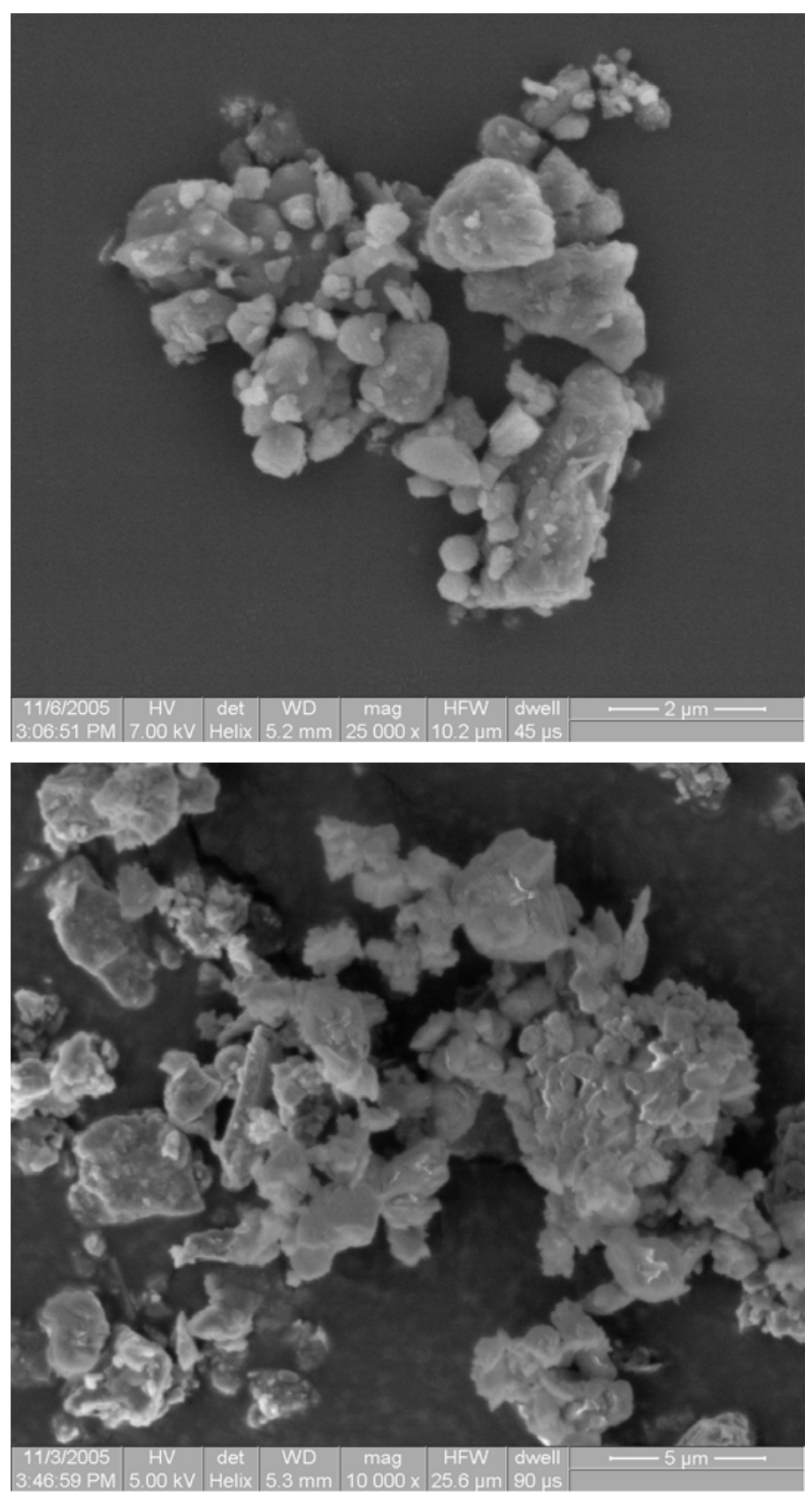

Figure 6-8 SEM micrographs of fresh III CKD 

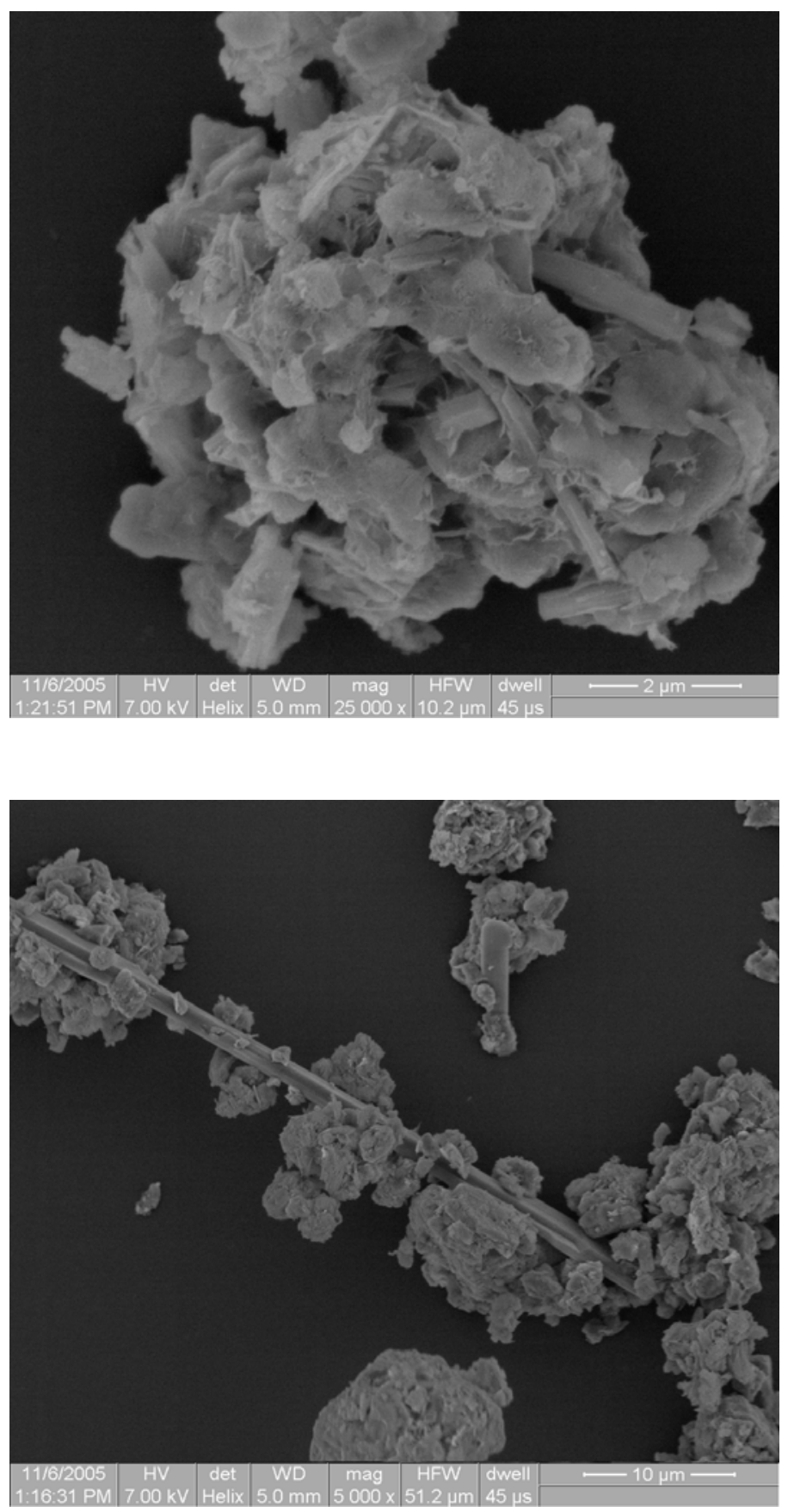

Figure 6-9 SEM micrographs of sample G from boring B1 

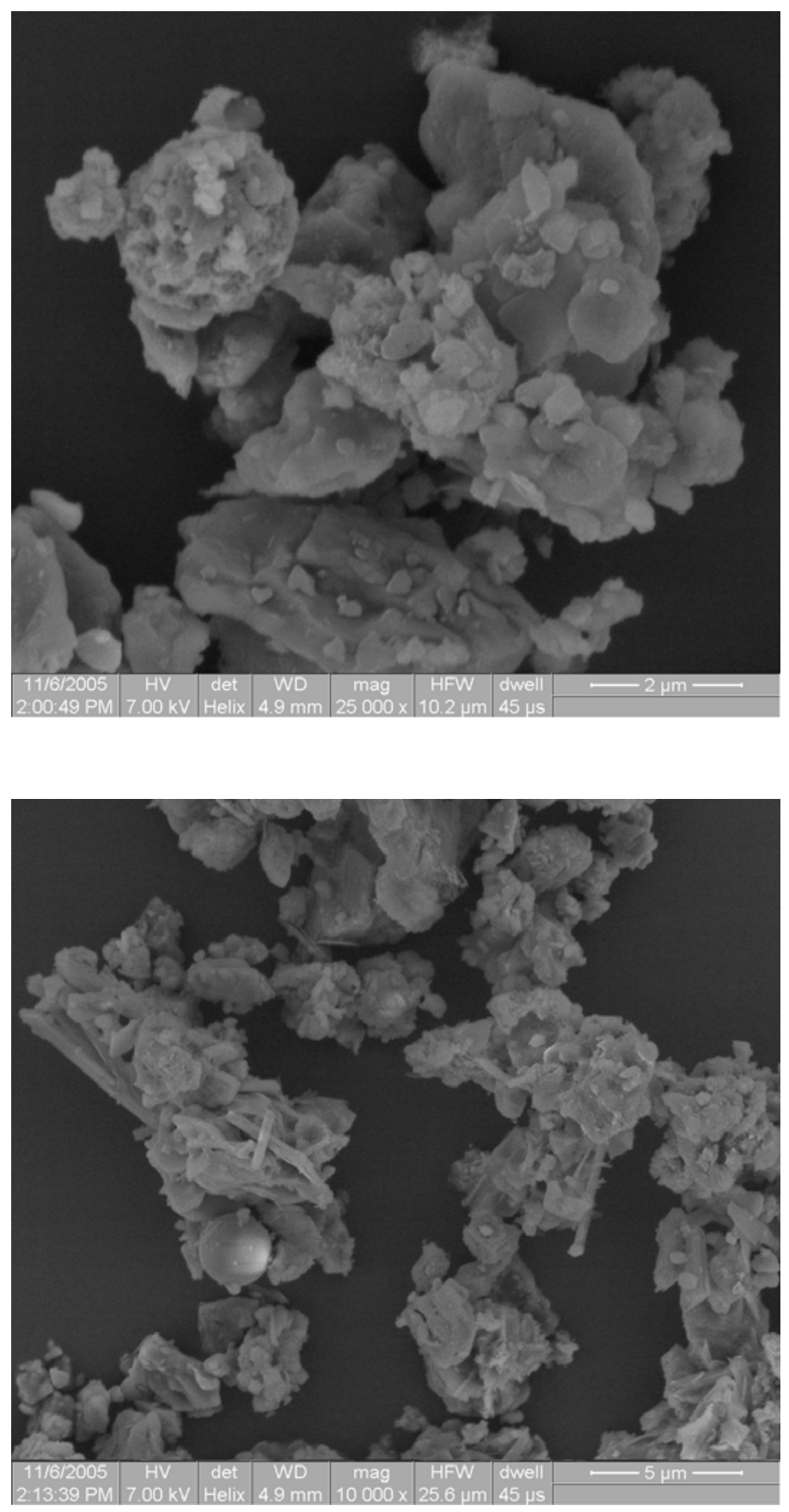

Figure 6-10 SEM micrographs of sample F from boring B2 

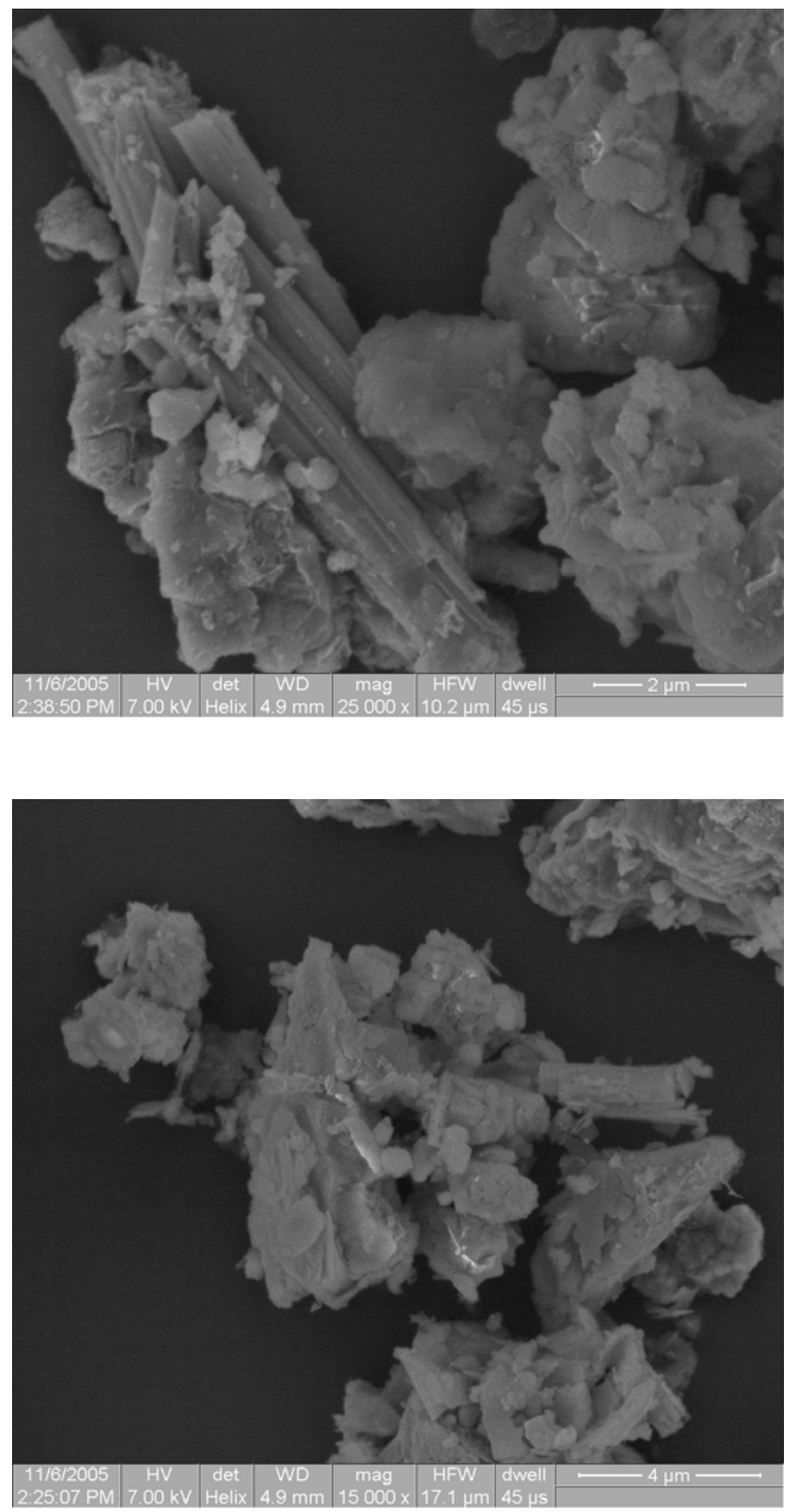

Figure 6-11 SEM micrographs of sample B from boring B3 

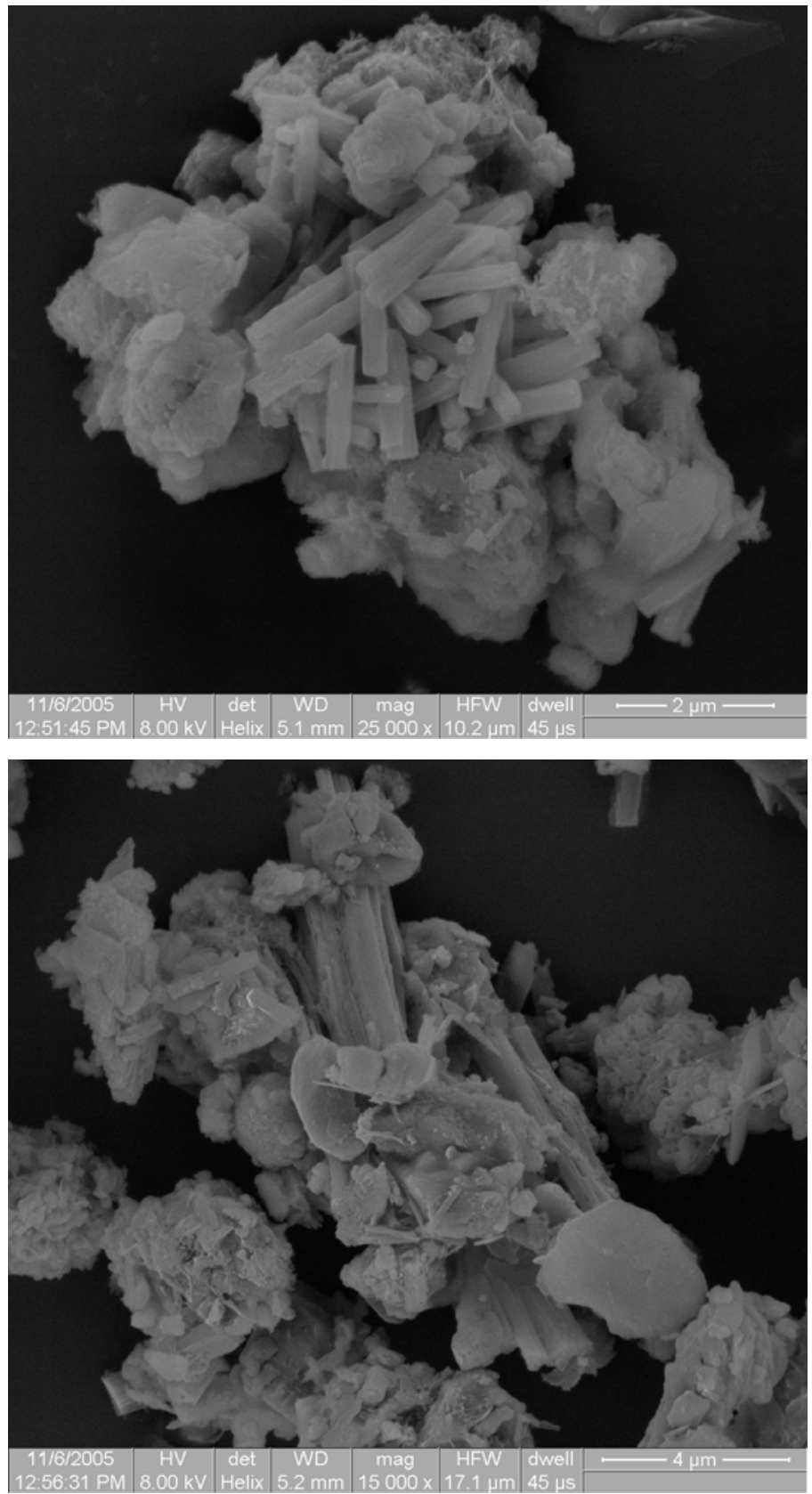

Figure 6-12 SEM micrographs of landfilled CKD 


\subsubsection{Specific Gravity}

Specific gravity measurements were conducted on all fresh samples as well as on the landfilled CKD. The average specific gravity of fresh CKD is 2.68 and that of landfilled CKD is 2.61. The relatively low specific gravity of landfilled CKD could be due to agglomeration of the CKD particles and its networked structure. This particle morphology would have aided the entrapment of air within the particle agglomerates. The low specific gravity could also be due to the characteristics of reaction products present in the landfilled CKD.

\subsubsection{Specific Surface Area}

The specific surface area of landfilled and fresh III CKD was measured by the Blaine air permeability method and the BET nitrogen adsorption method. Table 6-4 summarizes the test results. For comparison purposes, the table also includes the specific surface area for Type I portland cement (Neville, 1996; Ramachandran and Beaudoin, 2001) and fly ash (Malhotra and Ramezanianpour, 1994). The last column in the table shows the ratio of specific surface area measured by BET to Blaine method.

Table 6-4 Specific surface area of fresh and landfilled CKD

\begin{tabular}{lccc}
\cline { 2 - 3 } & \multicolumn{2}{c}{ Specific surface area $\left(\mathbf{c m}^{2} / \mathbf{g}\right)$} & \\
\cline { 2 - 3 } Material & $\mathbf{( 1 )}$ & $\mathbf{( 2 )}$ & $(\mathbf{1}) /(\mathbf{2})$ \\
\hline \hline Fresh III & 39,700 & 14,020 & 2.83 \\
Landfilled & 117,600 & 17,000 & 6.92 \\
Type I PC & 7,900 & $3,000-4,000$ & 2.50 \\
\hline Fly Ash & $4,800-89,000$ & $1,930-6,710$ & $2.3-24.3$ \\
\hline
\end{tabular}

The results in Table 6-4 show that the specific surface area of the landfilled CKD measured by both methods is higher than that of the fresh CKD. This is likely a result of 
the morphological differences described in section 6.3.1.4. The specific surface area depends on the particle shape, particle size and also on any imperfections or flaws present at the particle surface (Ramachandran and Beaudoin, 2001. As observed for other materials (e.g., see data for nine different fly ashes in Table 6-5), the specific surface area of CKDs measured by $\mathrm{N}_{2}$-adsorption is higher than that measured by the air-permeability method. The last column in Table 6-5 indicates the large difference in the specific surface areas measured by the two methods.

For both the fresh and the landfilled material the Blaine fineness is not only consistently greater than typical values for ordinary portland cement $\left(\sim 3000-5000 \mathrm{~cm}^{2} / \mathrm{g}\right)$, but also at the high end of values reported in the literature for other CKDs (2300 to $14000 \mathrm{~cm}^{2} / \mathrm{g}$ - see section 3.3.2 in Chapter 3 for more detail). This suggests that in the case of CKD, particle texture and morphology may play a significant role. The high fineness of CKD is likely to have bearing on the water susceptibility of the CKDs.

Table 6-5 Specific surface area of nine fly ashes (Malhotra and Ramezanianpour, 1994)

\begin{tabular}{cccc}
\cline { 2 - 3 } & \multicolumn{2}{c}{ Specific surface area $\left(\mathbf{c m}^{\mathbf{2}} / \mathbf{g}\right)$} & \\
\cline { 2 - 3 } Fly ash & $\mathbf{( 1 )}$ & $\mathbf{( 2 )}$ & $\mathbf{( 1 ) / ( 2 )}$ \\
\hline \hline A & BET & Blaine & 13.34 \\
B & 40,700 & 3,050 & 9.25 \\
C & 38,200 & 4,130 & 3.04 \\
D & 10,200 & 3,350 & 2.30 \\
E & 4,800 & 2,090 & 24.35 \\
F & 47,000 & 1,930 & 13.26 \\
G & 89,000 & 6,710 & 20.90 \\
H & 65,000 & 3,110 & 4.31 \\
I & 12,400 & 2,880 & 3.82 \\
\hline
\end{tabular}




\subsubsection{Physio - Chemical Test: Conclusions}

The following are the main conclusions drawn from this portion of the study:

- The oxide composition of fresh and landfilled CKD is consistent with the primary difference being the availability of free lime. The LOI values of all CKDs are at the high end of the values reported in the literature whereas the free lime is at the lower end. The main components of fresh CKD and landfilled CKD are calcite and silica.

- The chemical composition of all CKDs falls within the range of data reported in the literature.

- A distinct characteristic of both CKDs is the small particle size (80-95\% finer than $10 \mu \mathrm{m})$ at the low end of data available for other CKDs.

- $\quad$ All CKDs are alkaline with high $\mathrm{pH}$ values (11.5-12.5).

- Despite the similarity in size, the particle morphology of the two CKDs differs greatly due to the presence of reaction products in the case of the landfilled CKD. The fresh CKD particles are irregularly shaped and have a fairly smooth surface while the landfilled CKD shows clear evidence of reaction products.

- The specific surface area of the landfilled CKD is higher than that of the fresh CKD based on measurements conducted using both the $\mathrm{N}_{2}$ - sorption and the airpermeability method.

- Implementation of new process technology significantly affected the quality of the fresh CKD produced.

- The difference between fresh I and fresh III CKD highlights the changes to the chemical makeup of a CKD that can come about from modifications in the processing technology of the cement plant. This difference would not have been perceived based on comparison of the LOI, the oxide composition, and the particle size distribution, as these characteristics remained essentially unchanged. This highlights the importance of knowing the chemical composition of each batch of material collected and the plant operation history and the cement plant before widespread use of a CKD. 


\subsubsection{Mechanical and Engineering Properties}

\subsubsection{Binding Properties}

Figure 6-13 and Table 6-6 present the average compressive strength measured on cube samples of pastes made from fresh I and portland cement. The data indicate that, while both sets of values display a similar trend of increasing strength with curing time, at all curing times the compressive strength of the portland cement paste is greater by 8 to 50 times than that of the pastes prepared with CKD at the same water to binder ratio of 0.5. Compressive strength measurements on CKD pastes manufactured with other fresh CKDs and landfilled CKD show no development of strength and the samples were not dimensionally stable (Figure 6-14). As observed from the oxide composition and X-Ray diffraction, the major difference between fresh I CKD and other CKDs is the free lime content, which is the major source of reactivity.

Table 6-6 Compressive strength (in MPa) of pastes of fresh I CKD and cement

\begin{tabular}{|c|c|c|c|c|c|c|}
\hline & 1 day & 3 days & 7 days & 3 days & 28 days & 56 days \\
\hline \multirow{3}{*}{$\begin{array}{c}\text { CKD } \\
\text { w/c }=0.5\end{array}$} & $0.31 \pm 0.02$ & $0.33 \pm 0.02$ & $0.61 \pm 0.1$ & $0.89 \pm 0.12$ & $1.16 \pm 0.16$ & 1.48 \\
\hline & $(\mathrm{n}=3)$ & $(\mathrm{n}=3)$ & $(\mathrm{n}=3)$ & $(\mathrm{n}=4)$ & $(\mathrm{n}=4)$ & $(\mathrm{n}=1)$ \\
\hline & $\mathrm{COV}=6.3 \%$ & $\mathrm{COV}=5.1 \%$ & $\mathrm{COV}=15.6 \%$ & $\mathrm{COV}=13.5 \%$ & $\mathrm{COV}=13.6 \%$ & - \\
\hline \multirow{3}{*}{$\begin{array}{c}\mathrm{PC} \\
\mathrm{w} / \mathrm{c}=0.5\end{array}$} & $2.55 \pm 0.09$ & $16.3 \pm 0.27$ & $23.2 \pm 1.70$ & $33.6 \pm 3.16$ & $41.0 \pm 6.53$ & $54.5 \pm 7.08$ \\
\hline & $(\mathrm{n}=3)$ & $(\mathrm{n}=3)$ & $(\mathrm{n}=3)$ & $(\mathrm{n}=3)$ & $(\mathrm{n}=3)$ & $(\mathrm{n}=2)$ \\
\hline & $\mathrm{COV}=3.6 \%$ & $\mathrm{COV}=1.7 \%$ & $\mathrm{COV}=7.3 \%$ & $\mathrm{COV}=9.4 \%$ & $\mathrm{COV}=15.9 \%$ & $\mathrm{COV}=13.0 \%$ \\
\hline
\end{tabular}



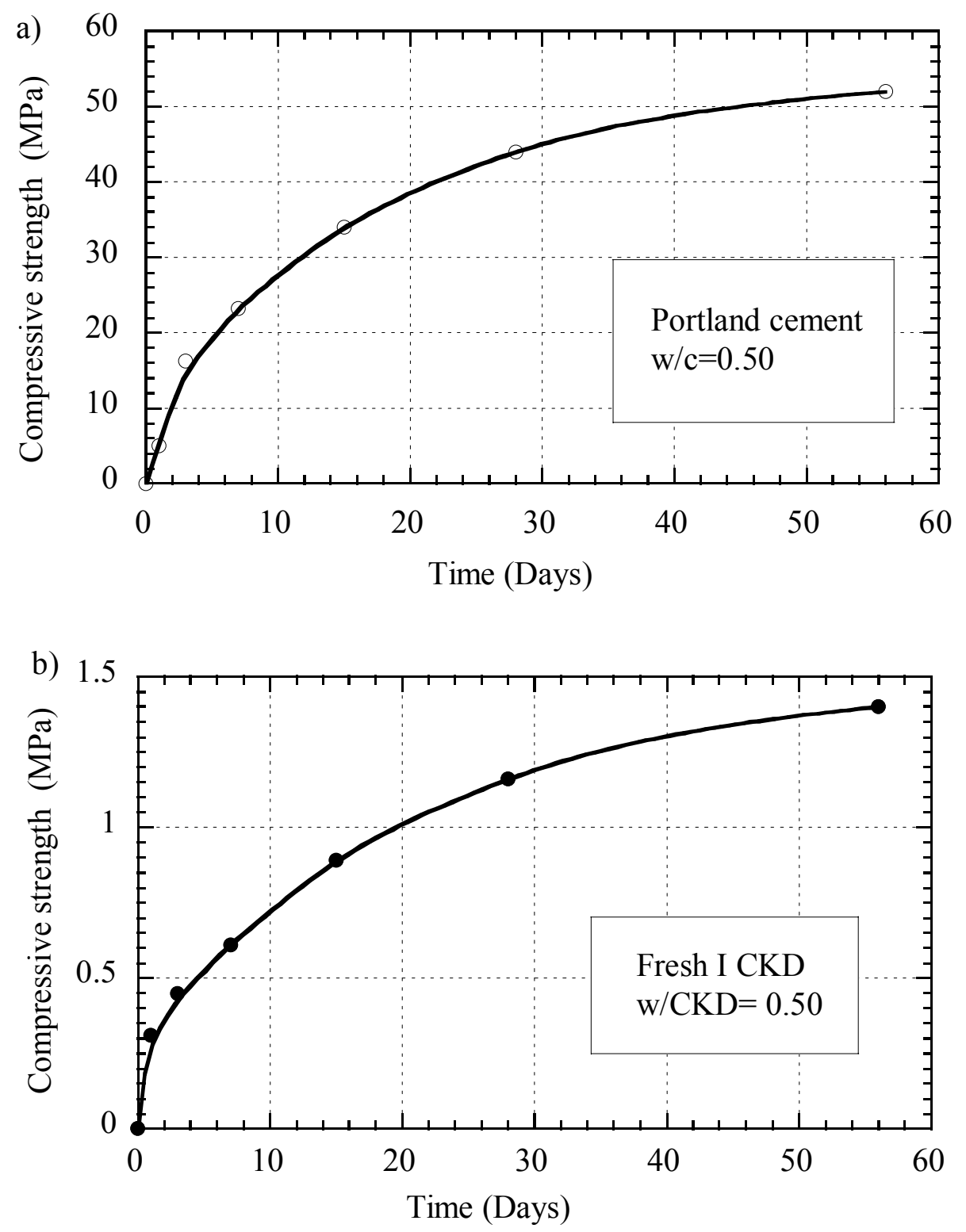

Figure 6-13 Average compressive strength of (a) cement and (b) CKD pastes 


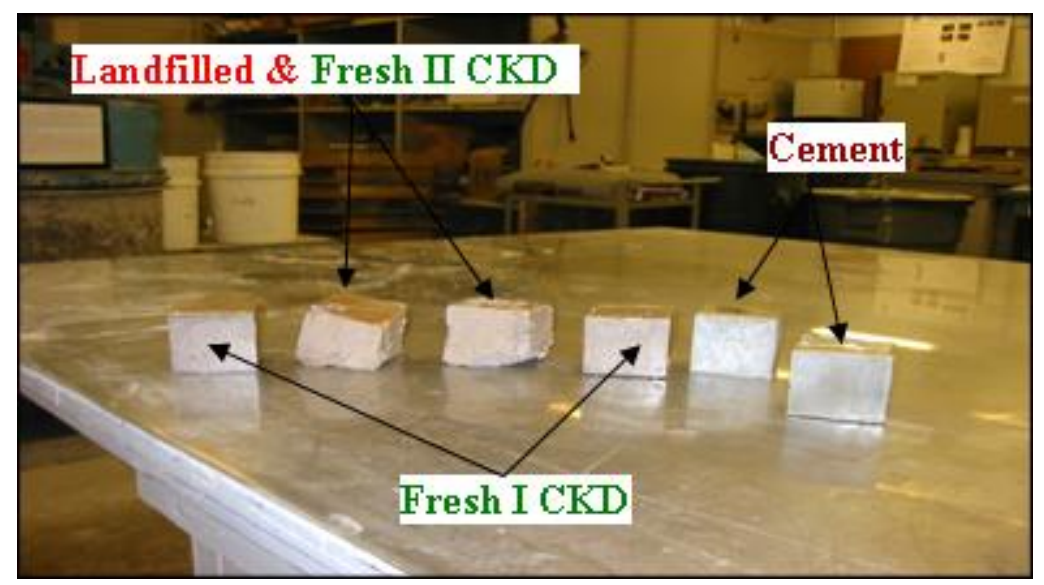

Figure 6-14 Dimensional stability of cube samples made from different CKDs

\subsubsection{Bleeding}

The results of bleeding measurements on water-CKD mixtures prepared at different water-CKD ratios are shown in Figure 6-15. As a result of the high fineness, for water-CKD ratios less than 0.75 both the fresh and the landfilled $\mathrm{CKD}$ showed no significance bleeding. At greater water-CKD ratios, the bleeding of the mixtures prepared with the landfilled CKD was consistently higher than that of fresh CKD. The relatively higher bleeding of landfilled CKD is in consistent with its larger particle size and also the presence of agglomerated particles present in the landfilled CKD. The scanning electron micrographs show evidence of particle cementation. The small lumps of CKD aggregate are present in landfilled CKD which have formed over the years. These aggregate might not have been thoroughly dispersed during mixing. 


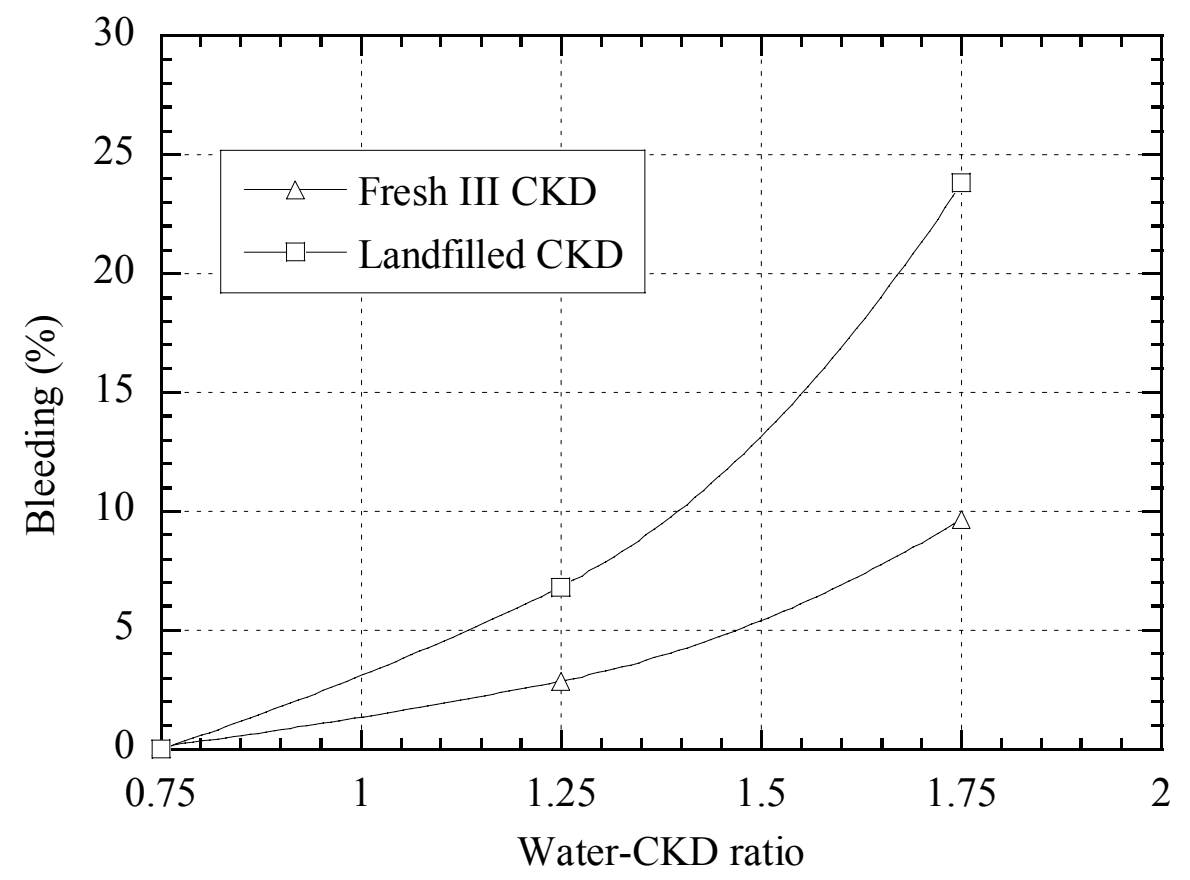

Figure 6-15 Bleed of water-CKD mixtures

\subsubsection{Moisture Density Relationship}

Compaction tests were conducted on the CKDs using the standard Proctor method. As discussed in section 5.2.2.2 in Chapter 5, tests were carried out both immediately after mixing the CKD with water, as well as after overnight mellowing of the CKD-water mixture. The mellowing was performed by keeping the CKD - water mixture in a thick zip-lock bag in the humid room $\left(\mathrm{T}=10^{\circ} \mathrm{C}\right.$ and $\left.\mathrm{RH}=98 \%\right)$.

Figure 6-16 summarizes the results of the laboratory compaction tests for both fresh and landfilled CKD. The figure show that the CKDs investigated respond to compaction in a manner similar to that observed for most fine grained soil, i.e. the dry density increases with water content up to a maximum and then decreases with further increase in water content. In the case of fresh $\mathrm{CKD}$, the compacted densities are lower and moisture requirement are considerably higher than those of a conventional low plasticity soil. 


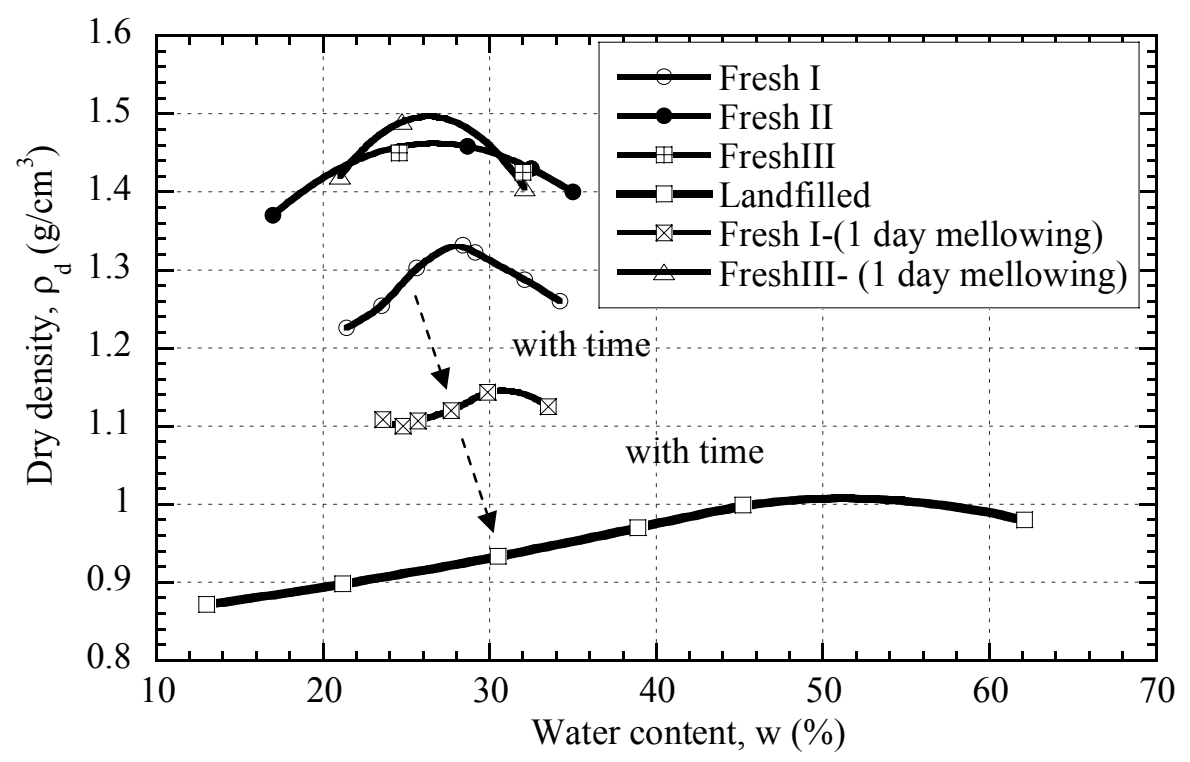

Figure 6-16 Moisture density relations of fresh and landfilled CKDs

Starting with the compaction behavior of fresh II and III CKDs it can be seen that these two materials show almost identical moisture density relationships (only two points tests were performed for fresh III CKD as the test results were consistent with those for fresh II CKD). This is expected as fresh II and fresh III are samples of essentially the same material obtained at two different times. Figure 6-16 also shows that mellowing has negligible impact on the compaction behavior of fresh III CKD. This is further evidence of the limited reactivity of this material.

In-spite of the fact that all fresh samples showed similar physical properties, the curve for fresh I CKD compacted immediately after being mixed with water falls significantly below those for the other fresh samples $\left(\rho_{\mathrm{dmax}} \sim 1.32 \mathrm{~g} / \mathrm{cm}^{3}\right.$ versus $1.46-1.5$ $\mathrm{g} / \mathrm{cm}^{3}$ for fresh II and fresh III). A marginal increase in the OMC is also observed (OMC $28 \%$ for fresh I and 26\% for fresh II and III). This shift in the compaction curve is likely a result of the greater reactivity of fresh I CKD: upon exposure to water the CKD reacts forming "aggregates" of greater dimension, and as a result the density to which the CKD can be compacted decreases. This hypothesis is supported by the fact that overnight mellowing causes a further and significant shift in the compaction curve. In addition, 
water content measurements taken after over night mellowing in the humid room were found to be 1-2 percentage points smaller than the values measured immediately after mixing. This "consumption" of free water is further evidence of the reactivity of this material.

The OMC and dry densities of all fresh CKDs are within the range of values reported in the literature (see for example data by Todres et al. (1992) presented in Chapter 3, which show OMC values between 19 and 28\% and maximum dry densities in the $1.35-1.52 \mathrm{~g} / \mathrm{cm}^{3}$ range). Both the data collected in this research, as well as the results presented in the literature indicate that $\mathrm{CKD}$ can be compacted to a higher dry density than fly ash. For example for fly ash, Gray and Lin (1972) report values of $\rho_{\mathrm{dmax}} \sim 1.12$ to $1.28 \mathrm{~g} / \mathrm{cm}^{3}$; and an extensive investigation of 110 samples of class $\mathrm{F}$ fly ash reported by McLaren (1987) showed average values of $\rho_{\mathrm{dmax}}$ and OMC, equal to $1.34 \mathrm{~g} / \mathrm{cm}^{3}$ and $25.3 \%$, respectively.

There is a significant difference in the compaction behavior of fresh and landfilled CKD. Under the application of the same compactive energy, the fresh CKD can be compacted to a density over $40 \%$ higher than that of the landfilled material. The compaction behavior of landfilled CKD is characterized by a broader bell curve with much lower maximum dry density $\left(\sim 1.0 \mathrm{~g} / \mathrm{cm}^{3}\right)$ and high water content at optimum (OMC $51 \%$ ). The comparison to the curve for fresh I CKD is particularly significant as this CKD is likely to be more representative of the material disposed of in the landfill. With respect to fresh I CKD, landfilled CKD displays a reduction of more than $30 \%$ in maximum dry density and an increase in over 20 percentage points in the OMC. This significant difference in behavior appears to be a reflection of the reactivity of the parent material, and is consistent with the observed effect of mellowing on the compaction behavior of fresh I CKD. A similar trend in compaction behavior was reported for fresh and ponded fly ash (Gray, 1972).

From the above discussion on the compaction behavior of different CKDs, it is evident that moisture density relations of CKD are largely governed by the morphology (given the similarity in particle size distribution) and free lime content or reactivity of the CKD. In the case of the landfilled CKD the presence of elongated fibers and of other 
reaction products and the altered particle morphology appears to offer greater resistance to reorientation and packing of the particles, resulting in an increased porosity of the compacted material (Sreekrishnavilasam and Santagata, 2006). It is also reasonably evident that in the case of reactive CKDs, the mellowing of samples before compaction and aging or weathering of sample has significant bearing on its compaction behavior. Further investigations are required to identify the long-term performance of compacted fills made with reactive CKDs.

\subsubsection{Unconfined Compressive Strength}

Typical stress strain curves obtained from unconfined compression tests performed on specimens of fresh III and landfilled CKD compacted using the Harvard miniature apparatus at different water contents are shown in Figure 6-17. While the strength of fresh CKD drops off sharply at water contents on the wet side of optimum (compare the curves for $\mathrm{w}=22.4 \%$ and $27.1 \%$ ), the landfilled $\mathrm{CKD}$ is observed to be much less sensitive to water content changes. In addition, as shown in Figure 6-18, the strength of fresh CKD is found to be significantly affected by the compaction energy. This effect is observed to be less significant for the landfilled CKD.

Overall the values of strength measured are consistent with data reported in the literature for compacted class F - fly ash (e.g., Gray et al. (1972) reported strength value of 110 - $405 \mathrm{kPa}$ for class F - fly ash compacted at OMC (17-32\%) using the standard Proctor procedure). 


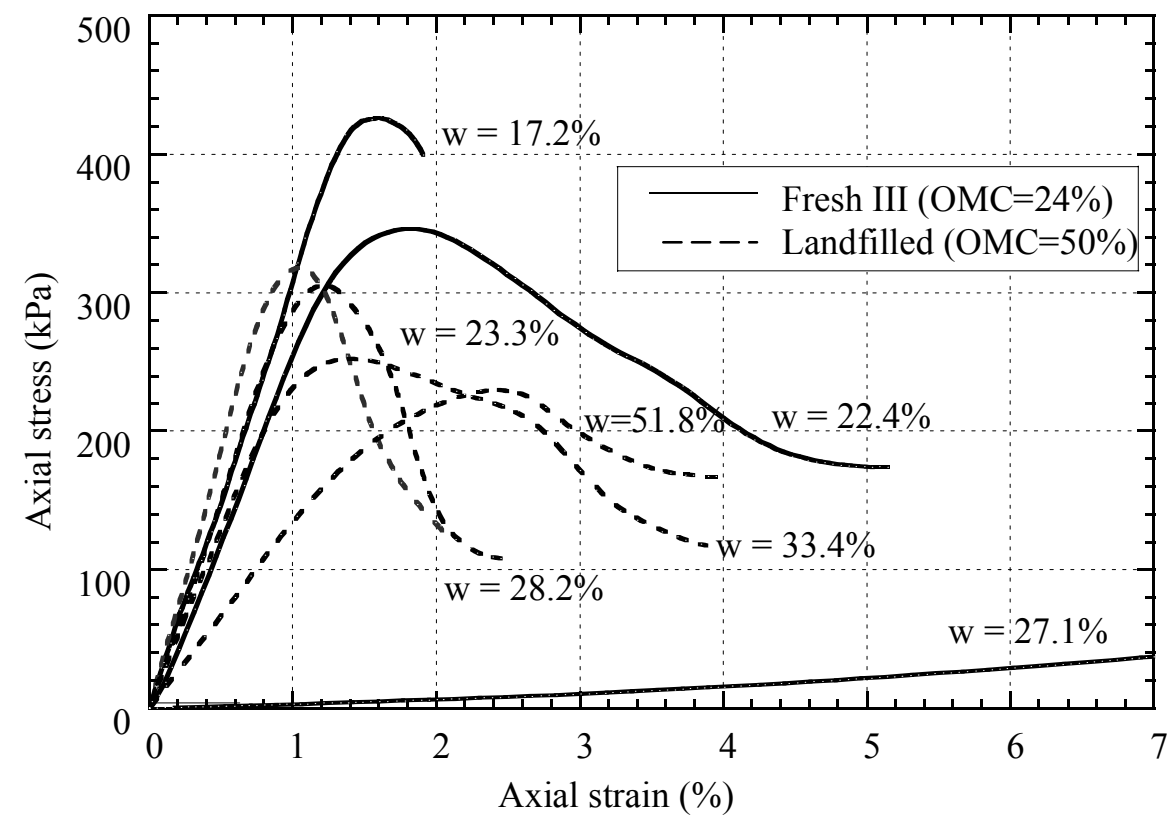

Figure 6-17 Stress strain behavior of fresh and landfilled CKD in unconfined compression

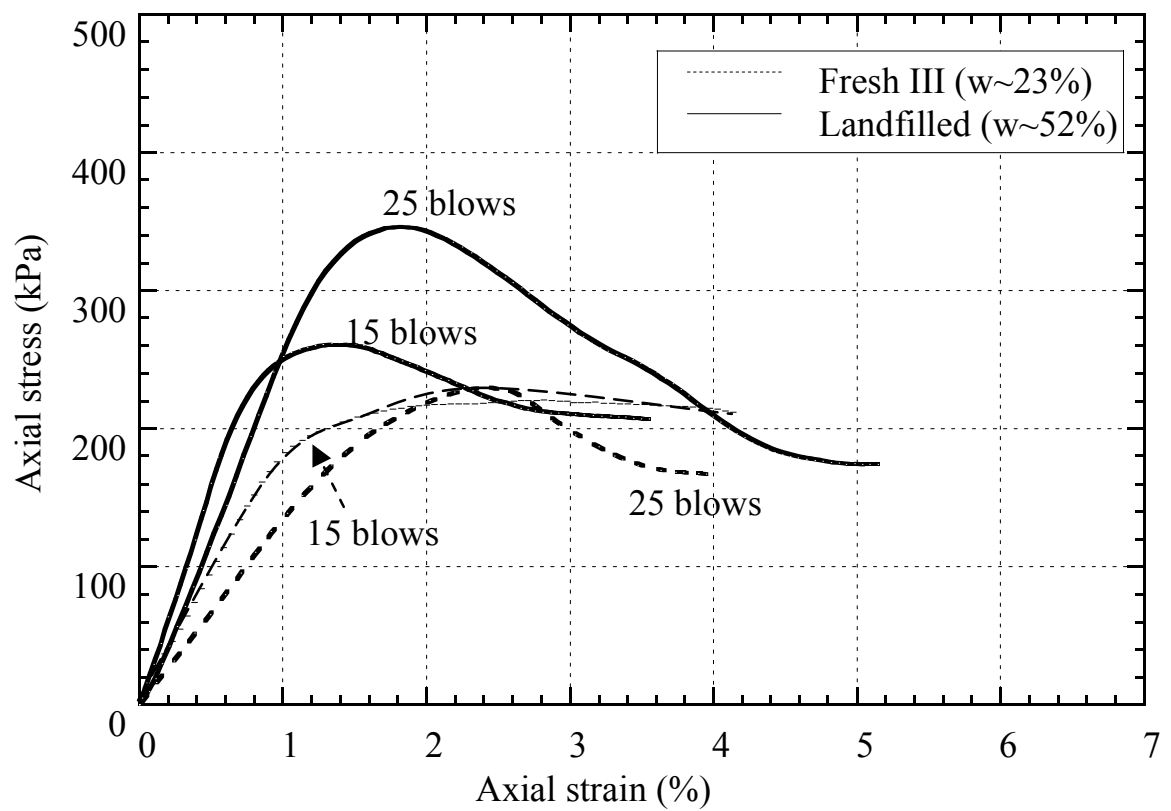

Figure 6-18 Effect of compaction energy on the strength of fresh and landfilled CKD 


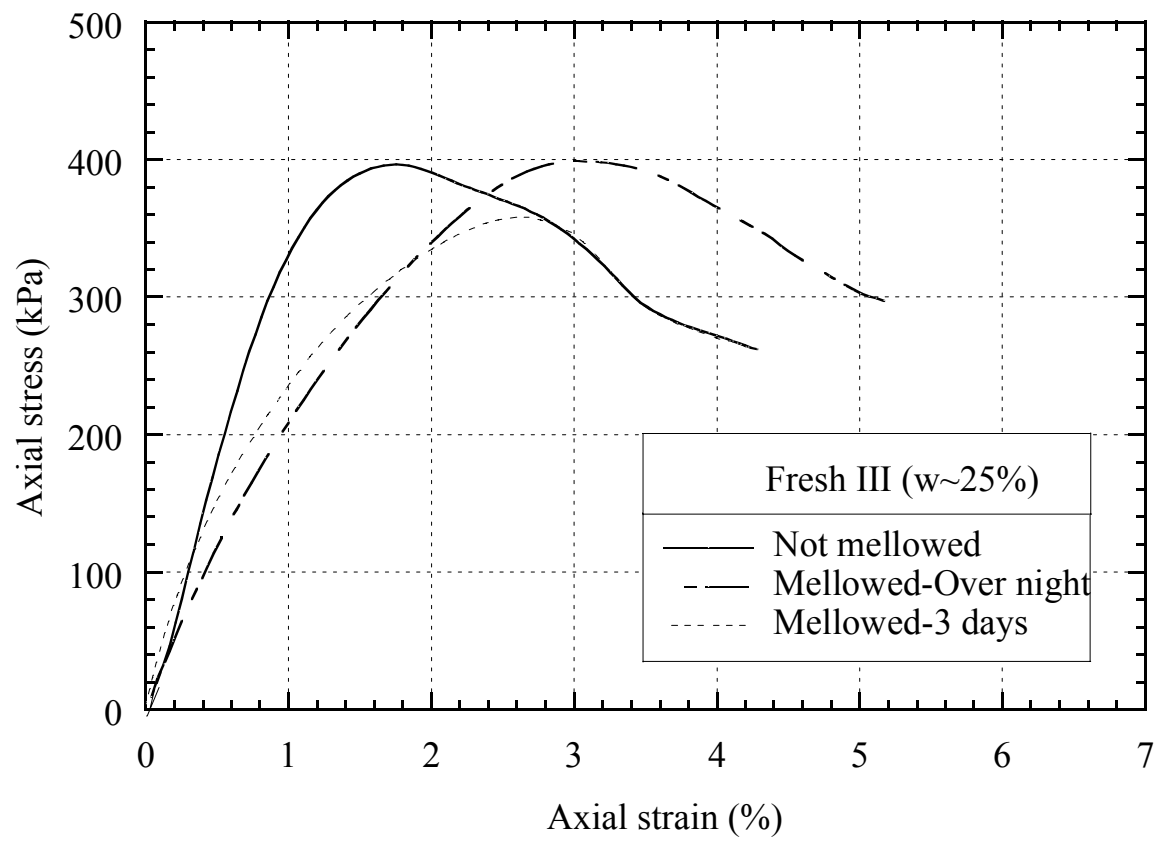

Figure 6-19 Effect of mellowing on the unconfined behavior of compacted fresh III CKD (standard Proctor compacted samples)

In the previous section on moisture-density relations of $\mathrm{CKD}$, it was observed that overnight mellwoing has no effect on the compaction behavior of fresh III CKD. As expected, no significant difference in strength is found between specimens prepared from mellowed and non-mellowed CKD-water mixture. This is shown in Figure 6-19, in which the stress strain curves for unconfined compression tests performed on fresh III CKD compacted after being tempered overnight and for three days are compared to the data for CKD compacted immediately after being mixed with water. Note that while all other unconfined strength data presented above were obtained from triaxial size $(\mathrm{H}=3.0$ ", $\mathrm{D}=1.5$ ") specimens obtained compacting the CKD with the Harvard miniature apparatus, the data in Figure 6-18 pertain to tests on specimens compacted in the Proctor mold $(\mathrm{D}=4.0 ", \mathrm{H}=4.5$ "). Given the geometry of the Proctor specimens (which does not meet the $2 / 1 \mathrm{H} / \mathrm{D}$ ratio) the values reported should be viewed as strength indexes, rather than as a true measure of the actual compressive strength of the compacted CKD. 


\subsubsection{Permeability and Drainage}

The hydraulic conductivity of both fresh and landfilled CKD was measured on samples compacted using the Proctor apparatus in a fixed wall permeameter having the same dimensions of a standard Proctor mold. As discussed in Chapter 5, the specimens were first saturated by flushing water through the specimen with a constant upward gradient, and then measurements of the hydraulic conductivity were conducted by both the constant head method and the falling head method. The results obtained from these tests on fresh III and landfilled CKD are presented in Table 6-7. The table presents the initial conditions of the compacted specimensas well as the permeability values measured by both the constant head and the falling head methods. For fresh III CKD the hydraulic conductivity values fall in the range of $1.4-1.6 \times 10^{-8} \mathrm{~m} / \mathrm{s}$. The $\mathrm{k}$ of the landfilled CKD $\left(0.99-1.82 \times 10^{-7} \mathrm{~m} / \mathrm{s}\right)$ is almost tenfold greater than that of the fresh CKD, most likely as a result of the lower dry densities of the compacted landfilled CKD. These values of $\mathrm{k}$ correspond to drainage characteristics that in soils would be defined as practically impervious to low permeability (Table 6-8). Hydraulic conductivity measurements were conducted over several days without observing any significant variation of the measured values. This is again consistent with the negligible cementing properties of this material.

Todres et al. (1992) conducted permeability tests on three different compacted CKD samples with free lime contents varying from 0.5 to $27 \%$ (see Table $3-10$ ) and reported a similar range in permeability for medium compaction energy. They also reported a decrease in permeability with time.

Table 6-7 shows that values of $\mathrm{k}$ measured on specimens compacted at water content ranging from $39 \%$ to $50 \%$ fall in a fairly narrow range $\left(0.99-1.55 \times 10^{-7} \mathrm{~m} / \mathrm{s}\right)$, i.e. as seen for the strength, the hydraulic conductivity of landfilled CKD is not particularly sensitive to compaction water content. While measurements were not conducted on samples compacted with different energies, given the results from the strength tests, it may be anticipated that the hydraulic conductivity of this CKD may also be fairly insensitive to compaction energy. 
Table 6-7 Permeability values of fresh and landfilled CKD

\begin{tabular}{lcccccc}
\hline \multicolumn{1}{c}{ CKD } & \multicolumn{3}{c}{ Initial specimen conditions } & \multicolumn{2}{c}{ Permeability k (m/s) } \\
\hline \hline & $\begin{array}{c}\text { Water } \\
\text { content density( } \\
\text { w (\%) }\end{array}$ & $\begin{array}{c}\text { Dry } \\
\text { g/cc) }\end{array}$ & $\begin{array}{c}\text { Void } \\
\text { ratio }\end{array}$ & $\begin{array}{c}\text { Degree of } \\
\text { saturation } \\
(\%)\end{array}$ & $\begin{array}{c}\text { Constant } \\
\text { head } \\
\text { method }\end{array}$ & $\begin{array}{c}\text { Falling } \\
\text { head } \\
\text { method }\end{array}$ \\
\cline { 2 - 7 } & 24.3 & 1.39 & 0.936 & 70.2 & $1.59 \times 10^{-8}$ & $1.40 \times 10^{-8}$ \\
$\begin{array}{l}\text { Fresh III } \\
\text { (OMC=23\%) }\end{array}$ & 48.0 & 0.95 & 1.790 & 69.1 & $0.99 \times 10^{-7}$ & $1.10 \times 10^{-7}$ \\
\hline $\begin{array}{l}\text { Landfilled } \\
(\text { OMC=51\%) }\end{array}$ & 43.3 & 0.92 & 1.883 & 59.5 & $1.12 \times 10^{-7}$ & $1.31 \times 10^{-7}$ \\
& 38.9 & 0.92 & 1.880 & 53.8 & $1.28 \times 10^{-7}$ & $1.82 \times 10^{-7}$ \\
\hline
\end{tabular}

Table 6-8 Range in permeability values for soils (Mitchell, 1993)

\begin{tabular}{cccc}
\hline Soil & Permeability & Soil type & k (m/s) \\
\hline \hline \multirow{2}{*}{ Free draining soils } & high & gravels & $>10^{-3}$ \\
& high & sands & $10^{-3}-10^{-5}$ \\
& low & silts and clays & $10^{-5}-10^{-7}$ \\
Impervious soil & very low & clays & $10^{-7}-10^{-9}$ \\
& practically impervious & clays & $<10^{-9}$ \\
\hline
\end{tabular}

\subsubsection{CKD Compressibility (Dry Powder)}

One dimensional compression tests were performed on the dry CKD powders in a rigid wall cell. Specimens were prepared in the three equal layers by applying a small static stress and loaded up to a vertical stress of 6-100 MPa. Figure 6-20 shows the typical non-linear volumetric compression behavior of the two CKDs observed in these tests. The data are presented in a conventional void ratio versus logarithm of vertical 
(effective) stress plot. Note the difference in initial void ratio values, which are a result of the packing difference of the two powders. For reference figure also shows curves for ground quartz (Pestana, 1994).

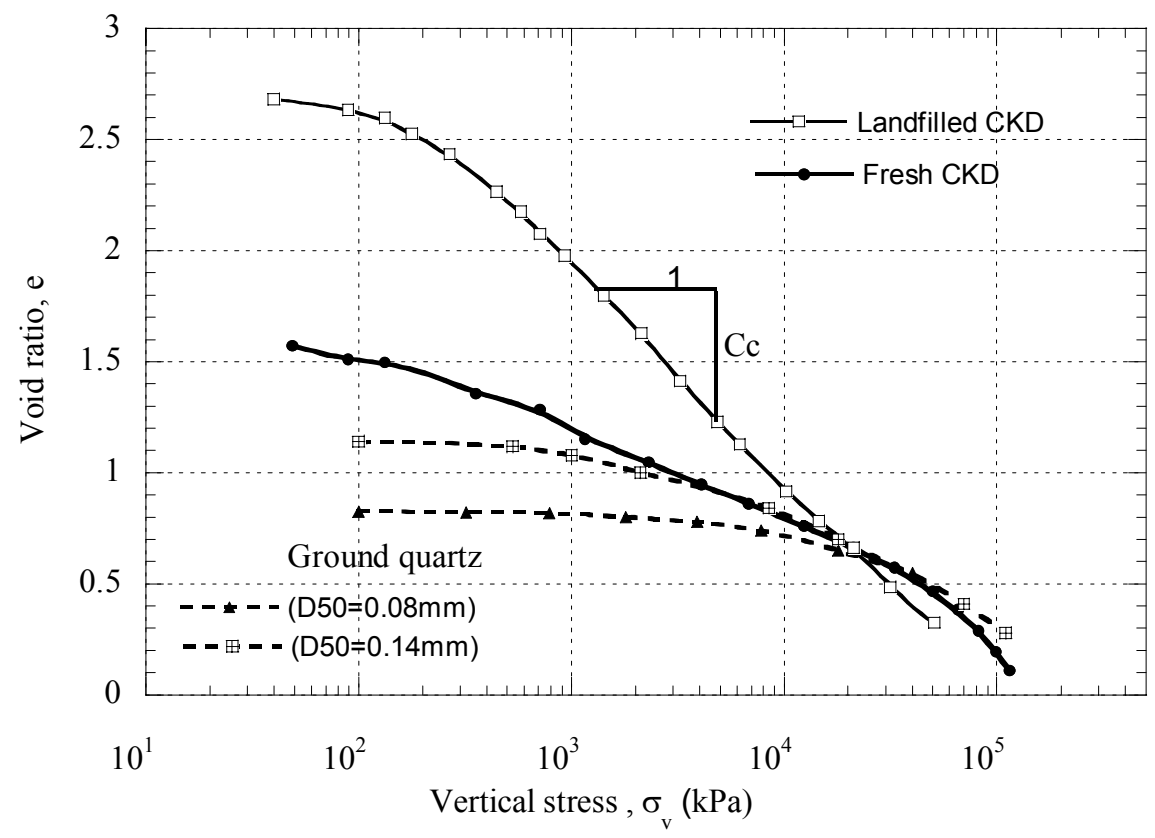

Figure 6-20 One dimensional compression of fresh III and landfilled CKD

Both CKDs show significant compressibility even at low stress levels. The average compression index $\left(\mathrm{C}_{\mathrm{c}}=-\mathrm{de} / \mathrm{d} \log \mathrm{S}_{\mathrm{v}}\right)$ for the landfilled $\mathrm{CKD}$ is, however, significantly greater than that of the fresh material (1.05 versus 0.42 ), and markedly higher than typical values for sands (0.3-0.5). Many factors affect the compression behavior of particulate materials, including density, fabric (particle arrangement), mineralogy, morphology and gradation. Two factors appear to control the high compressibility of the landfilled CKD: its lower initial density (it is known (Cumberland and Crawford, 1987) that the arrangement of particles and the consequent distribution of voids between particles have major influence on the subsequent behavior of the powder mass) and the particle morphology. With respect to the latter, it is suggested, on the basis 
of the SEM images shown in Figure 6-8 to Figure 6-11, that upon loading breakage of particularly the elongated crystals is responsible for the great compressibility of the landfilled CKD. Beyond approximately 20MPa the compression curves for the two CKDs cross-over with the landfilled material thereafter having smaller void ratio than the fresh CKD.

\subsubsection{Shear Properties (Dry Powder)}

Investigation of the shear properties of the powders in their dry state was carried out employing the direct shear apparatus. The internal friction angle was measured for different initial dry densities of the specimens over a range of applied normal stresses (33 to $200 \mathrm{kPa}$ ). The CKD specimens were prepared in the shear box at different dry densities following the procedure outlined in section 5.2.2.6 in Chapter 5. Table 6-9 summarizes the pre-shear values of the void ratio (and density) of the specimens, as well as the measured values of the friction angle (average values measured at each void ratio for different normal stress). For both CKDs over the range of void ratios considered, the friction angle appears to be essentially constant in the $34^{\circ}-37^{\circ}$ range. These values fall at the high end of the range reported in the literature for other particulate materials (e.g. see data in Table 6-10), despite the fact that the density of the CKD specimens is for the most part significantly smaller than that of other materials (with the possible exception of lime powder).

Comparison of the data for the fresh and landfilled CKD is not straightforward as the two materials were tested at significantly different void ratios. It is reported (Smith and Lohnes, 1987) that bulk solids behave like cohesionless soils. For these soils, it is customary to rely on the identification of limiting void ratios and relate strength parameters to the relative density $\left(\mathrm{Dr}=\left[\mathrm{e}_{\max }-\mathrm{e}\right] /\left[\mathrm{e}_{\max }-\mathrm{e}_{\min }\right]\right)$. Densification tests were performed on the CKD in the dry state, employing the methods (vibratory table method (ASTM D 4253-96) and tube method (ASTM D 4254-96) ) conventionally used in soil mechanics to characterize the limit density states of granular media. These methods were found not to be applicable to materials as fine as the CKD tested in this research. 
Table 6-9 Summary of specimen characteristics and peak friction angle from direct shear tests

\begin{tabular}{lccc}
\hline & Void ratio & $\begin{array}{c}\text { Dry density } \\
(\mathbf{g} / \mathbf{c c})\end{array}$ & $\begin{array}{c}\text { Peak friction } \\
\text { angle ( })\end{array}$ \\
\hline \hline Fresh CKD & 1.78 & 0.96 & 36.7 \\
& 1.47 & 1.08 & 36.6 \\
& 1.15 & 1.24 & 33.5 \\
\hline Landfilled & 3.14 & 0.63 & 36.6 \\
CKD & 2.84 & 0.68 & 34.9 \\
& 2.68 & 0.71 & 35.9 \\
& 2.48 & 0.75 & 36.6 \\
\hline
\end{tabular}

Table 6-10 Frictional characteristics of granular materials (Smith and Lohnes, 1984)

\begin{tabular}{lcc}
\hline Material & Density (g/cc) & $\boldsymbol{\Phi}\left({ }^{\circ}\right)$ \\
\hline \hline Portland cement & $1.34-1.60$ & $24-30$ \\
Coal (powder) & $0.8-1.12$ & $24-44$ \\
Grain (small) & $0.74-0.99$ & $23-37$ \\
Iron ore & 2.64 & 40 \\
Lime powder & 0.7 & 35 \\
Sand & $1.6-2.0$ & $25-40$ \\
\hline
\end{tabular}

Similar practical difficulties are reported for fine bulk solids like fly ash (Kim, 2003), as well as for non-plastic silts (Tawil, 1997).

Given the difficulties described above in identifying for such fine powders limit densities, the concept of relative density cannot be used to compare the two data sets. The similarity in the values of friction angle for both CKDs at significantly different void ratios (2.48-3.14 for the landfilled versus 1.15-1.78 for the fresh CKD) suggests, however, that particle shape and morphology play a significant role. 

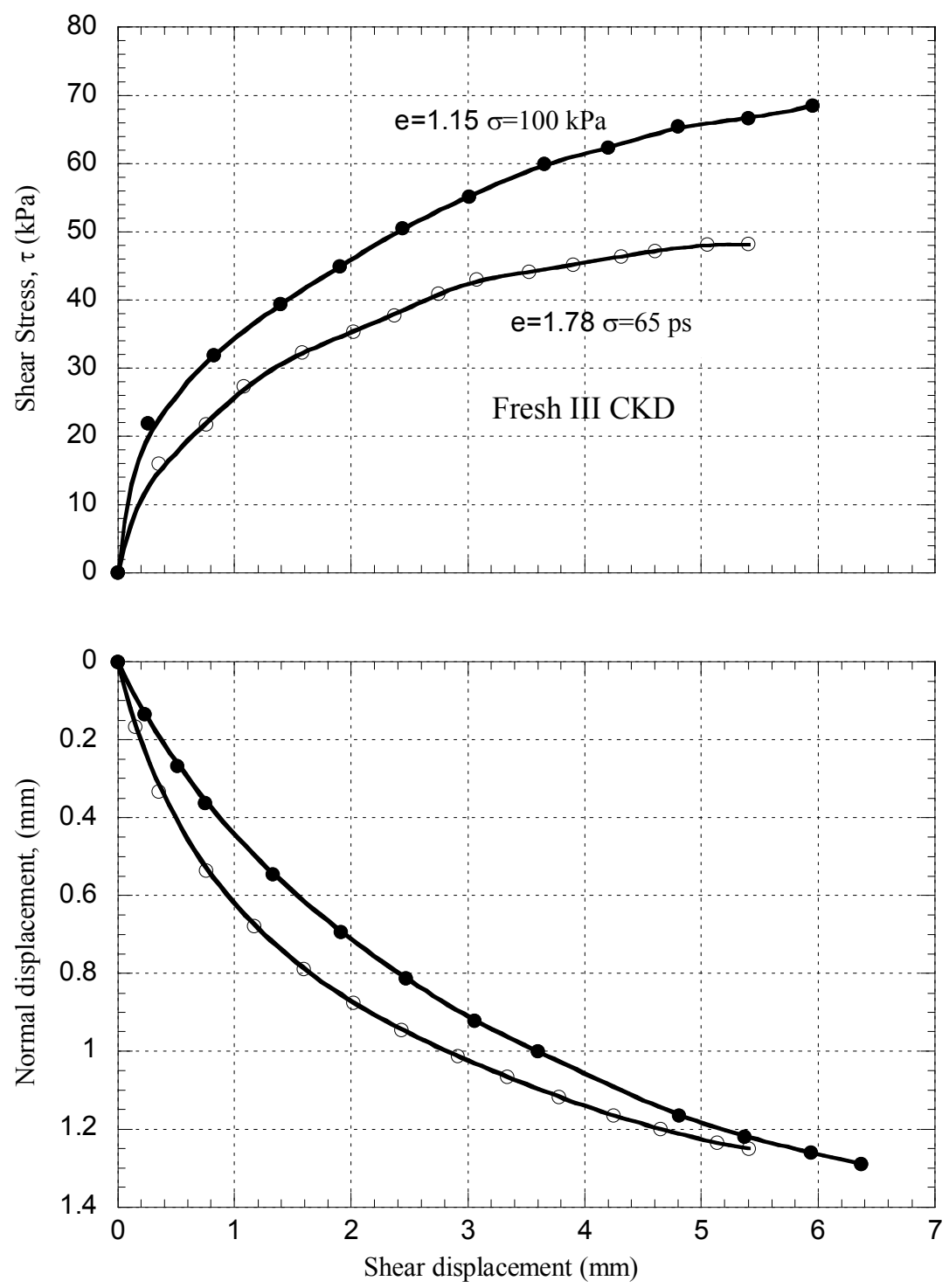

Figure 6-21 Typical shear behavior of fresh III CKD 

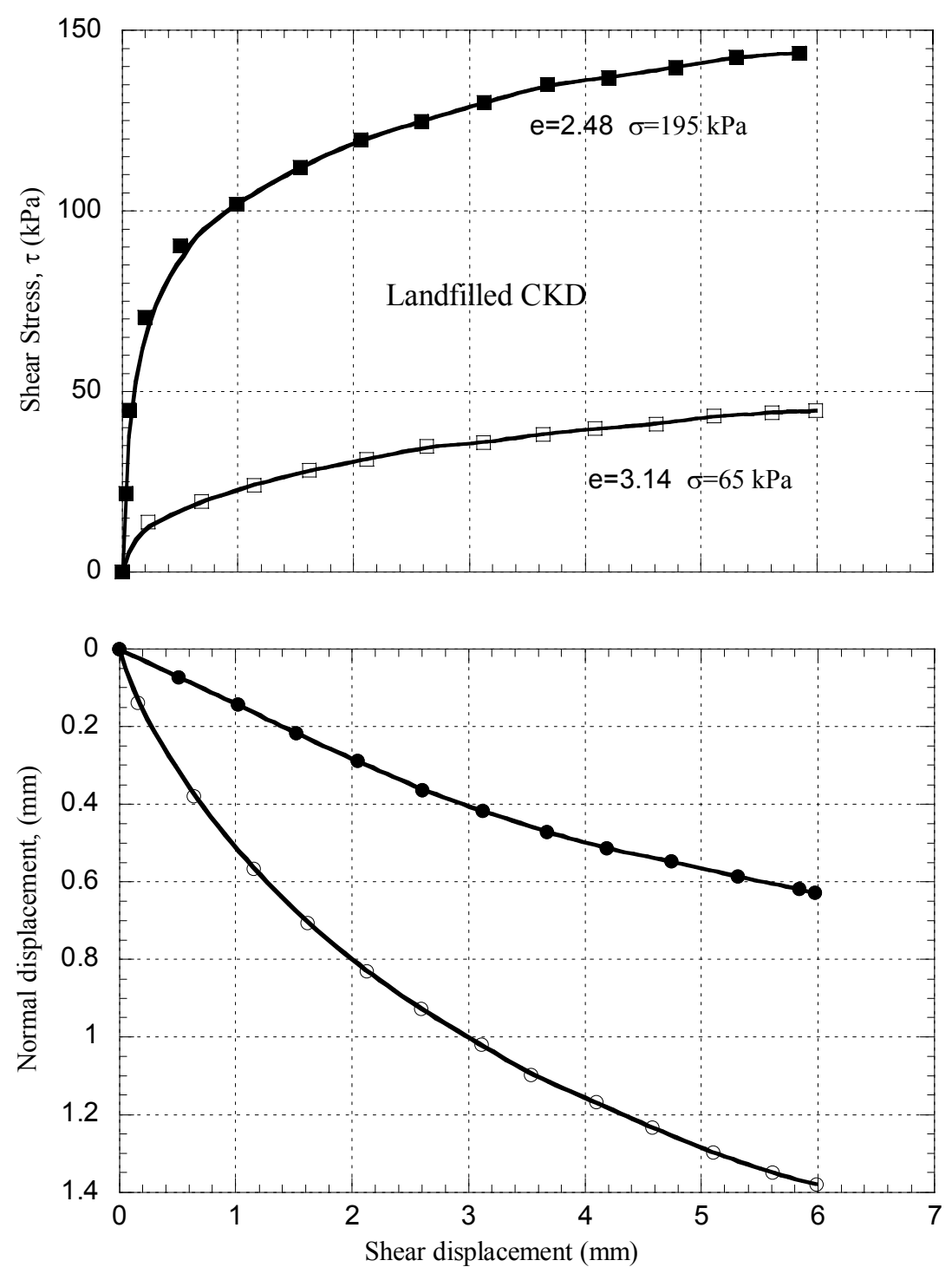

Figure 6-22 Typical shear behavior of landfilled CKD

Figure 6-21 and Figure 6-22 illustrate the behavior of the fresh and landfilled CKD powder during shearing. In addition to the similarity in the friction angle values, the two CKDs also display similar behavior during shear. Within the range of densities and normal stresses tested, the stress strain behavior of both CKDs shows no dilation behavior (Figure 6-21 and Figure 6-22). It is shown in the literature (Smith and Lohnes, 1987) that for a particulate system composed of soft "grains", even in the case of high 
initial density, shearing occurs without dilation, but with degradation of individual particles. It is likely that particularly in the case of the landfilled CKD, particle breaking is contributing to the generation of the contractive behavior observed during shear. This is in consistent with the compressibility behavior of this material.

\subsubsection{Mechanical and Engineering Properties: Conclusions}

The main conclusions drawn from the tests on the mechanical and engineering properties of both fresh and landfilled CKD are summarized below:

- $\quad$ The binding properties of CKD depend on the amount of free lime present. Only the fresh CKD with available free lime (fresh I CKD) showed some cementing properties. Both the landfilled CKD and the other two fresh samples (fresh II and III) were instead found to be almost chemically inert.

- There is a noticeable difference in the compaction characteristics of fresh and landfilled CKD. For the only reactive CKD tested (fresh I) significant changes in compaction behavior (increased OMC and reduced maximum dry density) were observed as a result of mellowing. For the less reactive CKDs, mellowing had no effect on the moisture density relations.

- $\quad$ The landfilled CKD has a low dry density and remarkably high optimum water content. It can be compacted with a wide range in water content on the dry side of optimum without significant change in dry density.

- The strength of fresh CKD drops off sharply on the wet side of optimum. The strength of landfilled CKD is instead found to be less sensitive to compaction water content, as well as to compaction effort.

- The permeability of compacted fresh CKD is almost one order of magnitude smaller than that of landfilled CKD ( $k_{\text {landfilled }}=0.99-1.82 \times 10^{-7} \mathrm{~m} / \mathrm{s}$ compared to $\left.\mathrm{k}_{\text {fresh }}=1.4-1.6 \times 10^{-8} \mathrm{~m} / \mathrm{s}\right)$. Both compacted CKDs can be considered impervious.

- One-dimensional compression tests on the dry powders demonstrate that the compressibility of the landfilled CKD (as measured by the compression index $(\mathrm{Cc}=-\mathrm{de} / \mathrm{d} \operatorname{logSv})$ is over two times greater than that of the fresh CKD. 
- Values of the friction angle obtained from direct shear tests for both materials are in the $34^{\circ}-37^{\circ}$ range. However the much lower density of the landfilled specimens suggests that also in these tests particle morphology plays a role.

\subsubsection{Environmental Suitability}

\subsubsection{Corrosiveness of CKD}

Many factors, including resistivity, levels of dissolved salts, moisture content, $\mathrm{pH}$, presence of bacteria and amount of oxygen determine whether an environment is corrosive. While it is generally agreed that no one parameter can be used to accurately forecast the corrosiveness of a particular media, a number of parameters can be used as indicators of corrosiveness, and as the basis for determining whether special corrosion mitigation measures, such as cathodic protection, should be taken for buried steel pipes in contact with the media.

In this research, the corrosivity of fresh III and landfilled CKD was evaluated by measuring the following four electrochemical characteristics: $\mathrm{pH}$, electrical resistivity (both before and after soaking the samples), soluble sulfate content and soluble chloride content. The results of this study are presented in Table 6-11, while Table 6-12 summarizes some of the threshold values for $\mathrm{pH}$ and resistivity that have been used to classify the degree of corrosivity of a soil. These data have been used for classifying the corrosivity of widely used by-product materials like bottom ash and fly ash (e.g., Kim, 2003).

Table 6-11 shows that for both CKDs the measured value of $\mathrm{pH}(\sim 11.5)$ is clearly outside the range (5-10) considered problematic for corrosion. On the other hand, the extremely low values of resistivity measured indicate that both CKDs are very corrosive, according to the criterion adopted by the American Petroleum Industry (1991). Both CKDs are also characterized by high chloride and sulfate content (for comparison see for example the data for fly ash reported in Table 6-12). While a high $\mathrm{pH}$ is typically deemed effective in inhibiting corrosion (see Figure 6-23) by effective passivation (Bentur et al., 1997), a high chloride content is known to cause destabilization of the passivation film formed. 
Based on extensive research on the corrosiveness of Indiana bottom ash, Lovell and Ke (1992) suggested the following thresholds for classifying an ash as non-corrosive:

- resistivity $>1,500 \mathrm{ohm}-\mathrm{cm}$

$-\mathrm{pH}<5.5$

- soluble chloride content $<200$ ppm

- soluble sulfate $<1,000 \mathrm{ppm}$.

Based on these thresholds both fresh III and landfilled CKD would be once again classified as very corrosive. Note that this is case for many other industrial by-products such as fly ash, bottom ash and sewage ash, which have been extensively used in the construction industry. For example, Table 6-13 summarizes some of the results of the study on bottom ashes conducted by Lovell and Ke (1992). Of the 11 ashes investigated, seven were classified as potentially corrosive. As a result, their use was recommended only in conjunction with corrosion-resistant steel structures. Analogous results have been reported by Kim (2003) who studied the corrosivity of fly ashes and fly ash-bottom ash mixtures. Similarly, Gray (1970) classified sewage ash as corrosive towards metals based on $\mathrm{pH}$ and redox-potential.

In conclusion, despite the relatively high $\mathrm{pH}$ of $\mathrm{CKD}$, the high content of soluble chlorides and sulfates and the high moisture retention capacity of CKD appear likely to produce an environment that will be corrosive to metal structures. In practice small scale prototype tests are required to confirm this assessment.

Table 6-11 Corrosivity parameters of fresh and landfilled CKD

\begin{tabular}{cccccc}
\hline CKD & Resistivity $(\mathbf{O h m}-\mathbf{c m})$ & $\mathbf{p H}$ & $\begin{array}{c}\text { Chloride } \\
(\mathbf{p p m})\end{array}$ & $\begin{array}{c}\text { Sulfate } \\
(\mathbf{p p m})\end{array}$ \\
\hline \hline \multirow{2}{*}{ Fresh III } & As -compacted & Soaked & & & \\
\cline { 2 - 3 } & 255 & 93 & 11.55 & 1406 & 4908 \\
Landfilled & 615 & 80 & $1.97 \pm 5.59$ & 1840 & 7383 \\
\hline
\end{tabular}


Table 6-12 Soil corrosivity classification (Kim, 2003)

\begin{tabular}{|c|c|c|c|c|c|}
\hline \multicolumn{6}{|c|}{ Classification } \\
\hline Parameter & $\begin{array}{l}\text { Little } \\
\text { corrosive } \\
\end{array}$ & $\begin{array}{l}\text { Mildly } \\
\text { corrosive }\end{array}$ & $\begin{array}{l}\text { Moderately } \\
\text { corrosive }\end{array}$ & Corrosive & $\begin{array}{l}\text { Very } \\
\text { corrosive } \\
\end{array}$ \\
\hline \multirow{2}{*}{$\begin{array}{l}\text { Resistivity } \\
(\text { Ohm-cm) }\end{array}$} & $>10,000^{\mathrm{a}, \mathrm{b}}$ & $2,000-10,000^{\mathrm{a}}$ & $1,000-2,000^{\mathrm{a}}$ & $500-1,000^{\mathrm{a}}$ & $<500^{\mathrm{a}}$ \\
\hline & & $5,000-10,000^{\mathrm{b}}$ & $2,000-5,000^{\mathrm{b}, \mathrm{c}}$ & $700-2,000^{\mathrm{b}, \mathrm{c}}$ & $<700^{\mathrm{b}, \mathrm{c}}$ \\
\hline $\mathrm{pH}$ & & $>5$ and $<10.0^{b}$ & & $5-6.5^{\mathrm{a}}$ & $<5^{\mathrm{a}}$ \\
\hline
\end{tabular}

Table 6-13 Corrosivity parameters of Indiana bottom ashes (Ke and Lovell, 1992)

\begin{tabular}{lccccc}
\hline Ash Name & $\begin{array}{c}\text { Resistivity } \\
(\mathbf{O h m}-\mathbf{c m})\end{array}$ & $\mathbf{p H}$ & $\begin{array}{l}\mathbf{C l}^{-} \\
\mathbf{( p p m )}\end{array}$ & $\begin{array}{c}\mathbf{S O}_{\mathbf{4}}{ }^{2-} \\
(\mathbf{p p m})\end{array}$ & $\begin{array}{c}\text { Overall } \\
\text { Corrosivity }\end{array}$ \\
\hline \hline Perry K. & 980 & 4.8 & 15.5 & 598 & $\mathrm{C}$ \\
Gibson & 2201 & 7.6 & 7.3 & 1127 & $\mathrm{C}$ \\
Schahfer 14 & $>6663$ & 9.6 & 0.4 & 50 & $\mathrm{NC}$ \\
Schahfer 17 & 3082 & 8.6 & 6.1 & 383 & $\mathrm{NC}$ \\
Gallegher & 335 & 9.1 & - & - & $\mathrm{C}$ \\
Mitchell & 1771 & 8 & - & - & $\mathrm{NC}$ \\
Wabash & 1051 & 8 & - & - & $\mathrm{C}$ \\
Richmond & 247 & 8.2 & - & - & $\mathrm{C}$ \\
Stout & 4249 & 6.6 & - & - & $\mathrm{NC}$ \\
Culley & 486 & 8.5 & - & - & $\mathrm{C}$ \\
Brown & 213 & 3.2 & - & - & $\mathrm{C}$ \\
\hline - not determined & & & & & \\
C-Corrosive, NC-Noncorrosive & & & &
\end{tabular}




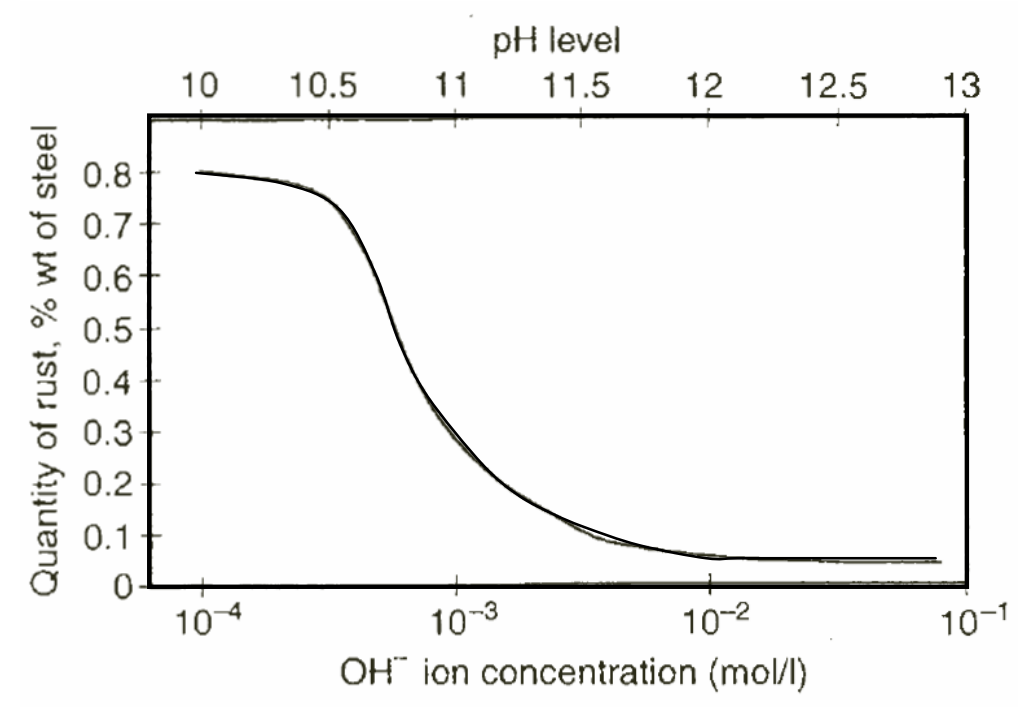

Figure 6-23 Corrosion of steel in water as a function of $\mathrm{pH}$ level (Bentur, 1997)

\subsubsection{Analysis of Trace Metals}

All "leachable" trace metals present in fresh, landfilled and a limited number of tube samples selected to spatially represent the landfill were measured with an Inductively Coupled Plasma spectrophotometer (ICP) in the Environmental Engineering Laboratory at Purdue University. The amount of leachable metals in each sample was evaluated using the U.S. Environmental Protection Agency (EPA) Toxicity Characteristic Leaching Procedure (TCLP), as discussed in Chapter 5. The samples were analyzed for seven RCRA metals (arsenic, barium, cadmium, chromium, lead, mercury and selenium) regulated in 40CFR261.24 under the Resources Conservation and Recovery Act (RCRA). Silver is also included in the RCRA list, but was not quantified in the present study. The samples were also analyzed for aluminum, iron, manganese, nickel and zinc which are in addition to the RCRA requirements.

Table 6-14 summarizes the concentration of metals present in the CKD leachate under test conditions. The samples tested include the fresh I and fresh III CKD and also selected tube samples. RCRA's limits (EPA's regulatory action levels, TCLP method) for metal concentration are also included. The table shows that metals are present in different concentrations in different samples. Many of the trace metals, while present in some 
amount, occur at levels too small to be meaningful. No samples exceeded the RCRA limits except B3-I for the level of mercury present. In B3-I the level of mercury is 0.217 $\mathrm{mg} / \mathrm{L}$ while the allowable limit is only 0.2 . Also the concentration of all metals detected (except chromium) present in this sample is higher than the average metal concentration calculated for the tube samples. It is important to note that B3-I is the deepest sample collected from the landfill bottom at a depth of almost (20m) from the upper level of the landfill (Figure 6-24).

It is possible that leaching from the upper layers over the years is responsible for the higher mercury concentration at this depth. This hypothesis is supported by the fact that other metals including aluminum, cadmium, chromium, iron, manganese, nickel and selenium are also present at relatively higher concentrations in this sample. The relatively high trace metal concentration at a greater depth suggests that prior to extensive mining of the landfill, some limit on the depth from which to excavate material might need to be determined.

The data for the landfilled CKD represents the metal content at the time of sampling. It is possible that the material originally disposed of in the landfill had a higher presence of metals which were partially leached out during the "storage" period. Given the high $\mathrm{pH}$ of the CKD (which reduces the mobility of the ions) and the low values of the hydraulic conductivity measured on the landfilled CKD $\left(1-1.8 \times 10^{-7} \mathrm{~m} / \mathrm{s}\right)($ which reduces the probability that extensive ground water percolation occurred), it appears likely that leaching was not too significant.

Section 2.3.4 in Chapter 3 summarized the data for the average values for leachable metals (see table 2-6) present in fresh CKD based on the analysis of the dust collected from several samples obtained from 79 US and 10 Canadian plants (PCA 1992). In that study also it was found that metal levels in CKD are typically well below the RCRA limits, and concluded that the single most important factor in determining the concentration of metals in CKD is the extent of recirculation within the plant. Comparison of these data with the results obtained in the present study shows that the ranges of metals in fresh CKDs are within the range reported. However the level of mercury in fresh III CKD is above the maximum value reported for other CKDs. 
In conclusion, the results obtained demonstrate that both fresh and landfilled CKD are not hazardous. Note also that the testing procedure (acidic leaching solution) employed represents a worst case scenario. Additionally the CKD from the tube samples was first ground before being exposed to the leaching solution. As a result the mass fabric was broken and a larger surface area was exposed to the leaching agent.

\subsubsection{Environmental Suitability: Conclusions}

The following are the main conclusions drawn from this portion of the study:

- Despite the high $\mathrm{pH}$, measurements of the resistivity, and the chloride and sulfate content indicate that both fresh and landfilled CKD are likely to be corrosive in nature.

- Measurements of the concentration of heavy metals that leached from each material are well below EPA-recommended TCLP limits and demonstrate the non hazardous nature of all CKDs tested. 
Table 6-14 Leachable (TCLP) metals in CKD samples tested (mg/L)

\begin{tabular}{lccccccccccc}
\hline & Fresh I & Fresh III & Landfilled B1-B & B1-I & B2-C & B2-F & B3-A & B3-I & $\begin{array}{c}\text { Average } \\
\text { RCRA* } \\
\text { Limit }\end{array}$ \\
\hline \hline Mercury & 0.001 & 0.06 & 0.004 & 0.00 & 0.012 & 0.085 & 0.130 & ND & 0.22 & 0.089 & $\mathbf{0 . 2}$ \\
Selenium & 0.011 & 0.13 & 0.256 & 0.21 & 0.009 & 0.732 & 0.953 & ND & 0.67 & 0.515 & $\mathbf{1 . 0}$ \\
Cadmium & 0.023 & ND & 0.019 & 0.00 & ND & 0.038 & 0.073 & 0.01 & 0.08 & 0.039 & $\mathbf{1 . 0}$ \\
Lead & 0.058 & ND & 0.296 & 0.02 & ND & 0.372 & 1.115 & 0.08 & 1.23 & 0.562 & $\mathbf{5 . 0}$ \\
Arsenic & 0.066 & 0.12 & 0.144 & 0.64 & 0.483 & 0.443 & 0.424 & ND & 0.37 & 0.473 & $\mathbf{5 . 0}$ \\
Nickel & 0.015 & ND & ND & 0.01 & ND & ND & 0.250 & ND & 0.29 & 0.181 & $\mathbf{7 0 . 0}$ \\
Barium & 0.040 & 0.06 & 0.039 & 0.29 & 0.175 & 0.103 & 0.181 & 0.07 & 0.08 & 0.150 & $\mathbf{1 0 0 . 0}$ \\
Chromium & 0.119 & 0.01 & 0.103 & 0.05 & 0.013 & 0.115 & 0.341 & 0.05 & 0.35 & 0.153 & $\mathbf{5 . 0}$ \\
Aluminum & 0.231 & 1.58 & 0.503 & 1.25 & 0.195 & 0.424 & 0.464 & 1.57 & 1.82 & 0.953 & $\mathbf{5 . 0}$ \\
Iron & 0.213 & 0.08 & 0.022 & 0.00 & ND & 0.065 & 0.114 & ND & 0.11 & 0.074 & - \\
Manganese & 0.048 & ND & 0.005 & ND & ND & 0.011 & 0.024 & 0.00 & 0.03 & 0.016 & - \\
Zinc & 0.216 & ND & 0.242 & 0.01 & ND & ND & 0.075 & ND & 0.07 & 0.052 & - \\
\hline
\end{tabular}

NOTES:

- Average values calculated only from tube samples

- The term "Landfilled" refers to the bulk samples of CKD collected at

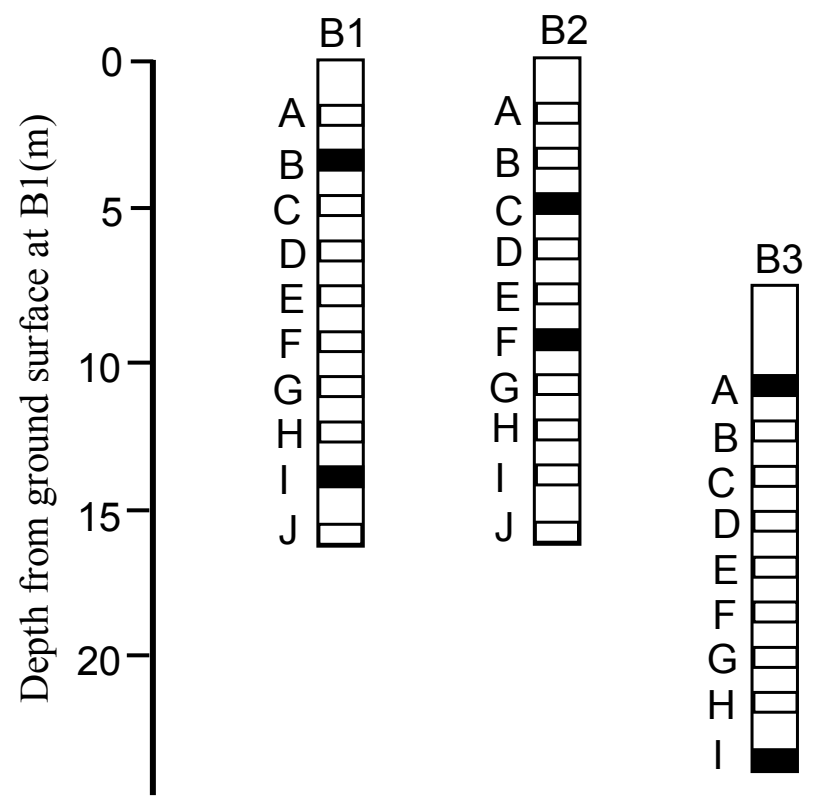

Figure 6-24 Tube samples used to determine heavy leachable metal concentrations shown in Table 6-14 (shaded in black) 


\subsection{Dynamic Nature of Reactive By-Products}

The above discussion on the physico-chemical and engineering properties of the CKDs tested highlighted the similarities and dissimilarities in the properties of fresh and landfilled CKD. Therefore the results presented in this report provide some insight into the changes to the properties of $\mathrm{CKD}$ that can occur due to long term exposure of this material to the environment. As discussed in Chapter 4, the landfilled CKD examined in this research was disposed over a period of approximately 12 years, between 1988 and 2000. The exact nature of the parent material of this CKD is not known, as all samples of the fresh CKD were instead obtained later (in 2000 and in 2003). Examination of historic data (including free lime values) provided by the manufacturer suggests, however, that the first sample of fresh CKD (fresh I) examined in this research project is likely to closely represent the CKD that was disposed in the landfill. Thus the comparison of fresh I and landfilled CKD provides direct insight into the changes in physico-chemical characteristics occurred after landfilling and into the resulting modifications in the engineering properties. Table 6-15 summarizes some of the key differences between fresh and landfilled CKD.

As discussed in section 6.3.1.1, fresh I CKD is the only of the CKDs examined that exhibited reactivity due to the presence of free lime, as demonstrated by the XRD analyses (Figure 6-3). Additionally, data provided by the manufacturer based on tests conducted as recently as April 2000 suggests that the free lime content of this material was in the $2-6 \%$ range. Only traces of free lime were instead detected in the landfilled CKD. This indicates that due to continuous exposure to the atmosphere for a long period this CKD underwent chemical alteration by hydration and carbonation resulting in a material that is today close to inert. The SEM images presented in Figures 6-9 through 612 show evidence of chemical alteration processes through the presence of various reaction products, often in the form of elongated fibers and an extremely networked structure. Associated with this particle morphology is a high specific surface $(>110,000$ based on the BET method - see Section 6.3.1.6). 
Table 6-15 Key difference in properties between fresh and landfilled CKD

\begin{tabular}{|c|c|c|}
\hline & Fresh I CKD ${ }^{a}$ & Landfilled CKD \\
\hline Free Lime & $2-6 \%{ }^{b}$ & traces \\
\hline Reactivity & some & none \\
\hline $\mathrm{D}_{50}(\mathrm{~mm})$ & 2 & $3-5 \mathrm{~mm}$ \\
\hline $\mathrm{D}_{95}(\mathrm{~mm})$ & 10 & 10 \\
\hline $\operatorname{BET~SSA~}\left(\mathrm{cm}^{2} / \mathrm{g}\right)$ & $39,700^{\mathrm{c}}$ & 117,600 \\
\hline Std. Proctor $\rho_{\mathrm{dmax}}\left(\mathrm{g} / \mathrm{cm}^{3}\right.$ & 1.32 & \\
\hline Std. Proctor OMC (\%) & 28.0 & 50.0 \\
\hline Compression indec, $\mathrm{C}_{\mathrm{c}}$ & $0.42^{\mathrm{c}}$ & 1.05 \\
\hline $\begin{array}{l}\text { Peak friction angle in } \\
\text { direct shear, } \mathrm{f}^{\prime}\left(\Phi^{\circ}\right)\end{array}$ & $35-37$ & $34-37$ \\
\hline
\end{tabular}

Unfortunately given the fact that this research was initiated after modifications made in 2001 to the Lehigh plant process technology led to changes in the nature of the CKD produced (see Section 6.3), limited testing was performed on fresh I CKD. For example, neither morphological studies through the SEM nor specific surface measurements were performed, and no data are available on the compressibility and internal friction angle of this CKD in the dry state.

It has been discussed how the latter two samples of fresh CKD (fresh II and fresh III) differed from fresh I CKD in terms of reactivity. However, all fresh CKDs exhibit very consistent particle size distribution (Figure 6-5), and beyond the presence of free lime in fresh I CKD, the XRD results (Figure 6-3) suggest that the mineralogy of the fresh CKD has remained consistent. Thus, it is hypothesized that the results for the more recent samples of fresh CKD (fresh II and fresh III) may be used to represent the physical properties (e.g. morphology and specific surface area) of fresh I CKD. Under this assumption, the data available for fresh II and III CKD suggest that environmental 
exposure led to significant changes in particle morphology (e.g. see Figure 6-7) and a close to threefold increase in the specific surface area (Table 6-4). These changes have significant effect on the particle arrangement (fabric) and engineering properties of these materials.

The results of the proctor compaction tests presented in Section 6.3.2.3 provide a clear illustration of some of the changes in engineering properties that are associated with the long term exposure of the CKD to the environment. As discussed in Section 6.3.2.3., and as shown in Figure 6-16, compared to fresh I CKD, the compaction behavior of the landfilled material is characterized, for the same compaction energy, by a decreased maximum dry density and a greatly increased optimum moisture content. In addition, the landfilled CKD can be compacted over a much wider water content range. These results demonstrate that the moisture density relations of these materials are controlled by particle morphology.

The results presented in Figure 6-16 also support the assumption that the modification in compaction behavior is a result of chemical alteration due to exposure to the environment (air and humidity) of the initially reactive fresh CKD. Figure 6-16 includes, in fact, compaction results for fresh I CKD compacted one day after it was given access to water during mixing. It is suggested that for this material, direct exposure to water during mixing has essentially accelerated the slow and gradual chemical alteration processes responsible for the changes observed in the landfilled CKD; and, in fact, the compaction curve for fresh I CKD compacted after mellowing is shifted downwards and to the right towards the curve for the landfilled CKD.

Comparison of the behavior of landfilled CKD and fresh III CKD provides further insights into the effects of the morphological differences described above on the engineering properties of these particulate materials. If the comparison is restricted to the powders in the dry state, it can be assumed that observations made for the fresh III CKD can be extrapolated to fresh I CKD (as discussed above fresh III CKD can be considered an un-reactive analogue of fresh I CKD), and thus to the parent material for the landfilled CKD. Under these assumptions, the results presented in Figure 6-20 indicate that associated with the chemical alteration processes that occurred in the field is the 
generation of a material that exhibits significantly greater one dimensional compressibility (by a factor of 2 or greater) than the original parent CKD. Crushing of the crystals observed in the SEM images (Figures 6-9 through 6-12) is likely to be responsible for this behavior.

Direct shear tests provide peak friction angles in the same range for both fresh and landfilled CKD (Table 6-9). However the much lower density of the landfilled CKD specimens suggests that also in these test particle morphology plays a role.

Overall the discussion above demonstrates the dynamic nature of reactive byproduct materials such as CKD. Given the degree to which the engineering properties of the CKD examined in this study changed as a result of exposure to the environment, it appears that these issues require serious consideration whenever by-product materials that have for example undergone extended storage in a disposal site are to be employed as geo-materials.

Finally, it should be noted that surface chemistry and surface contamination analyses were not performed on the CKDs examined in this research. Such studies appear necessary if the chemical alteration process occurring after placement of the CKD (or of any other by-product material) in a landfill and resulting particle characteristics are to be completely understood and characterized.

\subsection{Summary}

This chapter presented the results of a comprehensive investigation of the physiochemical and engineering properties of both fresh and landfilled CKD. While the data discussed pertains to CKDs from a single source, they provide insight into the nature and opportunities for possible reutilization of these materials in general.

The results presented in this chapter have highlighted the differences observed between the three samples of fresh CKD tested, thereby stressing how changes in the processing operations of a plant can markedly modify the nature of the CKD produced. The discussion has also emphasized the potential impact of chemical alteration on the physio-chemical and mechanical properties of reactive byproduct such as CKD when exposed to the environment, as in a disposal site. Hence the identification of applications 
for a waste by-product material needs to be founded on careful evaluation of its characteristics. Re-use of waste materials requires exploiting both the favorable and inferior properties of these materials.

\section{$\underline{6.6 \text { Key Properties and Potential Applications }}$}

The extensive study on the characterization of fresh and landfilled CKD conducted in this phase of the research work suggests that utilization of both the currently produced fresh CKD and the landfilled CKD should rely on exploiting some key properties. Table 6-15 summarizes the key properties of the fresh and landfilled CKDs identified through this study: high fineness, high alkalinity, low reactivity, ability to absorb water and non hazardous nature. A number of potential applications for the CKDs were identified based on the above properties. Table 6-15 shows which properties would be exploited for each of the applications considered. The applications for the CKDs that could potentially be considered are:

a) Soil modification, treatment of wet sub-grades, land reclamation projects

b) Controlled low strength materials

c) Stabilization/solidification of municipal waste water sludge

d) Grouting /Compaction grouting

e) Anti-stripping agents in asphalts

Additional applications to be considered involve the combined use of the CKD with other waste materials.

Overall, even once proven in the laboratory, practical implementation of any of these applications is far from an easy task. Many practical difficulties may be encountered (e.g. perception of CKD use as experimental, construction difficulties and inferior properties of similarly graded materials, air-borne problem, transportation and storage of CKD). Small scale pilot tests in the field are likely to be necessary before large scale applications can be pursued.

The following sections discuss the rationale behind the geotechnical applications that could provide the opportunity for reutilization of very large quantities of CKD (a-d in list above). Of these applications the first two ((a) and (b) in list above) were selected for 
a more in depth study, and additional experimental work was performed. The results of this work are presented in Chapter 7 (soil stabilization and treatment of wet subgrades) and Chapter 8 (controlled low strength materials).

Table 6-16 Summary of key properties for fresh III and landfilled CKD and potential applications

\begin{tabular}{llcccc}
\hline \multicolumn{5}{c}{ Applications } \\
\hline Key Properties & $\begin{array}{l}\text { Wet soil } \\
\text { treatment }\end{array}$ & $\begin{array}{l}\text { Sludge } \\
\text { CLSM } \\
\text { stabilization } \\
\text { /Solidification }\end{array}$ & $\begin{array}{l}\text { Compaction } \\
\text { grouting }\end{array}$ & $\begin{array}{l}\text { Anti-stripping } \\
\text { agents in } \\
\text { asphalts }\end{array}$ \\
\hline \hline Fineness & & $\sqrt{ }$ & $\sqrt{ }$ & $\sqrt{ }$ & $\sqrt{ }$ \\
Alkalinity & $\sqrt{ }$ & $\sqrt{ }$ & $\sqrt{ }$ & & $\sqrt{ }$ \\
Low/no reactivity & & $\sqrt{ }$ & & $\sqrt{ }$ & \\
Ability to absorb water & $\sqrt{ }$ & $\sqrt{ }$ & $\sqrt{ }$ & & \\
Low permeability - & & & & & $\sqrt{ }$ \\
following compaction & & & & & $\sqrt{ }$ \\
High friction angle & $\sqrt{ }$ & & $\sqrt{ }$ & & \\
Non hazardous & $\sqrt{ }$ & $\sqrt{ }$ & & & \\
\hline
\end{tabular}

6.6.1 Soil Improvement and Treatment of Wet Sub-grades

Recently, a number of researchers have investigated the use of CKD for subgrade stabilization/modification as an alternative to the use of traditional soil stabilizing agents such as portland cement or lime. The suitability of a CKD for soil stabilization is dependent on the presence of free lime. Considering the low free lime content of the CKDs investigated in this research, it appears unlikely that they may be considered for "traditional" soil stabilization. However the high specific surface area of these CKDs suggests that they may be used as "drying agents" for treating wet subgrades and water logged areas. While the simple addition of CKD, is likely not to generate any strength increase in the treated soil, it is suggested that the combined use of CKD with portland 
cement might prove to be an effective means to address construction on wet soils. This application of CKD is discussed in depth in Chapter 7.

\subsubsection{Controlled Low Strength Materials (CLSM)}

A typical flowable fill mix contains cement, fly ash, fine aggregate and water and sometimes chemical admixtures mixed in varying proportions to meet the requirements of strength and flowability. The primary property of flowable fill in all the applications is its flowability and self leveling properties. The consistency of flowable fill used in geotechnical applications is similar to that of a lean grout or slurry, yet several hours after placement the material hardens enough to support traffic loads without settlement. Maximum strength recommendations ensure that CLSM can be removed with conventional excavating equipment.

Researchers in the past decade have explored the use of many nonstandard waste materials in CLSM and reported promising results for the use of by-product fines such as foundry sand (Bhat and Lovell, 1994; Tikalsky et al., 2000), cement kiln dust (Katz and Kovler, 2004; Al-Jabri et al., 2002; and Pierce et al., 2003), and high fines limestone (Crouch and Gamble, 1997).

Consideration of the CKDs investigated in this research as candidate materials for CLSM is based on the following observations:

- Both CKDs are characterized by high fineness, which would help manufacture a CLSM which is homogeneous and flows like a heavy liquid ("pancake consistency") without segregation. These mixes would be highly desirable when CLSM needs to be pumped at great distance.

- The non-pozzolanic nature of CKD is likely to inhibit gain in strength with time and would be beneficial where the CLSM needs to be excavated in future.

- The heavy metals present in CKD are within RCRA limits.

\subsubsection{Stabilization/Solidification of Water Based Sludge}

Stabilization/solidification (S/S) of waste (solid or liquid) or contaminated soil in general, is the process of reducing the mobility of hazardous substances and contaminants 
through both physical and chemical means by the use of additives, so as to yield a product or material suitable for land disposal or for other beneficial uses. EPA defines these two terms (stabilization/solidification) separately (Conner, 1990). "Solidification physically limits the mobility of dangerous waste by reducing or eliminating free liquids in the waste (encapsulating the waste in a monolithic solid of high structural integrity) whereas stabilization limits the hazard potential of dangerous waste by converting the constituents into a less soluble complex form". Currently more than 100 million tons of waste water treatment sludge is being generated in the US.

Sludges are stabilized by using common cementitious (portland cement, slag cement, hydrated lime), pozzolanic (fly ash, silica fume), or byproduct (cement kiln dust, lime kiln dust) materials (MacKay and Emery, 1992).

Cementitious products reduce the mobility of heavy metals by providing a $\mathrm{pH}$ environment at which the solubility of metal hydroxides is the lowest and also by producing a final integral stabilized product. In the stabilization process, the stabilizer is added to the untreated sludge in sufficient quantity to raise the $\mathrm{pH}$ to 12 or more for sufficient contact time. The high $\mathrm{pH}$ creates an environment that is not conducive to the survival of microorganisms. Consequently, as long as the $\mathrm{pH}$ is maintained at this level, the sludge will not create odors, or pose a health hazard. The dosage of stabilizer depends on the type of sludge and its solid concentration. According to Stegemann and Cote (1990), the crucial properties of the stabilized matrix are its ability to retain contaminants and low permeability to ground water. Eventually the treated sludge should be environmentally safe (nonhazardous to human) and stable (integrity of the stabilized waste) for its end usage or disposal. The primary requirements of a stabilizer/solidifier are that it:

1. Retain the final $\mathrm{pH}$ of the stabilized material within a limited $\mathrm{pH}$ band at which the solubility of the metal hydroxides is the minimum.

2. Keep the level of pathogens below the specified RCRA limit.

3. Maximize the containment of environmental contaminants.

4. Provide structural integrity to the treated sludge long term durability. 
Limited research is reported on the use of CKD in sludge/contaminated soil stabilization (Angelbeck et al., 1989; MacKay and Emery, 1992; Burnham,1988, Burnham et al.,1992) with most of the work being focused primarily on the microbiological aspects of the treatment and no information on the engineering properties of the CKD treated waste. MacKay and Emery (1992) reported the combined use of $12 \%$ CKD with $3 \%$ portland cement (percentage of dry weight of soil) to successfully treat a contaminated road base in Canada.

The rationale for considering $\mathrm{CKD}$ as a candidate material for sludge stabilization/solidification is based on the following observations derived from the characterization study:

- Both fresh and landfilled CKD exhibit high water absorption capacity and may be effectively used as bulking agents for treating liquid non-hazardous wastes (the sludge resulting from wastewater treatment operations is usually in the form of a liquid or semisolid liquid with 0.15 to 12 percent solids by weight (Metcalf and Eddy, 1991) which may require solidification prior to land disposal as liquid waste is not allowed in EPA-approved waste storage sites).

- Both CKDs are characterized by high fineness, which is expected to be advantageous for producing a solidified waste that is homogeneous at the microscopic level. MacKay and Emery (1992) report that reduced leachability of contaminants after stabilization/solidification is largely the result of entrapment (encapsulation) of contaminants within the matrix, rather than chemical binding to the matrix. The encapsulating nature of CKD was quite visible when it was mixed with soil for soil treatment, and reflected the type of "granular" appearance that is considered desirable for a treated sludge. Note that obtaining this same result with cement requires large dosages.

- Both CKDs exhibit fairly high $\mathrm{pH}$, which, as mentioned above, is desirable for long term durability and necessary to provide an environment which minimizes solubility of metal hydroxides.

- Tests on compacted soils indicate that the combined use of CKD and cement has the potential to generate structurally stable stabilized system. 
Note that control of pathogens is not discussed in this report and is considered outside the scope of this study.

\subsubsection{Compaction Grouting}

Compaction grouting is a ground improvement method that involves injection of stiff mortar like grout under pressure into the ground thereby densifying the surrounding soil. ASCE Committee on Grouting (1980) defines compaction grout as "Grout injected with less than 1 in $(25 \mathrm{~mm})$ slump. Normally a soil-cement with sufficient silt sizes to provide plasticity together with sufficient sand size to develop internal friction". Warner (2003) reported that "many potential users of the procedures homed in on the one inch slump requirement but failed to appreciate the further dictum for development of internal friction". Hence one of the most important single factors affecting proper execution of compaction grouting is maintenance of the stiff grout consistency.

The rationale for considering $\mathrm{CKD}$ as a candidate material for compaction grouting is based on the following observations derived from the characterization study:

- In view of its silt sized particle size, CKD will serve as a good fine material in the grout mixture

- The high friction angle of CKD particles will contribute to manufacture a grout with sufficient internal friction

- Given its limited reactivity, unlike silts, CKD may provide some contribution to the strength of the grout

- The high water absorption capacity together with the low bleeding of CKD will assist in manufacturing low consistency uniform grout material 


\section{CHAPTER 7-- SOIL TREATMENT USING FRESH AND LANDFILLED CEMENT KILN DUST}

\subsection{Introduction}

This chapter summarizes the test results of the experimental work undertaken to evaluate fresh and the landfilled CKDs for soil treatment. Tests were performed in two stages on three Indiana low plasticity soils employing three different samples of fresh CKD and landfilled CKD.

In the first phase (performed during the proposal stage of this project) experiments were carried out employing two Indiana soils and fresh I CKD. The two soils obtained from Gibson county and Washington county, respectively, were selected by INDOT in close proximity to the cement plant to facilitate the subsequent probable trial field implementation. During this phase, most extensive testing was performed on "Gibson" soil, employing percentages of CKD equal to 8, 15 and 20\% (by dry mass of soil). The lower value was selected based on review of the pertinent literature, which indicated that at least $8 \%$ CKD was required to achieve effective soil stabilization (e.g. Miller and Azad, 2000; Bhatty et al., 1996 and Baghdadi et al., 1995). An upper value of $20 \%$ was fixed, based on the assumption that regardless of the potentially greater improvement in the mechanical properties, at higher dosages the costs associated with transportation and handling of the admixture would not make it a cost effective solution compared to lime and portland cement.

The results of the tests on the Gibson soil were used to provide an initial determination of the required percentage of $\mathrm{CKD}$, and helped define the testing program for the "Washington" soil, which focused almost exclusively on treatment with $15 \%$ CKD. To assess the performance of CKD with respect to other more traditional stabilizers, a limited number of tests were conducted employing portland cement. 
The second phase of the research on the use of CKD for soil stabilization started after the CKDs under consideration in this research (fresh II/III and landfilled CKD) had been characterized. At this time, a number of potential applications were identified. Given the limited reactivity of both the fresh and the landfilled CKD observed during the material characterization phase of the work, it was anticipated that the use of the two CKDs in traditional soil stabilization would likely not be effective. However, following interaction with members of the JTRP study advisory committee, it was decided that, given the strong interest of INDOT in identifying cost-effective alternatives for sub-grade treatment, preliminary tests should be conducted to see if the CKDs could be used alone or in combination with other additives for soil improvement. As is discussed in detail in this chapter, preliminary test results showed the incompetency of fresh III and landfilled CKDs to perform as stabilizing agents. However additional work showed the potential of using CKD in combination with a small amount of portland cement for treating wet subgrades or water logged areas. The soil used for this second testing phase was collected by INDOT from a construction site near the Indianapolis International Airport.

The following sections present and discuss the work performed to evaluate the potential of using the CKDs under consideration for soil treatment. While the majority of the data presented pertain to the second testing phase which involved fresh II/III and landfilled CKD, selected test results from the first phase of the study (with fresh I CKD) are also included in this chapter for comparative purpose. Note that this work is documented in a separate JTRP report (Santagata and Bobet, 2002) as well as in Sreekrishnavilasam et al. (2006).

\subsection{Soils Used}

Three low plasticity clays were used for the experimental work. The two soils obtained from Gibson county and Washington county, respectively, were selected by INDOT in close proximity to the cement plant to facilitate the subsequent probable trial field implementation. These soils are referred to in this report as "Soil G" and "Soil W", respectively. The third soil termed "Soil S" was collected from an INDOT construction site near the Indianapolis International airport. Soil samples, in the form of $20 \mathrm{lbs}$ bags 
were obtained by INDOT and delivered to the Purdue Geotechnical laboratory in different instances, as the need arose for more soil. The material obtained from all bags belonging to each batch was mixed in a concrete mixer to limit variability. Soil G was collected in three batches and soil $\mathrm{W}$ was collected in two batches while soil $\mathrm{S}$ was collected in one batch to limit soil variability.

The results of the classification tests performed on these soils are summarized in Table 7-1. Based on the results, all three soils can be classified as CL, low plasticity clays according to the Unified Soil Classification System (USCS) and as A-6 according to the AASHTO Classification System. Soil G was identified as a loess.

Table 7-1 Index properties and classification of soils used in the experimental program

\begin{tabular}{cccc}
\hline & G & W & S \\
\hline \hline Liquid Limit, LL(\%) & 33.7 & 36.0 & 41.0 \\
Plastic Limit, PL(\%) & 21.0 & 20.0 & 18.4 \\
Plasticity Index, PI(\%) & 12.7 & 16.0 & 22.6 \\
Specific Gravity, Gs & 2.707 & 2.704 & 2.700 \\
Clay Fraction (\%) & 19.0 & $17-29$ & 38.0 \\
Organic Content (\%) & 1.9 & 2.2 & 2.7 \\
pH & 5.5 & $4.5-5.0$ & 8.1 \\
Max.Dry Density (g/cm $\left.{ }^{3}\right)$ & 1.74 & 1.69 & 1.81 \\
OMC & 14.3 & 19 & 15.4 \\
USCS classification & CL & CL & CL \\
AASHTO classification & A-6 & A-6 & A-6 \\
\hline
\end{tabular}


Note that the characteristic properties reported in the table are the average values of different determinations performed on soils obtained from the different batches. One additional noteworthy observation on the results of the classification tests performed is the unusually low $\mathrm{pH}$ value of Soils $\mathrm{G}$ and $\mathrm{W}$.

\subsection{Experimental Program}

As discussed in previous sections the testing program was carried out in two distinct phases. The first phase made use of fresh I CKD and of soils G and W. The second phase of investigation was carried out using fresh III CKD and landfilled CKD and soil S. Table 7-2 summarizes the experiments carried out in the two phases of the experimental program. The most extensive testing was performed with soil G. The results of these tests helped limit the testing program for the two other soils. To assess the performance of CKD with respect to other traditional stabilizers, a limited number of tests were conducted employing cement. Testing with the landfilled CKD initiated in the second phase of the project, therefore involving only soil S. In this phase comparisons were made with the fresh material (fresh III) and selected tests were performed combining landfilled CKD with cement. Testing included compaction tests, unconfined compression tests, CBR-tests and swell tests. In addition, the effects of CKD on the soil's Atterberg limits and $\mathrm{pH}$ were also studied. 
Table 7-2 Summary of experimental program

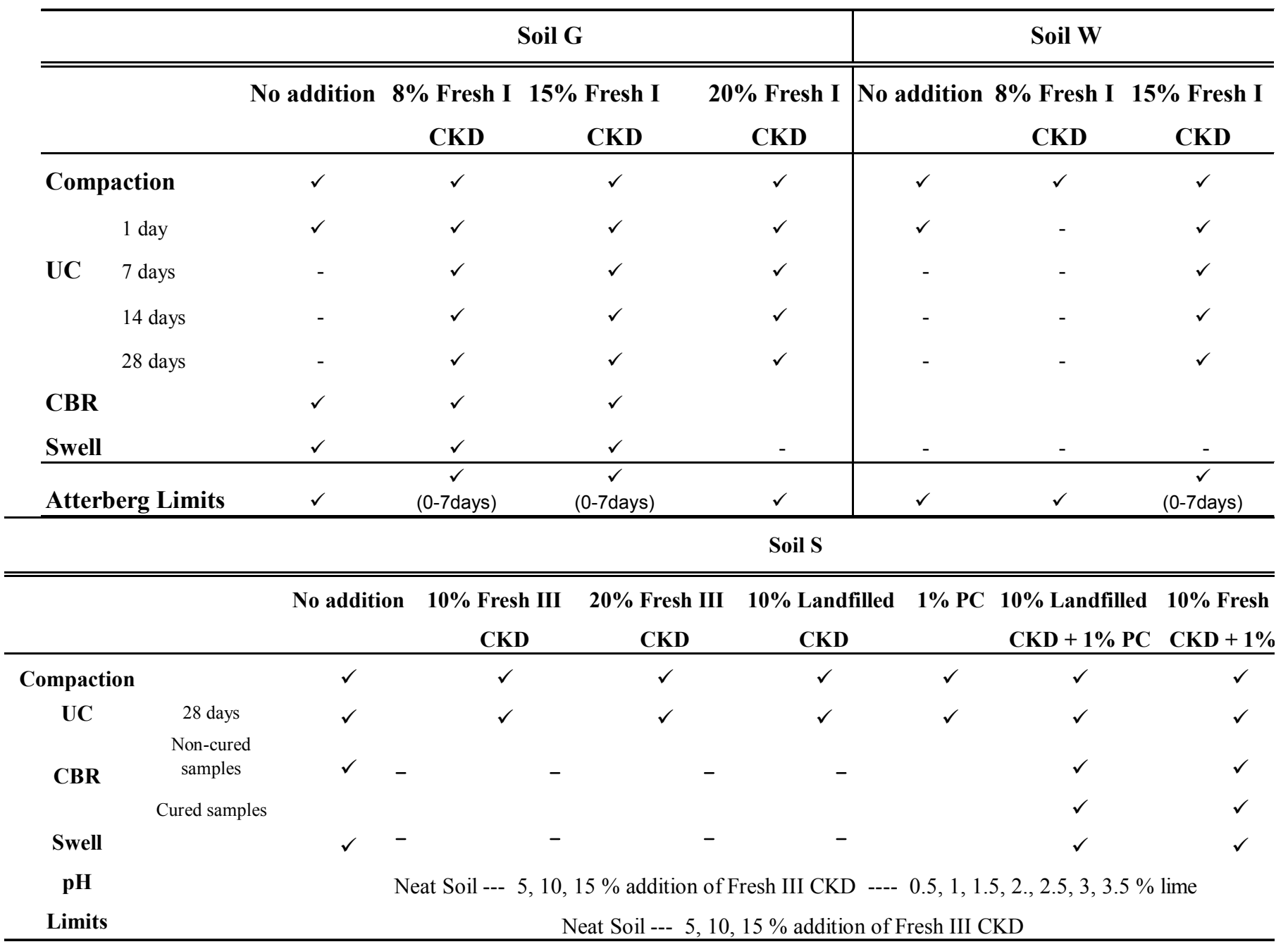




\subsection{Soil CKD Interaction- Rapid Ameliorating Effects}

\subsubsection{Atterberg Limits}

Table 7-3 summarizes the Atterberg limits of the neat soils and the soil CKD mixtures tested. For all soil-CKD combinations the data show a clear increase of the liquid limit (LL) and a slightly smaller increase of the plastic limit (PL) with CKD addition. The increase in both limits is proportional to the amount of CKD added. The plasticity index (PI) being a composite property increases only slightly.

Despite the difference in reactivity between fresh I and fresh III CKD, the effects of their addition on the liquid limit of soils $\mathrm{G}, \mathrm{W}$ and $\mathrm{S}$ are comparable. In the literature, trends of both increasing and decreasing LL with CKD percentages are reported depending on the soil and CKD used. For example Zaman et al. (1992) and Miller and Azad (2000) show that the LL increases in case of low plasticity clays and silts, while it decreases in the case of highly plastic clays. Given that the soils under consideration are CL clays, the results are consistent with previous experience.

In the case of the plastic limit, a difference is observed between fresh I and fresh III CKD, as the more reactive CKD produces a more significant change in PL, compared to fresh III CKD. For example with $15 \%$ fresh I CKD, the PL of soils G and W increases 4-5 percentage points; instead with $15 \%$ fresh III CKD, the change in the PL of soil is slightly above 1 percentage point (and possibly within experimental error). While the increase in PL with CKD addition is consistent with most data available in the literature (with the exception of some results by McCoy and Kriner (1971) for 5\% addition of a low lime, low alkali CKD), even in the case of fresh I CKD, the measured increase in PL is at the lower end of values reported by other researchers.

As discussed in detail later in section 7.6 in this chapter, following measurements of the strength, fresh I CKD was the only material found to be suitable for use in soil stabilization. It is interesting to note that the PL data are consistent with these results, i.e. a clear change in PL is measured only with the CKD that positively impacts the soil's strength. Moreover, the limited increase in PL measured for fresh I CKD, compared to other CKDs in the literature, is consistent with the fact that also the improvement in 
strength obtained with this material is at the low end of values reported by other researchers.

Overall, the above suggests that the change in PL (and not in LL) may be an indicator of the potential for stabilizing a soil. Note that also the lime fixation point, which is used to determine the quantity of lime required for stabilization, is based on the point of inflection of the plot of lime added versus PL (Hilts and Davidson, 1956).

The tests were not repeated with the landfilled CKD because of its limited reactivity. It is expected that the results would be similar to those obtained with fresh III CKD.

For soil S and fresh III CKD, the Atterberg limits were determined also after 1, 3, and 7 days after mixing the soil with the CKD. Overall the data indicate no significant change in the limits with time (Table 7-4).

Table 7-3 Atterberg limits and $\mathrm{pH}$ of soil-CKD mixtures

\begin{tabular}{lcccc}
\hline & & LL (\%) & PL (\%) & PI (\%) \\
\hline \hline \multirow{3}{*}{ Soil G } & 0\% Fresh I & 33.7 & 21.0 & 12.7 \\
& 15\% Fresh I & 37.7 & 21.3 & 16.4 \\
& 20\% Fresh I & 41.6 & 24.9 & 16.7 \\
Soil W & 0\% Fresh I & 41.0 & 25.9 & 15.1 \\
\hline \multirow{3}{*}{ Soil S } & 15\% Fresh I & 41.0 & 24.6 & 16.4 \\
\hline & 0\% Fresh III & 41.8 & 18.0 & 23.8 \\
& 5\% Fresh III & 41.0 & 17.8 & 23.2 \\
& $10 \%$ Fresh III & 44.5 & 19.2 & 25.3 \\
& 15\% Fresh III & 46.5 & 19.3 & 27.2 \\
& 20\% Fresh III & - & - & - \\
\hline
\end{tabular}


Table 7-4 Atterberg limits of soil $\mathrm{S}$ with fresh III CKD obtained at 0, 1, 3 and 7 days

\begin{tabular}{|c|c|c|c|c|c|c|}
\hline & \multirow{2}{*}{$\begin{array}{l}\text { Neat soil } \\
\text { (Average values } \\
\text { of limits) }\end{array}$} & \multirow{2}{*}{$\begin{array}{l}\text { Neat soil } \\
\text { (same used for } \\
\text { 5\% tests)* }\end{array}$} & \multicolumn{4}{|c|}{$5 \%$ CKD } \\
\hline & & & $\mathrm{t}=\mathbf{0 d a y s}$ & $\mathrm{t}=1$ day & $\mathrm{t}=\mathbf{3}$ days & $\mathrm{t}=7$ days \\
\hline LL(\%) & 41.8 & 41.8 & 41 & 42.25 & 41.4 & 41.4 \\
\hline $\operatorname{PL}(\%)$ & 18.4 & 17.73 & 17.82 & 17.4 & 16.91 & 17.03 \\
\hline \multirow[t]{3}{*}{$\mathrm{PI}(\%)$} & 22.6 & 23.28 & 23.98 & 24.85 & 24.49 & 24.37 \\
\hline & $\begin{array}{l}\text { Neat soil } \\
\text { (Average values } \\
\text { of limits) }\end{array}$ & $\begin{array}{l}\text { Neat soil } \\
\text { s (same used } \\
\text { for } 10 \% \text { tests)* }\end{array}$ & \multicolumn{4}{|c|}{$10 \%$ CKD } \\
\hline & & & $t=0$ days & $\mathrm{t}=1$ day & $\mathrm{t}=\mathbf{3}$ days & $\mathrm{t}=7$ days \\
\hline LL(\%) & 41.8 & 42.5 & 44.5 & 44.7 & - & 44.6 \\
\hline $\operatorname{PL}(\%)$ & 18.4 & 18.45 & 19.23 & 18.05 & - & 19.2 \\
\hline \multirow[t]{3}{*}{$\mathrm{PI}(\%)$} & 22.6 & 24.05 & 25.27 & 26.65 & - & 25.4 \\
\hline & $\begin{array}{l}\text { Neat soil } \\
\text { (Average values } \\
\text { of limits)* }\end{array}$ & $\begin{array}{l}\text { Neat soil } \\
\text { (same used for } \\
15 \% \text { tests)* }\end{array}$ & \multicolumn{4}{|c|}{$15 \%$ CKD } \\
\hline & & & $\mathrm{t}=\mathbf{0 d a y s}$ & $t=1$ day & $\mathrm{t}=\mathbf{3}$ days & $\mathrm{t}=7$ days \\
\hline LL(\%) & 41.8 & 42.5 & 46.5 & 46 & - & 45.2 \\
\hline PL(\%) & 18.4 & 17.85 & 19.29 & 18.5 & - & 19.74 \\
\hline PI(\%) & 22.6 & 24.65 & 27.21 & 27.5 & - & 25.46 \\
\hline
\end{tabular}

* Limits performed on soil used for tests with CKD, immediately prior to adding CKD.

\subsection{2 $\mathrm{pH}$}

$\mathrm{pH}$ values of soil $\mathrm{S}$ treated with different proportions of fresh III CKD are summarized in Table 7-5 The data show that the addition of up to $20 \%$ fresh III CKD is 
not able to elevate the $\mathrm{pH}$ of the soil-CKD system significantly, a condition necessary for the pozzolanic reaction between the soil and the free lime (if any) to occur.

In contrast, as expected, similar tests conducted adding $0.5 \%$ to $3.0 \%$ lime, show that a small percentage of lime is sufficient to elevate the $\mathrm{pH}$ above 12. Further addition of lime doesn't increase the $\mathrm{pH}$ beyond 12.4-12.45.

Table 7-5 pH values of soil, soil-CKD and soil-lime mixtures

\begin{tabular}{ll}
\hline Soil S & pH \\
\hline \hline $0 \%$ fresh III & 8.07 \\
$5 \%$ fresh III & 8.24 \\
$10 \%$ fresh III & 8.49 \\
$15 \%$ fresh III & 8.73 \\
$20 \%$ fresh III & 8.98 \\
\hline $0.5 \%$ lime & 11.74 \\
$1.0 \%$ lime & 12.12 \\
$1.5 \%$ lime & 12.30 \\
$2.0 \%$ lime & 12.42 \\
$2.5 \%$ lime & 12.45 \\
$3.0 \%$ lime & 12.40 \\
\hline
\end{tabular}




\subsection{Moisture Density Relations}

Compaction curves for all soil CKD combinations investigated in this study are shown in Figures 7-1 to 7-3, while Table 7-6 summarizes the optimum moisture content and maximum dry density for these mixtures. The figures show that as the percentage of CKD increases, the dry unit weight and optimum water content decrease and increase, respectively. This is the behavior typically associated with the addition of a binder to a cohesive soil (e.g. van Ganse (1971) for lime stabilized soils) and similar trends with the addition of CKD have been observed by other researchers (Zaman et al., 1991 and Miller and Azad, 2000). In contrast, Baghdadi et al. (1995) reported that for pure kaolinite the addition of CKD led to an increase in the compacted dry density and a slight decrease in the OMC. Note that the water content reported in all figures is calculated as the mass of the water divided by the mass of the soil alone (i.e. it represents the water content of the soil before treatment).

Overall, the same type of modification to the moisture-density relation is observed for all soil-CKD combinations explored (Figures 7-1 to 7-3). The degree to which the curve is shifted, is however, soil and CKD specific. For example, in the case of soil W (see Figure $7-2$ ), for up to $15 \%$ addition of fresh I CKD, there is hardly any change to the compaction curve. 


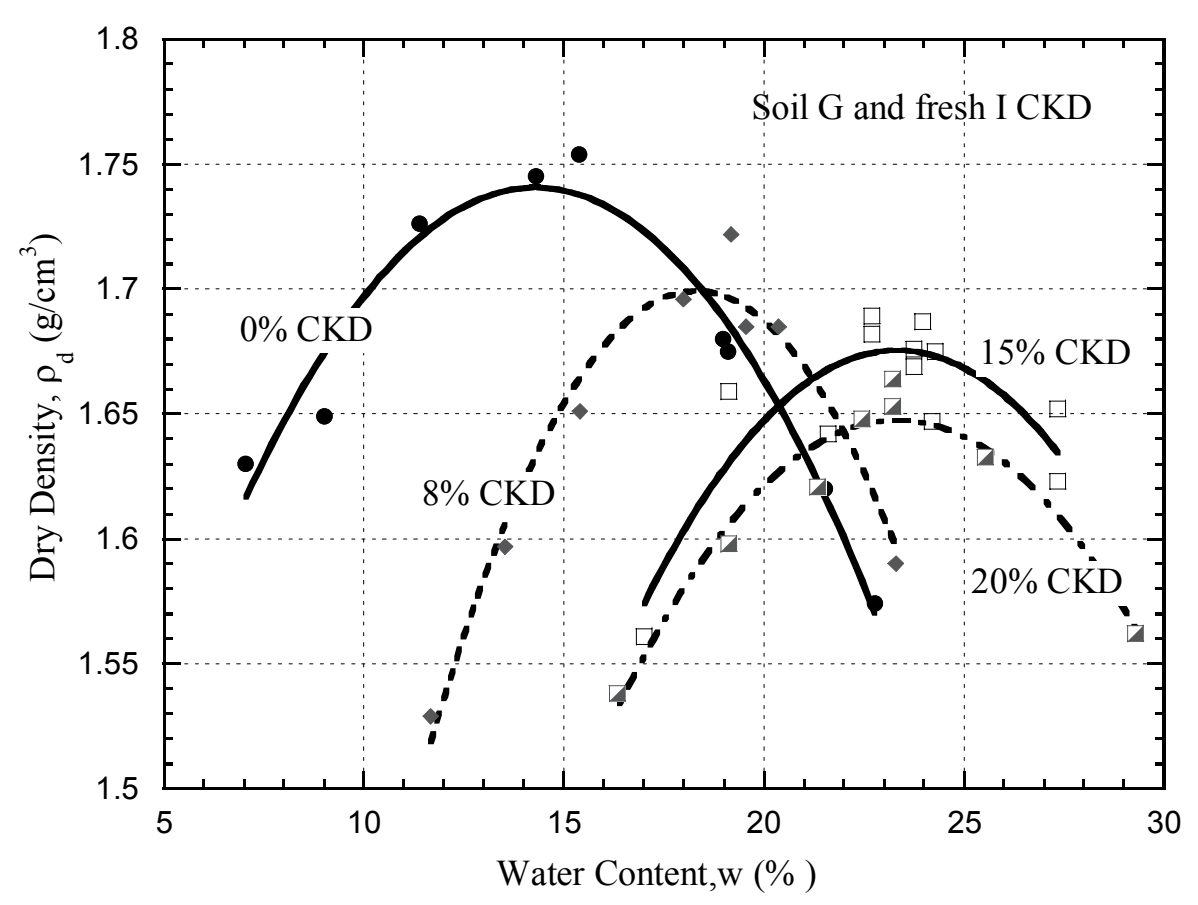

Figure 7-1 Moisture density relations for soil $\mathrm{G}$ treated with $0,8,15$ and $20 \%$ fresh I CKD

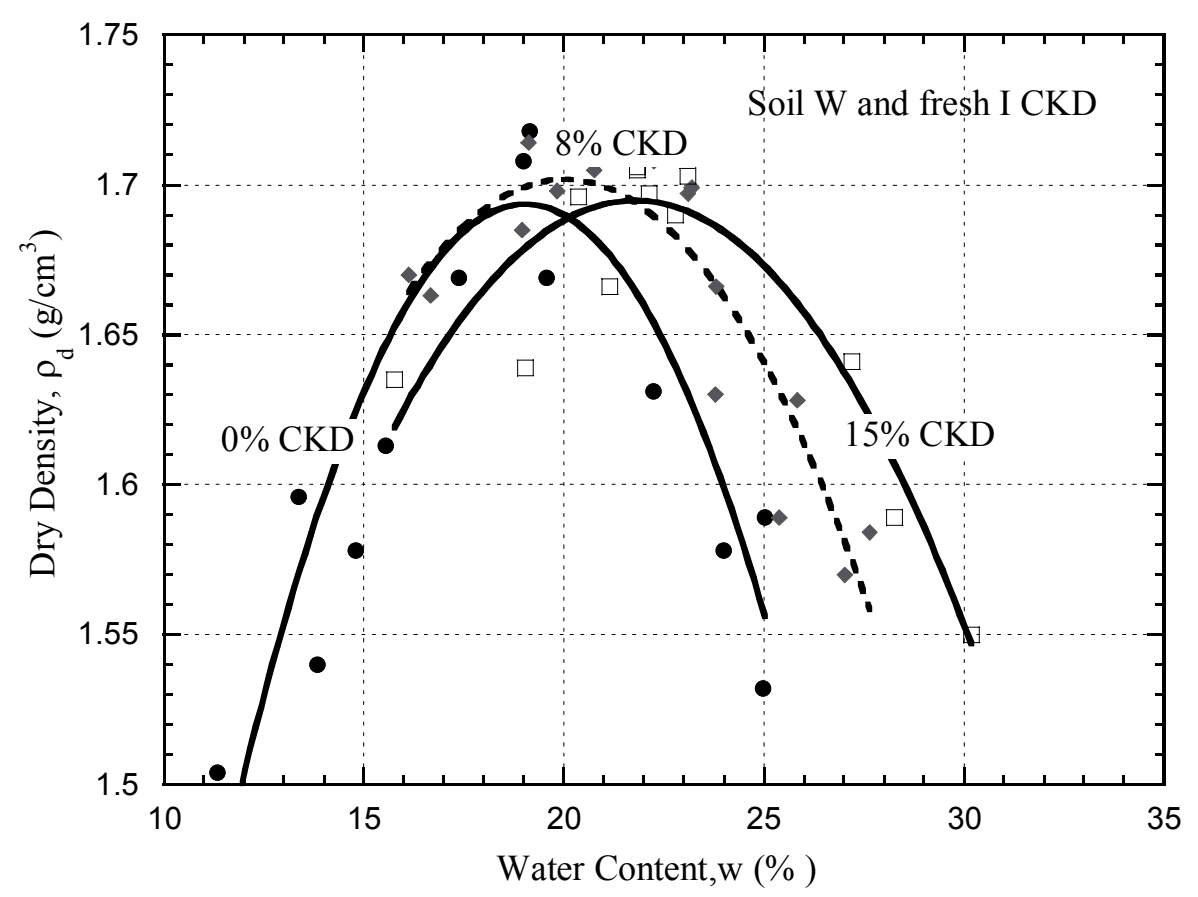

Figure 7-2 Moisture density relations for soil $\mathrm{W}$ treated with 0,8 , and $15 \%$ fresh I CKD 


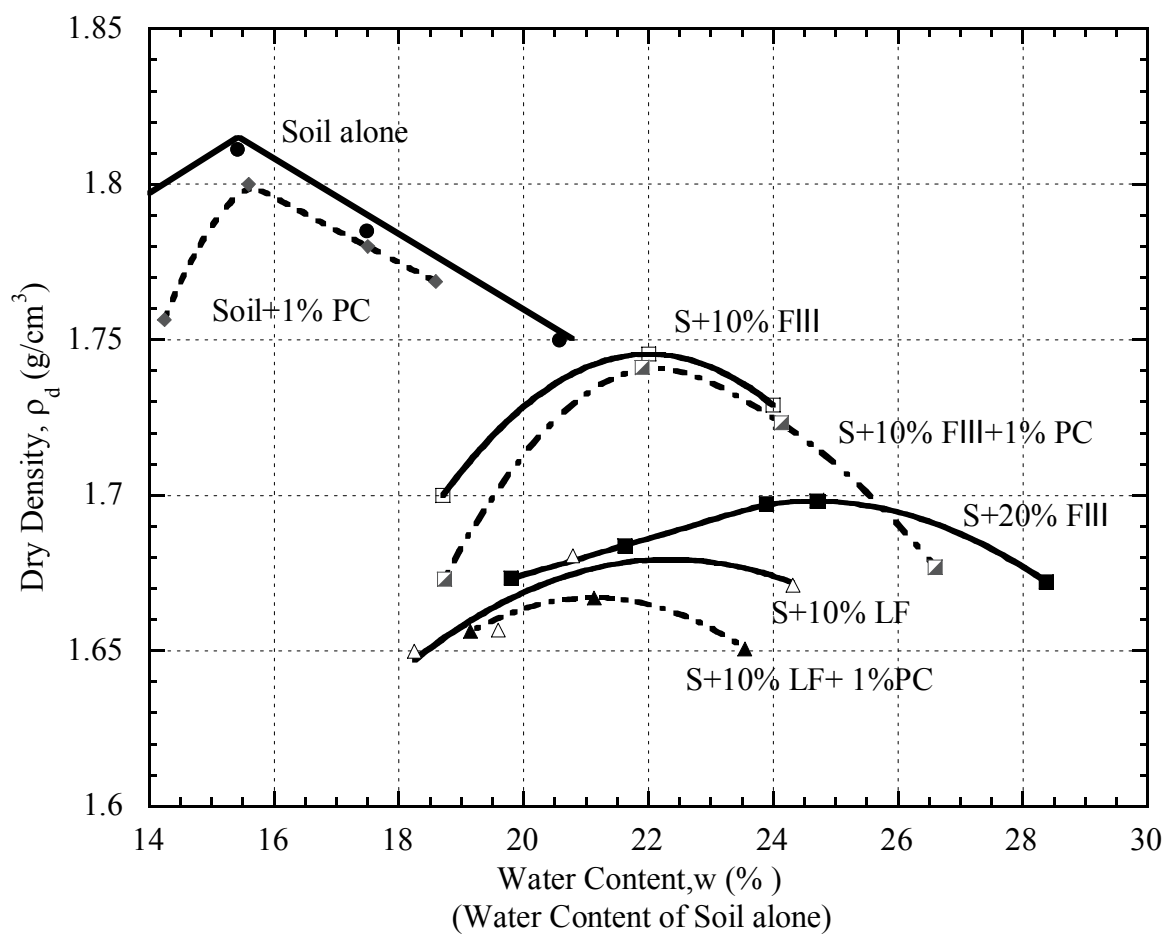

Figure 7-3 Moisture density relations for soil S treated with fresh III and landfilled CKD

The addition of landfilled CKD, used in the experimental program only in combination with soil $\mathrm{S}$, translates into the most significant change in compaction behavior (see Figure 7-3). For example, as observed from the above figures and Table 76, with $10 \%$ landfilled CKD the effects are similar to those caused by $20 \%$ of the fresh material. This is likely a by-product of the particular morphology of the landfilled CKD, which translates into a high water absorption capacity of this material. As a result, in presence of landfilled CKD, the soil remains workable and can be compacted at high water contents.

Table 7-6 also reports data for the same soil treated with 1\% cement, as well as with a mixture of $10 \%$ landfilled CKD and $1 \%$ of cement. It is shown that the addition of such a small amount of cement results in no significant change in the compaction curve (see Figure 7-3). The basis for these tests will be discussed later in the chapter. 
Table 7-6 Optimum moisture content and maximum dry density of soil-CKD mixtures

\begin{tabular}{|c|c|c|c|}
\hline & & OMC & $\rho_{d \max \left(g / \mathrm{cm}^{3}\right)}$ \\
\hline \multirow{5}{*}{ SoilG } & No addition & 14.3 & 1.74 \\
\hline & $8 \%$ Fresh I CKD & 19.5 & 1.70 \\
\hline & $15 \%$ Fresh I CKD & 23.7 & 1.65 \\
\hline & $20 \%$ Fresh I CKD & 23.3 & 1.65 \\
\hline & $4 \%$ Portland Cement & 17.0 & 1.72 \\
\hline \multirow{3}{*}{ Soil W } & No addition & 19.0 & 1.69 \\
\hline & $8 \%$ Fresh I CKD & 20.0 & 1.70 \\
\hline & $15 \%$ Fresh I CKD & 21.7 & 1.69 \\
\hline \multirow{7}{*}{ Soil S } & No addition & 15.4 & 1.81 \\
\hline & 10\% Fresh III CKD & 22.5 & 1.75 \\
\hline & $20 \%$ Fresh III CKD & 24.0 & 1.70 \\
\hline & $10 \%$ Landfilled CKD & 21.5 & 1.67 \\
\hline & $1 \%$ Portland Cement & 15.5 & 1.81 \\
\hline & $10 \%$ Fresh III $+1 \%$ PC & 21.5 & 1.74 \\
\hline & $10 \%$ Landfilled CKD $+1 \% \mathrm{PC}$ & 22.5 & 1.66 \\
\hline
\end{tabular}




\subsection{Unconfined Compressive Strength}

Due to the differences in the reactivity of the fresh I CKD compared to the fresh III and Landfilled CKDs, the unconfined compression test results for the two phases of the experimental program are discussed separately.

\subsubsection{Phase I - Tests with Fresh I CKD}

Unconfined compression tests were conducted using fresh I CKD in combination with both soils $\mathrm{G}$ and $\mathrm{W}$, with addition levels between 8 and $20 \%$, in the range of values reported in the literature for other CKDs. Some of the key results obtained on specimens compacted at OMC are summarized in Table 7-7. For soil G, for all percentages of CKD, measurements of the strength on specimens molded at the optimum moisture content showed some increase in the compressive strength. The magnitude of this increase $(\sim 35-$ $50 \%$ ) is quite modest (e.g., compare to more than $300 \%$ with $4 \%$ cement), and at the low end of the values reported in the literature for CL clays (e.g., Miller and Azad, 2000). This is undoubtedly in part a result of the substantial increase in OMC with addition of the $\mathrm{CKD}$, as the compressive strength reflects both the effects of the presence of the additive and the water content of the mixture. It is the interplay of these two factors that determines the degree to which the strength of the soil will be improved. So, for example, there does not seem to be any significant difference between the $8 \%$ and $15 \%$ CKD results (for $15 \% \mathrm{CKD}$ the $\mathrm{OMC}$ is higher). Also associated with the increase in $\mathrm{OMC}$ stemming from the addition of CKD is, as discussed below, a marked decrease in the unsoaked CBR strength. Following soaking, however, the CBR strength increases substantially as the CKD reacts, and no difference is observed between the neat and the CKD treated soil. 
Table 7-7 Unconfined compressive strength at optimum moisture content

\begin{tabular}{cccccc}
\hline Compressive Strength (kPa) & 1d & $\mathbf{7 d}$ & $\mathbf{1 4} \mathbf{d}$ & $\mathbf{2 8 ~ d}$ \\
\hline \hline & $0 \%(\mathrm{w}=14.3 \%)$ & 254 & - & - & - \\
G-soil + & $8 \%(\mathrm{w}=19.5 \%)$ & 365 & 401 & 364 & 392 \\
Fresh I & $15 \%(\mathrm{w}=23.7 \%)$ & 363 & 311 & 417 & 338 \\
CKD & $20 \%(\mathrm{w}=23.3 \%)$ & 590 & - & - & 710 \\
\hline G-soil + PC & $4 \%(\mathrm{w}=17.0)$ & 1069 & 1092 & 1063 & 1050 \\
\hline W-soil + & $0 \%(\mathrm{w}=19.0 \%)$ & 187 & - & - & - \\
Fresh I & $15 \%(\mathrm{w}=21.7 \%)$ & - & 511 & 531 & 545 \\
\hline
\end{tabular}

When the unconfined behavior of the CKD treated soil is compared at approximately the same water content the contribution of the additive is evident. For example, the strength measured with $20 \%$ CKD is much greater than for $15 \%$ CKD (the values of $\mathrm{OMC}$ are comparable). An additional illustration of this is presented in Figure $7-4$, which also highlights the effects of increased addition of CKD on the stress strain curve: the increased higher initial stiffness, the reduced strain at failure, and the overall more brittle behavior. Similar observations have been made in the case of cement treated soils.

Table 7-7, significantly greater improvement in strength $(\sim 180 \%)$ was measured in the case of soil $\mathrm{W}$ treated with $15 \% \mathrm{CKD}$. This is most likely linked to the negligible difference in the OMC, as for this soil the shift in the compaction curve up to $15 \%$ addition of CKD was negligible.

In all cases the compressive strength did not show any significant increase in time, most likely as a result of the low reactivity of the material and the limited access to water during curing. 


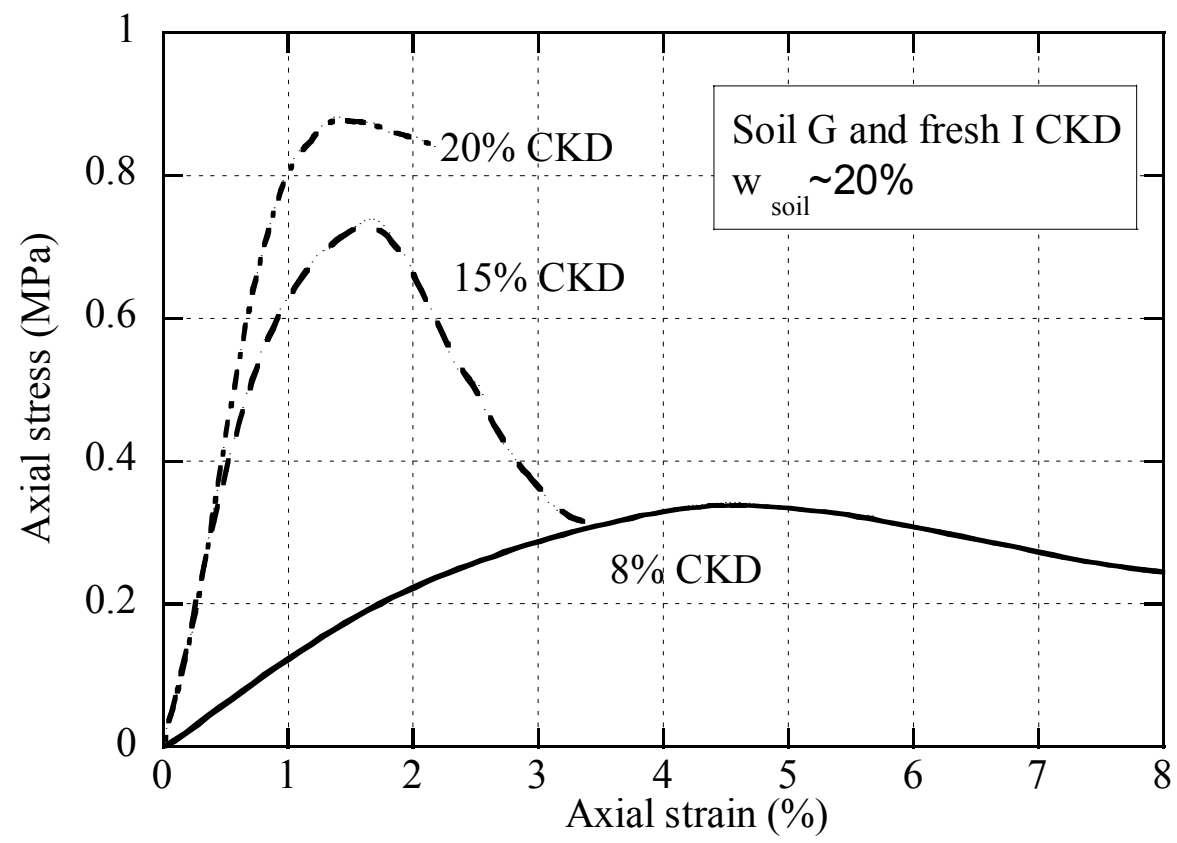

Figure 7-4 Stress-strain behavior of soil G treated with 8, 15 \& 20\% fresh I CKD (w 20\%)

\subsubsection{Phase II - Tests with Fresh III CKD and Landfilled CKD}

Testing with fresh III (10\% and 20\%) and landfilled (10\%) CKD involved only soil S. In all cases, the addition of CKD produced a clear reduction (20-50\%) in the compressive strength (Table 7-8). This is a result of the fact that for these basically nonreactive materials, it is the increase in water content that most affects the measured value of the strength. While the addition of CKD does most likely improve the frictional properties of the soil (see higher value of the UCS measured for $20 \%$ compared to $10 \%$ Fresh III CKD at basically the same water content), in this case this is probably a secondary effect.

Given these results, fresh III and landfilled CKD cannot be considered for "traditional" soil stabilization; there appear to be however potential advantages with the use of these materials for treating wet soils that could not be otherwise compacted. It was shown above that use of these fine additives allowed compaction at high water contents 
outside the range of compactability for the neat soil. Table 7-9 summarizes the UCS data measured on specimens obtained by compacting soil $\mathrm{S}$ at a water content of $23.6 \%$ and adding different additives.

Table 7-8 Unconfined compressive strength at optimum moisture content

\begin{tabular}{lcc}
\hline Compressive Strength $(\mathbf{k P a})$ & $\begin{array}{r}\text { 28d UCS } \\
\text { (kPa) }\end{array}$ \\
\hline \hline & No addition $(\mathrm{w}=15.4 \%)$ & 320 \\
+ & 200 \\
& $+20 \%$ Fresh III $(\mathrm{w}=22.5 \%)$ & 255 \\
S-soil & $+10 \%$ Landfilled $(\mathrm{w}=21.5 \%)$ & 150 \\
& $+1 \%$ Portland cement $(\mathrm{w}=15.5 \%)$ & 390 \\
& $+10 \%$ Fresh III $+1 \%$ PC $(\mathrm{w}=20.0 \%)$ & 500 \\
& $+10 \%$ Landfilled $+1 \%$ PC $(\mathrm{w}=21.5 \%)$ & 350 \\
\hline
\end{tabular}

Table 7-9 Effect of CKD on unconfined compressive strength of "wet" soil

\begin{tabular}{ccc}
\hline & & 28d UCS (kPa) \\
\hline \hline No addition & cannot be compacted \\
S-soil & $+1 \%$ Portland cement & cannot be compacted \\
& $+10 \%$ Fresh III & 150 \\
& $+10 \%$ Fresh III $+1 \%$ PC & 480 \\
$\mathbf{w}=\mathbf{2 3 . 6} \%$ & $+20 \%$ Fresh III & 255 \\
& $+10 \%$ Landfilled & 150 \\
& $+10 \%$ Landfilled $+1 \%$ PC & 350 \\
\hline
\end{tabular}

It is shown that due to the high water content both the neat soil and the soil with $1 \%$ cement (PC) cannot be compacted. The addition of the CKDs allows instead the soil to be compacted. If a small amount of cement is used in combination with either CKD the 
soil displays considerable strength. These results suggest that the two CKDs under investigation could be effectively used as "drying" agents for treating wet subgrades or water logged areas particularly in the colder seasons where simple drying of the soil might be problematic. The strength of the treated soil could then be improved by the addition of small quantities of cement.

\subsubsection{Selected Additional Unconfined Compressive Strength Data for Soil Treated with} Fresh and Landfilled CKD

Additional information from the unconfined strength tests on soil $\mathrm{S}$ treated with fresh II and landfilled CKD is presented in the following sections.

\subsection{Effect of CKD Percentage}

The following graph presents the 28-day stress strain results obtained from two unconfined compression tests performed on soil S compacted at approximately the same water content $(\sim 21 \%)$ with $10 \%$ and $20 \%$ fresh III CKD, respectively. The data indicate that at the same water content increasing percentage of fresh CKD translates into a marginal improvement in strength, and a reduced strain at peak. Similar observations were made for soil G treated with fresh I CKD (Figure 7-4). However the increase in strength with increase in fresh I CKD \% was much more significant than that observed in Figure 7-5. This is primarily due to the high reactivity (high free lime content) of fresh I CKD, compared to fresh III CKD. 


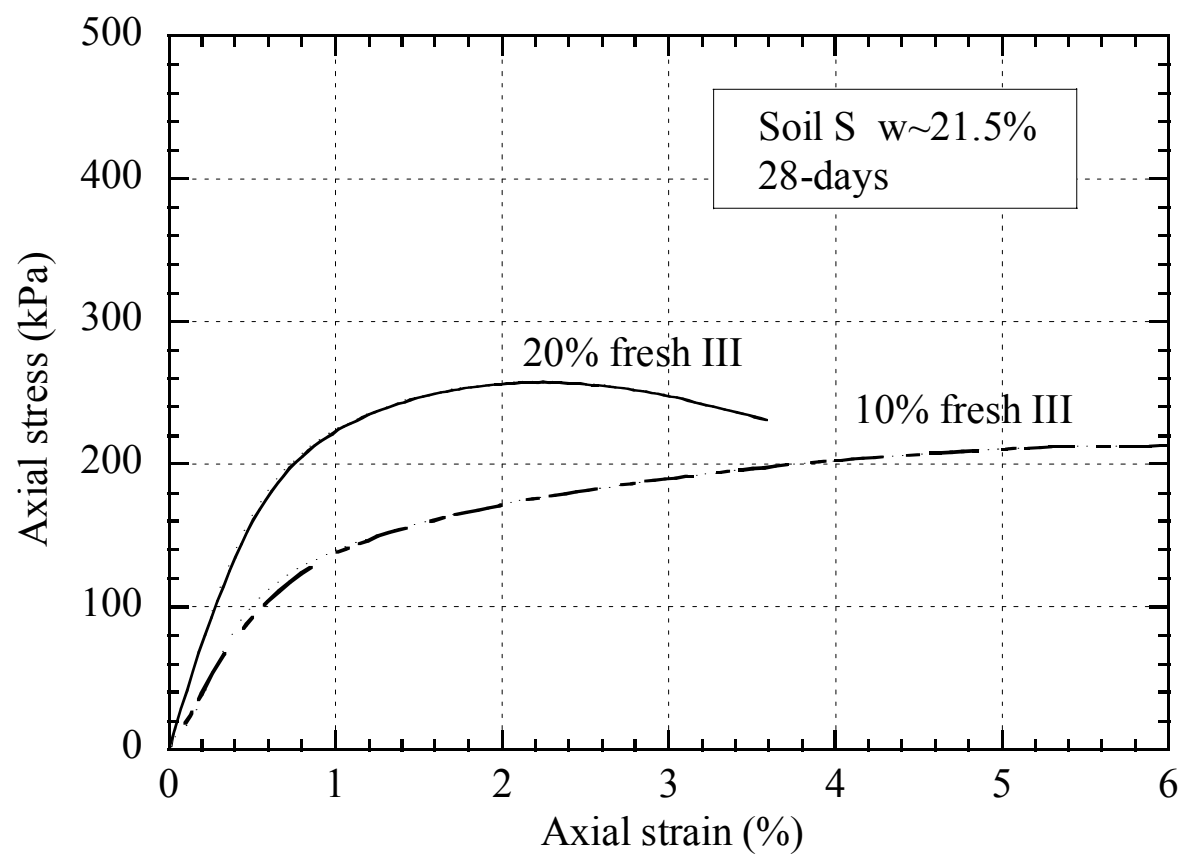

Figure 7-5 Effect of percentage of fresh III CKD on stress strain behavior

\subsection{Effect of Water Content}

Figure 7-6 presents the 28-day stress strain results obtained from three unconfined compression tests performed on soil S compacted with $20 \%$ fresh III CKD at water contents equal to 20,24 and $28 \%$. These data indicates that for the same percentage of $\mathrm{CKD}$ an increase in water content is associated with a decrease in compressive strength and an increase in strain at peak. Similar observations apply for soil treated with landfilled CKD (see Figure 7-7). 


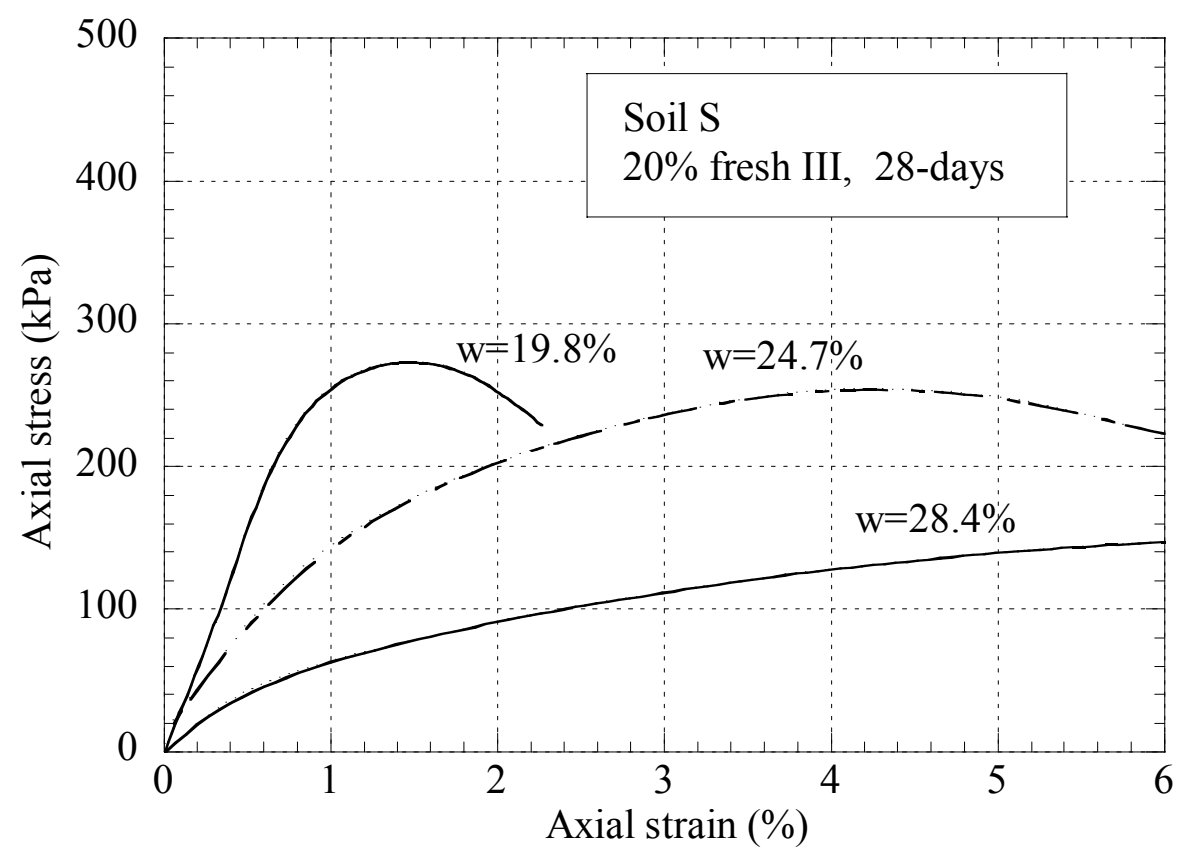

Figure 7-6 Effect of soil water content on stress strain behavior (soil S and with 20\% fresh III CKD)

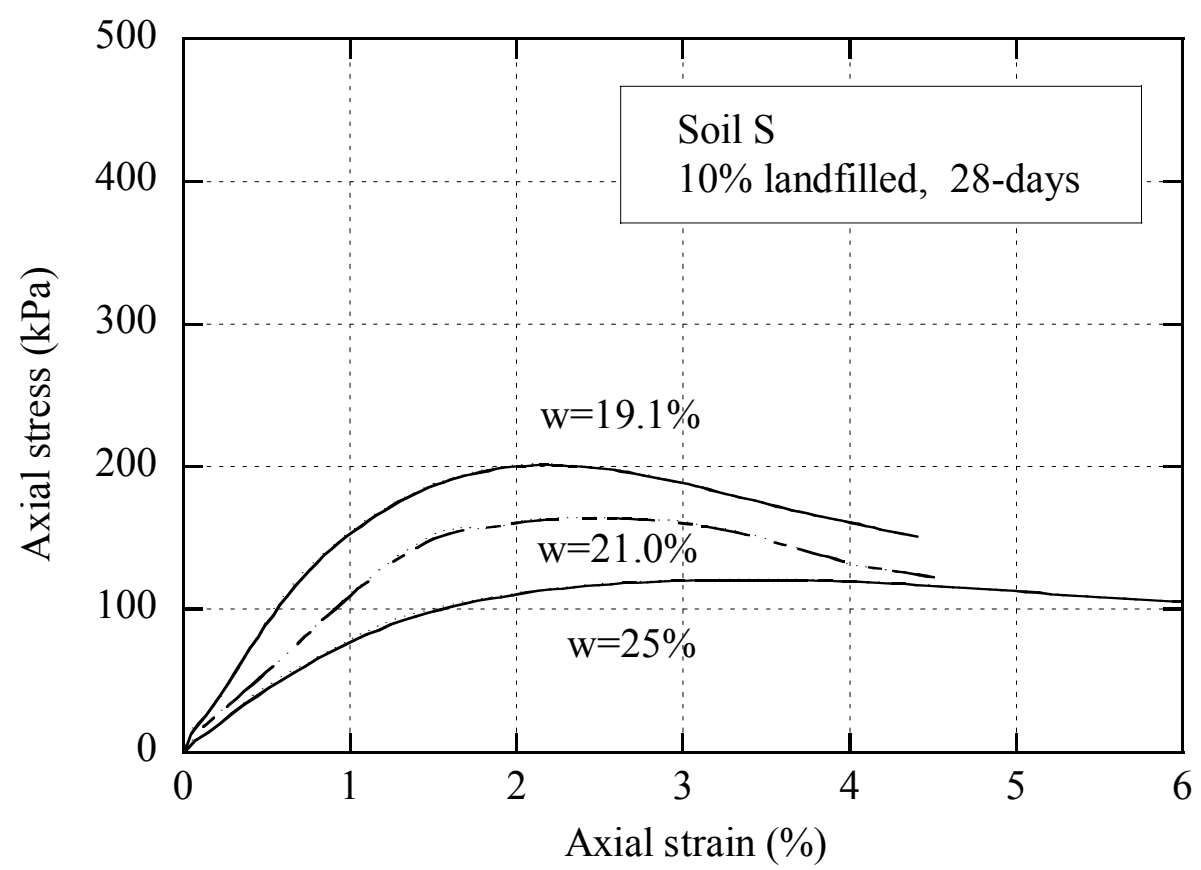

Figure 7-7 Effect of soil water content on stress strain behavior (soil S treated with $10 \%$ landfilled CKD) 


\subsection{Combined Use of CKD and Portland Cement}

As discussed in the previous sections in presence of $10-20 \%$ fresh III and landfilled CKD, soils at high water content (outside the range of compactability of neat soil) could be in fact compacted without difficulties and without needing any drying. However the strength of the CKD treated soil under these conditions was limited. This is a result of the fact that for these basically non-reactive materials, it is the increase in water content that most affects the measured value of the strength. The potential advantage with the use of fresh III and landfilled CKD for treating wet soil could be promoted by the addition of small amount of portland cement. Selected test results from the unconfined compressive strength tests performed on soil $\mathrm{S}$ treated with fresh III or landfilled $\mathrm{CKD}$ in combination with $1 \%$ portland cement are presented in Figures 7-8 through 7-10.

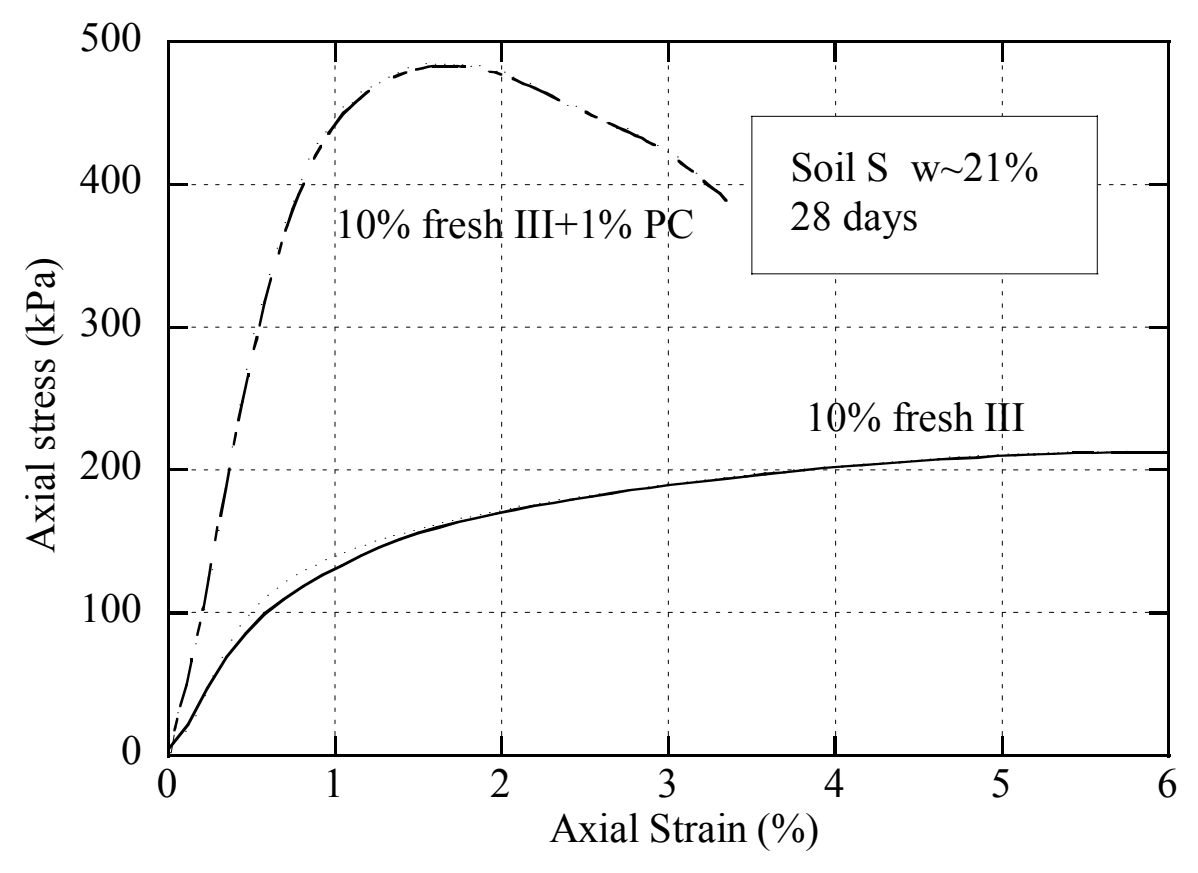

Figure 7-8 Effect of $1 \%$ portland cement on soil treated with $10 \%$ fresh III 


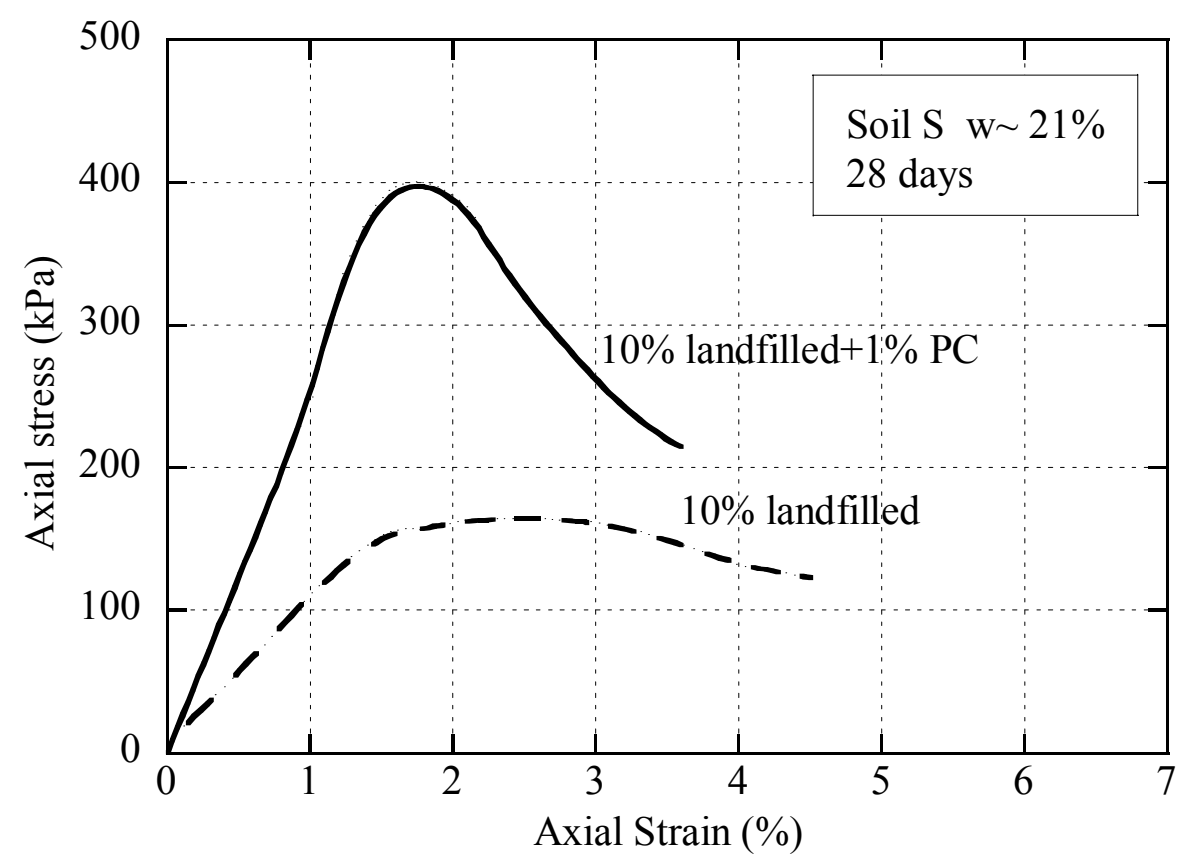

Figure 7-9 Effect of $1 \%$ cement on soil treated with $10 \%$ landfilled CKD ( $\mathrm{w}_{\text {soil }}$ OMC)

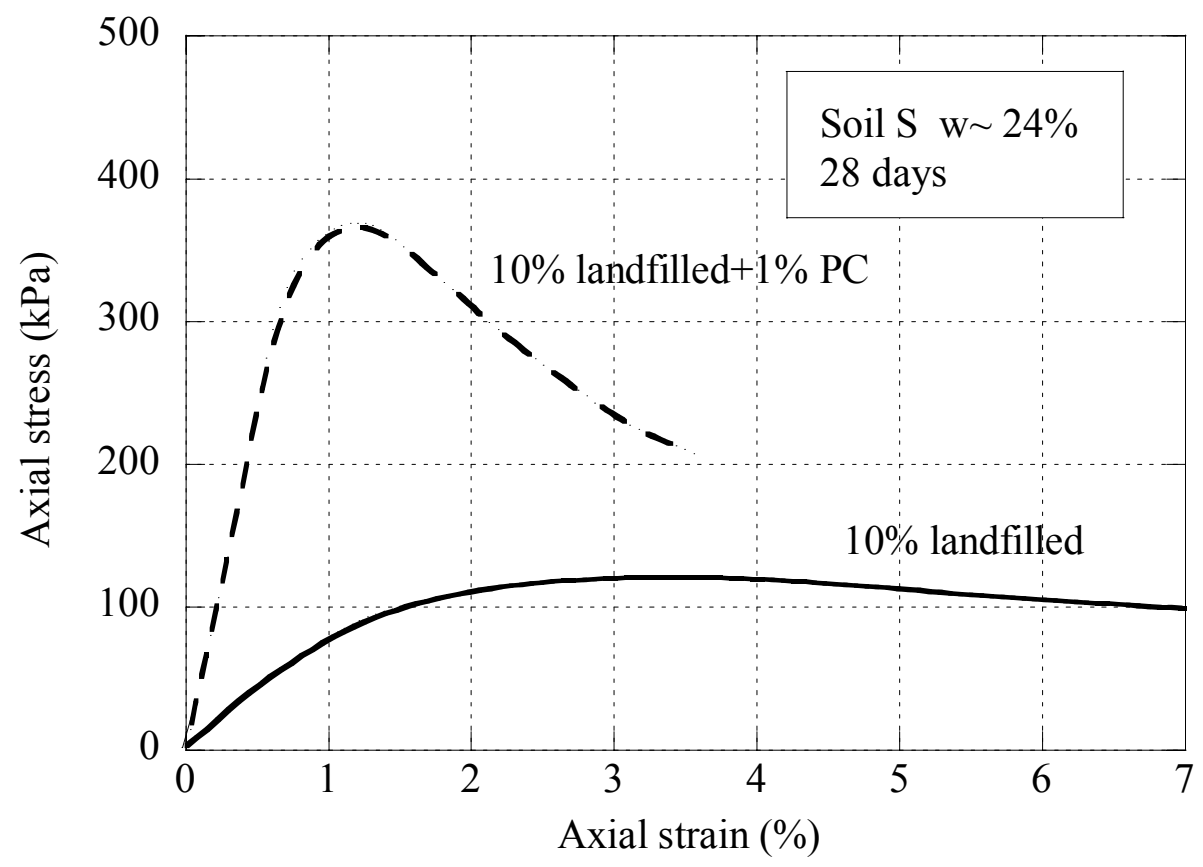

Figure 7-10 Effect of $1 \%$ cement on soil treated with $10 \%$ landfilled $\mathrm{CKD}\left(\mathrm{w}_{\text {soil }}>\mathrm{OMC}\right)$ 
Figure 7-8 shows the 28 day unconfined compressive behavior of soil $\mathrm{S}$ (compacted at a water content of $21 \%$ ) treated with $10 \%$ fresh III CKD and also with a combination of $10 \%$ fresh III CKD and 1\% PC. Significantly greater improvement in strength $(\sim 150 \%)$ was measured in the case of soil S treated with $10 \%$ fresh III CKD and 1\% portland cement compared to soil $\mathrm{S}$ treated with CKD alone. Figure 7-9 and Figure 710 presents similar test results for soil $\mathrm{S}$ compacted with landfilled CKD at water contents equal to $21 \%$ and $24 \%$ respectively. As observed for soil S treated with fresh III CKD, significant improvement in strength is observed by the addition of portland cement. It is noteworthy to mention again that at the above mentioned range of water contents the soil alone is out side the range of compactability. The significant increase in strength suggests that the combined use of landfilled or fresh III CKD and cement might prove to be an effective means to address construction on wet soils.

\subsection{CBR Results for Soaked and Unsoaked Specimens}

CBR tests were conducted on soil S with $10 \%$ fresh III and 10\% landfilled CKD in combination with $1 \%$ PC compacted at a water content approximately equal to $24 \%$. Note that this water content is significantly outside the range of compactability of the neat soil (see Figure 7-3). The compacted specimens were cured in the CBR mold in the humid room for 14 days allowing cementation reactions, if any, to take place. As discussed in Chapter 5, for each CKD percentage two tests were performed: one immediately after compaction (unsoaked) and one following 4-days of soaking in water (soaked). In the case of the neat soil two CBR specimens were prepared at a water content of approximately $19 \%$, significantly on the wet side of optimum and close to the maximum water content at which the soil could be compactable in the laboratory. Table 7-10 summarizes the tests results.

Additionally, CBR tests were also conducted on soil-CKD mixtures compacted at their respective optimum water contents. The specimens were tested without any curing. The results of these tests are summarized in Table 7-11. 
Table 7-10 CBR indices of specimens compacted at wet of OMC (CKD treated specimens cured in the humid room for 14 days before testing)

\begin{tabular}{lccc}
\hline & 0\% CKD & $\mathbf{1 0 \% F I I I + 1 \% P C}$ & $\mathbf{1 0 \%} \mathbf{L F + 1 \% P C}$ \\
\hline \hline CBR unsoaked & 6.5 & 39.9 & 33.1 \\
CBR soaked & 3.0 & 30.4 & 27.5 \\
Water content $(\%)$ & 19.5 & 23.5 & 23.5 \\
\hline
\end{tabular}

Table 7-11 CBR values of CKD treated soil compacted at OMC (no curing prior to testing)

\begin{tabular}{|c|c|c|c|}
\hline & 0\% CKD & $10 \%$ FIII+1\% $\%$ PC & $10 \% \mathrm{LF}+1 \% \mathrm{PC}$ \\
\hline CBR unsoaked & - & 27.5 & 18.1 \\
\hline CBR soaked & - & 22.9 & 11.6 \\
\hline Water content $(\%)$ & - & 20.0 & 21.5 \\
\hline
\end{tabular}

The results above show that:

1. The CBR index of soil treated with fresh III CKD is higher than that of soil trated with landfilled CKD,

2. Even at considerably higher water contents, the CBR value of the treated soil is higher than that of the neat soil,

3. A significant reduction in CBR index is observed following soaking most likely due to the high water absorption capacity of CKD. Note that data previously reported (Santagata and Bobet, 2001) for Gibson-soil treated with 8\% and 15\% fresh I CKD specimens showed a moderate increase in the CBR index following soaking.

4. Despite the higher water content, the CBR index of the specimens cured for 14 days is greater than that measured on the specimens prepared at optimum water 
content. This suggests that while the reactivity of both CKDs is modest, some reactions are indeed taking placing during the curing period.

\subsection{Swelling Behavior}

Data on the swelling behavior of CKD treated soil immersed in water was derived from both the soaking phase of the CBR tests as well as from long term swelling tests conducted on triaxial size specimens (see Chapter 5 sections 5.3.5 and 5.3.6).

\subsubsection{Swelling Behavior from CBR Tests}

This section presents the swelling data relative to the soaking phase preceding the CBR (soaked) penetration tests described in the previous section. For reference also the data for neat soil at a water content of $18 \%(\sim 2 \%$ above OMC) are shown. The figures provided below illustrate that in presence of CKD swelling of the soil during immersion in water is greatly reduced. This effect is likely to result from both the higher water content (and different degree of saturation) at which the soil CKD mixtures were compacted as well as from some effective contribution by the CKD in combination with small amount of portland cement. Similar observations were made for soil G treated with $15 \%$ fresh I CKD. As shown in Figure 7-13, in this case it was found that the reduction in swelling was comparable to that achieved with $4 \%$ portland cement. In the case of the tests performed with the G soil all specimens were prepared at OMC. Thus, the degree of saturation changed from specimen to specimen. In case of the neat soil (which showed the greatest swell) the degree of saturation is equal to approximately $70 \%$. In the two treated specimens the degree of saturation is estimated at approximately $77 \%$ (soil with $4 \%$ portland cement) and $90 \%$ (soil with $15 \%$ fresh I CKD). 


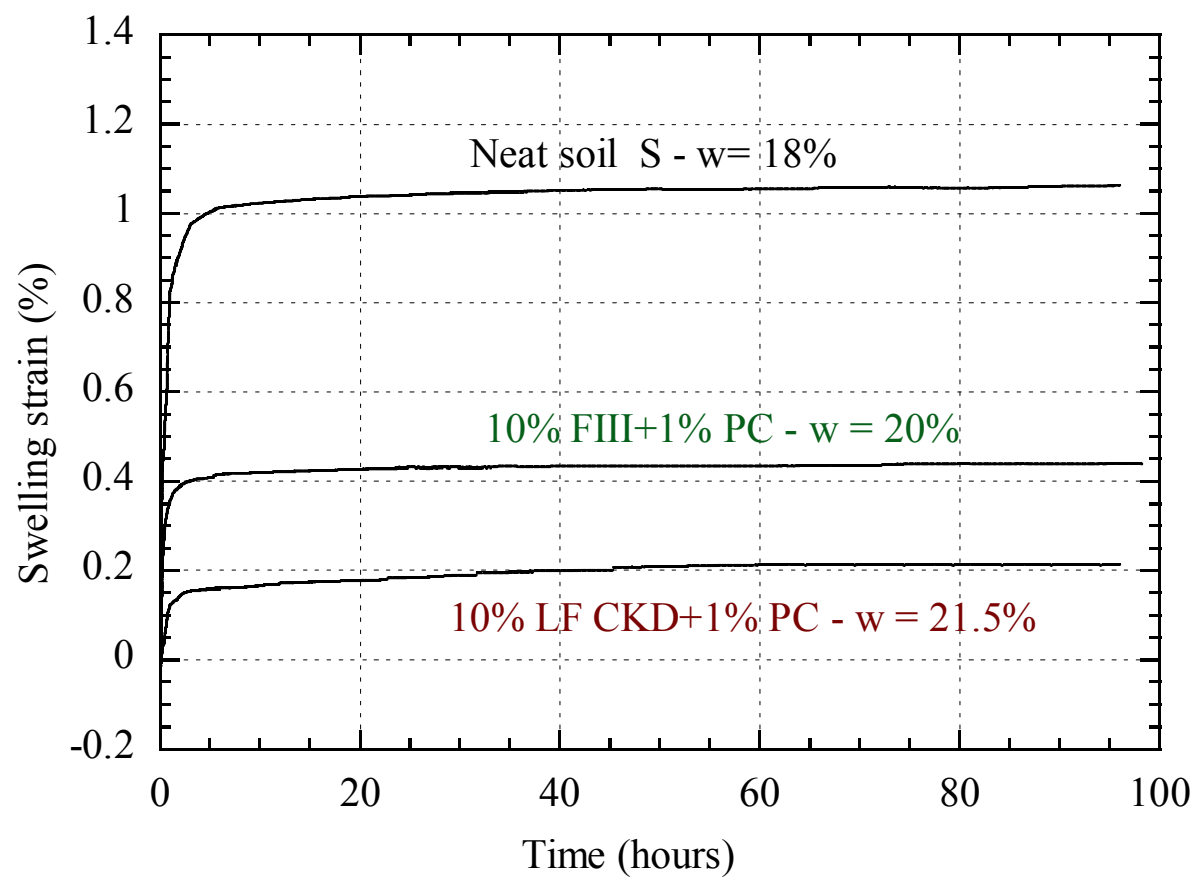

Figure 7-11 Swelling behavior of compacted CKD treated soil (Soil S) specimens at OMC

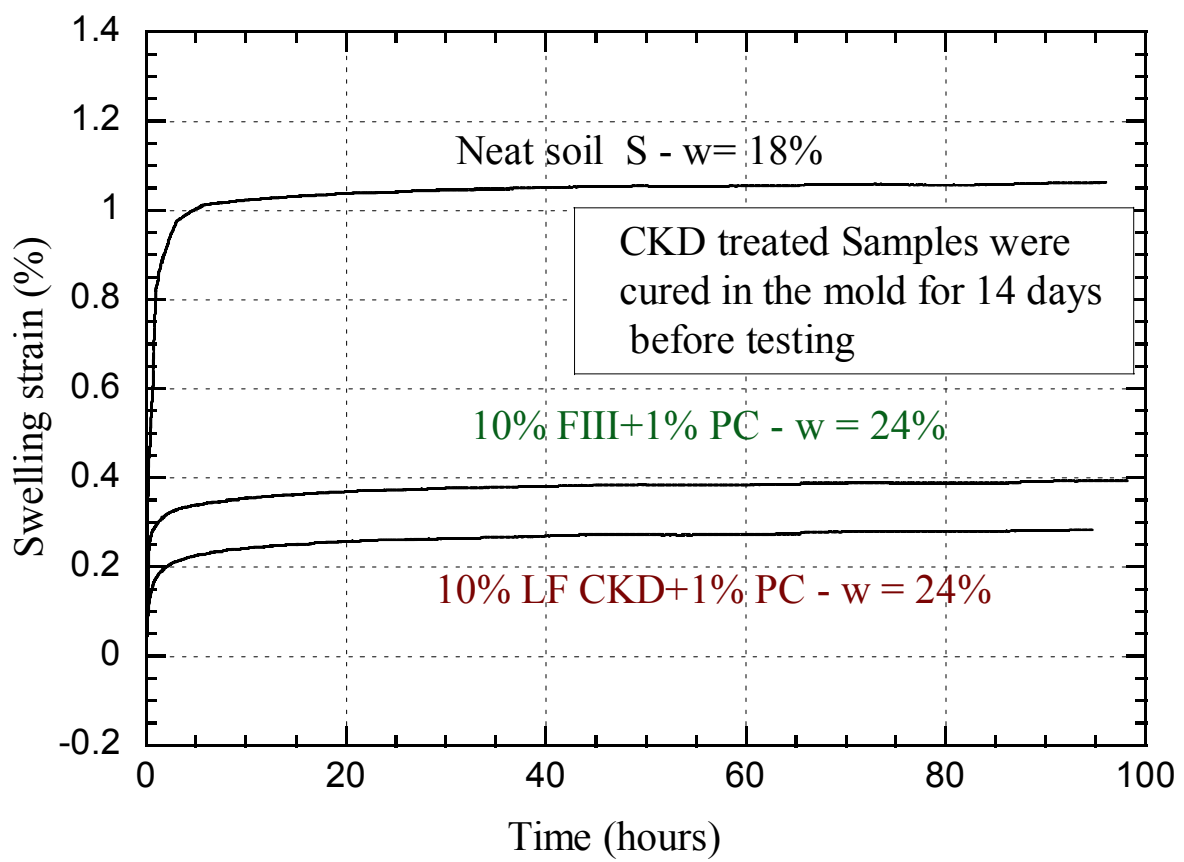

Figure 7-12 Swelling behavior of compacted CKD treated soil (Soil S) specimens (cured for 14 days) at higher water content 


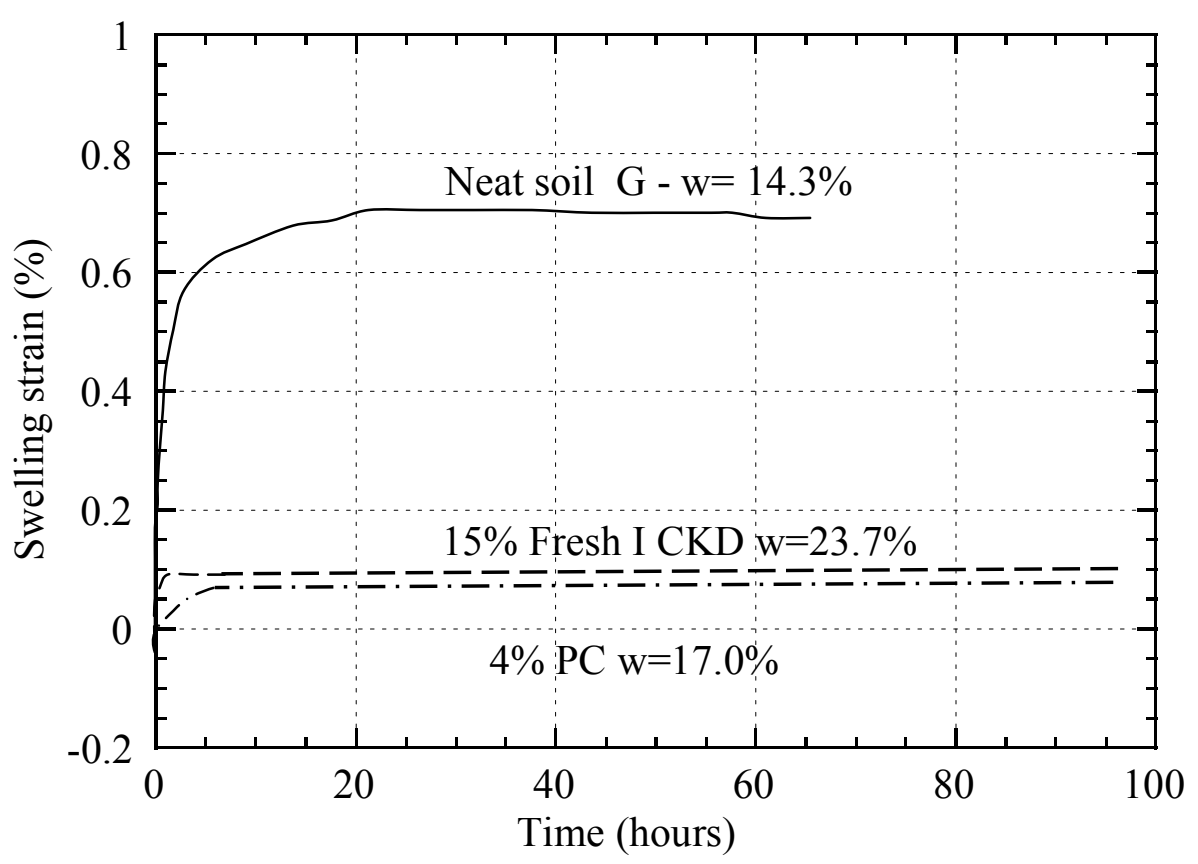

Figure 7-13 Effect of addition of Fresh I CKD and cement (PC) on the swelling behavior of soil $\mathrm{G}$

\subsubsection{Long Term Swelling Behavior}

Additional long term tests were performed in the custom designed setup described in Chapter 5 on specimens all compacted at a water content of $19.5 \%$ (the greatest water content at which the neat soil could be compacted by kneading). The goal of these tests was to assess the longer term swelling behavior of the CKD treated soils.

The results of these tests are shown in Figure 7-14. The data indicate that once the vertical swelling has fully developed during the first 100 hours of testing, the height of the specimen remains constant. Note that the results presented in Figure 7-14 cannot be directly compared to those presented in Figures 7-12 because the boundary conditions differ (access to water is only to the top of the specimen in the case of the CBR specimens, while the triaxial size specimens have access to water from the sides). 


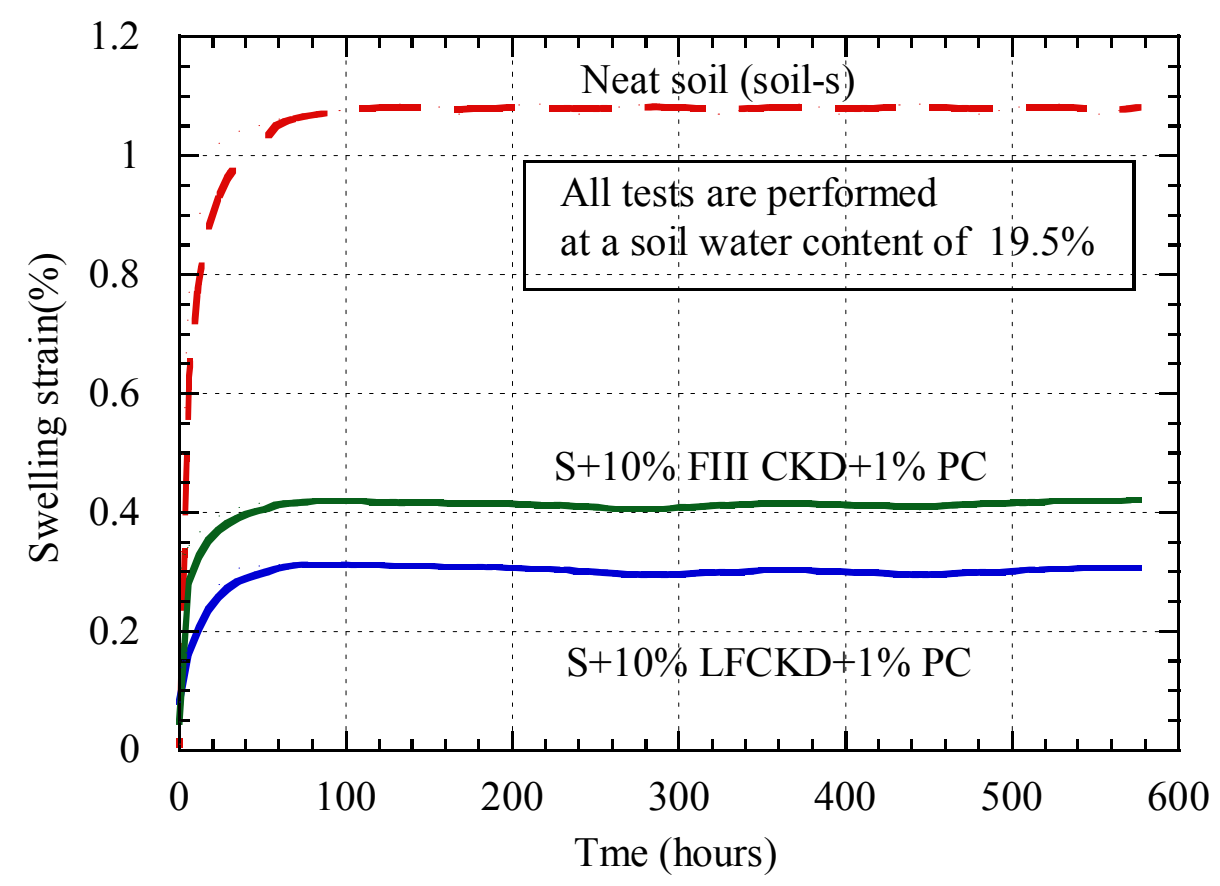

Figure 7-14 Results of long term swelling tests for soil S

Table 7-12 presents the range in vertical swelling obtained for neat soil and CKD modified soil for different testing conditions. Overall, it can be concluded that treatment with CKD and portland cement is effective in reducing the swelling of the soil during immersion in water.

Table 7-12 Maximum percentage vertical swell of tested specimens

\begin{tabular}{lccc}
\hline \multicolumn{1}{c}{ Test } & Neat soil & $\begin{array}{l}\text { Soil }+10 \% \text { fresh III } \\
+1 \% \mathrm{PC}\end{array}$ & $\begin{array}{l}\text { Soil }+10 \% \text { landfill } \\
+1 \% \mathrm{PC}\end{array}$ \\
\hline \hline $\begin{array}{l}\text { Swelling before } \\
\text { CBR(soaked) }\end{array}$ & $\begin{array}{c}1.0 \\
(\mathrm{w} \sim 18.0 \%)\end{array}$ & $\begin{array}{c}0.4-0.45 \\
(\mathrm{w} \sim 20.0-24 \%)\end{array}$ & $\begin{array}{c}0.22-0.26 \\
(\mathrm{w} \sim 21.5-24.5 \%)\end{array}$ \\
Long term swell & 1.0 & 0.4 & 0.3 \\
& $(\mathrm{w} \sim 19.5 \%)$ & $(\mathrm{w} \sim 19.5 \%)$ & $(\mathrm{w} \sim 19.5 \%)$ \\
\hline
\end{tabular}

$\mathrm{w}$ is the water content of the treated soil. 


\subsection{Conclusions}

This chapter presented the results of the experimental investigation on the use of cement kiln dust (CKD) for soil stabilization. Three CKDs were employed: two fresh ones (termed fresh I and fresh III) collected from the same US plant at different times (note that changes to the plant processing technology were implemented after collection of fresh I), and one landfilled CKD sampled from the landfill in proximity to the plant used for CKD disposal for more than 12 years. The experimental program included a variety of tests (compaction, unconfined compression, swell and limits, $\mathrm{pH}$.) on three Indiana low plasticity clays (indicated as soils $\mathrm{G}, \mathrm{W}$ and $\mathrm{S}$ ), combined with $8-20 \%$ of these CKDs (by dry mass of soil).

The main conclusions derived from this work can be summarized as follows:

- The suitability of a CKD for soil stabilization is dependent on the presence of free lime. While similar in oxide composition, LOI $(\sim 33 \%)$ and particle size distribution, the CKDs differed in the free lime content which was found to be negligible for fresh III and landfilled CKD, and estimated at 2-5\% for fresh I, based on historic data and XRD results. As a result, fresh I was found to have some reactivity and showed some promise for use in soil stabilization, while the other two CKDs behaved as essentially inert materials.

- While it appears from the literature that CKDs with lower loss on ignition (LOI) are generally more reactive, it is found that the LOI alone is not a good parameter for estimating the reactivity of a CKD. The three CKDs employed in the program had essentially identical LOI ( $\sim 33 \%)$ yet behaved differently.

- For most soil-CKD combinations investigated, probably due to the large percentages employed (8-20\% by dry mass of soil) and the fineness of the material, the addition of CKD leads to a substantial shift in the compaction curve (higher OMC and lower $\rho_{\mathrm{dmax}}$ with increasing $\mathrm{CKD} \%$ ). This indirectly affects the strength results as comparison between neat and CKD treated soils are performed on specimens compacted at OMC. 
- For the CKD (fresh I) that exhibited some reactivity, dosages equal or greater than $15 \%$, well in excess of those used for other binders, were necessary for increasing the strength of the soil.

- Despite the fact that the soils used were all CL clays, the improvement in the unconfined compressive strength was found to vary significantly from soil to soil. Limited improvement (35-50\%) in the strength was observed in the case of soil G (which was identified as loess), while significantly greater increase in strength $(\sim 180 \%)$ was observed for soil $\mathrm{W}$, for which the changes to the moisture density relationship with up to $15 \%$ CKD were minimal.

- For fresh I CKD, in addition to the improvement in strength, a reduction of the swelling strains associated with immersion in water, comparable to that obtained using 4\% cement, was observed.

- For the other two CKDs, the results of this research suggest that, thanks to the high specific surface, their use might be advantageous for saving time and costs in constructing on wet soils and/or water logged areas. In presence of 10-20\% of these CKDs, soils at high water content (outside the range of compactability of the neat soil) could be in fact compacted without difficulties and without needing any drying.

- While the strength measured under these conditions was limited, the addition of a small amount $(1 \%)$ of cement significantly increased the strength. This suggests that the combined use of landfilled or fresh III CKD and cement might prove to be an effective means to address construction on wet soils.

- Fresh III and landfilled CKD in combination with portland cement are effective in reducing the swelling of the soil during immersion in water.

- Measurements of the Atterberg limits of soil-CKD mixtures suggest that the change in plastic limit (PL) may be a good indicator of the potential for a CKD to stabilize the soil.

- While more limited $\mathrm{pH}$ data were available, it appears that the ability of a CKD to raise the $\mathrm{pH}$ of a soil might also be used to predict the reactivity and stabilizing potential of a CKD. 
A field trial implementation appears necessary to validate the conclusions presented and also to assess field performance, particularly in the long term. Recommendations for field implementation are provided in Chapter 9. 


\title{
CHAPTER 8 -- CKD IN CONTROLLED LOW STRENGTH MATERIALS
}

\begin{abstract}
$\underline{8.1 \text { Introduction }}$
An overview of controlled low strength materials (CLSM) and of the use of CKD in CLSM was presented in Chapter 2. This chapter presents the results of the experimental study conducted to determine the fresh and hardened-state properties of CLSM with CKD as one of the components. The properties of CLSM with CKD (CKDCLSM) are compared with two fly ash-CLSM (FA-CLSM) mixtures currently used by the Indiana Department of Transportation, INDOT. The properties studied include: flow behavior, bleeding, setting time, strength and excavatability. Additionally, the corrosiveness of selected CLSM mixes is studied by analyzing electrochemical parameters like $\mathrm{pH}$ and resistivity and also by conducting model corrosion tests. A brief discussion on the advantages and disadvantages of using CKD in CLSM concludes the chapter.
\end{abstract}

\subsection{Materials}

The CKDs used in this testing program include fresh III and landfilled CKD. The chemical and physical properties of these CKDs are discussed in detail in Chapter 6. The class $\mathrm{C}$ fly ash and sand used was obtained from the Materials Engineering laboratory of the School of Civil Engineering, Purdue University.

Table 8-1 summarizes the specific materials included in this study. The sand gradation is shown in Figure 8-1. Also shown are the upper and lower limits used by INDOT for the gradation of fine aggregates. 
Table 8-1 Types and properties of materials used in the CLSM

\begin{tabular}{ll}
\hline Material & Type or Class \\
\hline \hline Portland Cement & ASTM Type $\mathrm{I}\left(\mathrm{G}_{\mathrm{s}}=3.15\right)$ \\
Fly ash & ASTM Class C $\left(\mathrm{LOI}=1.34 \%, \mathrm{G}_{\mathrm{s}}=2.42\right)$ \\
Fresh III CKD & $\mathrm{G}_{\mathrm{s}}=2.68 \quad$ LOI $=34.98 \%$ \\
Landfilled CKD & $\mathrm{G}_{\mathrm{s}}=2.61 \quad$ LOI $=33.74 \%$ \\
Fine aggregate & ASTM C $33 \quad$ concrete sand $\left(\mathrm{G}_{\mathrm{s}}=2.62\right.$, \\
& Absorption $=1.82 \%, \mathrm{FM}=2.8)$ \\
\hline
\end{tabular}

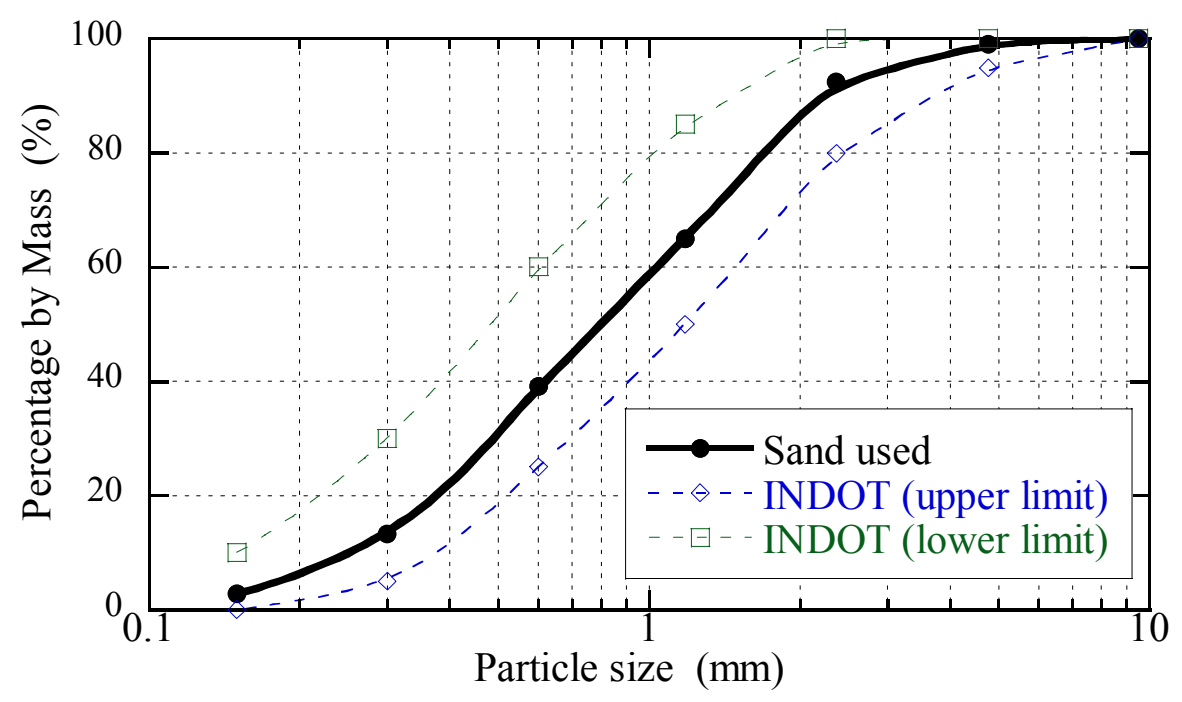

Figure 8-1 Particle size distribution of sand used

\section{$\underline{8.3 \text { Experimental Program }}$}

The testing program was aimed at determining the feasibility of using the fresh and landfilled CKD in CLSM and comparing their properties with commonly used INDOT fly ash-CLSM mixes. As the name indicates the primary property of flowable fill in most applications is its flowability and self leveling nature. CLSM requires no compaction and hence is ideal for use in tight and restricted-access areas where placing 
and compacting soil or granular fill would be difficult or even impossible. The consistency of flowable fills used in geotechnical applications is similar to that of a lean grout or slurry, yet several hours after placement the material hardens enough to support traffic loads without settlement. The strength requirements ensure that CLSM has adequate bearing capacity and does not deform excessively under load. Maximum strength recommendations also ensure that CLSM can be removed or excavated with conventional excavating equipment.

In this research the properties of both fresh (flowability, bleeding, unit weight and setting time) and hardened CKD-CLSM (unconfined compressive strength, excavatability) were studied. Given that the corrosion of metal structures (e.g. pipes) is a major concern, and given that the CKDs under the present investigation were identified as potentially corrosive (see Chapter 6), additional tests were conducted to explore the corrosiveness of CKD-CLSM further.

\subsection{Mix Proportions}

This section describes the proportions of the CLSM mixes used in this research. Table 8-2 summarizes the composition of the eleven mixtures investigated. Each mixture is denoted by a number (\#1-\#11) and by a label which indicates if the mixture has high, medium or low cement content and which by-product material was used.

As shown in Table 8-2, two mixtures manufactured with fly ash and not including any CKD were used for reference. The mix designs for this fly ash-CLSM were based on a written communication from Thoeming, N.E, Irving Materials, Inc. (APPENDIX II). The low fly ash mixture (\#2-LFA) is a commonly used mix for pipe fill and places where high flowability is required. It is reported that the drawback of this mix is the long setting time. The high fly ash mix (\#1-FA) is used where pumping long distances is required and where future excavation is likely not to be necessary. Issues with unsatisfactory strength development of this mix have been reported in the case of sands from certain sources like Lafayette and Crawfordsville (APPENDIX B).

The cement content used varied from approximately 15 to $50 \mathrm{~kg} / \mathrm{m}^{3}$ which is at the lower end of values reported in the literature. Katz and Kovler (2004) reported that 
the cement content is generally in the range of $50-100 \mathrm{~kg} / \mathrm{m}^{3}$ of CLSM to provide the desired strength. Given the low cement contents used in the INDOT reference mixes with fly ash, the decision was made to limit the cement dosage to $50 \mathrm{~kg} / \mathrm{m}^{3}$. In Table $8-2 \mathrm{HC}$, MC, LC denote the quantity of cement used: high $\left(\sim 50 \mathrm{~kg} / \mathrm{m}^{3}\right)$, medium $\left(\sim 30 \mathrm{~kg} / \mathrm{m}^{3}\right)$ and low $\left(\sim 15 \mathrm{~kg} / \mathrm{m}^{3}\right)$, respectively. Throughout this chapter, the term "high cement specimens" is used as a relative expression to refer to CLSM specimens with a cement content of $\sim 50 \mathrm{~kg} / \mathrm{m}^{3}$. FCKD stands for fresh CKD and LFCKD stands for landfilled CKD. Fly ash is denoted by FA. Mixes were prepared with CKD content of approximately 100 and $200 \mathrm{~kg} / \mathrm{m}^{3}$. Finally, two mixes (FA-FCKD1 \& FA-LFCKD1) were prepared with equal amounts of CKD and fly ash.

Table 8-2 Mix proportions for the CLSM used

\begin{tabular}{ccccccc}
\hline Mix \# & Mix Reference & $\begin{array}{l}\text { Cement } \\
\left(\mathbf{k g} / \mathbf{m}^{\mathbf{3}}\right)\end{array}$ & By -product material & $\begin{array}{l}\text { By- } \\
\text { product } \\
\text { content } \\
\left(\mathbf{k g} / \mathbf{m}^{\mathbf{3}}\right)\end{array}$ & $\begin{array}{l}\text { Sand } \\
\text { (dry } \\
\text { weight) } \\
\left(\mathbf{k g} / \mathbf{m}^{\mathbf{3}}\right)\end{array}$ & $\begin{array}{c}\text { Water } \\
\left(\mathbf{k g} / \mathbf{m}^{\mathbf{3}}\right)\end{array}$ \\
\hline \hline 1 & HFA & 15 & Fly ash C & 237 & 1560 & 285 \\
2 & LFA & 30 & Fly ash C & 80 & 1560 & 330 \\
3 & HC-FCKD2 & 47 & Fresh III & 186 & 1566 & 335 \\
4 & HC-FCKD3 & 50 & Fresh III & 100 & 1599 & 354 \\
5 & MC-FCKD1 & 29 & Fresh III & 190 & 1585 & 333 \\
6 & LC-FCKD1 & 14 & Fresh III & 190 & 1584 & 337 \\
7 & HC-LFCKD1 & 47 & Landfilled & 190 & 1520 & 351 \\
8 & HC-LFCKD2 & 50 & Landfilled & 100 & 1599 & 354 \\
9 & MC-LFCKD1 & 30 & Landfilled & 99 & 1585 & 366 \\
10 & FA-FCKD1 & 30 & Fly ash +Fresh III & $62+62$ & 1654 & 329 \\
11 & FA-LFKD1 & 29 & Fly ash +Fresh III & $61+61$ & 1626 & 338 \\
\hline
\end{tabular}

$\begin{array}{lll}\text { HFA-High fly ash } & \text { HC-High cement } & \text { FCKD-Fresh } \\ & \text { MC-Medium cement } & \text { LFCKD -Landfilled CKD }\end{array}$




\subsection{Properties of CLSM}

\subsubsection{Properties of Fresh CLSM}

\subsubsection{Flow Behavior}

Flowability is the most important attribute of flowable fill which allows the material to be placed without compaction. Flow consistency of the flowable fill mixture was measured using a straight tubing open ended plastic cylinder having dimensions 150 $\mathrm{mm} \times 75 \mathrm{~mm}$ as per ASTM D 6103-97. While measuring the flow consistency, it was observed that the CLSM mixtures containing CKD were cohesive, homogeneous and flowed as a heavy liquid without any segregation of particles (Figure 8-2). An important and necessary condition to obtain the constructive "pancake" consistency type flow is that fine particles present in the mix are able to hold water within its body without letting the water seep out in a short period of time.

By contrast, the fly ash mixtures, particularly the LFA mix, did not appear very homogeneous, and showed segregation and bleeding, which are known to adversely affect the pumpability of a mix. These differences are highlighted in Figure 8-2 which presents pictures of a LFA mixture and a CKD based mix taken immediately after the flowability test. Note that it is reported that INDOT uses the LFA mix generally where high flowability is required (APPENDIX II).

For all CLSM mixtures prepared with CKD, irrespective of the type and quantity of $\mathrm{CKD}$ used, the amount of water required to meet the flow requirement was between 335 and $370 \mathrm{~kg} / \mathrm{m}^{3}$ (Table 8 -2). Slightly smaller dosages of water are reported in the literature for other CKD-CLSMs. For example, Katz and Kovler (2004) reported a water demand of $320 \mathrm{~kg} / \mathrm{m}^{3}$ for a CKD-CLSM manufactured with a CKD coarser than those used in this study. In another study (Al-Jabri et al. 2002) with a low LOI (10\%) a water demand of $333 \mathrm{~kg} / \mathrm{m}^{3}$ was reported.

Considering the variability in physical and chemical characteristics of CKD, it is difficult to compare the water demand of CKD-CLSMs manufactured with CKDs from different sources. Note, however that the comparatively higher water demand observed for the CKDs under investigation in this research is consistent with their great fineness. 
Table 8-2 also indicates that for the same cement content and the same addition of fly ash or CKD, the CKD-CLSM has greater water demand than the fly-ash based mix (e.g. compare mix\#1 and mix \#6). This can be again attributed to the greater fineness of the CKD, as well as to the spherical morphology of fly ash particles. It has been reported (Katz and Kovler, 2004) that the water demand depends not only on the amount of fines present in the mix but also on their shape.

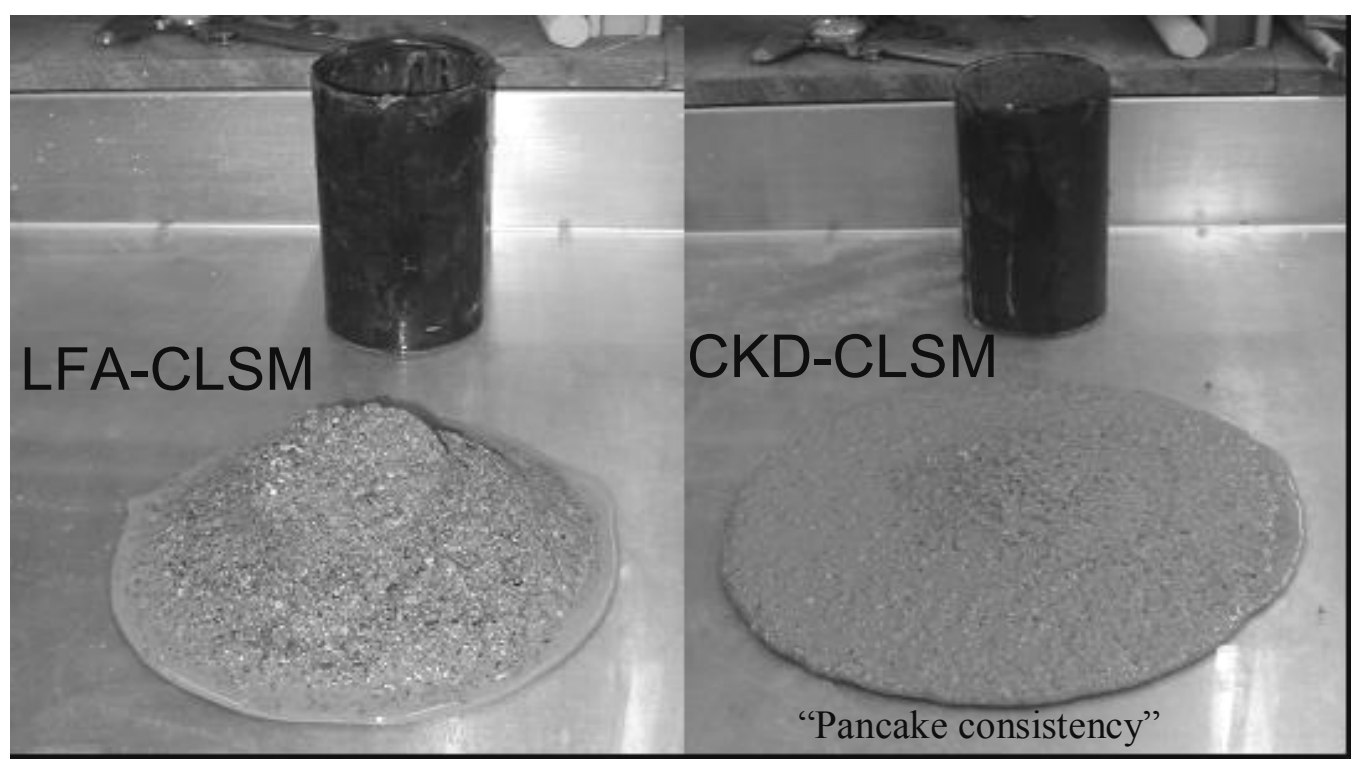

Figure 8-2 Flowability tests on LFA-CLSM and CKD-CLSM (HC-FCKD3) 
Table 8-3 Properties of fresh CLSM

\begin{tabular}{cllcccc}
\hline Mix \# & Mix Name & $\begin{array}{l}\text { By-Product } \\
\text { Material }\end{array}$ & $\begin{array}{l}\text { Total } \\
\text { Bleeding } \\
(\mathbf{\%})\end{array}$ & $\begin{array}{l}\text { Fresh Unit } \\
\text { Weight } \\
\left(\mathbf{k g} / \mathbf{m}^{\mathbf{3}}\right)\end{array}$ & pH & $\begin{array}{c}\text { Resistivity } \\
\text { (Ohm-cm) }\end{array}$ \\
\hline \hline 1 & HFA & Fly ash C & 5 & 2164 & 11.94 & 1200 \\
2 & LFA & Fly ash C & 3.12 & 2181 & - & - \\
3 & HC-FCKD2 & Fresh III & 2.07 & 2157 & - & - \\
4 & HC-FCKD3 & Fresh III & 3.05 & 2123 & 12.34 & 450 \\
5 & MC-FCKD1 & Fresh III & 1.8 & 2155 & - & - \\
6 & LC-FCKD1 & Fresh III & 2.38 & 2143 & - & - \\
7 & HC-LFCKD1 & Landfilled & 3.12 & 2090 & - & - \\
8 & HC-LFCKD2 & Landfilled & 1.52 & 2062 & 12.55 & 340 \\
9 & MC-LFCKD1 & Landfilled & 1.37 & 2086 & - & - \\
10 & FA-FCKD1 & Fly ash C+Fresh III & 0.33 & 2110 & 12.17 & 630 \\
& & & & & & 620 \\
\hline 11 & FA-LFCDK1 & Fly ash C+Fresh III & 0.24 & 2123 & 12.27 & 620 \\
\hline
\end{tabular}

\section{$\underline{8.5 .1 .2 \text { Bleeding }}$}

Volume stability of the mixes was measured by a bleeding test, conducted as per ASTM C-940-81. The results of these tests are summarized in Table 8-3. For the majority of the CKD-CLSM mixes, the bleeding value is within the specified limit of $2 \%$ (Hoopes, 1998). In general the bleeding of CKD-CLSM is lower than that of the FA-CLSM. Additionally, the CKD-CLSM mixes were observed to bleed at a slower rate compared to the fly ash-CLSM mixes. The bleeding period of CKD-CLSM lasted an average 5 to 6 hours. Gassman (2002) reports that 4 or less hours of bleeding are not necessarily detrimental in most construction applications as the removable of water leads to a reduction in the setting time.

Overall, these results are consistent with the data provided by Katz and Kovler (2004) who, in their study on the use of various by-product materials in CLSM, reported 
higher bleeding values for fly ash-CLSM than for CKD- CLSM (3 times greater). The low bleeding values of CKD-CLSM mixtures might be helpful in avoiding ponding of water on the CLSM surface, which in turn can contribute to the formation of a weak surface layer and can also delay the setting time (Hoopes, 1998).

\subsubsection{Unit Weight}

Unit weights of the fresh mixes were measured as per ASTM D 6023-96. The unit weight of the fresh mixes varied from 2062 to $2180 \mathrm{~kg} / \mathrm{m}^{3}$. A similar range in unit weight is reported by Katz and Kovler (2004) and Pierce et al. (2003). The CLSM with landfilled CKD has a relatively lower unit weight compared to the other mixes. The values of mass density of all mixes lie well within the normal density of CLSM, which ranges from 1840 to $2320 \mathrm{~kg} / \mathrm{m}^{3}$ (ACI committee 229,1999 ).

\subsubsection{Setting Time}

The set of the CLSM mixes investigated was measured based on ASTM C 40399. The results of these measurements are shown in Figure 8-3 to Figure 8-5, which plot penetration resistance versus time. Table 8-4 summarizes the initial setting time calculated as per the standard, which for the mixes investigated varied between 11 and 74 hours. Although these setting times do not have per se any practical significance (i.e. they do not translate into a strength that signifies that the CLSM, for example, can support workers), they provide a means to compare the various mixes. The following observations can be made based on the data provided in Figures 8-3 - 8-5 and Table 8-4:

- Both fly ash CLSMs set at a much faster rate than any of the CKD-CLSMs.

- The setting time of CKD-CLSM not only depends on the amount of cement but also on the type and amount of CKD present (Table 8-4). For a given quantity of cement and CKD, the fresh CKD-CLSMs set at a faster rate compared to the landfilled CKD-CLSMs.

- As the quantity of CKD increases the setting time increases significantly. This effect is particularly marked for the landfilled CKD (compare mixes \# 7 and \#8), 
with the setting time almost doubling when the dosage of the CKD is increased from $\sim 100$ to $\sim 200 \mathrm{~kg} / \mathrm{m}^{3}$.

- For CKD-CLSM, a minimum cement content of at least $\sim 50 \mathrm{~kg} / \mathrm{m}^{3}$ is required to have a setting time of less than 24 hours.

- In terms of setting time, there seems to be no advantage in the combined use of fly ash and CKD. While these mixes do show faster set than those manufactured with CKD alone and the same dosage of cement (compare mix\#10 to mix \#5, or mix\#11 to mix \#9), the setting times continue to exceed 24 hours.

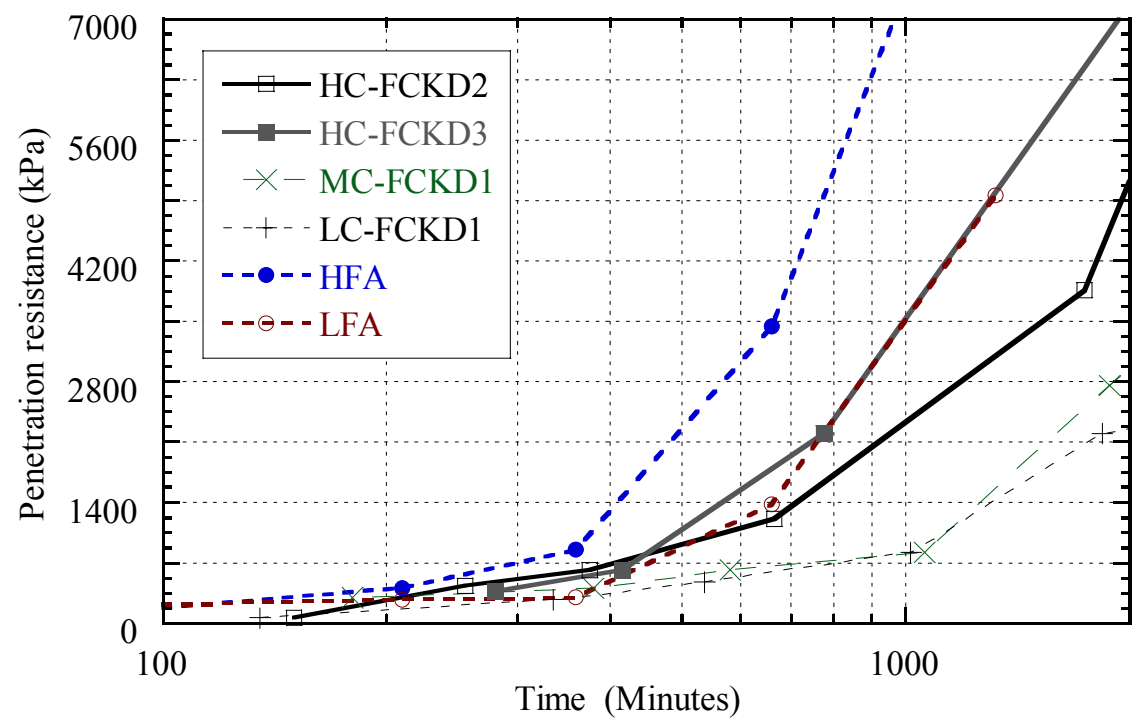

Figure 8-3 Setting curves for fresh CKD-CLSM 


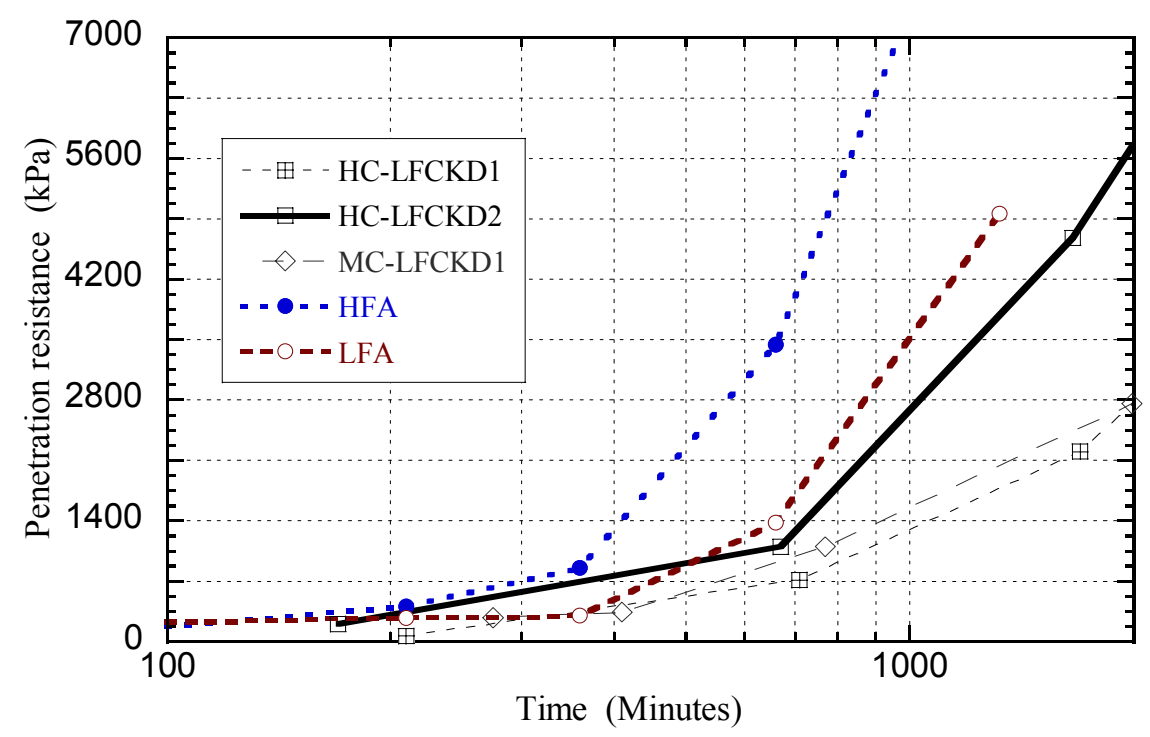

Figure 8-4 Setting curves for landfilled CKD-CLSM

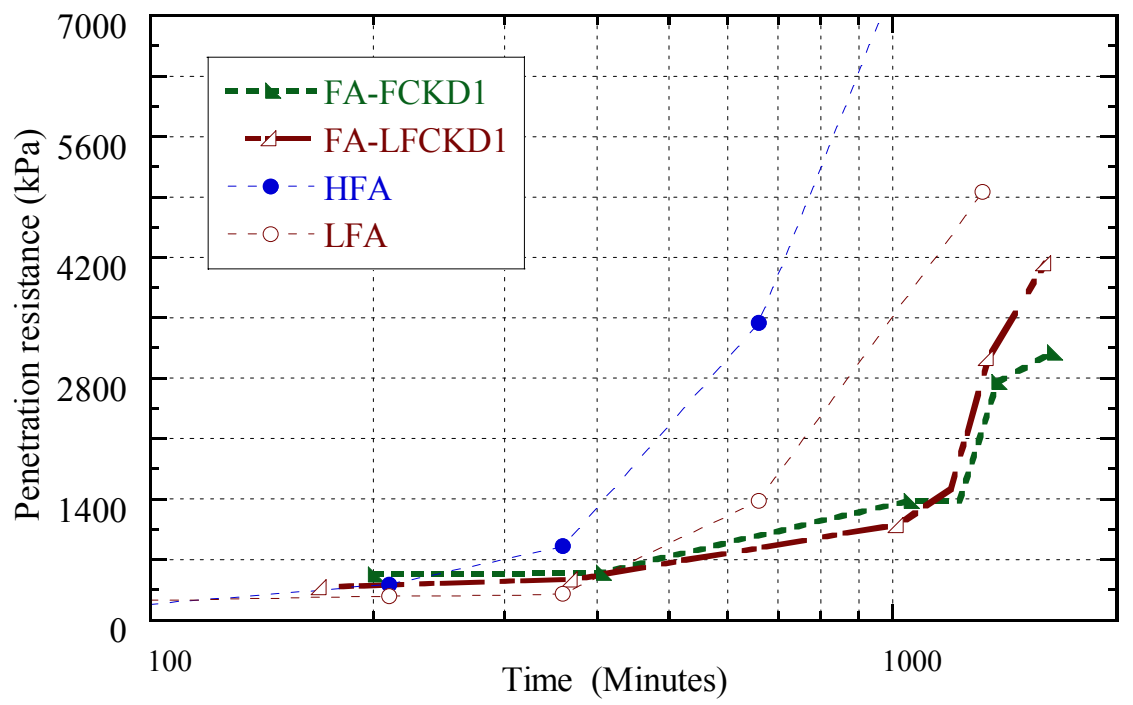

Figure 8-5 Setting curves for CLSM mixes with fly ash 
Table 8-4 Initial setting and walkability times from penetration resistance test

\begin{tabular}{clcc}
\hline Mix \# & Mix Reference & $\begin{array}{l}\text { Initial setting } \\
\text { time (hr) } \\
\text { ASTM C 403 }\end{array}$ & $\begin{array}{l}\text { Walkability } \\
\text { time (hr) } \\
\text { Bhat, 1996 }\end{array}$ \\
\hline \hline 1 & HFA & 11.17 & 3.75 \\
2 & LFA & 15.83 & 6.5 \\
3 & HC-FCKD2 & 22.39 & 5.69 \\
4 & HC-FCKD3 & 17.52 & 5.69 \\
5 & MC-FCKD1 & 44.83 & 8.12 \\
6 & LC-FCKD1 & 73.71 & 11.58 \\
7 & HC-LFCKD1 & 41.96 & 8.29 \\
8 & HC-LFCKD2 & 22.31 & 5.2 \\
9 & MC-LFCKD1 & 37.93 & 7.12 \\
10 & FA-FCKD1 & 27.59 & 5.37 \\
11 & FA-LFCDK1 & 33.7 & 6.53 \\
\hline
\end{tabular}

Katz and Kovler (2004) reported a setting time of approximately 30 hours for fresh CKD-CLSM for a cement content of $50 \mathrm{~kg} / \mathrm{m}^{3}$. They also reported a shorter time of 15 hours for fly ash-CLSM regardless of the cement content, and indicated that large quantities of fly ash in CLSM reduce the setting time. However, in case of CKDs higher quantities of CKD increased the setting time. These observations are consistent with the results obtained in this study.

CKD is almost inert; as such, the setting time primarily depends on the quantity of cement used. CLSM with low cement content will take a longer time to set and hence these mixes may not be feasible to use in situations where construction work has to be started immediately. According to Gassman et al. (2001), setting times of 24 hours are usually acceptable. 
Bhat and Lovell (1997) observed that the penetration resistance test is not very useful unless it is correlated with some strength parameter of flowable fill. In the field, the CLSM is assumed to become firm if it can support average foot loads. Bhatt and Lovell have reported that the walkability time may vary from three to four hours. In their study of the use of foundry sand as an aggregate in flowable fill, Bhat and Lovell found that the conditions for walkability translate into a penetration resistance of about $450 \mathrm{kPa}$ (65 psi).

The times corresponding to the development of a penetration resistance of 455 $\mathrm{kPa}$ were derived from the setting curves shown in Figures 8-3 to 8-5 and are summarized in Table 8-4. For all mixes the walkability time is more than 2 hours. Note that the walkability times (as well as the setting times) in the field may be reduced considerably depending on the drainage conditions of the surrounding soil. In particular for the two fly ash mixes the walkability time is found to be equal to 3.75 (\#1 - HFA) and 6.5 (\#2 - LFA) hours, respectively. Using these two results as a reference, of all the CKD based mixes, only those with a $\sim 50 \mathrm{~kg} / \mathrm{m}^{3}$ cement content and not more than $\sim 100 \mathrm{~kg} / \mathrm{m}^{3}$ of $\mathrm{CKD}$ are found to display acceptable walkability times. As the cement content decreases, the walkability time increases. The slower setting of CKD-CLSM may be an important factor restricting its use in the field particularly where the CLSM bed is to be opened for traffic at an early stage. The use of CKD-CLSM can be considered where there is ample time to wait for the mixture to harden and ready to take load. The setting time of CKD-CLSM may be improved through the use of quick setting cement or other accelerators.

\subsubsection{Properties of Hardened CLSM}

\subsubsection{Unconfined Compressive Strength}

The unconfined compressive strength data of cylindrical CLSM specimens tested at 14, 28 and 90 days are presented in Table 8-5. The strength provided is the average compressive strength of three specimens tested.

The following observations can be made based on these data: 
- $\quad$ The reference fly ash mixes, HFA and LFA, have almost similar 28 day and 90 day strengths (note that the decrease in strength of mix \#1 between 14 and 28 days has not found at this time an explanation).

- The 28-day strength of the CKD-CLSM specimens tested fall in a wide range from $78 \mathrm{kPa}$ ) (11psi) to $426 \mathrm{kPa}$ (60 psi) depending on the amount of cement and CKD and also on the type of CKD used in the mixes. For the majority of the mixes (\#5, \#6, \#7, \#8, \#10, and \#11) the 28 day strength is comparable to the values measured on the reference mixes. The two mixes (\#3 and \#4) manufactured with $\sim 50 \mathrm{~kg} / \mathrm{m}^{3}$ of cement and fresh CKD exhibit significantly greater strength (345 and $426 \mathrm{kPa})$. A much lower strength $(\sim 77 \mathrm{kPa})$ is measured for mix \#9 manufactured with landfilled CKD and only $\sim 30 \mathrm{~kg} / \mathrm{m}^{3}$ of cement.

- Comparing the strength of specimens made from fresh and landfilled CKD, the fresh CKD-CLSM specimens yielded higher strength compared to the landfilled CKD specimens for similar mixes (e.g., compare the strength of mix \# 4 and mix \#8 or of mix \#3 and mix \#7). 
Table 8-5 Properties of hardened CLSM

\begin{tabular}{|c|c|c|c|c|c|c|c|c|c|c|c|}
\hline \multirow[t]{2}{*}{ Mix \# } & \multirow[t]{2}{*}{ Mix reference } & \multirow[t]{2}{*}{$\begin{array}{l}\text { By-product } \\
\text { material }\end{array}$} & \multicolumn{2}{|c|}{$\begin{array}{l}14 \text { day } \\
\text { stength }\end{array}$} & \multicolumn{2}{|c|}{$\begin{array}{c}28 \text { day } \\
\text { strength }\end{array}$} & \multirow{2}{*}{$\begin{array}{c}\text { \% increase } \\
\text { in strength } \\
\text { from } 14 \\
\text { days to } 28 \\
\text { days } \\
\end{array}$} & \multicolumn{2}{|c|}{$\begin{array}{c}90 \text { day } \\
\text { strength }\end{array}$} & \multirow{2}{*}{$\begin{array}{c}\% \text { increase } \\
\text { in strength } \\
\text { from } 28 \\
\text { days to } 90 \\
\text { days }\end{array}$} & \multirow[t]{2}{*}{$\begin{array}{c}\text { Excavatability } \\
\text { (RE) }\end{array}$} \\
\hline & & & psi & $\mathbf{k P a}$ & psi & $\mathbf{k P a}$ & & psi & $\mathbf{k P a}$ & & \\
\hline 1 & HFA & Fly ash C & 29.7 & 209.3 & 24.3 & 171.4 & -18.1 & 65.1 & 458.5 & 167.4 & 0.64 \\
\hline 2 & LFA & Fly ash C & 16.3 & 114.6 & 28.3 & 199.7 & 74.2 & 65.8 & 463.5 & 132.1 & 0.70 \\
\hline 3 & HC-FCKD2 & Fresh III CKD & 56.3 & 396.4 & 60.5 & 426.1 & 7.5 & 87.4 & 616.0 & 44.6 & 1.00 \\
\hline 4 & HC-FCKD3 & Fresh III CKD & 40.3 & 284.1 & 48.9 & 344.2 & 21.2 & 55.9 & 393.7 & 14.4 & 0.88 \\
\hline 5 & MC-FCKD1 & Fresh III CKD & 26.2 & 184.7 & 26.1 & 184.1 & -0.4 & 34.2 & 241.2 & 31.0 & 0.66 \\
\hline 6 & LC-FCKD1 & Fresh III CKD & 20.8 & 146.9 & 20.1 & 141.9 & -3.4 & 18.7 & 131.6 & -7.3 & 0.57 \\
\hline 7 & HC-LFCKD1 & Landfilled CKD & 25.6 & 180.1 & 25.6 & 180.1 & 0.0 & 31.0 & 218.3 & 21.2 & 0.62 \\
\hline 8 & HC-LFCKD2 & Landfilled CKD & 25.4 & 179.1 & 27.3 & 192.4 & 7.4 & 39.5 & 278.1 & 44.6 & 0.63 \\
\hline 9 & MC-LFCKD1 & Landfilled CKD & 11.0 & 77.7 & 11.1 & 78.1 & 0.4 & 14.6 & 102.7 & 31.5 & 0.41 \\
\hline 10 & FA-FCKD1 & $\begin{array}{l}\text { Fly ash C/Fresh } \\
\text { III CKD }\end{array}$ & 13.6 & 95.7 & 21.5 & 151.5 & 58.3 & 45.8 & 323.0 & 113.2 & 0.58 \\
\hline 11 & FA-LFCDK1 & $\begin{array}{l}\text { Fly ash C/Fresh } \\
\text { III CKD }\end{array}$ & 16.7 & 117.9 & 22.5 & 158.5 & 34.4 & 36.0 & 253.1 & 59.7 & 0.60 \\
\hline
\end{tabular}


- In the case of fresh CKD, for a given cement content, the strength increases with increased CKD addition (compare the strength of mix\# 3 and mix\#4). Note that the data presented in the previous section showed that an increased CKD content adversely affected the setting time.

- In the case of landfilled CKD the strength is not observed to vary significantly with the amount of CKD added.

- As expected, both fly ash mixes show significant strength gain (132-167\%) between 28 and 90 days, and it is expected that further strength gain would be observed in time due to pozzolanic reactions (note that this is likely why the HFA mix is not recommended for situations where future excavation is needed).

- While almost all CKD, mixes show some gain in strength between 28 and 90 days this increase is much more modest $(\sim 14-44 \%)$ than that observed for the fly ash mixes. This is a result of the fact that strength development in the CKD mixes is for the most part a result of the cement reactions. Similarly for these mixes it is expected that further strength gain beyond 90 days should be minimal.

ASTM standards for CLSM recommend that 28 day strength less than $700 \mathrm{kPa}$ (100 psi) is adequate in most applications. However the standard does not specify any lower limit for the strength requirement. Trejo et al. (2004) reported that a 28 day compressive strength of $120-180 \mathrm{kPa}(20-30 \mathrm{psi})$ is a good index of strength for CLSM for its practical applications. Additionally, Gassman et al. (2001) reported that the strength of CLSM mixes used in South Carolina to backfill utility trenches is generally between 103 and $310 \mathrm{kPa}(15$ - $45 \mathrm{psi})$ at 28 days and between 172 and $448 \mathrm{kPa}(25-65$ psi) at 90 days. The 28-day strength of the CKD-CLSM specimens tested fall in a wide range from $78 \mathrm{kPa}(11 \mathrm{psi})$ to $426 \mathrm{kPa}$ (60 psi). The CKD-CLSM mixes with significantly lower 28 day strength (e.g. mix \# 9) would not meet the requirement of design strength criteria at the field. 


\subsubsection{Excavatability}

The excavatability of CKD-CLSM was assessed by calculating the "removability modulus" (RE) developed in Hamilton County, Ohio (Du et al., 2002), which is expressed as follows:

$$
R E=\frac{W^{1.5} \times 0.619 \times C^{0.5}}{10^{6}}
$$

where $\mathrm{W}$ is the in situ dry density of the CLSM $\left(\mathrm{kg} / \mathrm{m}^{3}\right)$ and C is the 28 day unconfined compressive strength $(\mathrm{kPa})$.

For a CLSM to be excavatable the RE needs to be less than one (It is not apparent how this correlation takes care of the long-term strength gain of fly ash-CLSM).

The last column of Table 8-5 reports the values of RE calculated for all the mixes investigated in this research. Note that the value of density measured at 28 days (hardened density) was employed for calculating RE. As seen from the table for all mixes other than \#3(HC-FCKD2) the removability modulus is much smaller than one. Accordingly all mixes are expected to be easily excavatable.

Criteria for excavation based on 28 day strength of CLSM are also used as indicator of excavatability. Table 8-6 summarizes the criteria for excavatability based on 28 day strength values reported by various agencies and researchers. The ACI committee specifies a 28 day strength of less than $300 \mathrm{kPA}$ (50 psi) for manual excavation of the CLSM, while it should be possible to excavate hardened CLSM with a backhoe if the strength is in the range of $700-1400 \mathrm{kPa}(100-200 \mathrm{psi})$. The table also presents the strength requirements listed by NRMC and Trejo et al. (2004). In additon, Du et al. (2002) in their investigation to study the effect of constituent materials (e.g. fly ash, bottom ash, foundry sand, concrete sand etc) and strength requirement of CLSM, proposed that if the 28 day compressive strength is $350 \mathrm{kPa}$ or less, the mixture is hand excavatable and if the 28-day strength is between 690 and $1400 \mathrm{kPa}$, the mixture is expected to be excavatable using a backhoe. As seen in Table 8-5, the 28-day strength of the CKD-CLSM specimens tested fall in a wide range from $78 \mathrm{kPa}$ ) (11psi) to $426 \mathrm{kPa}$ 
(60 psi). For all the CLSM specimens tested in this study, the 28 day compressive strength is less than $300 \mathrm{kPa}$ (50 psi) (Except for \#3 HC - FCKD2) and accordingly nearly all of the CLSM mixes considered in this study are expected to be easily excavatable by hand based on both strength requirement and removability modulus. For mix \#3 the measured 28 day strength is $\sim 425 \mathrm{kPa}$ which is at the higher end of strength requirement for manual excavation. However, this mix is easily excavatable by using a backhoe.

Table 8-6 Strength requirements reported in the literature

\begin{tabular}{|c|c|c|}
\hline Standards/Researchers & 28 day strength psi (kPa) & Remarks \\
\hline \multirow[t]{2}{*}{$\overline{\mathrm{ACI}}$} & $<50$ (300) (Manual excation) & \\
\hline & $\begin{array}{l}100-200(700-1400) \text { (Excavatable } \\
\text { by backhoe) }\end{array}$ & \\
\hline NRMC* & $\begin{array}{l}20-30(120-180) \text { (Manual } \\
\text { excation) }\end{array}$ & $\begin{array}{l}\text { Ultimate strength should } \\
\text { be less than } 150 \mathrm{psi}\end{array}$ \\
\hline Trejo et al.(2004) & 50-185 (300-1100) (Excavatable) & Good index of strength \\
\hline Du et al. (2002) & $\begin{array}{l}<50(350) \text { (Manual excavation) } \\
100-200(700-1400 \text { (Excavatable } \\
\text { by backhoe) }\end{array}$ & $\begin{array}{l}\text { Based on an } \\
\text { investigation to study the } \\
\text { effect of constituent } \\
\text { materials in CLSM }\end{array}$ \\
\hline
\end{tabular}

*From Crouch and Gamble, 1997 (NRMC-National Ready Mixed Concrete Association)

\subsubsection{Corrosiveness}

The corrosiveness of CLSM was investigated by measuring $\mathrm{pH}$ and electrical resistivity and also by conducting a mass loss test method. Table 8-7 summarizes the test results obtained from this study. In particular the last two columns of the table present the data derived from the mass loss tests: the mass loss measured on identical steel coupons 
(mass $\sim 7.5 \mathrm{~g}$ ) immersed in a CLSM mix for seven months, and the corrosion rate derived from these values (see Chapter 5 for procedure).

Note that the mass loss and corrosion rate presented are the average for two specimens. For reference Table 8-7 also presents results from steel coupons immersed in sand alone.

The data indicates that significantly lower corrosion rates were measured when the steel coupons were immersed in the CLSM, rather than in the sand alone. Additionally, marginally lower corrosion rates were measured in the case of the CKDCLSM, compared to the fly ash-CLSM.

Figure 8-6 shows one of the control coupons after extraction from the sand at the end of the seven month period before and after cleaning. The coupon presents clear signs of pitting on its surface. In contrast, the coupons embedded in CLSM were found to be dimensionally stable and only a color difference was observed on their surface. A very small spot of rust was observed on one edge of both specimens embedded in the fly ashCLSM while no such observation was made on the coupons from the CKD-CLSM. All coupons immersed in CLSM were observed to be well coated by the CLSM which, as suggested by Abelleria et al. (1998), is likely to have acted to protect the metal.

Table 8-7 Test results from corrosion study

\begin{tabular}{lcccc}
\hline Coupons in & $\mathbf{p H}$ & $\begin{array}{c}\text { Resistivity } \\
(\mathbf{\Omega}-\mathbf{c m})\end{array}$ & $\begin{array}{c}\text { Average mass } \\
\text { loss }(\mathbf{g})\end{array}$ & $\begin{array}{c}\text { Corrosion } \\
\text { rate }(\boldsymbol{\mu m} / \mathbf{y r})\end{array}$ \\
\hline \hline Sand & - & 7400 & 0.201 & 46.95 \\
HC-FCKD3 (\#4) & 11.94 & 450 & 0.0079 & 1.857 \\
HC-LFCKD2 (\#8) & 12.34 & 340 & 0.0045 & 1.063 \\
HFA (\#1) & 12.55 & 1200 & 0.01315 & 3.0967 \\
\hline
\end{tabular}



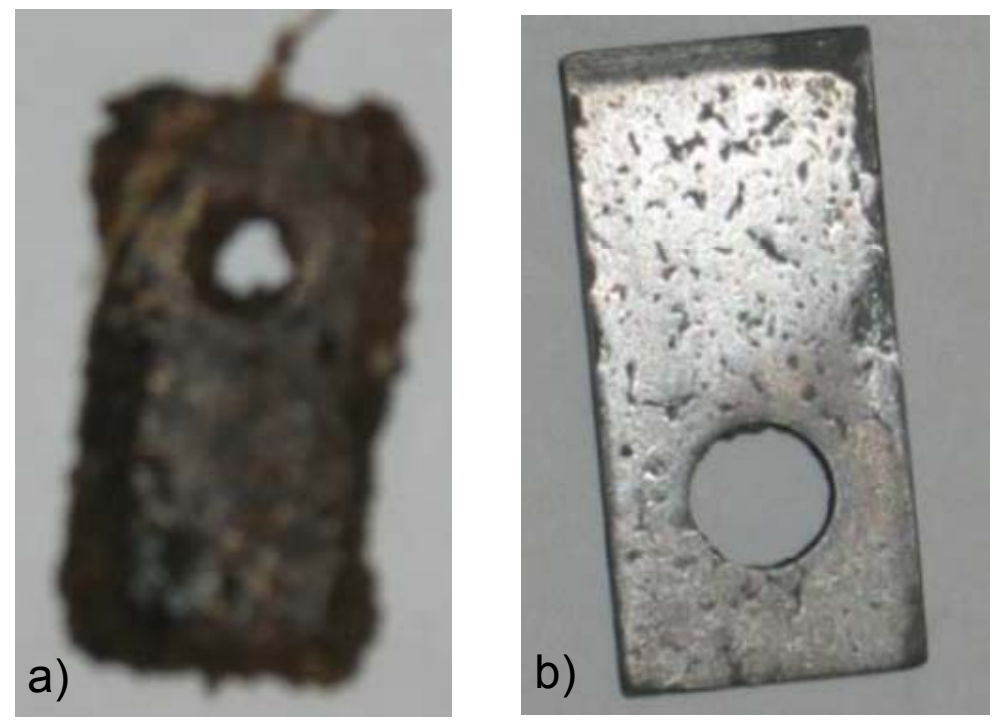

Figure 8-6 Steel coupons embedded in sand; a) before cleaning and b) after cleaning

As discussed in Chapter 6, electrochemical parameters like $\mathrm{pH}$ and resistivity are generally used to estimate the corrosiveness of soil and fly ash. The corrosiveness of CKD was studied based on these parameters and its chloride and sulfate content. Based on the results of these tests CKD was classified as corrosive (see Chapter 3). In fact, the values of resistivity would suggest that the CKD might be more corrosive in nature than the fly ash. These observations substantiate that resistivity parameters alone are not a good indicator of the corrosivity of a medium. The reduced corrosiveness of CLSM is likely due to the high $\mathrm{pH}$ environment provided by the pore fluid as well as to the low air circulation into the coupons.

While the laboratory tests conducted on the steel coupons provide some indication of the potential for corrosion of steel pipes placed in CKD-CLSMs, differences are to be expected between laboratory and actual field data. For example, while the experiments presented here were conducted at room temperature, using ordinary tap water, a more severe corrosive environment might be expected in the field depending on nature of the groundwater present and temperature fluctuations. In contrast, the higher embedment 
depth and lower air circulation for steel pipes embedded in CLSM might lead to a reduction in the measured corrosion rates.

Only limited studies have been conducted on the corrosion of commonly used pipe materials embedded in CLSM. More research is required in this area as by-product and waste materials are being recognized more in infrastructure applications.

\subsection{Advantages and Disadvantages of Using CKD in CLSM}

The successful and large scale environment-friendly utilization of by-product and waste materials is important to sustainable development. The estimated U.S. market for CLSM of all types is approximately 10 million cubic yards in 1997 (Crouch and Gamble, 1997). As stated by Trejo et al. (2004), "as the construction industry continues to recognize the importance of sustainable development, technologies such as controlled low-strength material have come to the forefront as viable means of safely and efficiently using by-product and waste materials in infrastructure applications". Researchers in the past decade have investigated the use of many nonstandard waste materials in CLSM ((e.g. foundry sand (Bhat and Lovell, 1994; Tikalsky et al., 2000); cement kiln dust (Katz and Kovler, 2004; Al-Jabri et al., 2002 and Pierce et al., 2003); high fines limestone (Crouch and Gamble, 1997)). The use of new by-product materials will positively permit the evolution of CLSM, so that it fills the needs of the construction industry well in the future and also allows large scale recycling of waste and by-product materials.

Whereas today fly ash remains the most commonly used by-product material in flowable fills, the excessive long term strength development of CLSM with fly ash (associated with pozzolanic reactions) makes this material a challenge to use and could result in a CLSM difficult to excavate in the future, if required (Pons et al., 1998). This is a significant problem that translates to added cost and labor for contractors and producers. Also, as pointed out by Pierce et al. (2003) fly ash has become so widely used in construction that it has become more of a commodity with an associated cost and less of a waste material.

Table 8-8 summarizes some of the observations made in evaluating fresh and landfilled CKD as alternatives to fly ash for manufacturing CLSM (the comments on the 
fly ash CLSM pertain specifically to the two reference mixes tested in this research). The primary advantage of incorporating CKD into CLSM is that it produces a homogeneous, cohesive mix having excellent flow behavior. CKD-CLSM flows like a heavy liquid holding all sand particles together without any segregation. The self-leveling consistency of the CKD-CLSM ensures that it will be placed with minimal effort and no vibration or tamping even where the access is limited. In this aspect the CKD-CLSM appears clearly superior to the two fly-ash based CLSMs employed for reference in this research.

An additional advantage of the CKD-CLSMS is the reduced level (and rate) of bleeding of CKD-CLSM, which indicate that essentially negligible subsidence is to be expected after the CLSM is placed. On the down side the very small bleed values suggest that the reduction in field setting times often observed as a by-product of water leaving the mixture after placement may not be observed when using CKD CLSMs.

The principal drawback of using CKD in CLSM is the slow setting nature of the mixes (even though the use of quick setting cement or some accelerators may be considered, if found to be economical). As a result, CKD-CLSMs require higher amounts of cement to meet setting time requirements compared to the fly ash-CLSMs. Even with cement content as high as $50 \mathrm{~kg} / \mathrm{m}^{3}$, it remains questionable whether the use of landfilled CKD can be practical.

The 90 day strength data show that CKD-CLSMs gain very limited strength with time. This suggests that their use may be advantageous where future excavations are likely to be required. Finally, the performance of CKD-CLSM with respect to corrosiveness was found to be equal or better than fly ash-CLSM. 
Table 8-8 Summary of flowable fill properties

\begin{tabular}{|c|c|c|c|}
\hline & Fresh CKD-CLSM & Landfilled CKD-CLSM & $\begin{array}{l}\text { Fly ash-CLSM (Used for } \\
\text { current study) }\end{array}$ \\
\hline Flowability & $\begin{array}{l}\text { Excellent even for low CKD } \\
\text { content }\end{array}$ & $\begin{array}{l}\text { Excellent even for low CKD } \\
\text { content }\end{array}$ & Depends on fly ash content \\
\hline Segregation & None & None & $\begin{array}{l}\text { Segregation of particles at low fly } \\
\text { ash content }\end{array}$ \\
\hline Workability & Cohesive and workable & Cohesive and workable & Depends on fly ash content \\
\hline Bleeding & $\begin{array}{l}\text { Within limits (Bleeds } \\
\text { slowly) }\end{array}$ & $\begin{array}{l}\text { Within limits (Bleeds } \\
\text { slowly) }\end{array}$ & $\begin{array}{l}\text { High bleeding for low fly ash } \\
\text { content CLSM (Leaves water } \\
\text { faster) }\end{array}$ \\
\hline $\begin{array}{l}\text { Setting time (Penetration } \\
\text { resistance of } 400 \mathrm{psi} \text { ) }\end{array}$ & $\begin{array}{l}17 \text { hours (with cement } \\
\text { content of } 50 \mathrm{~kg} / \mathrm{m}^{3} \text { ) }\end{array}$ & $\begin{array}{l}22 \mathrm{hrs} \text { (with cement content } \\
\left.\text { of } 50 \mathrm{~kg} / \mathrm{m}^{3}\right)\end{array}$ & 11 to 15 hours \\
\hline $\begin{array}{l}\text { Long term strength } \\
\text { development }\end{array}$ & $\begin{array}{l}\text { Not significant (CKD is non } \\
\text { pozzolanic in nature) }\end{array}$ & $\begin{array}{l}\text { Not significant (CKD is non } \\
\text { pozzolanic in nature) }\end{array}$ & $\begin{array}{l}\text { Long term strength development } \\
\text { due to pozzalanic reaction } \\
\text { (depends on the fly ash comtent) }\end{array}$ \\
\hline Diggability & Easily diggable & Easily diggable & Easily Diggable \\
\hline Corrossiveness & $\begin{array}{l}\text { Better or comparable } \\
\text { performance with fly ash } \\
\text { CLSM }\end{array}$ & $\begin{array}{l}\text { Better or comparable } \\
\text { performance with fly ash } \\
\text { CLSM. Less corrosive than } \\
\text { fly ash and fresh CKD- } \\
\text { CLSM }\end{array}$ & $\begin{array}{l}\text { Improves corrossiveness of steel } \\
\text { compared to coupons burried in } \\
\text { sand }\end{array}$ \\
\hline
\end{tabular}


In addition to technical considerations, practical and economical constraints will ultimately determine whether the use of CKD in CLSM is generally advantageous. For example, the type of storage facility required for CKD at the mixing plant as well as the distance over which the CKD must be hauled will play a key role.

\section{$\underline{8.10 \text { Summary }}$}

This chapter discussed the viability of using fresh and landfilled CKD in CLSM. The properties of both fresh and landfilled CKD-CLSMs were compared with those of commonly used INDOT fly ash-CLSMs. The following conclusions can be drawn from this study;

- Flow behavior and bleeding of CKD-CLSM are satisfactory. Unlike low fly ashCLSM, CKD-CLSM mixes are very cohesive, homogeneous and flow like a heavy liquid ("pancake consistency") without segregation. To attain pancake consistency high amount of fly ash is required, which however influences the long term strength development and the excavatability of CLSM.

- The flowability of CLSM depends not only on the amount of fine content in the mix but also on the morphology of the fines.

- The water demand for CKD-CLSM is higher than that for fly ash-CLSM for the same flow consistency.

- CKD-CLSM bleeds at a lower rate compared to fly ash-CLSM. The bleeding is well within limits reported in the literature.

- CKD-CLSM sets at a lower rate compared to fly ash-CLSM.

- Fresh CKD-CLSM has higher strength compared to landfilled CKD-CLSM and the strength is proportional to the amount of fresh CKD used. In contrast, the setting time is adversely affected by higher amounts of CKD.

- Higher amounts of landfilled CKD adversely affected the strength and setting time of CLSM.

- When using CKD, a minimum of $\sim 50 \mathrm{~kg} / \mathrm{m}^{3}$ of cement is required to obtain practical setting times and reach minimum strength requirements. 
- CKD-CLSMs are easily excavatable and are likely to exhibit limited gain in strength with time.

- The corrosion rate of steel coupons immersed in CKD-CLSM was marginally lower than that measured on steel placed in fly-ash CLSM. 


\section{CHAPTER 9 -- CONCLUSIONS, SIGNIFICANCE AND RECOMMENDATIONS}

\subsection{Overview}

The research work summarized in this report addressed the re-utilization of fresh and landfilled cement kiln dust generated in the Lehigh cement plant in Mitchell, Indiana.

Samples of fresh CKD were collected at three different times: once in 2001 before the start of this research and twice in 2002, shortly after changes to the plant processing technology had been implemented. Throughout this thesis these CKDs are referred to as fresh I, fresh II, and fresh III CKD. While fresh II and fresh III CKD can be essentially considered to represent the same material, key differences were observed with respect to fresh I CKD. As a result, in the following reference is made to the fresh "CKDs" produced by the plant and differences between these two fresh CKDs are carefully highlighted.

Tube samples of landfilled CKD were obtained using soil sampling equipment from the landfill facility in proximity to the Lehigh Mitchell plant at three different locations to depths exceeding $15 \mathrm{~m}$. Additionally, bulk samples were collected from an open front of the landfill where mining operations were underway.

The research involved an extensive testing program aimed at establishing the physico-chemical (particle size, surface morphology, specific surface area, chemical and mineralogical composition, $\mathrm{pH}$, metals content, corrosivity) and engineering (moisture density relations, strength, hydraulic conductivity, compressibility) properties of fresh and landfilled CKD. Additional tests were performed to evaluate the re-utilization of CKD in two selected applications: soil improvement and controlled low strength materials.

\section{$\underline{9.2 \text { Conclusions }}$}

The discussion of the main conclusions drawn from this research is organized in three separate sections. The first section (9.2.1) focuses on the conclusions from the 
characterization study. The following two (9.2.2 and 9.2.3) address the results of the tests conducted to evaluate the suitability of the CKDs in two specific applications.

\subsubsection{Conclusions from characterization study}

The results of the characterization study lead to conclusions that pertain: a) to the nature and properties of the fresh $\mathrm{CKD} ; \mathrm{b}$ ) to the effects of cement plant modifications on the nature of the CKD produced and to the validity of the loss on ignition as an indicator of the reactivity of a $\mathrm{CKD} ; \mathrm{c})$ to differences between the properties of the fresh and the landfilled CKDs and the effects of long term environmental exposure on its nature and properties; d) to the variability in properties of the landfilled CKD; e) to the effects of particle morphology on the engineering properties of fine powders; and $f$ ) to the opportunities for recycling the CKDs investigated.

\section{a) Nature and properties of fresh CKD}

One of the key contributions of this research lies in the thorough nature of the study performed on the CKDs from the Lehigh Mitchell plant. With few exceptions, previous studies on CKD focused on limited characteristics of this material (primarily chemical and mineralogical composition). As described in Chapter 6, with the aim of exploring geotechnical re-use applications, this research involved, instead, a comprehensive characterization of the chemical, mineralogical, physical, mechanical, and environmental properties of this material, providing insight into aspects of the behavior of this by-product previously not known.

From a chemical and mineralogical composition, the fresh CKDs investigated in this research fall within the range documented in the literature for this by-product material. However, given the variability in the nature and properties of CKD, the conclusions on the behavior of this material cannot be generalized to all CKDs. The measured properties can however represent a "starting" point when first considering the use of this material in a geotechnical application, and are likely to be representative of CKDs similar to those investigated in this research, i.e. characterized by low to no 
reactivity (as in the case of fresh I and fresh II/III CKD, respectively) and very small particle size (in both fresh I and fresh II/III $85-95 \%$ of the materials is finer than $10 \mu \mathrm{m}$ ).

Key conclusions on the properties of the fresh CKDs investigated in this research, which are most relevant to geotechnical applications, can be summarized as follows:

- The fresh CKDs investigated present moisture density relationships similar to those of most fine grained soil (bell shape curve), albeit with considerably lower dry densities $\left(1.15-1.5 \mathrm{~g} / \mathrm{cm}^{3}\right)$; optimum moisture contents determined through the standard Proctor test lie in the $25-30 \%$ range.

- The reactivity of the CKD greatly affects the compaction behavior. For the more reactive CKD (fresh I) the compaction curve was shown to be significantly affected by the time elapsed between mixing and compacting: as this time increases there is a reduction in maximum dry density and an increase in optimum moisture content;

- The hydraulic conductivity of compacted fresh CKD falls below $2 \times 10^{-8} \mathrm{~m} / \mathrm{sec}$, corresponding to conditions that in geotechnical terms would be defined as practically impervious.

- One dimensional compression tests performed on dry CKD indicate that the one dimensional compressibility of this material falls at the high end of values reported for sands $\left(\mathrm{C}_{\mathrm{c}} \sim 0.42\right)$.

- Direct shear tests performed with confining stresses in the 30-200 $\mathrm{kPa}$ range on specimens of dry CKD prepared at void ratios between 1.1 and 1.8 provide values of peak friction angle ranging between $34^{\circ}$ and $37^{\circ}$.

- Despite the high pH (11.5-12) of CKD, measurements of the resistivity, chloride content and sulfate content indicate the likely corrosive nature of this material.

- Measurements of the concentration of heavy metals are well below EPArecommended TCLP limits. 
b) Impact of plant changes and LOI as an indicator of CKD reactivity

The study highlighted a significant difference between the nature of the fresh CKD before (fresh I) and after (fresh II and III) implementation of modifications to the plant processing technology in 2001. Specifically it was found that while the fresh CKD produced before the changes to the plant exhibited some reactivity (as demonstrated by the strength measured on water-CKD pastes, the presence of free lime observed in XRD analyses, as well as free lime content data [2-6\%] provided by the manufacturer), samples of the fresh CKD collected after 2001 showed little to no free lime and behaved essentially as inert materials.

These results demonstrate the impact on the chemical make-up of CKD of changes to the plant processing technology, as well as the importance of knowing the chemical composition of each batch of CKD collected and the operation history of the plant from which CKD is obtained for re-use.

Another important conclusion drawn from this portion of the study is that changes in chemical make-up such as those existing between fresh I CKD and the latter batches of fresh CKD are not necessarily reflected in the other properties of the CKDs. All fresh CKDs tested in this research exhibited very similar particle size distribution, oxide composition and loss on ignition (LOI). The LOI is often considered an indicator of the reactivity of CKD. However, in the present study it was not found to reflect the significant change in reactivity of the CKD.

c) Fresh versus landfilled CKD: evolution of a reactive by-product material

This study offered the unique opportunity to compare the properties of fresh and landfilled CKD originating from the same plant, and thus to investigate the effects on this by-product material of extended "storage" in a landfill. Note that the CKD sampled in the field was landfilled over a period of approximately 12 years. Landfilling was halted around 2000, i.e. prior to sampling of the fresh CKD. Thus the exact nature of the parent fresh material for this CKD is not known (and is likely to have varied somewhat over the period the landfill was used). However, based primarily on historic data (e.g. free lime) provided by the manufacturer it is speculated that the first (fresh I) more reactive of the 
three fresh CKD samples investigated in this research best represents the parent fresh material of the landfilled CKD.

From a chemical point of view the landfilled CKD presents composition very similar to that of fresh I CKD. The two CKDs are instead different from a mineralogical point of view, as demonstrated by the XRD results. These analyses show that the landfilled CKD does not contain free lime (only traces were found from chemical analysis), and instead indicate the presence of reaction products (specifically ettringite). Compression tests on pastes manufactured with the landfilled CKD demonstrate that this material behaves essentially as an inert powder.

In terms of particle size distribution the landfilled CKD is slightly coarser than the fresh CKD material (e.g. $\mathrm{D}_{50}=3-5 \mu \mathrm{m}$ versus $2 \mu \mathrm{m}$ for the fresh CKD), but continues to remain at the very low end of the range based on literature data.

Significant differences between the fresh and the landfilled CKD are observed in the shape and the morphology of the particles. SEM images of the landfilled CKD show the presence of reaction products, often in the form of elongated fibers which represent evidence of chemical alteration arising from the long term exposure to the environment. SEM investigations of the fresh CKD were performed only on fresh II and fresh III CKD (but are likely to be representative also of fresh I CKD). These CKDs are characterized by irregular shaped particles with smooth surfaces. Specific surface measurements using the nitrogen adsorption method indicate that the morphological differences described above translate into a three times greater specific surface area of the landfilled CKD.

This research showed that the morphological differences described above lead to a significant difference in compaction behavior, with the landfilled CKD being characterized by the lowest maximum dry density $\left(\sim 1 \mathrm{~g} / \mathrm{cm}^{3}\right)$ and the greatest optimum moisture content (OMC) (in excess of 50\%), compared to all samples of the fresh CKD. It was also found that the permeability of compacted fresh CKD is about ten times smaller than that of landfilled CKD.

The results obtained illustrate the effects of the long term exposure to the environment on the chemical, mineralogical, physical and engineering properties of a reactive by-product. 


\section{d) Variability of landfilled CKD}

One of the goals of this research was to investigate re-use applications for the over 400,000 metric tons of CKD contained in the landfill located in proximity of the Lehigh plant in Mitchell. Thus, it appeared necessary to tackle, albeit in limited manner, the issue of the variability of this material. As result, as discussed above, tube samples were obtained at three different locations in the landfill to a depth of over $15 \mathrm{~m}$. Measurements of $\mathrm{pH}$ and loss on ignition conducted on all 29 tube samples collected from the landfill, as well as the determination of particle size distribution and chemical composition conducted on select tubes samples indicate that the landfilled CKD generally exhibits consistent physical and chemical characteristics.

Leachable metals contents were determined for a number of the landfill samples and, with one exception, were found, as in the case of the fresh CKD, to fall well within the RCRA (Resources Conservation and Recovery Act) limits. Comparable concentration of metals in fresh and landfilled CKD suggest that there was no significant leaching of the metals from the landfill. This is probably a result of the high $\mathrm{pH}$ and low permeability of the landfilled CKD which lessen the probability of extensive ground water percolation and the consequent danger of soluble material being leached out of the fill). One sample collected from the bottom of landfill showed concentration of mercury slightly above the prescribed limit. This suggests that additional sampling and characterization of the lower strata of the landfilled may be required before this material can be approved for recycling, and that potentially mining may have to be limited to the less deep material.

e) Effect of particle morphology on engineering properties of fine powders

As discussed above, the two CKDs most extensively investigated this research (fresh II/III and landfilled CKD) were observed to be characterized by similar particle size distribution, but by substantially different particle morphology. Comparison of the behavior of these powders in the dry state provided insight on the impact of particle morphology on the particle arrangement and engineering properties of fine powders. 
In terms of particle fabric it was found that specimens of the landfilled CKD were characterized by significantly greater void ratios than specimens of the fresh CKD prepared following identical procedures (e.g. compare $\mathrm{e}_{\max }$ of 3.76 versus 3.06).

One dimensional compression tests showed on the other hand that the presence of reaction products, many of which of elongated shape, in the landfilled CKD translated in compressibility of this material (as measured by the compression index $\mathrm{Cc}=-\mathrm{de} / \mathrm{dlog} \sigma_{\mathrm{v}}$ ) over two times greater than that of fresh CKD.

Effects of particle morphology were observed also in the direct shear tests. While for both materials the tests performed provided friction angle values in the $34^{\circ}-37^{\circ}$ range, the much lower density (higher void ratio) of the landfilled CKD specimens suggests that also in these tests particle morphology played a role.

\section{f) Opportunities for reutilization of the CKDs}

The results of the characterization study were used in this research as a basis for identifying re-use applications for the fresh (II/III only as fresh I is no longer produced by the plant) and landfilled CKDs. Specifically, it was concluded that the re-utilization of both materials should take advantage of the following:

- Both CKDs exhibit uniformity in chemical composition, high fineness, limited reactivity, high alkalinity and ability to water absorb water.

- Both CKDs are essentially non hazardous.

- Following compaction both CKDs are almost impervious in nature.

- Landfilled CKD can be compacted within a very large range of moisture content. In this range the maximum dry density, the unconfined compressive strength and the permeability of the CKD are largely insensitive to compaction water content and compaction energy.

Based on the above it was concluded that the following applications held promise for the CKDs investigated:

- Treatment of wet subgrades and water logged areas

- Sludge stabilization 
- Controlled low strength materials

- Grouting mixtures

\subsubsection{Conclusions on the use of the CKDs for soil improvement}

As discussed in detail in Chapter 7, investigations on the use of CKD for soil improvement were carried out employing both the fresh (fresh I, II and III) and the landfilled CKDs in combination with three Indiana low plasticity clays. The experimental program included a variety of tests (compaction, unconfined compression, swell, Atterberg limits, $\mathrm{pH}$ ) on soils combined with $8-20 \%$ of these CKDs (by dry mass of soil).

The satisfactory performance (in terms of unconfined compressive strength, CBR penetration and swelling reduction) of the soils treated with fresh I CKD leads to the conclusion that this by-product material can represent a valid alternative to other stabilizing agents (cement or lime), provided that it has sufficient reactivity, which is best measured by the free lime content. Based on the performance of fresh I CKD it may be hypothesized that $2-5 \%$ free lime can provide sufficient reactivity for utilization of CKD in soil improvement.

Even in the case of a fairly reactive CKD such as fresh I CKD, dosages well in excess of those used for other binders ( $15 \%$ by dry mass of the soil or greater) were found to be necessary to achieve the required strength increases. It was also found that the improvement in strength associated with CKD addition varies significantly from soil to soil. Measurements of the Atterberg limits of soil-CKD mixtures suggest that the change in plastic limit (PL) may be a good indicator of the potential for a CKD to stabilize the soil.

With the exception of fresh I CKD, all other CKDs exhibited poor performance in traditional soil improvement due to their essentially inert nature. The great fineness of these materials, and their ability to adsorb water (especially in the case of landfilled $\mathrm{CKD}$ ) led to explore the use of these materials for the improvement of wet subgrades/water logged areas. 
The results obtained in this research indicate that, CKDs as fine as those tested hold significant promise in this type of application. In presence of $10-20 \%$ of these CKDs, soils at very high water content (outside the range of compactability) could be compacted without difficulties and without needing any drying. While the strength measured under these conditions was limited, the addition of a small amount (1\%) of Portland cement significantly increased the strength. This indicates that the combined use of CKD and Portland cement might prove advantageous for saving time and costs in constructing on wet soils and/or water logged areas.

\subsubsection{Conclusions on the use of the CKDs in CLSMs}

As discussed in Chapter 8 , to evaluate the viability of using the CKDs under investigation for low strength flowable mixtures (CLSMs), tests were conducted on mixes manufactured with either the fresh (III) or the landfilled CKD, as well as on reference mixes with fly ash. Properties measured on the mixes included: flowability, setting time, bleeding, air content, unit weight and unconfined compressive strength. Excavatability and walkability time (Bhat and Lovell, 1997) were also estimated from these results.

The results of this portion of the experimental study lead to conclude that both the fresh and landfilled CKD investigated in this research have the potential to be effectively used in CLSMs.

All the CKD based mixes displayed excellent flow properties, superior to those of the fly ash based mixes. An additional advantage observed in the CKD based mixes was the reduced level and rate of bleeding. Setting and walkability times compatible with the practical use of the CKDs in the field (less than $24 \mathrm{~h}$ and $8 \mathrm{~h}$, respectively) required a minimum cement dosage of $50 \mathrm{~kg} / \mathrm{m}^{3}$ and a limitation of the CKD dosage to 200 and 100 $\mathrm{kg} / \mathrm{m}^{3}$ for the fresh and landfilled CKD, respectively. With these dosages the 28-day compressive strength of the CKD based mixes (190-420 kPa) was found to fall at the high end of the range typically recommended for CLSMs. Data at 90 days showed, however, a much less significant gain in strength with time than that observed in the mixes with fly ash. 
While electrical resistivity measurements indicated the potential corrosiveness of both CKDs (see also 9.2.1), a model mass test showed lower rate of corrosion for steel coupons immersed in CKD CLSM, compared to a fly-ash based mix.

\subsection{Significance and Impact of the Research Work}

The present cost penalties with the generation of CKD along with the legal responsibility for storing this material is persuading cement manufacturers to reduce the production of CKD as well as to promote its large scale recycling for industrial applications. As a result, the present study is expected to have significant environmental impact, as the results obtained may lead to large scale reuse of a waste product that today must be stockpiled or landfilled at considerable expense.

Moreover, the work cited so far in the literature has focused on freshly generated CKD, while the issue of reusing stockpiled or landfilled material has remained completely unexplored. The emphasis of this research on re-using previously landfilled material represents a novel approach to recycling industrial wastes, which could be extended to other landfilled industrial waste materials (e.g. fly ash) to limit/avoid the costs associated with excavation and re-storage, when the existing containment does not meet the requirements for permanent disposal facility as per EPA regulations. Mining of landfilled CKD would extend the life of existing landfills, and free disposal volume of wastes that cannot be easily reused.

In all recycling efforts, in addition to the advantages associated with the re-use of a waste material, there are additional benefits deriving from saving of other more precious materials including soils. If successful, the applications being investigated for CKD involve partial or total replacement of more costly binders (e.g. cement, lime) or of precious earthen materials on a large scale, adding greatly to the environmental impact of the work.

Preliminary analysis on the data from the literature shows that there is no unique CKD and that each CKD must be considered separately. In addition, efforts to characterize CKD have been for the most part limited to chemical/mineralogical tests. These factors represent the primary barriers to the vast recycling of CKD. If 
opportunities for re-use of CKD in construction are sought, it appears important that CKD be considered, characterized, and evaluated as a construction material, i.e., based on physical, chemical tests, and mechanical tests. No comprehensive study of this sort has been conducted so far to characterize any CKD, and the current research represents a "pilot" program in this area.

Comparison on the behavior of the two CKDs demonstrates the evolving nature of this by-product material and highlights the modifications associated with time and exposure to the environment that may affect this and any other reactive by-product materials. The results presented in this study highlights the potential impact of chemical alteration on the mechanical and engineering properties of reactive byproducts such as CKD when exposed to the environment, as in a disposal site. These findings propose the importance of a model study to understand the long-term performance of reactive by product material before being recommended as a geomaterial.

It might be observed that one drawback of the present study is that it is primarily restricted to CKD from a single source, with reactivity at the very low end of values reported in the literature. It is noteworthy to point out that the CKD employed in the present study is a "true waste" material and may be exemplary of "future CKDs" resulting from further optimization of cement plant processing technology which is continuously aimed at limiting as much as possible the amount of reactive material discarded as a waste.

\subsection{Recommendations for Future Research}

The recommendations for future research can be grouped into the following seven categories, each of which is separately discussed below:
a) field implementation and verification of proposed applications;
b) evaluation of other applications proposed in this study;
c) extension of the work performed to other CKDs;
d) preparation of a database on the properties and applications of CKD;
e) evolution in properties of by-product materials such as CKD due to exposure to the environment; 
f) development of test methods specific to by-product materials;

g) development of protocol for evaluation/acceptance of CKD for use in soil improvement.

The first two (a-b) discuss recommendation for further studies making use of the same CKDs employed in this research. Then (c-d) suggestions are provided for developing a broader knowledge base on this by-product material through experimental testing and collection of data on other CKDs. Recommendation (e) addresses one result of this research that warrants additional investigation, i.e. the evolution of the nature of the landfilled CKD over time due to chemical alteration processes. The second to last recommendation discusses the need for developing test methods specific to by-product materials such as CKD is raised (f). Finally, a practical issue associated with implementation of the research performed is addressed.

\section{a) Field implementation and verification of proposed applications}

As summarized in the previous sections, this research identified and evaluated in the laboratory two possible applications for fresh and landfilled CKD. The first application involves the use of the CKDs as "drying agents" in combination with small percentages of Portland cement for the treatment of wet subgrade soils. In the second the CKDs are used as the fine component of controlled low strength materials (CLSM).

While the laboratory results are encouraging and suggest that the CKDs may perform effectively in both applications, there are several issues that require consideration before a widespread use of these material in these two applications can be advocated. In the first place it appears critical to perform a field trial implementation to validate the laboratory conclusions and to assess field performance, particularly in the long term. Following trial treatment of a wet subgrade it will be possible, for example, to directly evaluate the in situ properties of the treated subgrade in time using techniques (e.g. falling weight deflectometer) that are more relevant to actual field performance than some of the tests used in the laboratory (e.g. unconfined compression test). Similarly, 
when using the CKDs in CLSMs, it will be possible to directly evaluate time required for setting, and other key properties that determine the performance of a CLSM mixture.

A field trial implementation is also likely to highlight practical construction issues that the laboratory study could not address. In the case of CKD there are likely to be issues related, for example, to dust control; powder storage; methods and equipment for effective delivery of both the CKD and the cement to the wet subgrade.

Finally, as with any other industrial by-product, before CKD can be considered as a practical alternative to other construction materials, regulatory issues, environmental stability and long term performance will have to be clearly addressed.

b) Evaluation of other applications proposed in this study,

While the majority of the work performed focused on two specific applications (treatment of wet subgrades and CLSMs), the results of the characterization study suggest (Section 6-6) that in particular the landfilled CKD (which is available in greater quantities and has greater specific surface area) could be effectively used in other applications including: grouting (permeation or compaction grouting); backfilling of abandoned mines; and stabilization of sludges (from wastewater plants, as well as various industries).

Evaluation of the performance of the landfilled CKD in any of these applications will require specialized laboratory testing (including, for example, microbiological tests in the case of sludge stabilization) and is likely to require partnerships with other researchers, agricultural, industrial or municipal partners (e.g. a waste water facility plant) or specialty contractors (e.g. a grouting contractor).

c) Extension of the work performed to other CKDs

To date only few potential applications have been isolated for CKD primarily because limited research has been conducted to extensively characterize this material (with almost no research conducted on landfilled CKD). Previous investigations of the reuse of CKD have focused on one particular application and thus have placed emphasis exclusively on the specific properties relevant to the application. To the author's 
knowledge no comprehensive study has been conducted so far to characterize CKD in a broader way, as an engineering material, as was done in this research. This research, however, focused on CKD from a single source, and it is not clear to what degree the lessons learned from this study can be extrapolated to other CKDs. A detailed characterization of CKD from other plants would extend the current knowledge on this by-product material and ultimately contribute to the development of guidelines for the reutilization of CKD. This type of work appears necessary for identifying a broader range of applications for this by-product and promoting its widespread effective and economical use.

d) Preparation of a database on the properties and applications of CKD

Currently, due to the variability in the chemical and physical properties, and the scarcity of information on CKD, the utilization of this material in construction has been quite limited (Sreekrishnavilasam et al., 2004). Much of the research that has been done on CKD has been limited to a single CKD source for a specific project and the results obtained are scattered in many publications. If one wishes to obtain generic information relevant to the properties and utilization of this material, it must be done by studying a large number of CKDs from various sources. However due to budget and time constraints this is rarely a feasible solution. The most recent comprehensive study on the composition of CKD from a large number of sources was performed in 1982 by Haynes and Kramer. In the past 20 years great advances have been made in recycling CKD, and new regulations have been implemented for its disposal, considerably changing the CKD "landscape". To address this issue, the development of a database on both the characteristics and utilization of CKD from published and unpublished sources is recommended. Such a database would represent a means for the dissemination of information and data on CKD and could become a useful resource for designers and practicing engineers interested in quickly understanding the nature and properties of this by-product material.

Additionally, the data collected could itself become the object of further study. Analysis of a large data base could in time provide the means, for example, to: identify 
interrelationships between the various properties of CKD; understand the key characteristics controlling the use of CKD in specific applications; establish performance related methods and criteria to evaluate the suitability of a CKD in a specific application; develop a classification system for CKD based on key chemical and physical parameters; evaluate current relationships employed to assess the reactivity of CKDs from basic oxide composition; compare the properties of CKD to other industrial wastes which have at this time already "penetrated" the construction industry (e.g. fly ash).

e) Evolution in properties of by-product materials such as CKD due to exposure to the environment.

This research identified significant differences in particle morphology of the landfilled CKD compared to freshly generated CKD. These differences, which were attributed to chemical alteration processes resulting from long term exposure to the

environment (air, humidity), were shown to have significant impact on the engineering properties of the CKD. Time and material constraints limited work on this particular topic (e.g. the comparison this not address changes in surface chemistry), which however appears of great interest given that it is not unusual for by-product materials to be recycled after an extended "storage" period. It is suggested that future research could be directed at further understanding the effects of environmental exposure on the nature and properties of by-product materials, particular reactive ones. Such studies could involve the controlled exposure of the material of interest to different environments, with subsequent characterization of the particle characteristics (e.g. particle shape, morphology, surface chemistry, and surface contamination).

f) Development of experimental methods specific to the by-product materials

Particulate by-product and waste materials (fly ash, foundry sand, CKD etc.) have increasingly been used in a variety of civil engineering applications to replace valuable earth materials. It has been pointed out in this thesis that careful characterization of an industrial by product and identification of its key properties is the first and critical step in the process aimed at isolating its potential applications. Given the particulate nature of 
these materials, by and large they are characterized as geomaterials by adapting testing procedures used for soils. As pointed out by Edil and Benson (1998), the standards for testing soils have been developed after many years of testing and are based not only on the proper understanding of a property and its testing but also on the relevance of that property to design and construction. Therefore, direct application of these testing methods to a solid industrial by-product is unwarranted without an investigation of applicability. As an example, difficulties were encountered in directly adapting some of the experimental methods used for cohesionless (e.g. for the determination of the minimum and maximum void ratio) soils to particulate by-products as fine as the CKDs investigated in this study (Sreekrishnavilasam and Santagata, 2006).

In conclusion, it is recommended that in any research project dealing with the utilization of a particulate by-product, specific efforts be directed towards the development of experimental methods and procedures for the characterization of such materials.

g) Development of protocol for evaluation/acceptance of CKD for use in soil improvement.

The review of the literature on CKD performed for this research demonstrates that the physical and chemical properties of CKD vary within a very wide range. Additionally, the extensive work done on different samples of CKD from a single source has highlighted that modifications to plant technology, as well as extended storage can lead to significant changes in the properties (in particular the reactivity) of the CKD. In particular it was shown that this resulted in significantly different performance in soil improvement. Effectiveness in soil stabilization/modification was also shown to be markedly soil dependent.

As a result of the above it is recommended that any widespread use of a particular CKD be accompanied by careful evaluation of its properties (e.g. free lime content) and possibly also of its effectiveness in combination with the specific soil(s) to be treated. At the same time, there appears also to be need for a regular verification over time of the 
properties of the CKD if its continues over an extended period of time. Thus, work is needed to develop a protocol containing guidelines for such material control procedures. 


\section{LIST OF REFERENCES}

Abeln, D.L., Hastings, R.J., Scxhreiber, R.J., and Yonley, C. (1993). "Detailed Illustration of Contingent Management Practices for Cement Kiln Dust," Research and Development Bulletin, SP115T, Portland Cement Association, Skokie, IL.

Abelleira, A., Berke, S.N., and Pickering, D.G. (1998). "Corrosion Resistance of Steel in Cementitious CLSM Versus that in Soil," The Design and Application of Controlled Low-Strength Material(Flowable Fill), ASTM STP 1331, Hward, A.K.,and.Hitch, L. eds., ASTM international, West Conshohocken, Pa, pp. 87-101.

Abelleira, A., Berke, S.N., and Pickering, D.G. (1998). "Development of Engineering Properties for Regular and Quick-set Flowable Fill," The Design and Application of Controlled Low-Strength Material (Flowable Fill), ASTM STP 1331,

Hward, A.K.,and.Hitch, L. eds., ASTM international, West Conshohocken, Pa.

Adaska, W.S., Tresouthick, S.W., and West, P.B. (1991). " Solidification and Stabilization of Waste Using Portland cement," Research and Development Bulletin, CA EB07, Portland Cement Association, Stokie, IL.

Al-Jabri, K., Taha,R., Al-Harthy, A., Al-Oraimi,S., and Al-Nuaimi,A.A. (2002). "Use of Cement by-pass Dust in Flowable Fill Mixtures," Cement, Concrete and Aggregates, 24 (2), pp. 53-57.

American Concrete Institute, ACI, Committee 229, (1994). "Controlled Low-Strength Material (CLSM)," ACI 229R-94), Concrete International Vol.16, No.7, July, pp.55-64. 
American Society of Testing and Materials, ASTM "Standard Test Method for Chemical Analysis of Hydraulic Cement," Designation C 114 -03 ASTM International, West Conshohocken, PA.

American Society of Testing and Materials, ASTM "Standard Test Method for Portland Cement," Designation C 150-05 ASTM International, West Conshohocken, PA.

American Society of Testing and Materials, ASTM, "Standard Test Method for Density of Hydraulic Cement," Designation C 188-95 ASTM International, West Conshohocken, PA.

American Society of Testing and Materials, ASTM, "Standard Specification for Concrete Aggregates," Designation C 33-03Annual Book of ASTM Standards, Vol. ASTM International, West Conshohocken, PA.

American Society of Testing and Materials, ASTM, "Standard Test Method for Fineness of Hydraulic Cement by Air-Permeability Apparatus," Designation C 204-00 ASTM International, West Conshohocken, PA.

American Society of Testing and Materials, ASTM "Standard Practice for Mechanical Mixing of Hydraulic Cement Paste and Mortars of Plastic Consistency," Designation C 305-99 ASTM International, West Conshohocken, PA.

American Society of Testing and Materials, ASTM "Standard Test Method for Expansion and Bleeding of Freshly Mixed Grouts for Preplaced Aggregate Concrete in the Laboratory," Designation C 940-98a ASTM International, West Conshohocken, PA. 
American Society of Testing and Materials, ASTM, "Standard Test Method for Particle Size Analysis of Soils," Designation D 422 -02 ASTM International, West Conshohocken, PA.

American Society of Testing and Materials, ASTM "Standard Test Method for Time of Setting of Concrete Mixtures by Penetration Resistance," Designation C 403/C403M-99 ASTM International, West Conshohocken, PA

American Society of Testing and Materials, ASTM D. "Standard Test Methods for Laboratory Compaction Characteristics of Soil Using Standard Effort (12,400 ft-lb/ft3 (600-kN-m/m3)," Designation 698-00a Annual Book of ASTM Standards, Vol.04.08. ASTM International, West Conshohocken, PA.

American Society of Testing and Materials,ASTM D 2166-00. "Standard Test Methods for Unconfined Compressive Strength of Cohesive soils", Annual Book of ASTM Standards. ASTM International, West Conshohocken, PA.

American Society of Testing and Materials, ASTM, "Standard Test Method for Permeability of Granular soil (Constant Head Method)," Designation D 2434-00 ASTM International, West Conshohocken, PA.

American Society of Testing and Materials, ASTM, "Standard Test Methods for Minimum Index Density and Unit Weight of Soils and Calculation of Relative Density," Designation D 4254-96 ASTM International, West Conshohocken, PA.

American Society of Testing and Materials, ASTM, "Standard Test Methods for Maximum Index Density and Unit Weight of Soils Using a Vibratory Table," Designation D 4254-96 ASTM International, West Conshohocken, PA. 
American Society of Testing and Materials, ASTM, "Standard Guide for Evaluating Effectiveness of Admixtures for Soil Stabilization," Designation D 4609-01 ASTM International, West Conshohocken, PA.

American Society of Testing and Materials, ASTM, "Standard Test Method for pH of Soils," D 4792-01 ASTM International, West Conshohocken, PA.

American Society of Testing and Materials, ASTM, "Standard Test Method for Preparation and Testing of Controlled Low Strength Materials (CLSM) Test Cylinders," Designation D 4832-95 Annual Book of ASTM Standards, Vol. 04.02, ASTM International, West Conshohocken, PA.

American Society of Testing and Materials, ASTM, "Standard Guide for Commercial Use of Lime Kiln Dusts and Portland Cement Kiln Dusts," D 5050-02, ASTM International, West Conshohocken, PA.

American Society of Testing and Materials, ASTM, "Standard practice for Sampling and Testing of Controlled Low Strength Materials (CLSM) Test Cylinders," Designation D 5971-96, Annual Book of ASTM Standards, Vol. 04.08. ASTM International, West Conshohocken, PA.

American Society of Testing and Materials, ASTM, "Standard Test Method for Unit Weight, Yield, Cement Content, and Air Content (Gravimetric) of Controlled Low Strength Materials (CLSM) Test Cylinders," Designation D 6023-96, Annual Book of ASTM Standards, Vol. 04.02. ASTM International, West Conshohocken, PA.

American Society of Testing and Materials, ASTM, "Standard Test Method for Ball Drop on Controlled Low Strength Materials (CLSM) Test Cylinders," Designation D 6024-96, Annual Book of ASTM Standards, Vol. 04.02. West Conshohocken, PA: ASTM International, West Conshohocken, PA. 
American Society of Testing and Materials, ASTM, "Standard Test method for Flow Consistency of Controlled Low Strength Material (CLSM)," Designation D 610397,Annual Book of ASTM Standards, Vol. 04.02 ASTM International, West Conshohocken, PA.

American Society of Testing and Materials, ASTM, "Standard test method for flow consistency of controlled low strength material (CLSM)," Designation D 6103-97, Annual Book of ASTM Standards, Vol. ASTM International, West Conshohocken, PA.

American Society of Testing and Materials, ASTM, (199). "Standard test method for using $\mathrm{pH}$ to estimate the soil- lime proportion requirement for soil stabilization," D 627699a, Annual Book of ASTM Standards, Vol.04.01. ASTM International, West Conshohocken, PA.

American Society of Testing and Materials, ASTM, (1995). " Standard test method for measuring $\mathrm{pH}$ of soil for use in corrosion testing," G 51-95 Annual Book of ASTM Standards, ASTM International, West Conshohocken, PA.

American Society of Testing and Materials, ASTM "Standard Test Method for Field Measurement of Soil Resistivity Using the Wenner Four-Electrode Method," Designation G 57-2001, West Conshohocken, PA: ASTM International, 2000.

Angelbeck,D., Burnham,J., and Nicholson,J.P. (1989). "A New Innovative Sludge Stabilization/Management Process: Cement Kiln Dust (CKD) Alkaline Stabilization Compared to Anaerobic Digestion-An Economic Analysis," Water Pollution Control Federation, December.

Baghdadi, Z.A., Fatani, N., and Sabban, N.A. (1995). "Soil Modification by Cement Kiln Dust," Journal of Materials in Civil Engineering, ASCE 7 (4), pp. 218-222. 
Bhat, S.T., and Lovell., C.W. (1997 "Use of Coal Combustion Residues and Waste Foundry Sands in Flowable Fill," Joint Highway Research Project., FHWA/IN/JHRP96/2. Final Report.

Bhatty, J. I. (1995). “Alternative Uses of Cement Kiln Dust,” Research and Development Bulletin, RP327, Portland Cement Association, Skokie, IL, USA.

Bhatty, J.I., Bhattacharja, S., and Todres, H.A. (1996). "Use of Cement Kiln Dust in Stabilizing Clay Soils", Research \& Development Bull, RP343, Portland Cement Assoc., Skokie, IL.

Bentur,A., Diamond, S., and Berke, A.S. (1997). "Steel Corrosion in Concrete," E \& FN SPON, New York.

Burnham, J.C. (1988). “Cement Kiln Dust/lime Treatment of Muncipal Sludge Cake:

Alternative Methods for Microbila and Odor Control," Proceedings of the National Conference on Muncipal Sewage Treatment Plant Sludge Management, Palm Beach, Florida. June, PP. 27-29.

Bye, G.C. (1983). "Portland Cement-Composition, Production and Properties," The Institute of Ceramics, Pergamon Press, USA.

Collins, R, J., and Emery, J. J. (1983). "Kiln Dust-Fly Ash System for Highway Bases and Subbases," Federal Highway Administration Report FHWA/RD-82/167, U.S Department of Transportation, Washington D.C.

Committee on Grouting of the Geotechnical Engineering Division (1980). "Preliminary Glossary of Terms Relating to Grouting," Journal of the Geotechnical Engineering Division, ASCE, Vol. 106, No. GT7, ASCE, New York, pp. 803-815. 
Conner, J.R. (1990). "Chemical Fixation and Solidification of Hazardous Waste," Van Nostrand Reinhold.

Crouch, L.K and Gamble, R. (1997). "High-Fines Limestone Screenings Prove Viable as Aggregate for Excavatable Controlled Low- Strength Material," Rock Products.

Cumberland, D.J., and.Crawford, R.J., (1987) “The Packing of Particles," Handbook of powder technology. Vol.6.

Diamond, S. and Kinter, EB. (1965). "Mechanism of Soil-Lime Stabilization- An Interpretive Review," Highway Research Record No.92.

Diamond, S. (2000). Class notes, “Cement Chemistry” Fall 2000, Purdue University.

Du, L., Folliard,K.J., and Trejo, D. (2002). "Effects of Constituent Materials and Quantities on Water Demand and Compressive Strength of Controlled Low-Strength Material," Journal of Materials in Civil Engineering, Vol. 14, No.6, December 1, pp. 485495.

Dyer, T.D., Halliday, J.E., and Dhir, R.K. (1999). "An Investigation of the Hydration Chemistry of Ternary Blends Containing Cement Kiln Dust," Journal of Materials Science ,34 (20), pp. 4975-4983.

Edil, T.B., and Benson, H.G. (1998). "Geotechnics of Industrial by-Products," Recycled Materials in Geotechnical Applications," Geotechnical Special Publications 79, American Society of Civil Engineers, Virginia.

El-Awady, M.H., and Sami, T.M. (1997). "Removal of Heavy Metals by Cement Kiln Dust," Bulletin of Environmental Contamination and Toxicology 59 (4), pp. 603-610. 
Gassman.S.L., pierce, E.P., and Schroeder, A.J. ( 2001). "Effects of Prolonged Mixing and Retempering on Properties of Controlled Low-Strength Material (CLSM)," ACI Material Journal, March-April.

Glasser, F.P., (2000). "Chemistry of Cement-Solidified Waste Forms," Chemistry and Microstructure of Solidified Waste Forms, Edited by Spence, R.D.

Green,H.B, Staheli, K., Bennett, D., and Walley, D.M. (1998). "Fly -Ash-Based Controlled Low Strength Material (CLSM) Used for Critical Microtunneling Applications," The Design and Application of Controlled Low-Strength Material(Flowable Fill), ASTM STP 1331, A.K.Hward and .L.Hitch, eds., ASTM international, West Conshohocken, Pa, pp. 87-101.

Greer.L.W., and Matz., T.L. (1996). "Cement Kiln Dust Enforceable Agreement-Yes or No?"., IEE-IAS.

Grindrod, P.S. (1970). "Application of the Andreasen Pipet to the Determination of Particle Size Distribution of Portland Cement and Related Materials," Fineness of Cement. ASTM STP 473, American Society for Testing Materials, pp. 45-70.

Haynes, W.B., and Kramer, G.W. (1982). "Characterization of U.S.Cement Kiln Dust," Information Circular \#8885, U.S Bureau of Mines, U.S. Department of the Interior, Washington D.C.

Hilt, G.H., and Davidson, D.T. (1960). "Lime Fixation in Clayey Soils," Highway Research Bull. 262, pp.20-32.

Hoopes, R.J. (1998). "Engineering Properties of Air-Modified Controlled Low-Strength Material," The Design and Application of Controlled Low-Strength Material(Flowable 
Fill) , ASTM STP 1331, A.K.Hward and j.L.Hitch, eds., ASTM international, West Conshohocken, Pa, pp. 87-101.

Kamon, M., and Nontananandh, S. (1991). "Combining Industrial Waste with lime for Soil Stabilization,” Journal of Geotechnical Engineering, Vol.117, No.1, January, pp.117.

Katz,A.M., and Kovler,K. (2004). "Utilization of Industrial by-Products for the Production of Controlled Low Strength Materials (CLSM)," Waste Managament Vol.24, Issue 5, pp. 501-512.

Ke , T.C and Lovell, C.W. (1992). "Corrosivity of Indiana Bottom Ash," Transportation Research Record.

Kessler, G.R. (1995). “Cement Kiln Dust (CKD) Methods for Reduction and Control," IEEE Transaction on Industry Applications 31(2), pp.407-412.

Klemm, W.A. (1980). "Kiln Dust Utilization," Martin Marietta Laboratories Report. MML 80-12, Baltimore, MD.

Kim, B. (2003). "Properties of Coal Ash Mixtures and their Use in Highway Embankments", PhD Thesis, Purdue University.

Konsta-Gdoutos M.S., and Shah, S.P. (2003). "Hydration and Properties of Novel Blended Cements Based on Cement Kiln Dust and Blast Furnace Slag," Cement and Concrete Research, 33 (8), pp.1269-1276.

Kumar,R., Kanaujia, V.K., and Ranjan, A. (2002). “An Experimental Study on Potential Cement Kiln Dust in Stabilization of Fy Ash," Cement, Concrete and Aggregates (24) 1, pp. $25-27$. 
Lowell,S and Shileds, J.E. (1984). “Powder Surface Area and Porosity,” John Wiley \& sons, Inc. New York.

MacKay, M.and Emery, J. (1992). "Stabilization and Solidification of Contaminated Soils and Sludges Using Cementitious System-Selected Case Histories," Transportation Research Record No. 1458, pp. 67-72.

Malhotra, V.M., and Ramezaniapour, A.A. (1994). "Fly Ash in Concrete," MSL 9445(IR), Canada Center for Mineral and Energy Technology.

McCoy, W.J., and Kriner, R.W., (1971). "Use of Waste Kiln Dust for Soil Consolidation,” Mill Session Papers, Portland Cement Association, Skokie, IL, U.S.A.

McLaren, R.J., and DiGioia Jr, A.M. (1987). “ The Typical Engineering Properties of Fly ash," Geotechnical Practice for Waste Disposal, Proceedings of a Specialty Conference, Ann Arbor, MI, 683-697.

Mehta, P.K., and Monterio., (1993). "Concrete- Microstructure, Properties and Materials" Prentice-Hall, Inc.

Metcalf and Eddy. (1991). "Wastewater Engineering Treatment, Disposal and Reuse," McGraw-Hill,Inc.

Miller, G.A., Zaman, M., Rahman, J., and Tan, K.N. (2003). "Laboratory and Field Evaluation of Soil Stabilization Using Cement Kiln Dust," Final Report, No. ORA 1255693, Planning and Research Division, Oklahoma Department of Transportation.

Miller,G.A., and Azad, S. (2000). "Influence of Soil Type on Stabilization With Cement Kiln Dust," Construction and Building Materials 14 (2), 89-97. 
Mitchell, J.K. (1993). "Fundamentals of Soil Behavior" $2^{\text {nd }}$ Edition, John Wiley and Sons Inc.

Mitchell, J.K and Dermatas, D. (1992). "Clay Soil Heave Caused by Lime Sulfate Reactions," Innovations and Uses for Lime. ASTM STP -1135.

Mullarky, J.I. (1998). "Long Term Strength Gain of Controlled Low Strength Materials", The design and application of controlled low-strength material(Flowable fill), ASTM STP 1331, A.K.Hward and J.L.Hitch, eds., ASTM International, West Conshohocken, Pa, pp. 87-101.

Muller, H.P. (1977). "What is Dust?: Characterization and Classification of Kiln Dust," $24^{\text {th }}$ Technical Meeting, Report No. MA 77/2505/E, Holderbank Management and Consulting Ltd., Technical Center, Material Division, Aargau, Switzerland.

Naik, T.R, Kraus, R.N, Sturzl, R.F, and Ramme, Kems., L. (1998). "Design and Testing of CLSM Using Clean Coal Ash,” The design and application of controlled low-strength material(Flowable fill) , ASTM STP 1331, A.K.Hward and J.L.Hitch, eds., ASTM international, West Conshohocken, Pa, pp. 87-101.

Nevilli,A.M., (1997). “Properties of Concrete," Fourth Edition, John Wiley \& Sons, Inc, New York, USA.

Nicholson, J.P. (1983). "Cement Kiln Dust: Where it is Going?," Pit and Quarry, July, pp. 98-104.

Nisbet., M. (1997). "The 3Rs and Cement Kiln Dust: Opportunities for Reduction, Reuse and Recycling," For Presentation at the Air \& Waste Management Association's 90th Annual meeting \& Exhibition, Toronto, Canada. 
Ohlheiser,R.T. (1998). "Utilization of Recycled Glass as Aggregate in CLSM, " The Design and Application of Controlled Low-Strength Material(Flowable Fill) , ASTM STP 1331, A.K.Hward and j.L.Hitch, eds., ASTM international, West Conshohocken, Pa, pp. 87-101.

Peethamparan, S., Olek, J., and Helfrich, K.E. (2006). "Evaluation of the Engineering Properties of Cement Kiln Dust (CKD) Modified Kaolinite Clay," the $21^{\text {st }}$ International Conference on Solid Waste Technology Management, March 26-29, Philadelphia, USA.

Pestana, J.M., (1994). “A UnifiedConstitutive Model for Clays and Sands,” Ph.D. Thesis, Massachusetts Institute of Technology (MIT), Massachusetts.

Pierce, C.E., Tripathi, H., and Brown, W.B. (2003). "Cement Kiln Dust in Controlled Low-Strength Materials," ACI materials journal, vol.100, No.6 pp 455-462.

Pons, F., Lanndwermeyer, and Kems, L. (1998). "Development of Engineering Properties for Regular and Quick-Set Flowable Fill," The design and application of controlled lowstrength material(Flowable fill) , ASTM STP 1331, A.K.Hward and j.L.Hitch, eds., ASTM international, West Conshohocken, Pa, pp. 87-101.

Portland Cement Association, (1992). "An Analysis of Selected Trace Metals in Cement and Kiln Dust,” SP109, Skokie, IL.

Ramachandran, V.S., and Beaudoin, J.J. (2001). "Handbook of Analytical Technique in Concrete Science and Technology," William Andrew Publishing/Noyes.

Salem,T.M., Ragai,S.M.(2001), "Electrical Conductivity of Granulated Slag Cement Kiln Dust-Silica Fume Pastes at Different Porosities," Cement and Concrete Research 31 (5), 781-787. 
Santagata, M.C., and Bobet, A. (2002). " The Use of Cement Kiln Dust (CKD) for Subgrade Stabilization/Modification,". Joint Transportation Research Program Report, SPR 2575. West Lafayette, IN.

Santagata, M.C. and Collepardi, M. (1998). "Selection of Cement-Based Grouts for Soil Improvement," Grouts and Grouting, GSP No. 80, ASCE, pp. 177-195.

Sayah, A.I. (1993). "Stabilization of Expansive Clay Using Cement Kiln Dust," M.S. Thesis, University of Oklahoma, Norman, OK, U.S.A.

Schreiber, R.J, and Riney, S.M. (1995). "Cement Kiln Dust: An Overview," Report No. 0-7803-2456-0/95, IEEE-IAS.

Shaffer, K.R. (2004). Indiana Geological Survey, Indiana University (Personal Communication)

Sharma, H.D. and Lewis, S.P. (1994). "Waste Containment System, Waste Stabilization, and Landfills: Design and Evaluation,” John Wiley \& Sons, Inc..

Shoaib, M.M., Balaha, M.M., and Abdel-Rehman A.G. (2000). "Influence of Cement Kiln Dust Substitution on the Mechanical Properties of Concrete," Cement and Concrete Research 30 (3), pp. 371-377.

Smith and Lohnes., (1984). "Behavior of Bulk Solids, Particle Characterization in Technology, Vol. 2 ed. by. Beddow.J.K.

Sreekrishnavilasam, A., King, S., and Santagata, M.C. (2006). "Characterization of Fresh and Landfilled Cement Kiln Dust for Reuse-in-Construction Applications," Journal of Engineering Geology (Article in press). 
Sreekrishnavilasam, A., and Santagata, M.C. (2006). "Effect of particle Characteristics on Frictional and Compression Properties of a Particulate By-Product Material," $5^{\text {th }}$ World Congress on Particle Technology, April 23-27, Orlando, Florida, USA

Sreekrishnavilasam, A., Rahardja, S., Kmetz, R., and Santagata, M.C (2006). "Soil Treatment Using Fresh and Landfilled CKD”, Journal of Building Construction and Materials(Article in press)

Stagemann, J.A. and Cote, P.L. (1990). "Summary of an Investigation of Test Methods for Solidified Waste Evaluation," Waste Management, Vol. 10, pp.41-52

Steuch, H.E. (1992). "Review of Dust Return System," Emerging Technologies for Kiln Dust Management, SP 113, Portland Cement Association, Stokie, Illinois, U.S.A.

Taylor, H.F.W. (1997). "Cement Chemistry," 2nd Edition, Thomas Telford Publishing, London, UK.

Tikalsky, P., Gaffney, M., and Regan, R. (2004). "Properties of Controlled Low Strength Material Containing Foundry Sand,” ACI materials journal, vol.97, No.6, pp. 698-702.

Todres, H.A., Mishulovich, J., and Ahmed, J. (1992). "Cement kiln Dust Management: Permeability," Research \& Development Bulletin RD103T, Portland Cement Assoc., Skokie, IL.

Trejo. D., Folliard, K.J., and Du, L. (2004. "Sustainable Development Using Controlled Low-Strength Material," International Workshop on Sustainable Development and Concrete Technology (Beijing, China).

Tolliver, D.L.(2002). Letter from Lehigh Cement Company, 
Udoeyo, F.F., and Hyee, A. (2002). "Strength of cement kiln dust concrete," Journal of Materials in Civil Engineering, ASCE 14 (6), pp.524-526.

USEPA, (1993). "Report to Congress on Cement Kiln Dust," Office of Solid Wastes. U.S. Environmental Protection Agency.

USEPA. (1998). "Technical Background Document on Ground Water Controls at CKD Landfills," Office of Solid Waste U.S. Environmental Protection Agency.

van Ganse R. (1971). "Quelques Aspects Théoriques et Pratiques de la Stabilisaton des sols à la Chaux (A Few Theoretical and Practical Aspects of the Treatment of Soils with Llime)," La Technique Routiere, 16(3).

Wang, K., Gdoutos, M.S.K., and Shah, S.P. (2002). "Hydration, Rheology, and Strength of Ordinary Portland Cement (OPC) - Cement Kiln Dust (CKD) - Slag Binders," ACI Materials Journal, 99 (2), 173-179.

Warner, J.(2003). "Fifty Years of Low Mobility Grouting," Grouting and Grout Treatment, Proceedings of the Third International Conference, Geotechnical Special Publication No. 120, Vol. 1., pp. 1-24.

Zaman,M., Laguros,J.G., Sayah.A. (1992). "Soil Stabilization Using Cement Kiln Dust," Proceedings 7th International Conference on Expansive Soils. Dallas, Texas, pp. 347351. 
APPENDICES 
Appendix A

A Heidelberger Technology Center Report on Free Lime Content

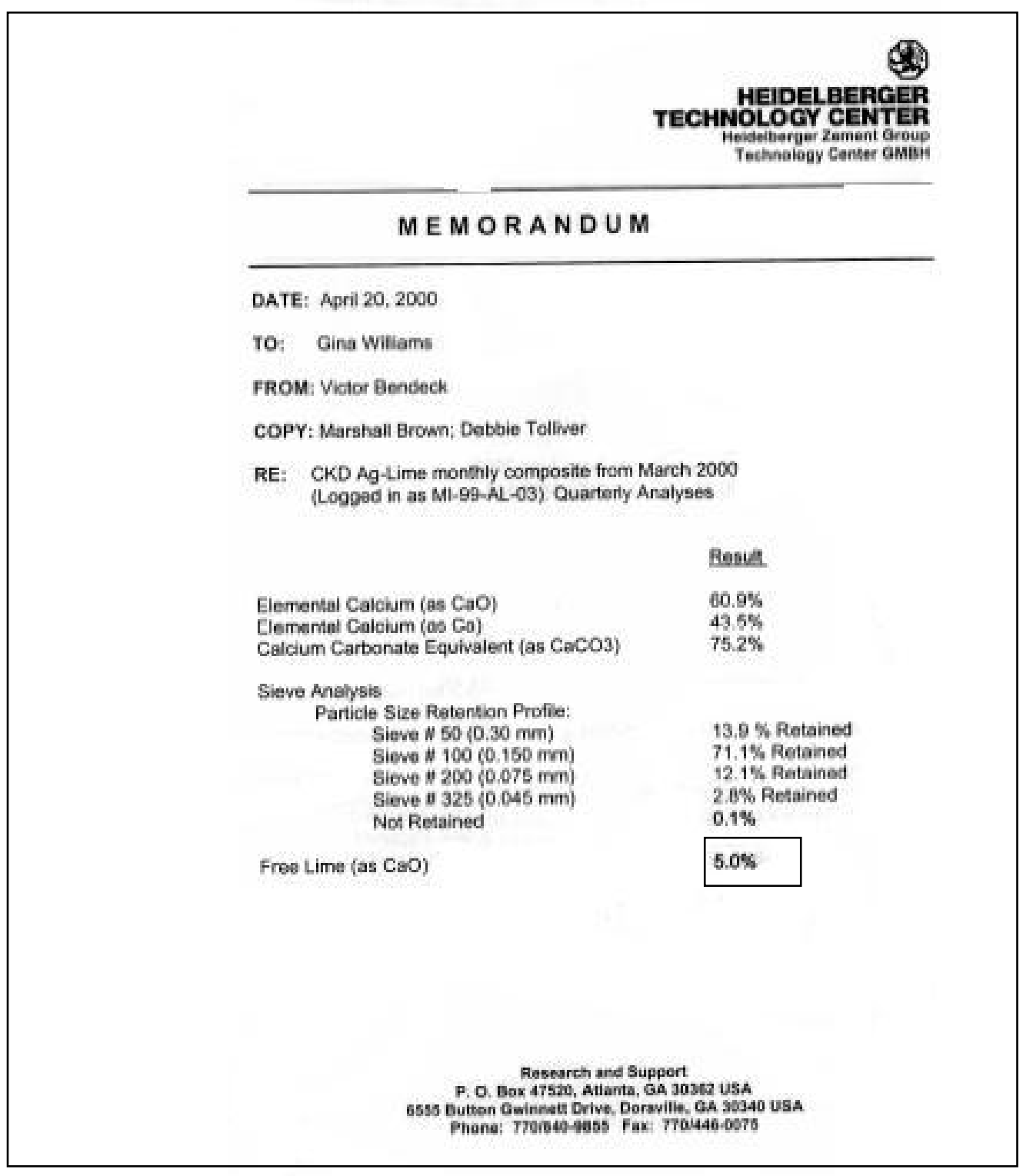




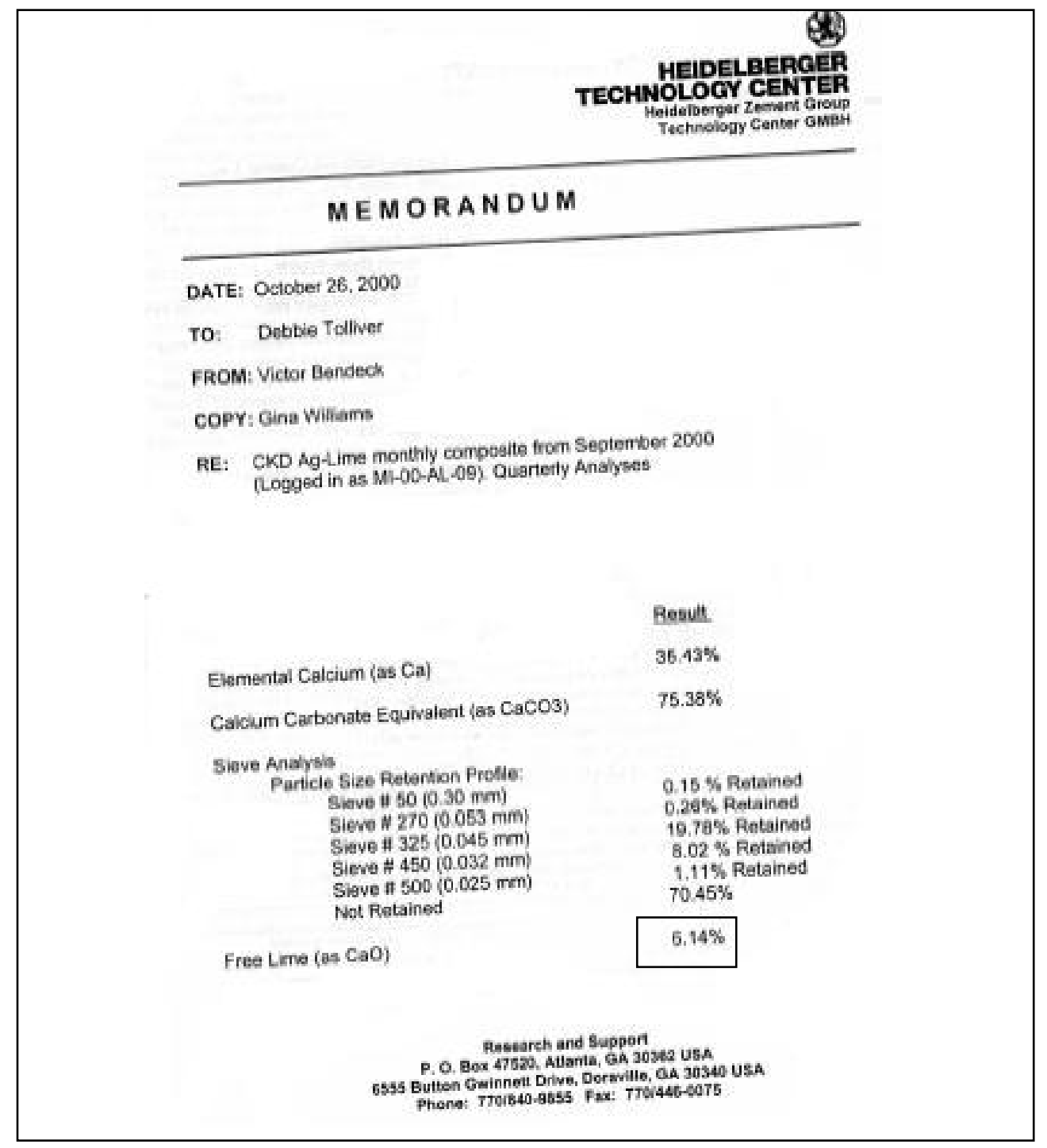




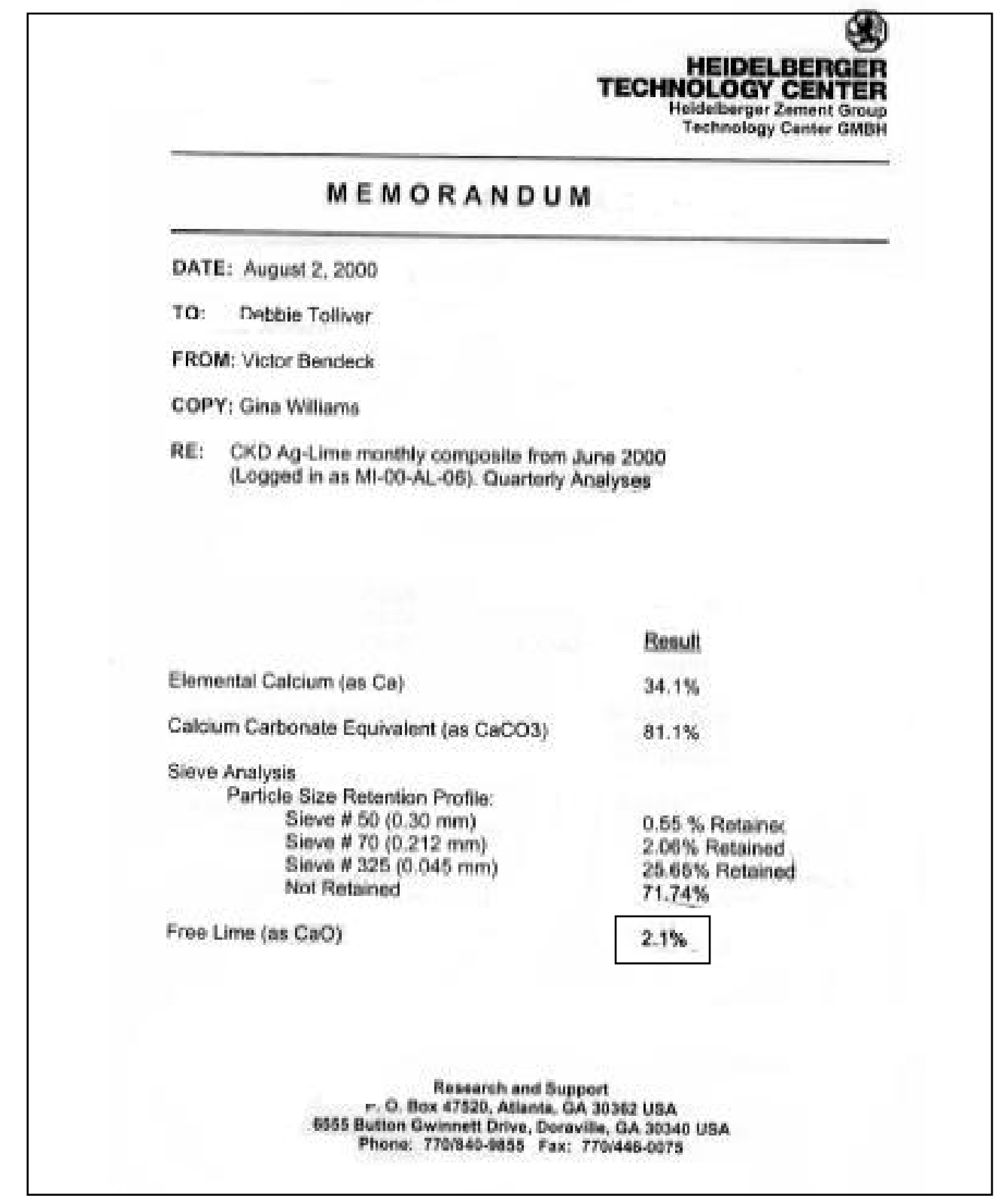




\section{Appendix B}

\section{Fly Ash CLSM Mix Design Data}

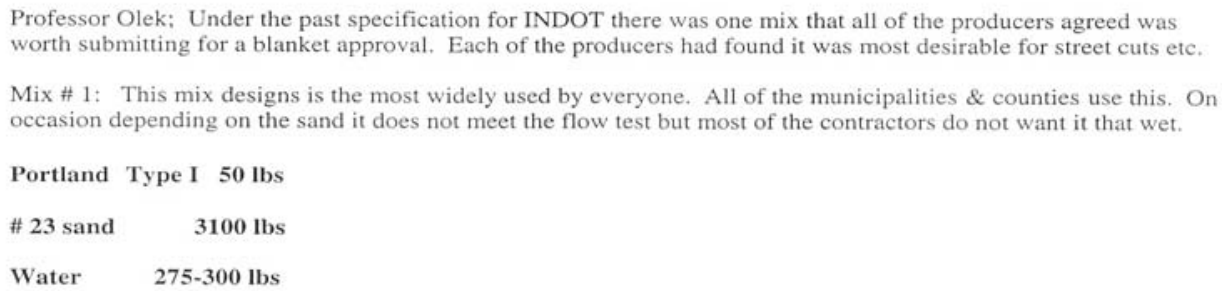

Mix \# 3 The following mix is used for places where pumping long distances is needed. We almost always insist that this be used in a situation where it does not need to be reomoved. However, we have discovered because it contains more cementitious the air generated is greater. In recent testing with Lafayette and Crawfordsville sands it was too weak.

Portland Type I 25 lbs

C fly ash $\quad 400$

Sand 2650

Darafill egg 1 per yard (or Master Builders Rheocell)

As far as the material used in Lafayette, contact either Drew Davis or Jim Shubert at 1-765-4232533 for Drew and for Jim (QC) 1-765-427-4690. They will know whatever was used.

I realize that the method of testing the mix designs dry wont work with the cellular mixes. However, they are popular. III be on vacation next week and back the $14^{\text {th }}$.

Jim Shubert can help if you need something else. As far as the samples of cement and ash we talked about they are assembled at our Eat Lafayette plant and I was waiting for Tommys lab to be done to deliver them. I can also put out the call for sand samples.

Norman E. Thoeming

Director of Technical Services

Irving Materials, Inc.

8032 N. State Road 9

Greenfield, Indiana 46140 